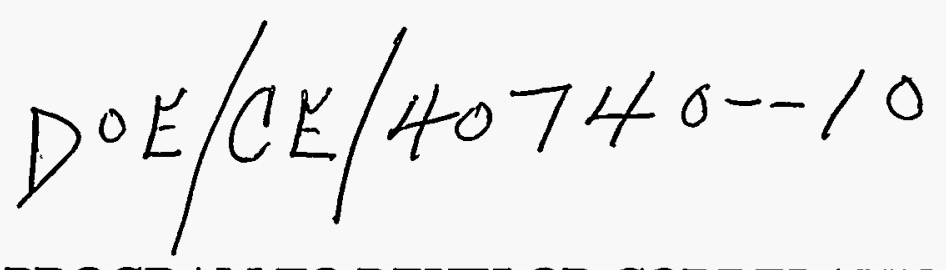

\title{
A COMPREHENSIVE PROGRAM TO DEVELOP CORRELATIONS FOR THE PHYSICAL PROPERTIES OF KRAFT BLACK LIQUOR- FINAL REPORT
}

By: Arthur L. Fricke and Abbas A. Zaman

$\begin{array}{cr}\text { MAY, } 1998 & \text { RECEIVED } \\ \text { Work Performed Under Grant: } & \text { DE-FG02-85CE40740 } \\ \text { JUN } 261998\end{array}$

Major Contributors:

Post-Doctoral Assistants:

A.A. Zaman, D.J. Dong, S.A. Tavares

PhD Students:

J.D. Small,Jr., G.W. Schmidl, M.A. Stoy, A.A. Zaman, D.J. Dong

MS and ME Students:

S. Stevens, R. Schaerfl, J.E. Kelly, J. Bellush, R. Knez

Undergraduate Students:

J. Deery, T. McNally, M. Crawford, C. Marino

Technicians:

B. Speck, A. Preston, J. Poole

For: US Department of Energy

Office of Industrial Programs

Conservation and Renewable Energy

Washington, DC 20585

By: The University of Florida

MASTER

Gainesville, Florida 32611 


\section{DISCLAIMER}

This report was prepared as an account of work sponsored by an agency of the United States Government. Neither the United States Government nor any agency thereof, nor any of their employees, make any warranty, express or implied, or assumes any legal liability or responsibility for the accuracy, completeness, or usefuiness of any information, apparatus, product, or process disclosed, or represents that its use would not infringe privately owned rights. Reference herein to any specific commercial product, process, or service by trade name, trademark, manufacturer, or otherwise does not necessarily constitute or imply its endorsement, recommendation, or favoring by the United States Government or any agency thereof. The views and opinions of authors expressed herein do not necessarily state or reflect those of the United States Government or any agency thereof. 


\section{DISCLAIMER}

Portions of this document may be illegible electronic image products. Images are produced from the best available original document. 


\section{EXECUTIVE SUMMARY}

This is a complete summary of research results for the program entitled: "A Comprehensive Program to Develop Correlations for the Physical Properties and Composition of Black Liquors" that has been supported by the U.S. Department of Energy, many industrial firms and the University of Florida.

A complete rationalization of black liquor behavior that is fundamentally sound and theoretically based has been developed and applied successfully to black liquor studies. Many new experimental methods for precise measurement of liquor properties and lignin characterization have been developed and improvements and refinements have been made for a number of analytical procedures.

Pulping experiments have been conducted and analyzed. Liquors from these experiments have been analyzed to define the solid composition as thoroughly and completely as possible. Lignins from these liquors have been characterized with respect to molecular weight and optical properties.

Correlations relating yield, Kappa numbers, lignin concentration, lignins number average molecular weight, and lignin weight average molecular weight to pulping conditions for kraft pulping of Slash Pine have been developed successfully. Molecular weight distributions have been determined by size exclusion chromatography and the effect of pulping conditions on various averages determined.

Density, heat capacity, heat of dilution, enthalpy-concentration, vapor pressure equilibria, and boiling point elevation have been determined for all of the Slash Pine black liquors. Data reduction correlations were developed for all of these properties. Correlations to relate density at solids concentrations below 65-70\%, heat capacity, heat of dilution and boiling point elevation at solids conscentraion below $85 \%$, and heat of combustion to pulping conditions for Slash Pine have been developed successfully. Correlations relating heat of combustion to solids composition have been developed. All behaviors examined have been shown to be general for all black liquors. 
Rheological behavior has been explored extensively. Basically, black liquor behavior can be divided into two regimes: low solids concentrations where liquors behave as a dilute polymer solution and high solids concentrations where liquors behave as a concentrated polymer solution or a plasticized glass. Behavior in the former is Newtonian, and behavior in the latter is nonNewtonian or viscoelastic. Two different models, one based on colligative properties and one based on combined activation energy and free volume theories, have been used successfully to reduce low solids concentration viscosity data. Constants for both have been correlated with respect to pulping conditions and liquor solids composition successfully for Slash Pine black liquors. Two models, one of which is empirical, have been used to reduce Newtonian viscosity data at high solids concentrations. Effects of pulping conditions and liquor solids composition have been critically examined. Models and superposition principles developed for non-Newtonian and viscoelastic behavior of polymer melts and concentrated polymer solutions have been applied successfully to black liquors. Effects of pulping conditions have been examined. A generalized shift factor for non-Newtonian behavior of Slash Pine black liquors has been developed. It has been shown that viscoelastic effects are not significant for liquor firing at $120^{\circ} \mathrm{C}$ and solids concentrations up to $85 \%$.

Technology has been transferred as developed. Five interim technical reports have been submitted to the U.S. Department of Energy. More than 25 reviewed research publications have appeared in research journals. Even more research papers have been presented before audiences at international or national technical society meetings or at DOE review meetings. In addition, numerous seminars and presentations have been given at universities and at industrial installations. 


\section{TABLE OF CONTENTS}

EXECUTTVE SUMMARY

$\begin{array}{lc}\text { TABLE OF CONTENTS } & 3\end{array}$

REVIEWED PUBLICATIONS INCLUDED IN REPORT 5

$\begin{array}{lll}1.0 & \text { INTRODUCTION } & 7\end{array}$

$\begin{array}{lll}2.0 & \text { PULPING } & 10\end{array}$

2.1 Pulping Conditions and Pulping Experimental Design 12

2.2 Pulp Yield and Kappa Number 16

2.2.1 Data Analysis and Correlation $\quad 17$

$\begin{array}{lll}3.0 & \text { LIQUOR ANALYSIS } & 35\end{array}$

3.1 Lignin Analysis $\quad 40$

3.2 High Molecular Weight (Acid Precipitated) Lignin 59

4.0 CHARACTERIZATION OF HIGH MOLECULAR WEIGHT (ACID

4.1 Weight Average Molecular Weight $\left(\mathrm{M}_{\mathrm{W}}\right)$ Determination 61

4.2 Number Average Molecular Weight $\left(\mathrm{M}_{n}\right)$ Determination 73

$\begin{array}{lll}4.3 & \text { Molecular Weight Distribution (MWD) Determination } & 73\end{array}$

4.4 Intrinsic Viscosity Determination $\quad 90$

4.5 Internal Calibration of HTHPLC Molecular Weight Distribution Results 96

$\begin{array}{lll}5.0 & \text { PULPING AND LIGNIN MOLECULAR WEIGHT } & 109\end{array}$

$\begin{array}{lll}6.0 & \text { SIGNIFICANT OBSERVATIONS OF LIQUOR THERMAL BEHAVIOR } & 138\end{array}$

$\begin{array}{lll}7.0 & \text { HEAT OF COMBUSTION } & 146\end{array}$

$\begin{array}{lll}8.0 & \text { DENSITY } & 158\end{array}$

$\begin{array}{lll}9.0 & \text { HEAT CAPACITY } & 204\end{array}$

10.0 HEAT OF DILUTION AND ENTHALPY-CONCENTRATION RELATIONS 214

10.1 Development of Experimental Method 214

$\begin{array}{lll}10.2 & \text { Enthalpy Concentration } & 214\end{array}$ 
10.3 Enthalpy-Concentration Model 230

$\begin{array}{lll}11.0 & \text { VAPOR-LIQUID EQUILIBRIA } & 254\end{array}$

11.1 Experimental Method and Initial Results 254

11.2 Vapor-Liquid Equilibria Correlation 278

$\begin{array}{lll}12.0 & \text { VISCOSITY AND RHEOLOGICAL BEHAVIOR } & 299\end{array}$

$\begin{array}{lll}12.1 & \text { Instruments } & 300\end{array}$

$\begin{array}{ll}12.2 \text { Viscosity Regimes } & 304\end{array}$

12.3 Low Solids (<50\%) Viscosity 305

12.4 Rheological Behavior at High (> 50\%) Solids Concentraton 364

12.4.1 Zero Shear Rate Viscosity 367

12.4.2 Non-Newtonian Viscosity 393

12.4.3 Viscoelasticity 432

13.0 OVERVIEW AND GENERAL SUMMARY 445

$\begin{array}{lll}14.0 & \text { TECHNOLOGY TRANSFER } & 478\end{array}$

$\begin{array}{lll}15.0 & \text { REFERENCES } & 483\end{array}$ 


\section{REVIEWED PUBLICATIONS INCLUDED IN REPORT}

Zaman. A.A., D.J. Dong, and A.L. Fricke, "Kraft Pulping of Slash Pine," AIChE 1991 Forest Products Symposium, 49-57 (1992).

Dong, D.J. and A.L. Fricke, "UV-Visible Response of Kraft Lignin in Softwood Black Liquor," Material Research Society Proceedings, 197, 77-86 (1990).

Dong, D.J. and A.L. Fricke, "Investigation of Optical Effect of Lignin Solution and

Determination of $\mathrm{M}_{\mathrm{w}}$ of Kraft Lignin," J. Appl. Polymer Sci., 50, 1131-1140 (1993).

Schmidl, G.W., D.J. Dong, and A.L. Fricke, "Molecular Weight and Molecular Weight Distribution of Kraft Lignins," Materials Research Society Symposium Proceedings, 197, 2130 (1990).

Dong, D.J. and A.L. Fricke, "Intrinsic Viscosity and the Molecular Weight of Kraft Lignin," Polymer, 36, 2075-2078 (1995).

Dong, D.J. and A.L. Fricke, "Effects of Multiple Pulping Variables on the Molecular Weight and Molecular Weight Distribution of Kraft Lignin," Journal of Wood Chemistry and Technology, 15(3), 369-393 (1995).

Zaman, A.A. and A.L. Fricke, "Effects of Pulping Conditions and Black Liquor Composition on the Heat of Combustion of Slash Pine Black Liquor," AIChE Symposium Series, Advances in Pulp and Papermaking, 21(307), 154-159 (1995).

Zaman, A., M.O. Wight, and A.L. Fricke, "Density and Thermal Expansion of Black Liquors," TAPPI Journal, 77(8), 175-181 (1994).

Zaman, A.A., J.S. Deery, T.W. McNally, and A.L. Fricke, "Effect of Pulping Variables on Density of Slash Pine Kraft Black Liquors: Predictive Models," TAPPI Journal, 80(9), 199207 (1997).

Zaman, A.A., S.A. Tavares, and A.L. Fricke, "Studies on the Heat Capacity of Slash Pine Kraft Black Liquors: Effects of Temperature and Solids Concentrations," Journal of Chemical and Engineering Data, 41(2), 266-271 (1996).

Stoy, M.A. and A.L. Fricke, "Development of a Method for Measuring the Heat of Dilution of Kraft Black Liquor and Water," TAPPI Journal, 77, 8, 169-174 (1994).

Stoy, M.A. and A.L. Fricke, "Enthalpy Concentration Relations for Black Liquor," TAPPI Lournal, 77, 9, 103-110 (1994).

Zaman, A.A. and A.L. Fricke, "Heat of Dilution and Enthalpy-Concentration Relations for Slash Pine Kraft Black Liquors," Chem. Eng. Comm., 155, 197-216 (1996).

Stoy, M.A., A.A. Zaman, and A.L. Fricke, "Vapor-Liquid Equilibria for Black Liquors," 1992 International Chemical Recovery Conference, 495-511 (1992).

Zaman, A.A., T.W. McNally, and A.L. Fricke, "Vapor Pressure and Boiling Point Elevation of Slash Pine Black Liquors: Predictive Models with Statistical Approach," Ind. \& Eng. Chem. Res., 1998(37), 275-283 (1998). 
Zaman, A.A. and A.L. Fricke, "Viscosity of Black Liquor Up to $130^{\circ} \mathrm{C}$ and $84 \%$ Solids," Forest Products Symposium, AIChE Proceedings, $59-77$ (1991).

Zaman, A.A. and A.L. Fricke, "Correlations for Viscosity of Kraft Black Liquors at Low Solids Concentrations," AIChE Journal, 40(1), 187-192 (1994).

Zaman, A.A. and A.L. Fricke, "Viscosity of Softwood Kraft Black Liquors at Low Solids Concentrations: Effect of Solids Content, Degree of Delignification and Liquor Composition," Journal Pulp and Paper Sci., 21(4), J119-J126 (1995).

Zaman, A.A. and A.L. Fricke, "Effects of Pulping Conditions and Black Liquor Composition of Softwood Kraft Black Liquors: Predictive Models," TAPPI Journal, 78(10), 107-119 (1995).

Zaman, A.A. and A.L. Fricke, "Newtonian Viscosity of High Solids Kraft Black Liquors: Effects of Temperature and Solids Concentrations, I\&EC Research, 33(2), 428-435 (1994).

Zaman, A.A. and A.L. Fricke, "Effect of Pulping Conditions and Black Liquor Composition on Newtonian Viscosity of High Solids Kraft Black Liquors," I\&EC Research, 35(2), 590-597 (1996)

Zaman, A.A. and A.L. Fricke, "Steady Shear Flow Properties of High Solids Softwood Kraft Black Liquors: Effects of Temperature, Solids Concentration, Lignin Molecular Weight, and Shear Rate," Chem. Eng. Comm., 139, 201-221 (1995)

Zaman, A.A. and A.L. Fricke, "Kraft Black Liquor Rheological Behavior with Respect to Solids Concentration, Temperature, and Shear Rate," AIChE Symp. Series, Advances in Pulp and Papermaking, 21(307), 162-171 (1995)

Zaman, A.A. and A.L. Fricke, "Viscoelastic Properties of High Solids Softwood Kraft Black Liquors," I\&EC Research, 34(1), 382-391 (1995).

Fricke, A.L. and A.A. Zaman, "Black Liquor Properties," International Industrial Energy Technology Conference, Houston, Texas (1994) 


\subsection{INTRODUCTION}

An involved research program entitled: "A Comprehensive Program to Develop Correlations for the Physical Properties and Composition of Black Liquors" has been conducted at the University of Florida under the sponsorship of the U.S. Department of Energy, industrial firms, and the University of Florida. The overall objective of the program was to develop correlations to predict physical properties within requirements of engineering precision from a knowledge of pulping conditions and of kraft black liquor composition, if possible. These correlations were to include those relating thermodynamic properties to pulping conditions and liquor composition.

The basic premise upon which the research was based is the premise that black liquor behaves as a polymer solution. This premise has proven to be true, and has been used successfully in developing data reduction methods and in interpreting results.

From previous work, it was known that response of several physical properties tested was non-linear with respect to pulping conditions. Further, no systematic study of the total effect of pulping conditions on properties had been made; the most complete studies made had been only two-level studies of the effects of pulping variables. Therefore, carefully controlled pulping experiments were planned and conducted in order to supply liquors for properties studies where the liquors originated from known conditions and were produced on a scale that could be expected to duplicate pulping in mills.

A three phase effort involving pulping, analysis of liquor composition, and measurement of liquor properties was conducted that is best illustrated in Figure 1.1. Controlled pulping experiments were conducted to totally explore the major pulping variables for a single species over a wide range of Kappa Number and yield. The results of pulping were analyzed. The compositions of the black liquors produced were determined as completely as possible and results correlated with respect to pulping conditions. Physical and thermodynamic properties of the liquors that are of importance, with the exception of surface tension and thermal conductivity, were determined for each liquor as a function of the variables-concentration, temperature, shear rate- 
Figure 1.1

Schematic Illustration of Experimental Approach for the Program

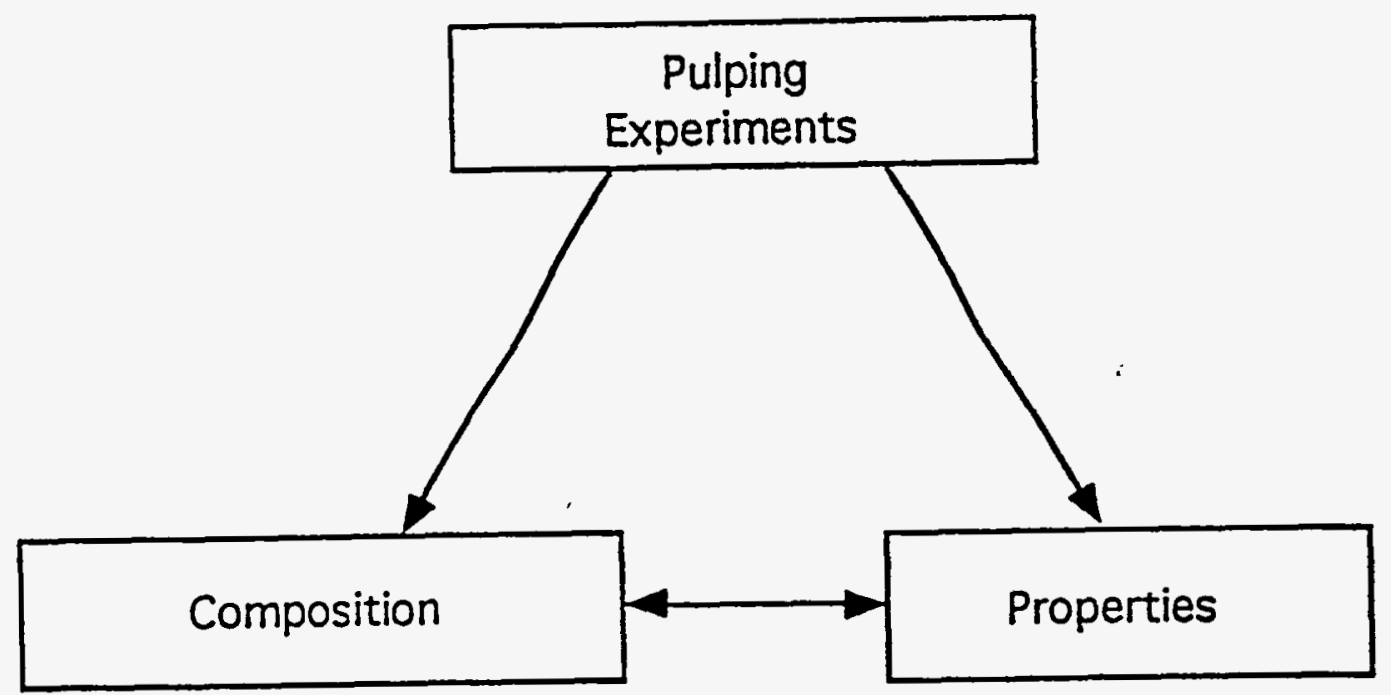


affecting that property. Data reduction methods were developed for each of these properties. The constants developed by data reduction were then correlated with pulping conditions. Finally, the constants for reduced properties data were correlated with liquor composition in most cases. In a few cases, the complexity of the problem prevented successful development of correlation of data reduction constants with liquor composition. However, even in these cases, methods were developed to drastically reduce the experimental effort to quantify that property for a liquor.

Finally, considerable effort was devoted to generalization to liquors produced from kraft pulping of other species and to liquors produced from other types of pulping. In all cases, data reduction methods and interpretations of results were found to be valid. Kraft liquors examined included those from pulping Western softwoods, Mid-Atlantic hardwoods, and Northern hardwoods as well as those produced by sulfite, carbonate, and semi-chemical pulping.

More than 25 reviewed research publications on this work have been published in leading research and technical journals. More than 30 research presentations have been made at national and international technical meetings. In addition, numerous presentations have been made in seminars before audiences of various sizes at other universities and at industrial locations. 


\subsection{PULPING}

Originally, we had planned to contract with industry for pulping in industrial laboratories to supply liquors for study that had been produced under known pulping conditions. This was not possible. Therefore, the first step in the program was to design and construct a digester, and to select and install a liquor concentration system at the University of Florida. This was done with the advice and guidance of industrial researchers. The system that was built, housed in a building constructed by the University for this purpose, has been fully described in earlier technical reports to the U.S. Department of Energy (Fricke, 1989, Fricke, 1990).

The digester is a $3.5 \mathrm{ft}^{3}\left(0.100 \mathrm{~m}^{3}\right)$ jacketed vessel with an I.D. of 12 inches $(0.305 \mathrm{~m})$ and an overall length of nearly 68 inches $(1.73 \mathrm{~m})$ with an interior straight side of 56.63 inches $(1.438 \mathrm{~m})$. The digester is mounted on tumbrels so that the digester can be rotated end-over-end at a rate of 0.25 to $2.5 \mathrm{rpm}$. Steam is fed to the jacket and condensate removed through rotary joints in the tumbrels. The maximum supply steam pressure is $250 \mathrm{psig}(1.72 \mathrm{MPa})$, but the supply steam can be pressure and flow controlled so that jacket temperature or rate of heat input can be controlled.

Chips are contained in a thin walled cylinder with filter screen packs at the top and bottom of the cylinder. The bottom is conical to fit the digester. This proved to be a very good arrangement for loading and unloading the digester without loss of pulp as well as for liquor circulation during pulping.

A pressurized feed tank for white liquor and a feed tank for water for pulp washing are included. The contents of these tanks can be temperature controlled. The white liquor tank capacity is approximately 27 gallons $\left(0.102 \mathrm{~m}^{3}\right)$ and the water tank capacity is 184 gallons $(0.695$ $\mathrm{m}^{3}$ ). Liquids are fed to the digester under batch control by a centrifugal pump that can deliver 20 gpm $\left(0.076 \mathrm{~m}^{3} / \mathrm{min}\right)$ at a $45 \mathrm{ft}(13.7 \mathrm{~m})$ head. Thus, the vacant space in the digester when loaded with chips can be filled with liquid in less than one minute.

The bottom of the digester is equipped with a full opening ball valve. For discharging the digester, the valve is connected to a 4-inch flex hose with the other end of the hose connected to the 
top of a 125 gallon $\left(0.473 \mathrm{~m}^{3}\right)$ receiver equipped with a $10 \mathrm{ft}^{2}\left(0.93 \mathrm{~m}^{2}\right)$ U-bend heat exchanger. The receiver can be evacuated to eliminate air.

When digestion is completed, the flex hose is connected and the liquor discharged into the tank. The bottom valve is closed, the digester filled with a metered quantity of wash water that is also discharged into the receiver after a specified wash period. The wash procedure is repeated. The original liquor plus two washes are cooled to below $100^{\circ} \mathrm{F}\left(37.8^{\circ} \mathrm{C}\right)$ and discharged from the receiver through a polishing filter into a portable plastic tank. The pulp is then washed exhaustively with hot water, the digester opened, the pulp unloaded, weighed, and sampled.

During development, we added an additional feature to the system-liquor circulation. A short section with a cylindrical screen pack was placed upstream of the full opening valve at the bottom of the digester. The drain from this screen pack was connected to a diaphragm pump with variable speed control and the liquor discharged from the pump returned to the top of the digester. The pump is capable of pumping $30 \mathrm{gpm}(0.114 \mathrm{~m} / \mathrm{min})$. This also offered the advantage, since the digester is stationary, of measuring temperature at different points in the bed and of measuring digester pressure during digestion.

The digester can be operated as a closed batch autoclave, as a rotating closed batch autoclave, or as a batch autoclave with liquid circulation. The digester was operated in all three modes in this work, but most of the digestion was done using the digester as a batch autoclave with liquid circulation. Digestion and washing were done under conditions that eliminated or minimized exposure to oxygen at temperatures above $100^{\circ} \mathrm{F}\left(37.8^{\circ} \mathrm{C}\right)$.

The digestion system proved to be extremely flexible with good control response. Chips could be preheated, liquid could be loaded precisely to $\pm 0.1 \%$ of the quantity desired at a temperature within less than $\pm 0.5^{\circ} \mathrm{C}$ of the temperature desired. Liquor loading time was about one minute. Heat up to digestion temperature could be controlled. It is possible to ramp the temperature linearly to the digestion temperature in about 5 minutes, but a heat-up time of about 20 minutes without linear ramping was normally used to simulate mill conditions. Digestion temperature could be controlled uniformly within the digester to better than $\pm 0.5^{\circ} \mathrm{C}$ when liquor 
circulation was used and total digestion time could be controlled to within \pm 5 seconds or less. Wash water quantities and washing times could be controlled to similar precisions. The discharged liquor and two washes contained about $97 \%$ of the total liquor solids, and results of a number of analyses showed that the solids composition for the liquor collected and for the final exhaustive wash were identical; therefore, the liquor collected is representative of the total liquor.

A sample of the liquor-wash solution was taken and retained for analysis. The black liquor-wash solution was then concentrated in two steps using an Artisan horizontal, wiped film, nominal one $\mathrm{ft}^{2}\left(0.093 \mathrm{~m}^{2}\right)$ evaporator. A full description of this evaporator system has been given in earlier reports (Fricke, 1987, Fricke, 1990). The liquor was first evaporated to a concentration of $27-29 \%$ solids, cooled, and the soap removed by decanting. The liquor was then concentrated in a second step to $43-47 \%$ solids, placed in 5 gallon (18.9 liter) HDPE containers, nitrogen blanketed, and sealed. These were stored at $4^{\circ} \mathrm{C}$ until needed for properties studies. Earlier work had shown that kraft black liquor stored in this fashion remains unchanged for very long periods of time.

A schematic illustrating the path that was used for every liquor produced in this program is given in Figure 2.1. There was only one reversal of this path. Liquor that had been soap skimmed and stored at $43-47 \%$ solids and $4{ }^{\circ} \mathrm{C}$ was used for properties evaluation at solids concentrations below $43-47 \%$ by diluting the liquor with water to the desired concentration. This was done to conserve cold storage space, but does yield valid results. Earlier work had shown that diluted liquors exhibit the same properties as fresh liquors of the same concentration if the kraft black liquor to be diluted is at less than $50 \%$ solids.

\subsection{Pulping Conditions and Pulping Experimental Design}

There are many pulping variables that could be investigated, but the principal ones are effective (or active) alkali, sulfidity, temperature, and time at temperature. A multi-level, BoxWilson rotatable composite experimental design with limited center point replicates was adopted for

the four variable experiment. The actual ranges for the variables were set with the advice of 
Figure 2.1

Schematic of Process Path

for Black Liquor Treatment and Handling

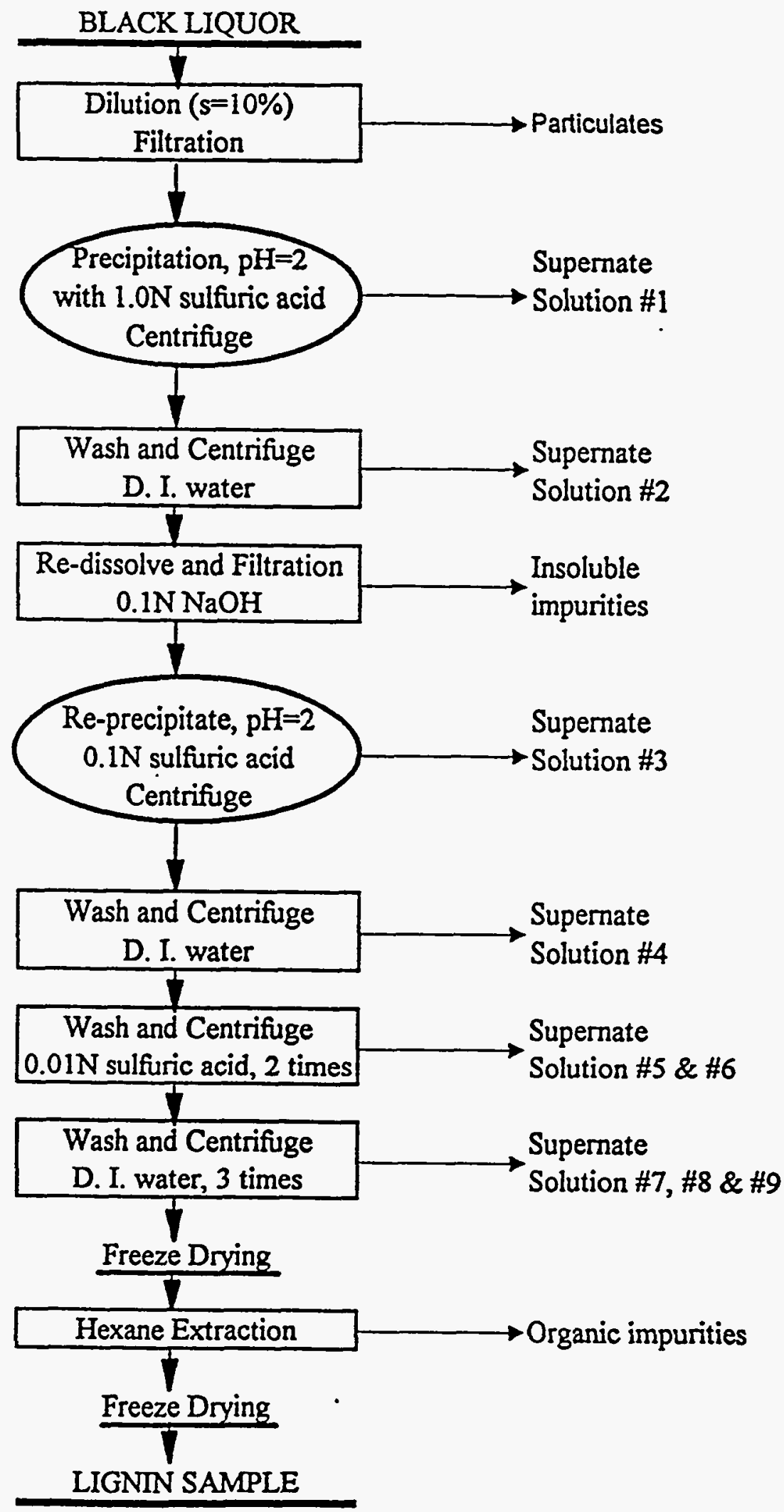


industrial experts to include all important conditions for pulping Southern softwood. The ranges set for pulping variables were:

$\begin{array}{ll}\text { Effective Alkali: } & 11.5-17.5 \% \\ \text { Sulfidity: } & 12.5-42.5 \% \\ \text { Temperature: } & 320-360^{\circ} \mathrm{F}\left(433.3-455.8^{\circ} \mathrm{K}\right) \\ \text { Time at Temperature: } & 20-100 \text { minutes }\end{array}$

The coded and actual conditions for each experimental point in the design are given in Table 2.1. It was expected that pulp with Kappa Numbers ranging from 20 to $90+$ would result.

Synthetic white liquors were used and a number of pulping variables were set. Synthetic white liquors were prepared from chemical grade $\mathrm{NaOH}, \mathrm{Na}_{2} \mathrm{~S}, \mathrm{Na}_{2} \mathrm{CO}_{3}$, and $\mathrm{Na}_{2} \mathrm{SO}_{4}$ to be equivalent to a liquor at $93 \%$ reduction and $85 \%$ causticizing efficiency. The wet chip load was kept relatively constant at $65-70 \mathrm{lbs}(29.5-31.7 \mathrm{kgs})$, and the liquor-to-dry wood ratio used was always 4/1. Time-to-temperature was constant at 20 minutes. Two washes, each equivalent to half the liquor charge, were used. The final wash that was discarded was 100 gallons $\left(0.379 \mathrm{~m}^{3}\right)$ or slightly more.

Commercial slash pine chips obtained from a local mill were used. This introduced variation in chips, because all chips were not the same; chips were obtained periodically in lots sufficient for six to eight digester runs. However, the variation introduced no doubt reflects the variation to be expected at mills. The chips as received were spread thinly and chips with bark removed by hand. The chips used had a maximum dimension of $2.88 \mathrm{~cm} \pm 0.88 \mathrm{~cm}$. After bark removal, the chips were thoroughly mixed, sampled, divided into batches of about $70 \mathrm{lbs}$ ( 31.75 $\mathrm{kgs}$ ), and sealed in plastic bags until used. The chip samples (usually three samples of $0.5 \mathrm{kgs}$ each) were oven dried to determine chip moisture as per TAPPI standards.

A digester cook normally required nearly 2 man-weeks to complete, including liquor concentration and soap skimming. Digester cooks were duplicated at each experimental condition. 
TABLE 2.1

Kraft Pulping Experimental Design

\begin{tabular}{|c|c|c|c|c|c|c|c|c|}
\hline \multirow[b]{3}{*}{ No. } & \multicolumn{8}{|c|}{ VARIABLES } \\
\hline & \multicolumn{4}{|c|}{ Coded } & \multicolumn{4}{|c|}{ Values } \\
\hline & $\mathrm{EA}$ & $S$ & $\mathbf{t}$ & $\mathrm{T}$ & EA, \% & $S, \%$ & $t$, Min. & $\mathrm{T},{ }^{\circ} \mathrm{F}$ \\
\hline 1 & -1 & -1 & -1 & -1 & 13 & 20 & 40 & 330 \\
\hline 2 & -1 & -1 & 1 & 1 & 13 & 20 & 80 & 350 \\
\hline 3 & 1 & -1 & 1 & -1 & 16 & 20 & 80 & 330 \\
\hline 4 & 1 & -1 & -1 & 1 & 16 & 20 & 40 & 350 \\
\hline 5 & -1 & 1 & 1 & -1 & 13 & 35 & 80 & 330 \\
\hline 6 & -1 & 1 & -1 & 1 & 13 & 35 & 40 & 350 \\
\hline 7 & 1 & 1 & -1 & -1 & 16 & 35 & 40 & 330 \\
\hline 8 & 1 & 1 & 1 & 1 & 16 & 35 & 80 & 350 \\
\hline 9 & -1 & -1 & 1 & -1 & 13 & 20 & 80 & 330 \\
\hline 10 & -1 & -1 & -1 & 1 & 13 & 20 & 40 & 350 \\
\hline 11 & 1 & -1 & -1 & -1 & 16 & 20 & 40 & 330 \\
\hline 12 & 1 & -1 & 1 & 1 & 16 & 20 & 80 & 350 \\
\hline 13 & -1 & 1 & -1 & -1 & 13 & 35 & 40 & 330 \\
\hline 14 & -1 & 1 & 1 & 1 & 13 & 35 & 80 & 350 \\
\hline 15 & 1 & 1 & 1 & -1 & 16 & 35 & 80 & 330 \\
\hline 16 & 1 & 1 & -1 & 1 & 16 & 35 & 40 & 350 \\
\hline 17 & 0 & 0 & 0 & 0 & 14.5 & 27.5 & 60 & 340 \\
\hline 18 & 0 & 0 & -2 & 0 & 14.5 & 27.5 & 20 & 340 \\
\hline 19 & 0 & 0 & 2 & 0 & 14.5 & 27.5 & 100 & 340 \\
\hline 20 & 0 & 0 & 0 & -2 & 14.5 & 27.5 & 60 & 320 \\
\hline 21 & 0 & 0 & 0 & 2 & 14.5 & 27.5 & 60 & 360 \\
\hline 22 & -2 & 0 & 0 & 0 & 11.5 & 27.5 & 60 & 340 \\
\hline 23 & 2 & 0 & 0 & 0 & 17.5 & 27.5 & 60 & 340 \\
\hline 24 & 0 & -2 & 0 & 0 & 14.5 & 12.5 & 60 & 340 \\
\hline 25 & 0 & 2 & 0 & 0 & 14.5 & 42.5 & 60 & 340 \\
\hline
\end{tabular}

$\mathrm{EA}=$ effective alkali, $\%$

$\mathrm{T}=$ Temperature, ${ }^{\circ} \mathrm{F}$
$\mathrm{S}=$ sulfidity,$\%$

$\mathrm{t}=$ time at temperature, minutes 
A complete rotatable designed experiment was done with liquor circulation and a partial design was done with a closed, rotating digester. If the Kappa Number and the pulp yield for duplicate cooks did not agree within certain limits, the black liquors and pulp were discarded and the digestion at that experimental condition was repeated. Approximately 100 total cooks were performed. However, the quantitative evaluation of properties is based upon the black liquors produced in the rotatable composite Box-Wilson design with liquor circulation during digestion.

A complete description of the experimental design used with coded and actual values for each of the four variables is given in Table 2.1.

\subsection{Pulp Yield and Kappa Number}

Time and temperature were treated as separate and independent pulping variables for purposes of black liquor properties variation. However, it is known that a combination of these two variables, called the H-Factor can be used as a variable for correlating some responses. The H-Factor is defined as (Vroom, 1957):

$$
H-\text { Factor }=H=\int_{0}^{t} \exp [43.2-16,113 / T] d t
$$

where: $\quad \mathrm{T}=$ temperature, ${ }^{\circ} \mathrm{K}$

$$
\mathrm{t}=\text { time, hours }
$$

Complete results for yield, Kappa Number, and H-Factor for each cook for the experiments conducted with liquor circulation are given elsewhere (Dong, 1993). 


\subsubsection{Data Analysis and Correlation}

Our general approach was to use response surface analysis. A complete quadratic model:

$$
Y=a_{o}+\sum_{i=1}^{k} a_{i} X_{i}+\sum_{i=1}^{k} a_{i c} X_{i}^{2}+\sum_{i<j}^{k} a_{i j} X_{i} X_{j}
$$

was tested where:

$$
\begin{aligned}
& Y=\text { estimate of response (dependent variable) } \\
& X_{i}=\text { independent variable, } i \\
& a_{0}, a_{i}, a_{i i}, a_{i j}=\text { regression parameters }
\end{aligned}
$$

This types of model was tested using RSREG procedures and Mallow's statistic as a criterion. The parameters determined for the best fits of Kappa Number and yield are given in Table 2.2.1. These equations can be used to construct contour surfaces for yield and Kappa Number response to any two of the four pulping variables with the other two set at constant values. The regression coefficient is only about 0.92 for these variables. As will be discussed in a publication included as part of this report, analysis of an earlier experiment conducted in a rotating digester with the same wood species, but where all digester cooks were conducted using one lot of chips, gave the regression coefficients were about 0.98 . It appears that the difference is due principally to lot-tolot variations in the chips in the circulation experiments.

Inspection of the parameters in Table 2.2.1 shows that the linear effects dominate with significant contributions of only a few of the higher order effects. This, as well as results of prior studies directed us toward evaluation of simpler models. Yield was related to Kappa Number for results of both our circulation pulping data and the earlier rotating digester data taken with the same wood species. These are equations of the form:

$$
\mathrm{A}+\mathrm{BK}
$$


TABLE 2.2.1

Parameters for Predictive Models for Kappa Number and Pulp Yield

\begin{tabular}{|c|c|c|c|}
\hline \multicolumn{2}{|c|}{ Pulp Yield } & \multicolumn{2}{|c|}{ Kappa Number } \\
\hline INTERCEPT & $1.844 \mathrm{E}+2$ & INTERCEPT & $5.206 \mathrm{E}+2$ \\
\hline $\mathrm{EA}$ & $5.148 \mathrm{E}+1$ & $\mathrm{EA}$ & $9.069 \mathrm{E}+1$ \\
\hline$S$ & $-3.904 \mathrm{E}+0$ & $S$ & $-1.077 \mathrm{E}+1$ \\
\hline $\mathrm{t}$ & $-8.880 \mathrm{E}+0$ & $\mathbf{t}$ & $-7.053 \mathrm{E}+0$ \\
\hline EA*EA & $-3.517 \mathrm{E}-1$ & $t^{*} t$ & $9.667 \mathrm{E}-3$ \\
\hline $\mathrm{t}^{*} \mathrm{t}$ & $5.393 \mathrm{E}-3$ & $\mathrm{EA} * \mathrm{~S}$ & $-2.627 \mathrm{E}+0$ \\
\hline $\mathrm{EA} * \mathrm{~S}$ & $-1.283 E+0$ & $\mathrm{EA}^{*} \mathrm{t}$ & $-6.346 \mathrm{E}-1$ \\
\hline $\mathrm{EA}^{*} \mathrm{t}$ & $1.032 \mathrm{E}-1$ & $\mathrm{EA} * \mathrm{~T}$ & $-3.294 \mathrm{E}-1$ \\
\hline $\mathrm{EA} * \mathrm{~T}$ & $-1.553 \mathrm{E}-1$ & $\mathrm{~S} * \mathrm{t}$ & 8.130E-1 \\
\hline$S^{*} \mathrm{t}_{\mathrm{t}}$ & $2.447 \mathrm{E}-1$ & $\mathrm{EA} * \mathrm{~S} * \mathrm{t}$ & $-1.160 \mathrm{E}-2$ \\
\hline$T * t$ & $1.913 \mathrm{E}-2$ & $\mathrm{EA} * \mathrm{~S} * \mathrm{~T}$ & $9.262 \mathrm{E}-3$ \\
\hline $\mathrm{EA} * \mathrm{~S} * \mathrm{~T}$ & $4.484 \mathrm{E}-3$ & $\mathrm{EA} * \mathrm{t} * \mathrm{~T}$ & $2.749 \mathrm{E}-3$ \\
\hline $\mathrm{S} * \mathrm{~T} * \mathrm{t}$ & $-6.040 \mathrm{E}-4$ & $\mathrm{~S} * \mathrm{~T} * \mathrm{t}$ & $-1.789 \mathrm{E}-3$ \\
\hline$E A * W * T * t$ & $-7.300 \mathrm{E}-6$ & & \\
\hline$p$ & 13.00 & & 12.00 \\
\hline $\mathrm{Cp}$ & 10.54 & & 7.76 \\
\hline R-square & 0.9445 & & 0.9332 \\
\hline AdjR-square & 0.9177 & & 0.9082 \\
\hline SQroot MSE & 2.26 & & 7.94 \\
\hline P-value & 0.0001 & & 0.0001 \\
\hline
\end{tabular}

Note

EA -- effective alkali (\%), S -- sulfidity (\%), t -- time-at-temperature (minute), $\mathrm{T}$-- cooking temperature $(\mathrm{F}), \mathrm{p}$-- number of non-constant terms in the model, $\mathrm{Cp}$-- Mallow's statistic, P-value - significant value.

SQroot MSE -- square root of the residual mean square. 
and

$$
\mathrm{Y}=\mathrm{A}+\mathrm{BK}+\mathrm{CK}^{2}
$$

where:

$\mathrm{Y}=$ pulp yield, $\%$

$\mathrm{K}=$ Kappa Number

$\mathrm{A}, \mathrm{B}, \mathrm{C}=$ regression constants

$$
\begin{aligned}
& \text { reprint removed. } \\
& \text { Edifor excludes use } \\
& \text { in qn electronis }
\end{aligned}
$$

Complete analysis is given in the publication: Zaman, A.A., D.J. Dong, and A.L. Fricke, "Kraft Pulping of Slash Pine" AIChE 1991 Forest Products Symposium, 49-57 (1992), which is included as part of this report. In addition, non-linear models for yield and Kappa Number were developed using the H-Factor that are of the form:

$$
\mathrm{Y}, \mathrm{K}=\mathrm{A}-\mathrm{B}[\ln \mathrm{H}][\mathrm{EA}]^{\mathrm{c}}[\mathrm{S}]^{\mathrm{d}}
$$

where:

$$
\begin{aligned}
& \mathrm{Y}=\text { pulp yield } \% \\
& \mathrm{~K}=\text { Kappa Number } \\
& \mathrm{H}=\mathrm{H} \text {-Factor } \\
& \mathrm{EA}=\text { effective alkali } \\
& \mathrm{S}=\text { sulfidity }
\end{aligned}
$$

A, B, c, d = regression constants

Values for the constants for each equation are given in the publication. 
The second order equations (equation 2.2.3) yielded regression coefficients of 0.98 and 0.92 for rotational and circulation experiments. Again, the difference is probably due principally to chip variations in the circulation digester experiment. Non-linear equations of the form of equation 2.2.4 were fitted to both sets of data with improvements in the correlation coefficients to $0.98+$ for both sets of data for both Kappa Number and yield. Data at constant sulfidity (two-levels) were fitted to:

$$
\mathrm{Y}=\mathrm{A}-\mathrm{B}[\ln \mathrm{H}][\mathrm{EA}]^{\mathrm{c}}
$$

as suggested by Hatton (Hatton, 1972, Hatton, 1973), with regression coefficients of $0.99+$ for both experiments. As expected, effective alkali has the greater effect on yield and sulfidity has the greater effect on Kappa Number.

The recommended non-linear equations for yield and Kappa Number for circulation and rotational digestion of slash pine are:

Rotation:

$$
\begin{aligned}
& \mathrm{Y}=112.48-3.135[\ln \mathrm{H}][\mathrm{EA}]^{0.316}[\mathrm{~S}]^{0.056} \\
& \mathrm{~K}=463.56-18.24[\ln \mathrm{H}][\mathrm{EA}]^{0.337}[\mathrm{~S}]^{0.085}
\end{aligned}
$$

Circulation:

$$
\begin{aligned}
& \mathrm{Y}=118.27-2.315[\ln \mathrm{H}][\mathrm{EA}]^{0.438}[\mathrm{~S}]^{0.06} \\
& \mathrm{~K}=303.78-6.53[\ln \mathrm{H}][\mathrm{EA}]^{0.492}[\mathrm{~S}]^{0.11}
\end{aligned}
$$


These equations summarize quantitatively our pulping results. Pulping experiments performed after these equations were developed yielded results in agreement with the equations. Graphs of results are included in the publication on pulping that is part of this report (Zaman, Dong, Fricke, 1992). 


\subsection{LIQUOR ANALYSIS}

Analysis of the liquors produced in the digester experiments was an integral part of the total program. Detailed descriptions of the analytical procedures used have been given in an earlier report (Fricke et al., 1997). Analysis of each liquor consisted of quantitative determination of sulfide, sulfite, thiosulfate, sulfate, carbonate, and oxalate negative ions; sodium, potassium, calcium, and magnesium content; formate, acetate, lactate/glycolate, and lignin content; and pH, residual active alkali, and sulfated ash (organic-to-inorganic ratio). These were all reported as a mass fraction or wt\% of total black liquor solids.

Results are given in Table 3.0.1. Generally, results summed to 78 to $85 \%$. The remainder is presumed to be cellulosic degradation products that are higher in molecular weight than lactate. The potassium, magnesium, calcium, and chloride were present in traces in the chemical used to make synthetic white liquors and some of these constituents were also extracted from the wood chips. All are present only in small quantities in the liquors with no significant correlation with respect to pulping conditions. In general, sulfide is converted substantially to other, more oxidized, sulfur ions or is reacted with the lignin. The sum of quantities of oxalate, formate, acetate, and glycolate/lactate is a significant quantity, but there is no significant correlation with pulping conditions. However, sodium and lignin content and organic/inorganic ratio varied significantly with pulping conditions, as expected. These, particularly lignin content, were explored extensively in correlating properties.

If considerable amounts of some of the ions present here in only small amounts-chloride, magnesium, potassium, and calcium—should be present in a mill white liquor in significant amounts, effects on some properties (particularly viscosity) could be substantial because of the resulting association effects with organics. This has been investigated to some extent in auxiliary work on zeta-potential changes for lignin with respect to concentration of these ions (Dong, 1993, Dong et al., 1996). However, that is not part of this study. 


\begin{tabular}{|c|c|c|c|c|c|c|c|c|c|}
\hline$\% 0 \div 59$ & $\%<\cdot 19$ & $\% 269$ & $\% 6 ' 59$ & $\% 029$ & $\% 9: \angle 9$ & $\% 1.89$ & $\% 9 \%$ & $\% L^{\prime} 69$ & Spuebso \% \\
\hline $98 \% \mathrm{~L}$ & $19 \%$ & 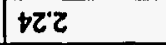 & 66.1 & E9! & $60 \% 2$ & $\$ 1 \cdot 2$ & $29 \cdot 2$ & $0 \varepsilon 2$ & O|fes o|uebsou!/p|uebso \\
\hline †ध६०० & $25 \varepsilon^{\circ} 0$ & $082 ' 0$ & $\angle 0 \varepsilon^{\prime} 0$ & $\varepsilon 0 \varepsilon^{\circ} 0$ & 1820 & 2020 & $\varepsilon \Delta Z^{\circ} 0$ & $\angle E Z^{\prime} O$ & श|ue61ou! \\
\hline $619^{\circ} 0$ & 9990 & $\angle 29^{\circ} 0$ & $769^{\circ} 0$ & S6to & $\angle 8 S^{\circ} 0$ & LOS'O & E190 & tog.0 & गlueBı \\
\hline $75 \cdot 8$ & 066 & $00^{\circ} \mathrm{L}$ & LI' $\varepsilon$ & $\forall N *$ & $8 \varepsilon^{\prime} 9$ & $2 L^{\circ} 6$ & $9 \varepsilon^{\prime} !$ & SL'Z & OZEN \&B ᄀ/B Z ZVZ \\
\hline$\rightarrow O L$ & OLLL & $z r^{\circ} L$ & $\varepsilon Z^{\prime S}$ & OL:bl & $62 \cdot \varepsilon$ & $59^{\circ} 9$ & $08 \%$ & $2 s^{\prime} L$ & OZEN $\triangle 87 B$ L $\forall Y$ \\
\hline \multicolumn{10}{|c|}{ 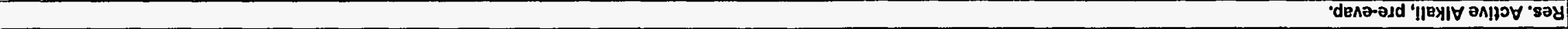 } \\
\hline l'9ع & $8^{\prime} 9 \varepsilon$ & 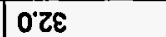 & t $\varepsilon \varepsilon$ & $9.2 \varepsilon$ & $L \cdot t \varepsilon$ & $\varepsilon^{\prime}\llcorner\varepsilon$ & 2.62 & $9.1 \varepsilon$ & HOEN \% 'yse pajejuns \\
\hline $00+\exists 8 \angle 00^{\circ} \mathrm{L}$ & 10-تGLER: 6 & $10-\exists 6 S 61.6$ & LO-JLELO'6 & $00+\exists 0<Z+Z$ & LO-J1225'8 & 10-30902'8 & 10- 368958 & $10-36668.2$ & sfuasoduros fo uns \\
\hline ES6:0 & 8160 & $\angle 06{ }^{\prime} 0$ & $006^{\prime} 0$ & $\angle 6 L^{\circ} O$ & $898^{\circ} 0$ & EZ8'0 & 9980 & $08 L^{\circ} 0$ & $2-5$ Jnou!!M 'wns \\
\hline $9 \angle 60^{\circ} 0$ & $856^{\circ} 0$ & $2266^{\circ} 0$ & 8160 & $\$ 180$ & $2 \angle 8^{\prime} 0$ & $9288^{\circ}$ & $298^{\circ} 0$ & S8L'0 & sjuauoduros jo uns \\
\hline$+0-3989$ & $60-39 L^{\circ} S$ & $+0-\exists 0 L L$ & 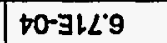 & $60-3 \angle 9^{\prime} \varepsilon$ & $\varepsilon 0-\exists 80^{\circ} \mathrm{L}$ & เ0-7เ6'9 & $\$ O-\exists \angle 9^{\circ} \angle$ & EO-Jgl'L & un|sse\}̧od \\
\hline 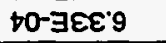 & to-ヨLE'S & to- 359.2 & t0- $\exists \angle 8.6$ & $+0-3 b z !$ & t0- 326.9 & $60-381^{\prime} 9$ & $80-381 \%$ & $+0-\exists \varepsilon<\prime 9$ & unţsaubeu \\
\hline 80-בL8! & EO-3LE'L & $80-329^{\circ} !$ & $80-\exists 8 L 2 Z$ & $50-316.9$ & $80-36 b^{\circ} !$ & $80-36 t^{\circ}$ & 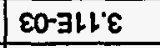 & $80-\exists 88^{\circ}$ & un!iㅣㅣㅇ \\
\hline $826 \varepsilon^{\circ} 0$ & $8 \varepsilon 8 \varepsilon^{\circ} 0$ & DLLtOO & $\nabla L Z \nabla^{\circ} 0$ & Etrot'o & $\angle 800^{\circ} 0$ & $86 \angle E^{\circ} 0$ & 9tet'o & $005 \varepsilon^{\circ} 0$ & u!uB!! \\
\hline $20-\exists \angle z^{\prime} z$ & $20-\exists 66^{\circ} \varepsilon$ & $20-39911$ & $20-3181$ & $20-399 \div$ & $\varepsilon 0-\exists \varepsilon 0^{\circ} t$ & $80-309 ' 2$ & to- $360^{\prime} \mathrm{C}$ & $80-398^{\circ} t$ & әpıщ]ns \\
\hline $10-\exists \angle 0^{\circ} 2$ & 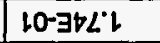 & $10-\exists \angle b^{\prime} L$ & Lo-ヨ96'L & $10-\exists 28 \mathrm{~L}$ & LO-J09:L & LO-JZLLL & 10-3tE:L & 10-ヨZS'L & unipos \\
\hline $20-3+6.6$ & $20-386^{\circ} t$ & $20-37 L ' S$ & $20-391^{\circ} \mathrm{t}$ & $20-391 \cdot 2$ & $20-\exists 9 L^{\prime} \varepsilon$ & $20-3266^{\circ}$ & ZO-J8L' $\varepsilon$ & $20-\exists 61.9$ & өзе|әэв \\
\hline $20-\exists \angle L \angle$ & $20-\exists 089$ & $20-3 \varepsilon L 2 L$ & $20-380 \% 9$ & $20-\exists \varepsilon b^{\circ} t$ & $20-\exists 2099$ & 20-39L'S & $20-35099$ & $20-396 \% 9$ & จุвسرо। \\
\hline 20-3L6 6 & $20-\exists \varepsilon 9^{\prime} 9$ & $20-320 \% \mathrm{~L}$ & $20-38899$ & $20-31272$ & $20-\exists 9+2$ & $20-3 \angle<9$ & $20-389 \%$ & $20-\exists 89: 9$ & 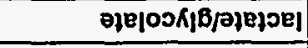 \\
\hline $20-\exists 999$ & $20-\exists 9899$ & $20-\exists 89^{\prime} 9$ & $20-\exists 9 \phi^{\circ} \mathrm{s}$ & $20-\exists Z L L$ & $20-3 Z 1 \cdot 9$ & $20-388^{\prime} \mathrm{Z}$ & 20- $32 \varepsilon: 9$ & $20-368^{\prime} z$ & 캉oqjes \\
\hline $20-\exists Z \varepsilon \cdot 9$ & $20-\exists 8 Z^{\prime} L$ & $20-\exists L L \cdot \varepsilon$ & $20-389 ' s$ & ZO-JZL'E & $20-3966^{\circ} Z$ & $Z 0^{\prime}-\exists Z \sigma^{\prime} \varepsilon$ & ZO-ヨZL:Z & ZO- $\exists 8 Z^{\prime} \varepsilon$ & 카jnsolul \\
\hline 80-ヨ8l:s & $\varepsilon 0-\exists 9 \varepsilon \varepsilon^{\prime} t$ & $80-300 \mathrm{~s}$ & $\varepsilon 0-\exists 9 L^{\circ} \mathrm{s}$ & $\varepsilon 0-\exists 92 \cdot 2$ & $\varepsilon 0-\exists \angle 9^{\prime} S$ & EO- $3 \angle Z^{\prime} 9$ & EO-JS6"t & $80-36 \varepsilon^{\circ} 9$ & 갈exo \\
\hline $20-\exists 80 ' z$ & $20-\exists \varepsilon 6^{\circ} L$ & zo-झzs'z & $20-\exists Z 2 Z 2$ & $E 0-3 \angle L L$ & $20-300^{\circ} 1$ & $20-361$. & $20-\exists 871$ & $20-\exists z \theta^{\circ}$ & әృеग्रs \\
\hline عO-ヨGLE & $\varepsilon 0-\exists \vdash L 2$ & $80-\exists+\angle ' S$ & $80-36 l^{\circ} \mathrm{s}$ & so- $\exists 01 \% s$ & $\varepsilon 0-\exists Z Z^{\prime} \varepsilon$ & $\varepsilon 0-\exists L L L$ & $\varepsilon 0-\exists 81 \varepsilon$ & $\varepsilon 0-\exists 8 L Z$ & ə)!yns \\
\hline$\varepsilon 0-\exists 0)^{\prime} \varepsilon$ & $80-3+6 \cdot 2$ & $80-369^{\circ} Z$ & $\varepsilon 0-\exists z t^{\circ} z$ & 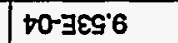 & 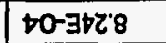 & $10-3296$ & t0-310'9 & $\varepsilon 0-\exists Z \Omega^{\prime} Z$ & әр!נ잉 \\
\hline \multirow[t]{2}{*}{8} & 2 & 9 & 9 & $b$ & 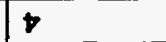 & $\varepsilon$ & 2 & 1 & -oN juawjJadxヨ Bu!d!nd \\
\hline & & & & & & & & & 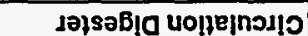 \\
\hline
\end{tabular}

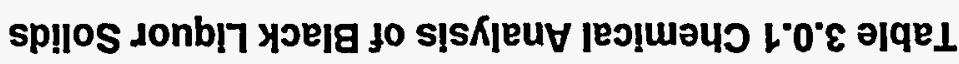


Table 3.0.1 Chemical Analysis of Black Liquor Solids

\begin{tabular}{|c|c|c|c|c|c|c|c|c|c|}
\hline \multicolumn{10}{|l|}{ Circulation Digester } \\
\hline Pulping Experiment No. & 9 & 10 & 11 & 12 & 13 & 14 & 15 & 16 & $\overline{17}$ \\
\hline chloride & $<1.10 \mathrm{E}-05$ & $<1.10 E-05$ & 4.31E-03 & 3.77E-03 & $2.89 E-03$ & 1.70E-03 & 9.34E-04 & 2.51E-03 & 3.47E-03 \\
\hline sulfite & $3.10 E-03$ & $3.40 E-03$ & $1.92 \mathrm{E}-03$ & 2.31E-03 & $3.98 E-03$ & $5.46 E-03$ & $2.50 \mathrm{E}-03$ & $3.39 E-03$ & 2.94E-03 \\
\hline sulfate & $1.62 E-02$ & $1.72 \mathrm{E}-02$ & $1.73 E-02$ & $1.05 \mathrm{E}-02$ & $1.60 \mathrm{E}-02$ & $1.24 E-02$ & 1.10E-02 & $2.38 \mathrm{E}-02$ & 2.44E-02 \\
\hline oxalate & 6.59E-03 & 6.47E-03 & 6.99E-03 & $6.16 \mathrm{E}-03$ & $3.75 E-03$ & 2.92E-03 & 2.27E-03 & 4.79E-03 & $6.22 E-03$ \\
\hline thiosulfate & $3.43 E-02$ & $3.21 E-02$ & $4.23 E-02$ & $4.23 E-02$ & $6.11 E-02$ & $2.92 \mathrm{E}-02$ & $2.05 E-02$ & 6.23E-02 & $4.70 E-02$ \\
\hline carbonate & $4.65 E-02$ & 6.17E-02 & $6.91 E-02$ & $4.54 E-02$ & $2.42 E-02$ & $1.54 \mathrm{E}-02$ & $6.44 E-03$ & $2.26 \mathrm{E}-02$ & $6.02 E-02$ \\
\hline lactate/glycolate & $7.85 E-02$ & $7.75 \mathrm{E}-02$ & $7.71 \mathrm{E}-02$ & 6.93E-02 & 6.47E-02 & $5.19 \mathrm{E}-02$ & $2.67 E-02$ & 6.17E-02 & 8.06E-02 \\
\hline formate & $6.95 \mathrm{E}-02$ & 7.01E-02 & 6.01E-02 & 5.64E-02 & $6.38 \mathrm{E}-02$ & $4.89 E-02$ & $2.16 E-02$ & 5.19E-02 & 7.08E-02 \\
\hline acetate & 5.07E-02 & $4.70 \mathrm{E}-02$ & $3.75 \mathrm{E}-02$ & $3.59 E-02$ & $5.04 E-02$ & $3.02 \mathrm{E}-02$ & $1.60 E-02$ & $3.14 \mathrm{E}-02$ & 5.49E-02 \\
\hline sodium & 1.46E-01 & 1.62E-01 & $1.80 \mathrm{E}-01$ & $1.60 E-01$ & $1.64 E-01$ & 1.37E-01 & 1.65E-01 & $1.53 \mathrm{E}-01$ & 1.53E-01 \\
\hline sulfide & $4.42 E-03$ & $<2.00 E-05$ & 1.30E-03 & $9.82 E-03$ & 2.69E-02 & $1.60 \mathrm{E}-02$ & $3.31 E-02$ & 2.96E-02 & 1.87E-02 \\
\hline lignin & 0.4075 & 0.4274 & 0.3444 & 0.4397 & 0.3785 & 0.4227 & 0.4062 & 0.4041 & 0.4178 \\
\hline calcium & $1.48 \mathrm{E}-03$ & $1.39 \mathrm{E}-03$ & $1.78 \mathrm{E}-03$ & $1.26 \mathrm{E}-03$ & $1.00 E-03$ & $1.52 \mathrm{E}-03$ & 9.14E-04 & 9.22E-0.4 & $2.22 \mathrm{E}-03$ \\
\hline magnesium & $7.48 \mathrm{E}-04$ & 7.00E-04 & $6.56 \mathrm{E}-0.4$ & 5.23E-04 & $4.56 \mathrm{E}-0.4$ & $6.09 E-04$ & 4.03E-04 & $4.15 \mathrm{E}-04$ & $7.77 \mathrm{E}-04$ \\
\hline potassium & $6.25 E-04$ & 7.04E-04 & 6.78E-04 & 5.27E-04 & 4.84E-04 & $3.27 E-04$ & $3.43 E-04$ & 5.79E-04 & 7.17E-04 \\
\hline sum of components & 0.863 & 0.890 & 0.831 & 0.886 & 0.887 & 0.775 & 0.717 & 0.866 & 0.953 \\
\hline sum, without S-2 & 0.858 & 0.890 & 0.830 & 0.876 & 0.860 & 0.759 & 0.683 & 0.836 & 0.935 \\
\hline Sum of components & $8.6611 E-01$ & $9.0711 E-01$ & $8.4574 E-01$ & $1.4646 E+01$ & $1.5810 E+01$ & $1.6310 E+01$ & $1.7114 E+01$ & $1.8555 E+01$ & $1.8831 E+01$ \\
\hline sulfated ash, \% $\mathrm{NaOH}$ & 34.2 & 32.7 & 35.9 & 34.6 & 33.7 & 28.6 & 31.9 & 31.6 & 33.2 \\
\hline \multicolumn{10}{|c|}{ Res. Active Alkall, pre-evap. } \\
\hline RAA 1 gll as Na2O & 5.69 & 2.46 & 9.63 & 7.82 & 8.12 & 3.32 & 8.27 & 12.00 & 6.77 \\
\hline RAA 2 gh as Na2O & 3.25 & 3.98 & 9.42 & 5.10 & "NA & 4.34 & 8.93 & 9.71 & 6.08 \\
\hline organic & 0,613 & 0.628 & 0.526 & 0.607 & 0.561 & 0.557 & 0.473 & 0.554 & 0.630 \\
\hline Inorganlc & 0.245 & 0.262 & 0.304 & 0.269 & 0.299 & 0.202 & 0.211 & 0.283 & 0.304 \\
\hline organic/inorganic ratio & 2.50 & 2.40 & 1.73 & 2.26 & 1.88 & 2.75 & 2.24 & 1.96 & 2.07 \\
\hline$\%$ organic & $71.4 \%$ & $70.6 \%$ & $63.4 \%$ & $69,3 \%$ & $65.2 \%$ & $73.3 \%$ & $69.2 \%$ & $66.2 \%$ & $67.4 \%$ \\
\hline
\end{tabular}




\begin{tabular}{|c|c|c|c|c|c|c|c|c|c|c|}
\hline$\% 6^{\circ}<9$ & $\% 0 \notin 9$ & $\% 829$ & $\% 1$ s9 & $\%<289$ & $\% 9$ & $\% S^{\prime 2 L}$ & $\% 9^{\circ} \varepsilon 9$ & $\% 5^{\prime} 09$ & $\% \varepsilon^{\prime 09}$ & गjueBso \% \\
\hline$H \cdot 2$ & $0 L ' L$ & 69.1 & $98 \%$ & $6 L \cdot Z$ & $\forall L^{\circ} L$ & $69 \cdot 2$ & $9 L^{\circ} \mathrm{L}$ & $\varepsilon g^{\prime \prime}$ & ZS:L & Olןes गุueBsou|/p)ueBso \\
\hline 8920 & 6620 & $\angle O E^{\prime} O$ & $0 \angle Z O$ & 9920 & $92 \varepsilon^{\prime} 0$ & 8920 & $0 Z \nabla^{\circ} 0$ & $098^{\circ} 0$ & $062 \% 0$ & OjueBsou| \\
\hline S99.0 & $809^{\prime} 0$ & 6LG'0 & tog'0 & L89'0 & $999^{\prime} 0$ & $089^{\circ} 0$ & 98\%० 0 & $299^{\prime} 0$ & $00 t 0$ & 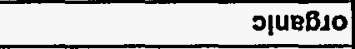 \\
\hline $6 L^{\prime \prime} \phi$ & $\angle 0^{\circ} 8$ & 86.9 & ob' $\varepsilon$ & $6 b^{\prime} 1$ & $\forall N$. & $t+6$ & $\forall N$. & $\forall N$. & 86.2 & OZEN SB T/B Z VVY \\
\hline \multirow[t]{2}{*}{$\mathrm{Ll} 6$} & $t \varepsilon^{\prime} 6$ & $60^{\circ} 6$ & th $\varepsilon$ & $90^{\prime} 2$ & sl. & SLt' & $69^{\prime} 6$ & 90.9 & $20 \%$ & OZEN $807 / B, \forall \forall Y$ \\
\hline & & & & & & & & & & 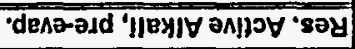 \\
\hline $82 \varepsilon$ & $t z \varepsilon$ & 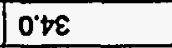 & $6.6 \varepsilon$ & 762 & t.le & $6.1 \varepsilon$ & $Z \angle \varepsilon$ & $0 \mathrm{Oz}$ & $6.9 \varepsilon$ & HOEN \% '4se poqej|ns \\
\hline $10+\exists 98+99^{\circ} z$ & $10+\exists L 9 t s i 2$ & $10+\exists \varepsilon 09^{\prime} Z$ & Lo+ヨZtEt $Z$ & LO+JtSSt $Z$ & $10+3 \varepsilon 89 \varepsilon^{\prime} z$ & LO+JZSBE: $Z$ & $10+\exists Z 9 \angle Z Z^{\prime} Z$ & $10+\exists Z \varepsilon \angle L \cdot 2$ & $10+\exists Z 120^{\circ} Z$ & s\}uauoduos to uns \\
\hline EE8'O & $808^{\circ} 0$ & $928^{\circ} 0$ & $7 \angle L O$ & 9780 & $268^{\circ} 0$ & $886^{\circ} 0$ & $506^{\circ} 0$ & 2160 & OEL'O & $z-5$ znoul!m 'wns \\
\hline$E E 8^{\prime} 0$ & $1 \varepsilon 8^{\prime} 0$ & $5+8^{\circ} 0$ & $28 \angle \cdot 0$ & $\angle S^{\circ} 0$ & $268^{\circ} 0$ & $\angle 96^{\circ} 0$ & $\angle Z 6^{\circ} 0$ & 9260 & $16 \angle 0$ & s\}uauoduros jo uns \\
\hline $40-\exists 6 \varepsilon^{\circ} L$ & $50-399^{\circ} L$ & $+0-\exists 90.9$ & to- $\exists \varepsilon+1 \varepsilon$ & $+0-\exists 8 L^{\prime} \mathrm{s}$ & $60.36 t 8$ & to- $36 t^{\prime} 9$ & t0-399:s & to- $\exists \varepsilon L^{\circ} \varepsilon$ & †0-JEع $\varepsilon$ & unlssejod \\
\hline t0-ISt'S & t0- $329^{\circ} \mathrm{L}$ & $60-3992 \mathrm{~L}$ & $50-369 \%$ & $80-3096$ & $50-\exists 6 L L$ & to-329.9 & 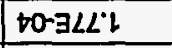 & to-369'L & $50-\exists 50^{\circ} \mathrm{L}$ & un!səuBeu \\
\hline$\varepsilon 0-\exists Z L: L$ & SO- $\exists \& L^{\prime} 6$ & $80-389^{\circ} \mathrm{Z}$ & SO- $\exists 61 ' 8$ & $\varepsilon 0-\exists 6 Z^{\prime 2} Z$ & SO- $\exists 96^{\circ} 9$ & $80-\exists Z 2 ! L$ & SO- $30 L^{\prime} 8$ & SO-JZL'9 & SO- $\exists \angle 8^{\circ} t$ & un!̣|go \\
\hline ELGE'O & t968'0 & $2900^{\circ} 0$ & t8680 & $691+0$ & ELEt 0 & $8627^{\circ} 0$ & SGEE'O & oostio & $2 S 9 \varepsilon^{\circ} 0$ & แ!ฺB!! \\
\hline tO-JELLL & $20-\exists 5 \varepsilon^{\circ} Z$ & $20-396.1$ & 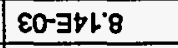 & $20-\exists 80^{\circ} \mathrm{L}$ & $00+\exists 00^{\prime} 0$ & $20-\exists Z 6$ ' & $20-3 \angle 1 \cdot 2$ & $20-\exists \angle \varepsilon^{\prime} L$ & $20-390^{\circ} !$ & әp!yıns \\
\hline Lo-35t't & 10- $399 \%$ & 10-3ts! 1 & LO-JLS' & 10-3001 & $10-\exists\langle b|$ & LO-JIS'L & 10-30L'L & 10-3tt: & LO- $369^{\circ} \mathrm{L}$ & unipos \\
\hline $20-\exists 21^{\circ}$ & $20-\exists b z^{\prime} \varepsilon$ & $20-\exists \angle 9^{\circ} \varepsilon$ & $20-\exists+1 \cdot \varepsilon$ & $20-38 z^{\circ}$ & $20-\exists 92 \varepsilon$ & $20-30 \varepsilon^{\prime} \mathrm{s}$ & $20-368^{\circ} t$ & $20-\exists 92 \cdot \varepsilon$ & $20-\exists+\varepsilon \cdot z$ & 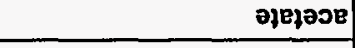 \\
\hline $20-\exists 08^{\prime} \mathrm{g}$ & $20-3 \angle 9^{\circ} 9$ & $20-\exists 0 t^{\prime} 9$ & $20-\exists Z 9 ' 9$ & $20-3+6.9$ & $20-300 \%$ & $20-367^{\circ} 8$ & $20-\exists Z E \angle$ & $20-35 t^{\circ} 9$ & $20-398^{\circ} \varepsilon$ & әявய1101 \\
\hline $20-\exists 9 Z^{\prime} 9$ & $20-3 \rightarrow z \cdot z$ & $20-329^{\circ} 1$ & $20-3 \angle 9^{\circ} l$ & $20-30 L 9$ & $20-3 \angle L \cdot 2$ & 10- $390 \%$ & $20-398$ ' & $20-\exists \rightarrow 2 \cdot 2$ & $20-\exists 00^{\circ} \mathrm{L}$ & 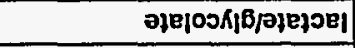 \\
\hline $20-\exists z+\sigma^{\circ} 9$ & $20-366^{\circ} \mathrm{L}$ & $20-380^{\circ} 9$ & 20-3L8'9 & $20-79 b^{\circ} 9$ & $10-\exists \angle 1 \div$ & $20-3+S^{\prime} \varepsilon$ & 10- $\exists 82:$ & 20-ヨเฉ'6 & $20-\exists Z 6^{\circ} \mathrm{S}$ & әреuоqueo \\
\hline 20-3Es' & $20-3<0^{\circ} t$ & $20-\exists 80 \% 9$ & 20-JLE'S & $20-\exists 6 z \varepsilon$ & $20-\exists 90^{\circ} \mathrm{s}$ & $20-\exists 26^{\circ} \varepsilon$ & $20-39 L^{\prime} 6$ & $20-3 \varepsilon 6^{\circ} \mathrm{L}$ & $20-\exists \varepsilon 0^{\circ} \mathrm{s}$ & 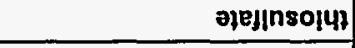 \\
\hline$\varepsilon 0-\exists 88^{\circ} \mathrm{S}$ & $80-\exists 69^{\circ} L$ & $80-\exists 19.9$ & $80-391 \cdot 2$ & E0-3Ll's & ع0-ヨع9" & Eo-3lt'9 & Eo-att's & $80-\exists+66^{\prime} Z$ & $80-\exists 66^{\circ} \mathrm{L}$ & 라팆o \\
\hline ZO-تZLL & $80-\exists 9 l^{\circ} 9$ & $20-386^{\circ} \mathrm{L}$ & $\varepsilon 0-\exists \angle \varepsilon 8$ & $20-3+1 \cdot 2$ & $20-329^{\circ} 1$ & 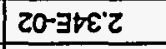 & $20-\exists 8 \varepsilon^{\prime} z$ & $20-362 \%$ & $80-\exists 8 L^{\circ} 6$ & әౌеңns \\
\hline$\varepsilon 0-3 \angle 9^{\circ} L$ & †O-J৮E:L & $80-396 \cdot 2$ & $\varepsilon 0-\exists 19 !$ & $\varepsilon 0-\exists 6 \varepsilon \mathrm{s}$ & $50-366^{\circ} \mathrm{L}$ & $80-36 t^{\circ} t$ & عo-398'L & SO-JOL'L> & 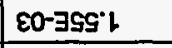 & D)111ns \\
\hline EO-ヨเฉ'Z & $50-\exists \angle 0^{\circ} \angle$ & E0-ヨเ9'Z & Eo- 3 LL! & 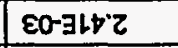 & 80-3HLL & $\varepsilon 0-\exists 90^{\circ} \varepsilon$ & $\varepsilon 0-\exists Z L: L$ & $\varepsilon 0-\exists \varepsilon \varepsilon^{\prime} !$ & to- 380 '9 & әр!10|40 \\
\hline$t 2$ & $\varepsilon z$ & $\varepsilon z$ & 22 & 22 & 12 & 12 & 02 & 61 & 81 & 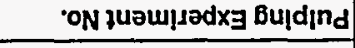 \\
\hline & & & & & & & & & & 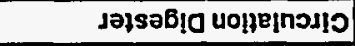 \\
\hline
\end{tabular}

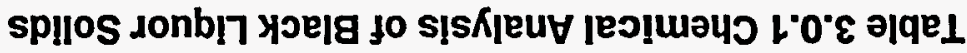


Table 3.0.1 Chemical Analysis of Black Liquor Solids

\begin{tabular}{|c|c|c|c|}
\hline \multicolumn{4}{|l|}{ Circulation Digester } \\
\hline Pulping Experiment No. & 24 & 25 & 25 \\
\hline chloride & 1.95E-03 & $1.93 \mathrm{E}-03$ & 2.38E-04 \\
\hline sulfite & 3.97E-04 & 1.57E-03 & 8.86E-04 \\
\hline sulfate & $6.97 E-03$ & $1.54 \mathrm{E}-02$ & $9.75 E-03$ \\
\hline oxalate & $3.42 E-03$ & 3.11E-03 & 2.11E-03 \\
\hline thiosulfate & $2,42 E-02$ & $1.02 E-01$ & 9.54E-02 \\
\hline carbonate & $1.22 \mathrm{E}-01$ & 4.48E-02 & $8.58 \mathrm{E}-02$ \\
\hline lactate/glycolate & $1.78 \mathrm{E}-02$ & 5.57E-02 & $1.74 \mathrm{E}-02$ \\
\hline formate & $5.41 E-02$ & $5.20 \mathrm{E}-02$ & 5.55E-02 \\
\hline acetate & $3.17 E-02$ & $3.69 \mathrm{E}-02$ & $3.06 \mathrm{E}-02$ \\
\hline sodlum & 1.48E-01 & $1.53 E-01$ & $1.68 \mathrm{E}-01$ \\
\hline sulfide & 5.47E-03 & 1.71E-02 & $4.52 \mathrm{E}-02$ \\
\hline lignin & 0.3838 & 0.4131 & 0.3940 \\
\hline calcium & 6.33E-0.5 & 4.45E-04 & $1.07 \mathrm{E}-04$ \\
\hline magnesium & 1.35E-04 & 2.87E-04 & $1.81 \mathrm{E}-04$ \\
\hline potassium & $3.80 \mathrm{E}-04$ & 5.95E-0.4 & 7.47E-04 \\
\hline sum of components & 0.795 & 0.903 & 0.900 \\
\hline sum, without S-2 & 0.790 & 0.886 & 0.855 \\
\hline Sum of components & $2.6386 E+01$ & $2.7686 \mathrm{E}+01$ & $2.7661 E+01$ \\
\hline sulfated ash, $\% \mathrm{NaOH}$ & 38.0 & 32.4 & 32.7 \\
\hline \multicolumn{4}{|c|}{ Res. Active Alkali, pre-evap. } \\
\hline RAA 1 g/L as Na2O & 7.56 & 7.12 & 5.90 \\
\hline RAA 2 g/h as Na2O & 7.31 & 6.62 & *NA \\
\hline organic & 0.491 & 0.561 & 0.500 \\
\hline inorganic & 0.299 & 0.325 & 0.355 \\
\hline organic/inorganic ratlo & 1.64 & 1.73 & 1.41 \\
\hline$\%$ organic & $62.1 \%$ & $63.3 \%$ & $58.4 \%$ \\
\hline
\end{tabular}




\subsection{Lignin Analysis}

Since variations in lignin were expected to affect liquor properties substantially, a great deal of effort was devoted to refining the method used for analysis for concentration and for refinement and development of methods for characterizing lignin molecular weight.

UV-visible analysis was chosen as the preferred method for determination of lignin concentration in black liquor. Uncertainties existed, however, and it was determined to conduct a preliminary study to determine the effects of concentration, $\mathrm{pH}$, lignin molecular weight and molecular weight dispersion, and temperature on the UV-visible response of lignin, and to check the analytical method developed against a material balance of all solutions produced during lignin purification from kraft black liquor.

Details of this development and results are given in the publication: Dong, D.J. and A.L. Fricke, "UV-Visible Response of Kraft Lignin in Softwood Black Liquor," Material Research Society Proceedings, 197, 77-86 (1990) that is included as part of this report. reprint re moved.

In summary, measurements made at a $\mathrm{pH} \geq 13$ are unaffected by lignin molecular weight and molecular weight dispersion with absorbance that is linear with respect to concentration up to a concentration of about $0.08 \mathrm{gm}$ per liter. In $\mathrm{NaOH}$ solution, purified softwood lignins obtained from experimental liquors and from mill liquors exhibited a plateau in absorbance at wavelengths from $275-295 \mathrm{~nm}$. It is to be noted that lignins isolated from hardwood mill liquors exhibit a linear decrease in absorbance with respect to wave length over the range of $275-295 \mathrm{~nm}$, at a constant concentration, and absorbance at a constant wave length within this range is linear with respect to concentration up to about $0.08 \mathrm{gm}$ per liter (Dong, 1993).

The application of this method to determine lignin concentration in black liquor was checked with more than four liquors containing lignins of differing molecular weights by comparing material balance results. A black liquor was adjusted to a $\mathrm{pH}$ of 13 and the lignin concentration determined by UV-visible absorbance. The lignin was then purified, and the lignin content of each solution discarded during purification determined. The purified lignin mass was determined, corrected for impurities. The sum of the purified lignin mass and the mass of lignin 
lost in each solution discarded was compared to the lignin content determined for the black liquor. The largest difference was $4.2 \%$ and most differences were about $1 \%$, based on lignin content as per cent of black liquor solids. The sum for material balance was always smaller than the lignin content determined directly by UV-visible analysis of the liquor.

The lignin content of the black liquors made by circulation digestion are given in Table 3.1.1. Lignin contents, as wt\% of black liquor solids, ranged from 35.86 to $44.35 \%$ for these liquors. These data were subjected surface response analysis using RESREG techniques and using Mallow's statistic to select the simplest, statistically significant model.

The canonical form for a linear quadratic model with interactions was used. This is

$$
Y=a_{o}+\sum_{i=1}^{k} a_{i} X_{i}+\sum_{i=1}^{k} a_{i i} X_{i}^{2}+\sum_{i<j}^{k} a_{i j} X_{i} X_{j}
$$

where:

$\mathrm{Y}=$ response (lignin content, \% of solids)

$\mathrm{X}_{\mathbf{i}}=$ independent variables

$a_{0}, a_{i}, a_{i i}, a_{i j}=$ regression coefficients (parameters)

The values of the parameter for a full model that results in a regression coefficient of about 0.86 are given in Table 3.1.2. The simplest statistically significant model with a regression coefficient of about 0.85 involves eleven parameters. Values for the parameters are given in Table 3.1.3. This is our recommended equation and the one used to fit properties data with the variables and regression parameters defined as in Table 3.1.3. This equation (or the 15 parameter model described earlier) is very useful in visualizing the effects of pulping variables on lignin content by construction of response surfaces for any two pulping variables at constant levels for the other two variables. 
TABLE 3.1.1

Lignin Concentration in Black Liquors from the Circulation Digester Experiments

\begin{tabular}{|c|c|}
\hline $\begin{array}{c}\text { Digester Experiment } \\
\text { Number }\end{array}$ & $\begin{array}{c}\text { Lignin Concentration, } \\
\text { wt } \% \text { solids }\end{array}$ \\
\hline 1 & 36.55 \\
\hline 2 & 44.35 \\
\hline 3 & 39.70 \\
\hline 4 & 40.90 \\
\hline 5 & 41.57 \\
\hline 6 & 40.06 \\
\hline 7 & 39.13 \\
\hline 8 & 38.98 \\
\hline 9 & 41.37 \\
\hline 10 & 42.95 \\
\hline 11 & 39.74 \\
\hline 12 & 40.25 \\
\hline 13 & 39.02 \\
\hline 14 & 43.27 \\
\hline 15 & 40.58 \\
\hline 16 & 41.27 \\
\hline 17 & 42.61 \\
\hline 18 & 36.48 \\
\hline 19 & 41.27 \\
\hline 20 & 32.15 \\
\hline 21 & 43.52 \\
\hline 22 & 43.72 \\
\hline 23 & 42.67 \\
\hline 24 & 35.86 \\
\hline 25 & 42.14 \\
\hline
\end{tabular}


Table 3.1.1a Chemical Analysis of Impurities in Lignins

\begin{tabular}{|c|c|c|c|c|c|c|c|c|c|}
\hline Circulation Digester & & & & & & & & & \\
\hline Pulping Experiment No. & 1 & 2 & 3 & 4 & 5 & 6 & 7 & 8 & 9 \\
\hline \multicolumn{10}{|l|}{ Components, g/g solids } \\
\hline chloride & "nd & "nd & "nd & "nd & "nd & "nd & "nd & nd & "nd \\
\hline sulfite & $3.29 E-03$ & $2.40 E-03$ & $3.23 E-03$ & $3.92 E-03$ & $4.09 E-03$ & $2.61 E-03$ & $2.62 E-03$ & $3.88 E-03$ & $2.49 E-03$ \\
\hline sulfate & $6.38 E-03$ & 4.12E-03 & $3.78 E+02$ & $5.33 E-03$ & $8.69 E-03$ & $6.51 E-03$ & 3.17E-03 & $3.94 E-03$ & $3.50 E-03$ \\
\hline oxalate & $7.57 E-03$ & 4.14E-03 & $4.02 E-03$ & $7.05 E-03$ & 4.57E-03 & $7.68 E-03$ & $3.20 \mathrm{E}-03$ & 3.70E-03 & 3.66E-03 \\
\hline thiosulfate & 1.15E-02 & 6.70E-03 & $6.44 E-03$ & $6.00 E-03$ & 1.01E-02 & $7.36 \mathrm{E}-03$ & 3.13E-02 & 3.77E-02 & 7.12E-03 \\
\hline lactate/glycolate & $3.64 E-03$ & 2.90E-03 & $3.12 E-03$ & $3.71 \mathrm{E}-03$ & 2.49E-03 & $3.53 E-03$ & 2.33E-03 & 2.57E-03 & 3.01E-03 \\
\hline formate & 2.16E-02 & $1.86 \mathrm{E}-02$ & $1.76 \mathrm{E}-02$ & $2.10 E-02$ & $1.90 \mathrm{E}-02$ & $2.55 E-02$ & $1.72 \mathrm{E}-02$ & $1.75 E-02$ & $1.70 \mathrm{E}-02$ \\
\hline acetate & 1.10E-02 & $7.99 E-03$ & $6.29 E-03$ & $7.68 \mathrm{E}-03$ & $7.00 E-03$ & $9.47 E-03$ & $6.28 E-03$ & $6.60 E-03$ & $6.60 \mathrm{E}-03$ \\
\hline calcium & 2.45E-05 & $1.06 \mathrm{E}-05$ & $3.78 E-05$ & $6.42 E-05$ & $3.38 E-05$ & $2.20 \mathrm{E}-06$ & "nd & 1.81E-05 & $1.21 \mathrm{E}-04$ \\
\hline magnesium & $1.58 E-05$ & 2.87E-05 & $8.33 E-06$ & $8.34 E-06$ & $1.29 E-05$ & $2.86 E-06$ & $4.10 E-05$ & 1.22E-05 & $2.78 E-05$ \\
\hline potassium & $3.38 E-0.5$ & $3.13 E-05$ & 2.96E-05 & $2.20 \mathrm{E}-0.5$ & $4.56 \mathrm{E}-0.5$ & $4.81 E-0.5$ & 4.08E-05 & $3.39 \mathrm{E}-05$ & 4.80E-05 \\
\hline sodlum & 2.17E-0.4 & $2.17 E-04$ & 2.17E-04 & 2.17E-0.4 & 2.17E-04 & 2.17E-04 & 2.17E-04 & 2.17E-04 & 2.17E-04 \\
\hline sum of components & 0.0652711 & 0.0471376 & 378.0409927 & 0.05500154 & 0.0562493 & 0.06293016 & 0.0663988 & 0.0761712 & 0.0437938 \\
\hline
\end{tabular}




\section{Table 3.1.1a Chemical Analysis of Impuritles in Lignins}

\begin{tabular}{|c|c|c|c|c|c|c|c|c|c|}
\hline Circulation Digester & & & & & & & & & \\
\hline Pulping Experiment No. & 10 & 11 & 12 & 13 & 14 & 15 & 16 & 17 & 21 \\
\hline \multicolumn{10}{|l|}{ Components, g/g solids } \\
\hline chloride & "nd & "nd & "nd & "nd & "nd & nd & "nd & *nd & *nd \\
\hline sulfite & $2.96 \mathrm{E}-03$ & $3.18 \mathrm{E}-03$ & 4.13E-03 & 1.90E-03 & 2.84E-03 & $2.84 E-03$ & 2.92E-03 & $3.08 \mathrm{E}-03$ & 2.80E-03 \\
\hline sulfate & 3.74E-03 & $6.10 \mathrm{E}-03$ & $1.02 E-02$ & $3.84 E-03$ & $3.60 \mathrm{E}-03$ & $6.86 \mathrm{E}-03$ & 5.69E-03 & $6.67 E-03$ & $4.30 \mathrm{E}-03$ \\
\hline oxalate & $3.72 E-03$ & $6.93 E-03$ & $2.32 E-03$ & $5.62 E-03$ & 2.99E-03 & $6.80 \mathrm{E}-03$ & $5.63 E-03$ & $5.80 \mathrm{E}-03$ & $3.41 E-03$ \\
\hline thiosulfate & $7.28 \mathrm{E}-0.3$ & 7.97E-03 & $5.09 E-02$ & 2.25E-03 & $1.79 E-02$ & $1.74 E-02$ & $1.82 \mathrm{E}-02$ & $7.63 E-03$ & $9.74 E-03$ \\
\hline lactate/glycolate & 2.79E-03 & $3.78 E-03$ & $2.95 E-03$ & $3.51 E-03$ & 2.61E-03 & $3.50 \mathrm{E}-03$ & 3.73E-03 & $3.66 \mathrm{E}-03$ & $2.04 E-03$ \\
\hline formate & $1.58 E-02$ & 2.85E-02 & $1.88 E-02$ & $2.25 E-02$ & $1.52 \mathrm{E}-02$ & $1.92 E-01$ & 2.36E-02 & $2.02 E-02$ & $1.55 E-02$ \\
\hline acetate & $5.89 E-03$ & 1.13E-02 & 7.01E-03 & 8.01E-03 & $5.70 E-03$ & $6.62 E-03$ & $8.11 E-03$ & $7.23 E-03$ & $6.29 E-03$ \\
\hline calcium & $6.80 \mathrm{E}-05$ & $9.12 \mathrm{E}-05$ & 6.77E-05 & $1.52 \mathrm{E}-04$ & $2.45 E-05$ & $2.20 E-06$ & 3.38E-05 & $3.24 E-05$ & $1.14 \mathrm{E}-05$ \\
\hline magneslum & $4.11 E-06$ & 5.39E-05 & 1.21E-05 & $3.09 E-05$ & $1.28 E-05$ & 1.18E-05 & $1.29 \mathrm{E}-05$ & $1.63 E-05$ & 5.78E-06 \\
\hline potassium & 4.79E-05 & 4.77E-05 & 4.54E-04 & 4.07E-05 & 5.01E-05 & $6.46 E-05$ & 4.33E-0.5 & $4.78 E-05$ & 5.25E-05 \\
\hline sodium & 2.17E-04 & 2.17E-04 & 2.17E-04 & 2.17E-04 & 2.17E-04 & $2.17 \mathrm{E}-0.4$ & 2.17E-04 & 2.17E-0.4 & 2.17E-04 \\
\hline sum of components & 0.04251701 & 0.0681698 & 0.0970608 & 0.0480706 & 0.0511444 & 0.2363156 & 0.068187 & 0.0545835 & 0.04436668 \\
\hline
\end{tabular}


Table 3.1.1a Chemical Analysis of Impuritles in Lignins

\begin{tabular}{|c|c|c|c|c|c|c|c|c|c|}
\hline \multicolumn{10}{|l|}{ Circulation Digester } \\
\hline Pulping Experiment No. & 22 & 23 & 24 & 25 & 23 & 25 & 22 & 24 & 20 \\
\hline \multicolumn{10}{|l|}{ Components, g/g solids } \\
\hline chloride & ind & "nd & "nd & "nd & - nd & ind & - nd & "nd & "nd \\
\hline sulfite & $1.08 \mathrm{E}-02$ & 2.51E-03 & $1.79 \mathrm{E}-03$ & $1.57 E-03$ & $1.31 E-03$ & $1.42 E-03$ & $1.18 E-03$ & 1.19E-03 & $1.46 \mathrm{E}-03$ \\
\hline sulfate & $1.41 E-02$ & $3.41 E-03$ & 2.72E-03 & 2.77E-03 & 3.45E-03 & 1.17E-02 & $6.52 \mathrm{E}-03$ & $2.42 E-03$ & 3.31E-03 \\
\hline oxalate & $1.23 E-02$ & 2.54E-03 & 2.29E-03 & 2.33E-03 & $2.80 \mathrm{E}-03$ & $1.96 \mathrm{E}-03$ & $3.84 \mathrm{E}-03$ & $1.88 E-03$ & 1.91E-03 \\
\hline thiosulfate & $1.32 E-02$ & 9.73E-03 & 1.60E-03 & $1.42 E-03$ & $1.47 E-04$ & 4.95E-03 & $3.72 E-03$ & $3.66 \mathrm{E}-04$ & $1.68 \mathrm{E}-03$ \\
\hline lactate/glycolate & $3.51 E-03$ & $3.69 \mathrm{E}-03$ & 2.33E-03 & $1.51 E-03$ & $4.91 \mathrm{E}-04$ & $1.59 E-03$ & $2.82 E-03$ & $1.47 E-03$ & $9.80 \mathrm{E}-04$ \\
\hline formate & $1.90 E-02$ & $1.46 E-02$ & $1.56 \mathrm{E}-02$ & $1.57 \mathrm{E}-02$ & $6.65 \mathrm{E}-03$ & $2.14 E-03$ & $2.78 \mathrm{E}-03$ & $2.14 E-03$ & $1.26 \mathrm{E}-03$ \\
\hline acetate & 7.54E-03 & 6.03E-03 & $5.89 E-03$ & 5.46E-03 & $6.05 E-04$ & 2.06E-04 & $3.06 E-04$ & 2.06E-04 & $2.06 E-04$ \\
\hline calclum & $3.11 E-05$ & $2.20 \mathrm{E}-06$ & $1.09 \mathrm{E}-0.4$ & "nd & $4.28 \mathrm{E}-05$ & $7.43 E-06$ & 2.43E-05 & $4.80 E-05$ & $5.26 E-05$ \\
\hline magnesium & 1.67E-05 & $1.08 E-05$ & 2.32E-05 & 9.95E-06 & $3.25 E-06$ & 3.67E-06 & $2.40 \mathrm{E}-06$ & $6.18 \mathrm{E}-06$ & $1.08 \mathrm{E}-05$ \\
\hline potasslum & 6.52E-05 & $5.60 E-05$ & 5.27E-0.5 & 5.03E-05 & 5.01E-05 & $3.83 E-05$ & 4.27E-05 & 4.07E-05 & 4.33E-05 \\
\hline sodium & 2.17E-04 & 2.17E-04 & 2.17E-04 & 2.17E-04 & 2.17E-04 & 2.17E-04 & 2.17E-04 & $2.17 E-04$ & 2.17E-04 \\
\hline sum of components & 0.08078 & 0.042796 & 0.0326219 & 0.03103725 & 0.01576615 & 0.0242324 & 0.0214524 & 0.00998388 & 0.0111297 \\
\hline
\end{tabular}


Table 3.1.1a Chemical Analysis of Impurities in Lignins

\begin{tabular}{|l|r|r|r|r|}
\hline Circulation Digester & & & & \\
\hline Pulping Experiment No. & 21 & 19 & 18 & 4 \\
\hline Components, g/g solids & & & & \\
\hline chloride & $1.21 \mathrm{E}-03$ & $1.33 \mathrm{E}-03$ & $1.06 \mathrm{E}-03$ & $1.41 \mathrm{E}-03$ \\
\hline sulfite & $2.70 \mathrm{E}-03$ & $1.14 \mathrm{E}-02$ & $3.04 \mathrm{E}-03$ & $8.31 \mathrm{E}-03$ \\
\hline sulfate & $1.92 \mathrm{E}-03$ & $1.69 \mathrm{E}-03$ & $1.62 \mathrm{E}-03$ & $1.97 \mathrm{E}-03$ \\
\hline oxalate & $2.52 \mathrm{E}-04$ & $6.40 \mathrm{E}-03$ & $1.19 \mathrm{E}-03$ & $3.36 \mathrm{E}-03$ \\
\hline thiosulfate & $2.34 \mathrm{E}-03$ & $1.47 \mathrm{E}-03$ & $1.23 \mathrm{E}-03$ & $3.67 \mathrm{E}-04$ \\
\hline lactatelglycolate & $1.26 \mathrm{E}-03$ & $1.14 \mathrm{E}-03$ & $1.14 \mathrm{E}-03$ & $1.66 \mathrm{E}-03$ \\
\hline formate & $1.55 \mathrm{E}-04$ & $1.55 \mathrm{E}-04$ & $1.55 \mathrm{E}-04$ & $1.55 \mathrm{E}-04$ \\
\hline acetate & $5.50 \mathrm{E}-05$ & $3.36 \mathrm{E}-05$ & $4.67 \mathrm{E}-05$ & $1.40 \mathrm{E}-05$ \\
\hline calcium & $6.64 \mathrm{E}-06$ & $5.77 \mathrm{E}-06$ & $8.27 \mathrm{E}-06$ & $1.14 \mathrm{E}-06$ \\
\hline magnesium & $5.27 \mathrm{E}-05$ & $2.67 \mathrm{E}-05$ & $1.05 \mathrm{E}-05$ & $2.21 \mathrm{E}-05$ \\
\hline potassium & $2.17 \mathrm{E}-04$ & $2.17 \mathrm{E}-04$ & $2.17 \mathrm{E}-04$ & $2.17 \mathrm{EE}-04$ \\
\hline sodium & 0.01016834 & 0.02386807 & 0.00971747 & 0.01748624 \\
\hline sum of components & & &
\end{tabular}


TABLE $\quad 3.1 .2$

Parameters for Predictive Model for Lignin Content in Black Liquor

\begin{tabular}{|c|c|}
\hline Variable & Regression Parameter \\
\hline Intercept & $-8.78 \mathrm{E}+2$ \\
\hline$E A$ & $6.54 \mathrm{E}+0$ \\
\hline$S$ & $5.78 \mathrm{E}+0$ \\
\hline$T$ & $4.15 \mathrm{E}+0$ \\
\hline$t$ & $1.82 \mathrm{E}+0$ \\
\hline$E A * E A$ & $-1.70 \mathrm{E}-1$ \\
\hline$S * S$ & $-9.83 \mathrm{E}-3$ \\
\hline$T * T$ & $-4.79 \mathrm{E}-3$ \\
\hline$t^{*} \mathrm{t}$ & $-1.17 \mathrm{E}-3$ \\
\hline$E A * S$ & $-1.49 \mathrm{E}-3$ \\
\hline$E A * T$ & $-3.97 \mathrm{E}-3$ \\
\hline$E A * t$ & $-8.25 \mathrm{E}-3$ \\
\hline$S * T$ & $-1.47 \mathrm{E}-2$ \\
\hline$S * t$ & $-3.21 \mathrm{E}-3$ \\
\hline$T * t$ & $-4.11 \mathrm{E}-3$ \\
\hline$R-s q u a r e d$ & 0.856 \\
\hline
\end{tabular}

$\mathrm{EA}=$ effective alkali, \%

$\mathrm{S}=$ sulfidity, \%

$\mathrm{T}=$ cooking temperature, ${ }^{\circ} \mathrm{F}$

$\mathrm{t}=$ time at temperature, minutes 
TABLE 3.1.3

Parameters for Recommended Predictive Model for Lignin Content in Black Liquors

\begin{tabular}{|c|c|}
\hline Variable & Regression Parameter \\
\hline \hline Intercept & $-2.497 \mathrm{E}+2$ \\
\hline$S$ & $-7.858 \mathrm{E}+0$ \\
\hline$t$ & $7.066 \mathrm{E}+0$ \\
\hline $\mathrm{T}$ & $8.210 \mathrm{E}-1$ \\
\hline $\mathrm{EA}^{*} \mathrm{~S}$ & $8.889 \mathrm{E}-1$ \\
\hline $\mathrm{EA}{ }^{*} \mathrm{t}$ & $-3.862 \mathrm{E}-1$ \\
\hline $\mathrm{S} * \mathrm{~T}$ & $2.340 \mathrm{E}-2$ \\
\hline $\mathrm{T} * \mathrm{t}$ & $-2.019 \mathrm{E}-2$ \\
\hline $\mathrm{EA} \mathrm{S}^{*} \mathrm{~T}$ & $-2.586 \mathrm{E}-3$ \\
\hline EA*t*T & $1.128 \mathrm{E}-3$ \\
\hline EA*S*t*T & $-7.000 \mathrm{E}-7$ \\
\hline R-square & 0.855 \\
\hline Adjusted R-square & 0.812 \\
\hline
\end{tabular}

$\mathrm{EA}=$ effective alkali, $\%$

$\mathrm{S}=$ sulfidity, $\%$

$\mathrm{T}=$ temperature, ${ }^{\circ} \mathrm{F}$

$\mathrm{t}=$ time-at-temperature, minutes 


\subsection{High Molecular Weight (Acid Precipitated) Lignin}

The molecular weight of lignin undoubtedly affects some liquor properties, particularly rheological properties. Unfortunately, average molecular weights for all of the lignin in black liquor cannot be determined. The best that can be done at present is to characterize the high molecular weight fraction that can be isolated and purified by acid precipitation, washing, and extraction. Fortunately, it appears that the average molecular weight of the acid soluble fraction is quite low, and this fraction can essentially be considered to be a "plasticizer" with respect to rheological behavior.

High molecular weight fractions were isolated and purified by precipitation, washing, and extraction procedures described earlier (Dong, 1993) and in our earlier DOE report (Fricke et al., 1997). The fraction of total lignin recovered as purified high molecular weight lignin from black liquors made in the circulation pulping experiment are reported in Table 3.2.1. The purified lignins were each analyzed for impurities using procedures developed for black liquors. Impurities varied from 3.5 to $5.1 \mathrm{wt} \%$ of the purified lignins. Values given in Table 3.2.1 have been corrected for impurity levels. The high molecular weight lignin contained in these liquors varies from about 23.1 to $29.9 \%$ of total liquor solids. This is significantly less than the total lignin content, but a substantial quantity of high molecular weight material that can dominate at high solids concentrations. 
TABLE $\quad 3.2 .1$

High Molecular Weight Lignin in Black Liquors from the Circulation Digester Experiments

\begin{tabular}{|c|c|c|}
\hline $\begin{array}{c}\text { Digester Experiment } \\
\text { Number } \\
\end{array}$ & $\begin{array}{c}\text { High Mol. Wt. Fraction } \\
\text { of Total Lignin } \\
\end{array}$ & $\begin{array}{l}\text { High MoI. Weight } \\
\text { Lignin, \% Solids } \\
\end{array}$ \\
\hline 1 & 0.614 & 22.44 \\
\hline 2 & 0.606 & 26.88 \\
\hline 3 & 0.636 & 25.25 \\
\hline 4 & 0.667 & 27.28 \\
\hline 5 & 0.614 & 25.52 \\
\hline 6 & 0.632 & 25.32 \\
\hline 7 & 0.656 & 26.18 \\
\hline 8 & 0.599 & 23.95 \\
\hline 9 & 0.636 & 26.31 \\
\hline 10 & 0.610 & 26.20 \\
\hline 11 & 0.633 & 25.16 \\
\hline 12 & 0.639 & 25.72 \\
\hline 13 & 0.635 & 24.78 \\
\hline 14 & 0.691 & 29.90 \\
\hline 15 & 0.653 & 26.50 \\
\hline 16 & 0.613 & 25.30 \\
\hline 17 & 0.630 & 26.84 \\
\hline 18 & 0.632 & 23.06 \\
\hline 19 & 0.604 & 24.93 \\
\hline 20 & 0.656 & 21.09 \\
\hline 21 & 0.611 & 26.59 \\
\hline 22 & 0.682 & 29.82 \\
\hline 23 & 0.683 & 28.52 \\
\hline 24 & 0.666 & 23.88 \\
\hline 25 & 0.664 & 27.98 \\
\hline
\end{tabular}




\subsection{CHARACTERIZATION OF HIGH MOLECULAR WEIGHT (ACID PRECIPITATED) LIGNIN}

Since the high molecular weight lignin contained in black liquor can affect liquor properties, particularly rheological properties at high solids concentrations, it was important to characterize the molecular weight of this fraction of black liquor solids as carefully as possible. Methods developed earlier (Kim, 1985, Kim, 1984, Fricke, 1985, Fricke, 1987) for measurement of number average molecular weight $\left(\mathrm{M}_{\mathrm{n}}\right)$ by Vapor Pressure Osmometry (VPO) and weight average molecular weight $\left(M_{\mathrm{W}}\right)$ by low angle laser light scattering spectrophotometry (LALLS), which are measurement methods that are based on first principles, were thoroughly reviewed and reevaluated. In addition, techniques and methods for measurement of molecular weight distribution (MWD) by high temperature liquid chromatography (HTHPLC) were tested, evaluated, and further developed. This is a secondary analytical method, where accurate results require accurate calibration data. Various calibrations were tested and results for $\mathbf{M}_{\mathbf{W}}$ and $\mathbf{M}_{\mathbf{n}}$ calculated from the MWD curve from HTHPLC were compared to those obtained from LALLS and VPO.

\subsection{Weight Average Molecular Weight $\left(M_{\mathrm{w}}\right)$ Determination}

The basic experimental method used in this work was developed by Kim (Kim, 1984, Kim, 1985, Fricke, 1983), but some questions remained. Since $M_{W}$ of lignin can be expected to be a significant factor affecting rheological properties of liquors at high solids concentrations,

methods developed by Kim were reevaluated. Firstly, precipitation and purification procedures for separating high molecular weight lignin from black liquor were improved and precision of measurement of impurities in the lignin improved. The revised methods for purification and impurity analysis have been described in detail in an earlier interim report to DOE describing experimental methods (Fricke et al., 1997).

Lignin is an optically active, heterogeneous, and ionically sensitive polymer whose $M_{W}$ is very difficult to determine; the large variations in $\mathrm{M}_{\mathrm{W}}$ for lignins that have been reported from 
various studies attest to the difficulties and uncertainties. It was important to quantitatively assess the optical effects of lignin in various solvents and to determine the $\mathrm{M}_{\mathrm{W}}$ of single lignins in a number of solvents as a critical test of the method. This was done very systematically and successfully (Dong, 1993). Transmittance, differential refractive index, fluorescence, and anisotropy effects for lignin dissolved in three very different solvents-pyridine, dimethyl formamide (DMF), and 0.1N sodium hydroxide were evaluated carefully. Complete description of this work has been published (Dong, 1993) and in the publication: Dong, D.J. and A.L. Fricke, "Investigation of Optical Effect of Lignin Solution and Determination of $\mathbf{M}_{\mathrm{W}}$ of Kraft Lignin," $\mathbf{L}$ Appl. Polymer Sci., 50, 1131-1140 (1993), which is included as part of this report. Re print re ved. It is important to note that $M_{W}$ values reported from various investigations conducted in the past on basically similar kraft lignins vary by a factor of more than 20 , which is clearly unacceptable. The work reported here demonstrates that $\mathrm{M}_{\mathrm{W}}$ determined for the same lignin using three very diverse solvents varied by $10 \%$ or less. This is a yast improvement and gives credence to our claim of having developed an accurate method for determining $M_{W}$ of lignin. When one considers that six experimental measurements at a number of concentrations using three instruments are required for a single $\mathrm{M}_{\mathrm{W}}$ determination, and that we are comparing three such measurements, a $10 \%$ difference is excellent agreement.

Determination of $\mathrm{M}_{\mathrm{W}}$ by LALLS is extremely tedious and time consuming. Lignin separation, purification, and analysis requires an elapsed time of nearly three weeks and more than one man-week of effort. $M_{\mathrm{W}}$ measurement, including required auxiliary measurements to correct for optical effects requires nearly two man-weeks of effort. Therefore, determination of $M_{W}$ is costly in time and labor. Other methods that are more efficient are needed. Our efforts to develop these are described later in this report. 


\subsection{Number Average Molecular Weight $\left(M_{n}\right)$ Determination}

Number average molecular weight of lignins has been determined by VPO by a number of investigators. Kim (Kim, 1985, Fricke, 1983) improved the method and developed a method for correcting for impurities contained in lignin. Dong (1993) used a newer model Wescan (model 233) VPO and thoroughly reviewed the procedures. He improved techniques to increase sensitivity and improved instrument calibration. Several solvents were used and Theta temperatures for lignin in these solvents determined. For measurements with lignins from our work, DMF was used as the solvent and measurements were made at $80^{\circ} \mathrm{C}$, which is slightly above the Theta temperature for lignin in DMF.

Complete description of the procedure have been given in an earlier report (Fricke et al., 1997) and in a Ph.D. thesis (Dong, 1993). The $\mathrm{M}_{\mathbf{n}}$ of all of the lignins produced in the designed pulping experiment were determined and results are presented in a later section of this report.

Measurement of $M_{n}$ by VPO is also tedious and time consuming; VPO measurement alone requires more than a man-week of effort. Also, in spite of all precautions, $\mathbf{M}_{\mathbf{n}}$ determinations of lignin are subject to uncertainty due to the impossibility of removing all low molecular weight impurities from lignin. This uncertainty is minimized by applying the corrections developed by Kim (1985) and used by Dong (1993). However, even with this correction, the value determined for $\mathrm{M}_{\mathrm{n}}$ for a lignin may be uncertain by as much as an estimated $7 \%$.

\subsection{Molecular Weight Distribution (MWD) Determination}

The ratio $\left(\mathrm{M}_{\mathrm{w}} / \mathrm{M}_{\mathrm{n}}\right)$, called the "polydispersity index" (PI) is one measure of the molecular weight distribution (MWD), but it is only a measure of dispersion. It gives no information on skewness nor multi-modality of the distribution. In addition, as we have pointed out in previous sections, measurement of $M_{n}$ and $M_{w}$ is tedious and very time consuming. Therefore, other methods are needed. Equilibrium sedimentation can be used, but this method is also tedious, expensive, and time consuming and requires calibration. Another secondary method, size exclusion chromatography, is an attractive alternative. There are numerous reports of application 
of this method, called HPLC, in the literature, but results are not in agreement and calibration is in error in nearly every case.

As part of this program, we have attempted to develop a HPLC method for lignin where the analysis is run at high temperature. This is called high temperature high performance liquid chromatography (HTHPLC) for size exclusion. If successfully developed, this procedure could be used to replace LALLS and VPO measurements while giving a complete MWD in addition. Furthermore, the measurement could be completed in hours rather than the weeks of effort required for LALLS, VPO, and equilibrium sedimentation.

A Water 150c HTHPC with refractive index (RI) and UV-visible detectors was obtained for this work and combinations of columns, carrier solvents, and detectors investigated. More than 60 combinations of columns and carrier solvent were investigated. Full details of all trials are given in a Ph.D. thesis (Schmidl, 1992). A report of early work that is illustrative of the procedure of investigation has been published in: Schmidl, G.W., D.J. Dong, and A.L. Fricke, "Molecular Weight and Molecular Weight Distribution of Kraft Lignins," Materials Research Society Symposium Proceedings, 197, 21-30 (1990) that is included as part of this report. Reprint re Moved.

The problems inherent in using HTHPLC to determine the MWD of lignin are amply illustrated (Schmidl et al., 1990). Association in solution, adsorption on the column material, and sensitivity of detection are all problems. The greatest problem, however, is lack of appropriate standards for calibration. Values of $\mathrm{M}_{\mathrm{W}}$ calculated from MWD chromatographs are not in agreement with $M_{W}$ values determined by LALLS for the same lignins, nor are $M_{n}$ values in agreement. In general, $\mathrm{M}_{\mathrm{W}}$ values determined from chromatographs by using any of several monodisperse calibration standards are lower than those determined by LALLS. Also, the ratio $M_{W} / M_{n}$ (P.I.) determined from chromatographs is considerably lower than the ratio determined by LALLS and VPO methods. However, the chromatographs do show the bimodality of most lignins and do illustrate that the MWD is skewed.

HTHPLC offers so many potential advantages that an extensive development effort was included as a part of this program. Complete details of all trials have been published (Schmidl, 
1992). The final system that was selected for complete study includes a number of elements and operating conditions. The basic instrument used was a Waters 150c ALC/GPC integrated HTHPLC system with DRI detector, outboard Waters 486 UV-visible tunable absorbance detector, 16 sample carousel, automatic injector, and Kontes mobile phase handling system. The experimental unit is interfaced with a computer workstation for real-time data acquisition and processing. The mobile phase selected was dimethyl sulfoxide (DMSO) with $0.1 \mathrm{M} \mathrm{LiBr}$, and measurements were made at $85^{\circ} \mathrm{C}$ and a mobile phase nominal flow rate of $1.1 \mathrm{ml} / \mathrm{min}$ (an actual measured flow rate of $1.03 \mathrm{ml} / \mathrm{min}$ ). The columns selected as the best for the extended work were a set of Jordi Gel $10^{3}+10^{4} \AA$ GBR columns supplied by Jordi Associates, Bellingham, MA. These columns contain basically highly cross-linked poly-divinyl benzene (DVB), and the GBR column gel is modified by glucose amine groups added to the DVB. This deactivates the aromatic rings with respect to adsorption interactions and renders the gel compatible with both aqueous and polar organic mobile phases. The $10^{3} \AA$ column is $10 \mathrm{~mm} \mathrm{ID} \mathrm{x} 50 \mathrm{~cm}$ long and the $10^{4} \AA$ column is $10 \mathrm{~mm} \mathrm{ID} 25 \mathrm{~cm}$ long. The columns are stable up to $150^{\circ} \mathrm{C}$ and the columns are reproducible. Polysaccharide (linear polymaltotrioses) obtained from Pressure Chemical Company, Pittsburgh, PA were used as standards for column calibration.

The calibration curve for polysaccharides with the Jordi Columns using DMSO + $0.1 \mathrm{M}$ $\mathrm{LiBr}$ at $85^{\circ} \mathrm{C}$ as the mobile phase is:

$$
\log M_{i}=41.24-3.97 t_{R}+0.1439 t_{R}^{2}+0.001786 t_{R}^{3}
$$

where:

$$
\begin{aligned}
& \mathrm{M}_{\mathrm{i}}=\text { molecular weight, } \mathrm{gm} / \mathrm{mol} \\
& \mathrm{t}_{\mathrm{R}}=\text { retention time, } \mathrm{min} . \\
& \mathrm{t}_{\mathrm{R}}=\mathrm{V} / \mathrm{V} \\
& \mathrm{V}=\text { total eluent volume, } \mathrm{ml}
\end{aligned}
$$


$\dot{\mathrm{V}}=$ eluent volumetric flow rate, $\mathrm{ml} / \mathrm{min}(1.03 \mathrm{ml} / \mathrm{min})$

The correlation coefficient for this calibration, based on eleven polymer standards, was 0.9967 . The equation is valid for polysaccharide molecular weights from 130 to more than 950,000 .

Typical chromatograms for four of the lignins from liquors made in the circulation pulping experiments are shown in Figure 4.3.1. The differences are very obvious and bimodality is obvious. Lignins from other sources were also investigated. Indulin AT from Westvaco, a kraft lignin derived from pulping sugar maple, and a lignin derived from organosolv pulping of hardwood were purified as described earlier and chromatograms run. The chromatograms for these are shown in Figure 4.3.2. Also, lignins from kraft pulping of birch and mixed hardwoods were studied.

$M_{n}$ and $M_{W}$ values for a number of lignins using the system described with calibration with polysaccharides are presented in Table 4.3.1. These include five of the circulation digester experimental lignins as well as four other kraft lignin and an organosolv lignin. In all cases, $M_{W}$ determined by light scattering is greater than $\mathrm{M}_{\mathrm{W}}$ determined from the chromatogram and this difference generally increases with increasing $\mathrm{M}_{\mathrm{W}}$ as determined by light scattering. This is undoubtedly due to the configurational and conformational differences between lignins and the polysaccharide standards. The ratio of the two $M_{W}$ values can be as great as 9.6 , but appears to be generally in the range of 3 to 9.6. As might be expected, the $M_{n}$ values, which are dominated by the lower molecular weight components where the differences between the lignins and the standards have less effect, are in closer agreement with VPO values, but are generally also lower than $M_{n}$ values obtained by VPO.

The advantages and disadvantages of HTHPLC are clear. An analysis, including solution preparation, requires less than one day and results are highly reproducible. Distinct differences in MWD of different lignins is readily apparent, and skewness and modality of the distribution are obvious. The method could probably be extended to yield MWD of lignin in black liquor directly by dissolving freeze dried black liquor solids in DMSO, filtering the solution, determining lignin 


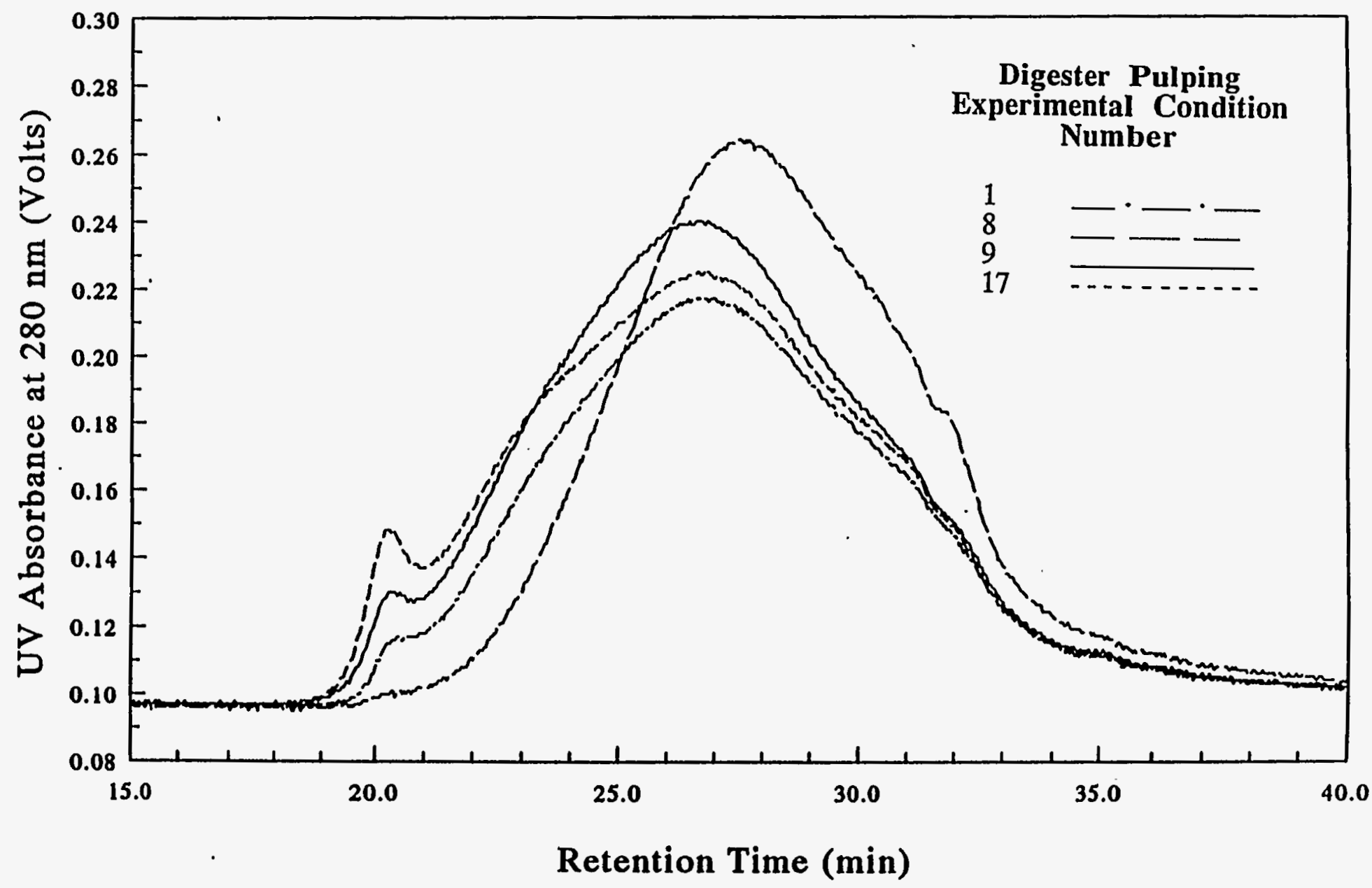

Figure 4.3.1

SEC Chromatograms for Selected Lignins from Circulation Digester Pulping of Slash Pine Run in DMSO $+0.1 \mathrm{M} \mathrm{LiBr}$ at $85^{\circ} \mathrm{C}$ Using a Jordi Gel $10^{3}+10^{4} \AA$ GBR Column Set 


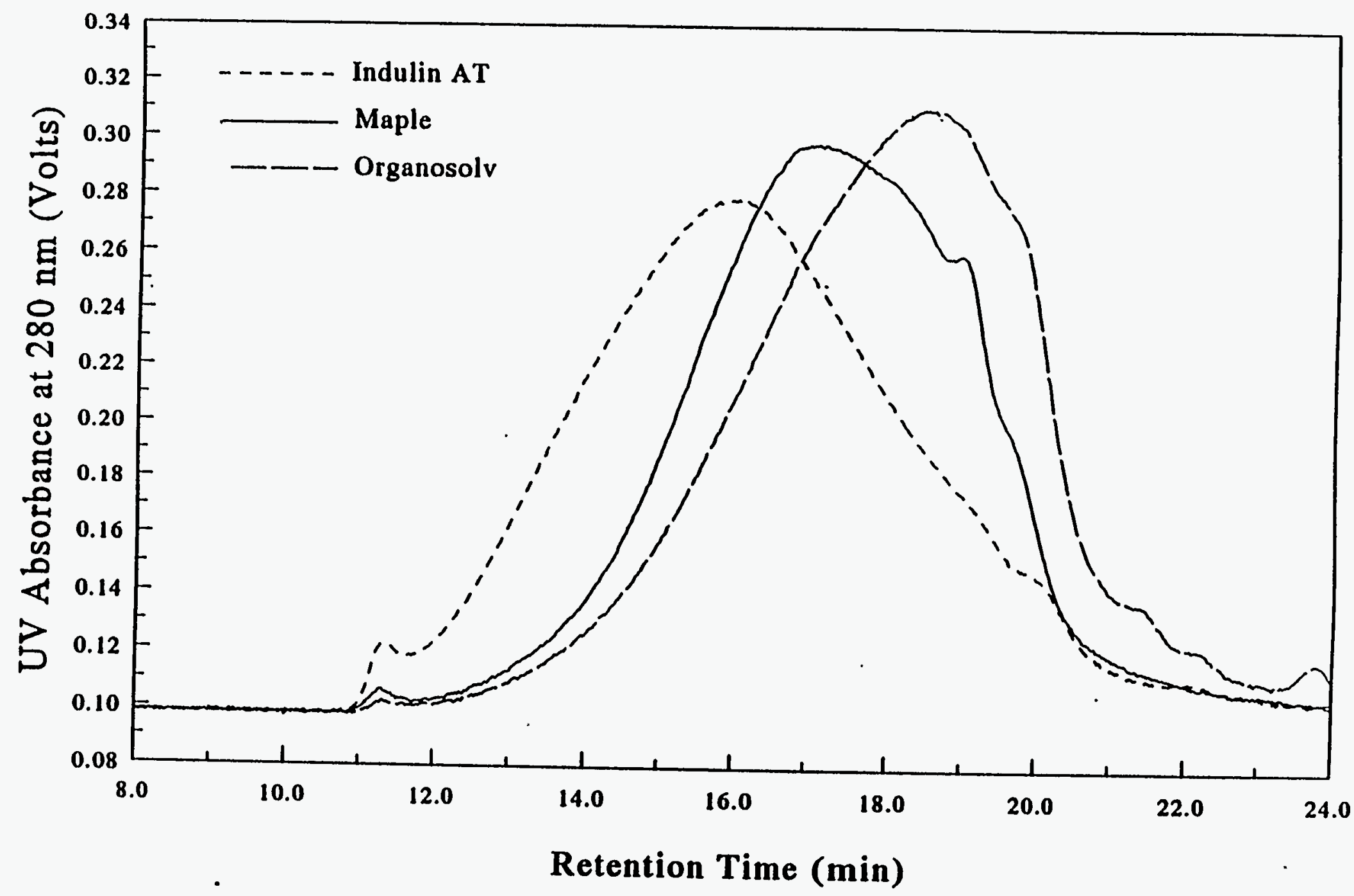

Figure 4.3.1

SEC Chromatograms for Selected Lignins from Circulation Digester Pulping of Slash Pine Run in DMSO + 0.1 M LiBr at $85^{\circ} \mathrm{C}$ Using a Jordi Gel $10^{3}+10^{4} \AA$ GBR Column Set 
TABLE $\quad$ 4.3.1

Lignin Molecular Weights from HTHPLC for Lignins in DMSO +

$0.1 \mathrm{M} \mathrm{LiBr}$ at $85^{\circ} \mathrm{C}$

Standard: Polysaccharide

\begin{tabular}{|c|c|c|c|c|c|}
\hline Lignin & $\mathbf{M}_{\mathbf{n}}$ & $\mathrm{M}_{\mathrm{w}}$ & $\mathbf{M}_{\mathrm{w}} / \mathbf{M}_{\mathbf{n}}$ & $\mathrm{M}_{\mathrm{w}_{\mathrm{LS}}}$ & $\mathrm{M}_{\mathrm{w}_{\mathrm{L}} \mathrm{s}^{\mathrm{M}}}$ \\
\hline Indulin AT & 1,332 & 5,142 & 3.859 & 49,380 & 9.60 \\
\hline Mixed Hardwood & 997 & 3,357 & 3.36 & -- & -- \\
\hline Birch & 1,148 & 3,128 & 2.725 & 29,710 & 9.50 \\
\hline Maple & 1,196 & 3,229 & 2.70 & 12,900 & 4.00 \\
\hline Organosolv & 954 & 2,907 & 3.047 & -- & -- \\
\hline \multicolumn{6}{|l|}{ Circulation Expt. No. } \\
\hline 1 & 1,387 & 6,411 & 4.621 & 19,630 & 3.06 \\
\hline 3 & 1,521 & 8,687 & 5.711 & 83,000 & 9.55 \\
\hline 9 & 1,519 & 7,960 & 5.242 & 21,930 & 2.76 \\
\hline 14 & 1,251 & 5,589 & 4,468 & 18,920 & 3.39 \\
\hline 17 & 1,543 & 9,672 & 6.269 & 42,930 & 4.44 \\
\hline
\end{tabular}

$\mathrm{M}_{\mathrm{W}_{L S}}=\mathrm{M}_{\mathrm{W}}$ determined by LALLS 
concentration by UV-visible analysis, and producing the chromatogram. This has yet to be attempted. The disadvantage is that molecular weights determined by HTHPLC are extremely inaccurate using present calibration methods, and these inaccuracies increase with increasing molecular weight. A solution to eliminate this disadvantage has been developed and this is discussed in a later section.

\subsection{Intrinsic Viscosity Determination}

Intrinsic viscosity studies using selected lignins from the circulation pulping experiments were conducted for several reasons. It might be possible to develop a relation between relative viscosity and molecular weight that could be used for universal calibration for HTHPLC or it could be used, if successful, to determine a molecular weight (the viscosity average molecular weight) that is close to $\mathrm{M}_{\mathrm{W}}$ and used as a cheap replacement for LALLS. Finally, intrinsic viscosity studies can permit inferences to be made with respect to the conformation and solvation of the macromolecule in solution.

This work has been published. The publication: Dong, D.J. and A.L. Fricke, "Intrinsic Viscosity and the Molecular Weight of Kraft Lignin," Polymer, 36, 2075-2078 (1995) is included as part of this report. Reprint removed.

Kinematic viscosities of lignins of various $\mathrm{M}_{\mathrm{w}}$ dissolved in DMF, and in $0.5 \mathrm{~N} \mathrm{NaOH}$ were determined as a function of the lignin concentration at 303.2 and $318.2^{\circ} \mathrm{K}$. Kinematic viscosities were converted to absolute viscosities using density relations. Concentrations ranged from slightly above zero to $0.1 \mathrm{gm} / \mathrm{ml}$. Reduced viscosities were calculated as a function of concentration. Due to very low values of reduced viscosity at low concentrations in $0.5 \mathrm{~N} \mathrm{NaOH}$, data taken at concentrations below $0.005 \mathrm{gm} / \mathrm{ml}$ were discarded. Reduced viscosity was linear with concentration above $0.005 \mathrm{gm} / \mathrm{ml}$ for solutions in $\mathrm{NaOH}$. Reduced viscosity in DMF was higher for each lignin, but reduced viscosity was linear over two regions of concentration. Above $0.02 \mathrm{gm} / \mathrm{ml}$, reduced viscosity increased more rapidly with concentration than below $0.02 \mathrm{gm} / \mathrm{ml}$. 
Based on these results, reduced viscosities for concentrations ranging from 0.02 to $0.1 \mathrm{gm} / \mathrm{ml}$ were used to determine intrinsic viscosities.

Intrinsic viscosities were determined for five of the lignins from the experimental pulping conditions. These lignins possessed $\mathrm{M}_{\mathrm{W}} \mathrm{s}$ ranging from 22,000 to above 59,000. Intrinsic viscosity vs. molecular weight should fit the Kuhn-Mark-Houwink-Sakaruda relation:

$$
[\mathrm{n}]=\mathrm{KM}_{\mathrm{w}}^{\alpha}
$$

where:

$$
\begin{aligned}
& {[\mathrm{n}]=\text { intrinsic viscosity, } \mathrm{ml} / \mathrm{gm}} \\
& \mathrm{M}_{\mathrm{W}}=\text { weight average molecular weight, } \mathrm{gm} / \mathrm{mol} \\
& \mathrm{K}, \alpha=\text { experimental constants }
\end{aligned}
$$

The fit was excellent for lignin in DMF and reasonably good in $0.5 \mathrm{~N} \mathrm{NaOH}$. However, the values of $\alpha$ were very low, which indicates that the molecules assume a nearly spherical shape in solution.

The specific viscosity was determined as a function of the volume fraction of lignin in solution. The initial slopes for $0.5 \mathrm{~N} \mathrm{NaOH}$ and DMF were 13.33 and 8.22 , respectively. The slope for a spherical, non-solvated, constant density particle is 2.5 . Therefore, the diameter of spherical particles of lignin is increased only about $50 \%$ in $0.5 \mathrm{~N} \mathrm{NaOH}$ and 75\% in DMF which results in volume expansions of 2.3 and 4.3 , respectively.

This explains why HTHPLC results, based on standards that are highly solvated, are grossly in error. Also, due to these effects, intrinsic viscosity offers little promise for use as an accurate method for determination of lignin molecular weight. 


\subsection{Internal Calibration of HTHPLC Molecular Weight Distribution Results}

As pointed our earlier, differences of $M_{W}$ determined by LALLS and by HTHPLC using available standards that range from a factor of 3 to a factor of 10 or more are unacceptable. However, HTHPLC is rapid, convenient, and could yield a complete MWD if a system could be accurately calibrated. Internal calibration using the data can be done by resolution of moments.

For any distribution, moments of distribution about the origin are defined as:

$$
\mu_{k}=\int_{0}^{\infty} X^{k} f(X) d X / \int_{0}^{\infty} f(X) d X
$$

where:

$$
\begin{aligned}
& \mu_{\mathrm{k}}=\mathrm{k}^{\text {th }} \text { moment about the origin } \\
& X=\text { independent variable } \\
& \mathrm{f}(\mathrm{X})=\text { function of the independent variable }
\end{aligned}
$$

In theory, any distribution can be resolved into moments. This has been used successfully for chromatographic separations of simple materials, but not for polymers. We have applied this to our HTHPLC data to determine MWD of lignins more accurately.

If we let $w\left(t_{R}\right)$ represent the chromatographic distribution of polymer mass with respect to retention time (the chromatograph curve) which is proportional to retention volume (V), and let w(M) represent the molecular weight distribution curve where $M$ is the molecular weight of the polymer at $t_{R}$ (or $V$ ), it can be shown that:

$$
\mathrm{w}(\mathrm{V}) \mathrm{dV}=-\mathrm{kw}(\mathrm{M}) \mathrm{dM}
$$


which can be rewritten as:

$$
\quad w(M) d M=-\frac{w(V) d V}{k}
$$

where $\mathrm{k}$ is a proportionality constant.

$\mathrm{M}_{\mathbf{n}}$ is the first moment of the molecular weight distribution about the origin. It can be written in normalized form as:

$$
M_{n}=\mu_{1}=\int_{0}^{\infty} M w(M) d M / \int_{0}^{\infty} w(M) d M
$$

or as:

$$
M_{n}=\mu_{1}=\int_{0}^{\infty} w(M) d M / \int_{0}^{\infty} \frac{w(M) d M}{M}
$$

substituting for the unknown values of $w(M)$ and $M$ :

$$
M_{n}=\int_{0}^{\infty} w(V) d V / \int_{0}^{\infty} \frac{w(V) d V}{M(V)}
$$

This can be rewritten as:

$$
M_{n} \int_{0}^{\infty} \frac{w(V) d V}{M(V)}-\int_{0}^{\infty} w(V) d V=0
$$

In a similar manner, $\mathbf{M}_{\mathrm{W}}$ can be written as: 


$$
M_{w}=\frac{\int_{0}^{\infty} M(V) w(V) d V}{\int_{0}^{\infty} w(V) d V}
$$

This can be rewritten as:

$$
\int_{0}^{\infty} M(V) w(V) d V-M_{w} \int_{0}^{\infty} w(V) d V=0
$$

For any lignin studied, $\mathrm{M}_{\mathrm{w}}, \mathrm{M}_{\mathrm{n}}$, and $\mathrm{w}(\mathrm{V})$ are known. Equations 4.5.6 and 4.5.8 are two working equations for determining $M(V)$ from the chromatograph. If we assume that the relation for $M(V)$ or $M\left(t_{R}\right)$ is:

$$
\ell n M=\sum_{i=0}^{k} a_{i} V^{k}
$$

Given sufficient sets of chromatograms and values of $M_{n}$ and $M_{W}$, it is possible to determine the constants, $\mathrm{a}_{\mathrm{i}}$, for equation (4.5.9), assuming that the polymers are similar in chemistry and conformation. This is exactly our situation.

Success of this method depends upon having accurate chromatograms with very precisely defined retention time (elution volume), precisely defined base line corrected for any drift, and an accurate total retention time for the chromatogram. Analysis of the end points by first and second derivative methods permitted these to be defined precisely.

Subsets of the chromatograms for which $M_{n}$ and $M_{W}$ values were known were used to determine the coefficients of a common polynomial for equation (4.5.9) from third to eighth order. We also tested the use of Chebyshev polynomials, to fit equation (4.5.9), but this was not successful. 
The best result was obtained with a fourth order polynomial:

$$
\ln (M)=a_{0}+a_{1}(V / 40)+a_{2}(V / 40)^{2}+a_{3}(V / 40)^{3}+a_{4}(V / 40)^{4}
$$

The values for the constants are:

$$
\begin{aligned}
& a_{0}=19.340 \\
& a_{1}=-4.9990 \\
& a_{2}=-15.262 \\
& a_{3}=-12.774 \\
& a_{4}=+18.605
\end{aligned}
$$

The resulting calibration curve is drastically different from that for the polysaccharide standards that was used earlier.

Before presenting results, it is well to describe molecular weight averages and their relation to moments. As pointed our earlier, $M_{\mathbf{n}}$ is the true mean and the first moment about the origin. It can be calculated from the chromatogram using equation (4.5.5) now that $M(V)$ (the calibration curve) is known. $M_{W}$ is given by:

$$
\begin{aligned}
M_{w} & =\int_{0}^{\infty} M(V) w(V) d V / \int_{0}^{\infty} w(V) d V \\
& =\frac{\int_{0}^{\infty} M(V) w(V) d V / \int_{0}^{\infty} \frac{w(V) d V}{M}}{\int_{0}^{\infty} w(V) d V / \int_{0}^{\infty} \frac{w(V) d V}{M}} \\
& =\mu_{2} / \mu_{1}
\end{aligned}
$$


That is, $M_{W}$ is the ratio of the second to the first moment about the origin. Similarly, $M_{z}$ (zaverage molecular weight) is given by:

$$
\begin{aligned}
M_{z} & =\int_{0}^{\infty}[M(V)]^{2} w(V) d V / \int_{0}^{\infty} M(V) w(V) d V \\
& =\frac{\int_{0}^{\infty}[M(V)]^{2} w(V) d V / \int_{0}^{\infty} w(V) d V}{\int_{0}^{\infty} M(V) w(V) d V / \int_{0}^{\infty} w(V) d V} \\
& =\mu_{3} / \mu_{2}
\end{aligned}
$$

That is, $M_{z}$ is the ratio of the third to the second moment about the origin. Also, $M_{z+1}$ (the $z+1$ average molecular weight is given by:

$$
\begin{aligned}
M_{z+1} & =\int_{0}^{\infty}[M(V)]^{3} w(V) d V / \int_{0}^{\infty}[M(V)]^{2} w(V) d V \\
& =\mu_{4} / \mu_{3}
\end{aligned}
$$

That is, $\mathrm{M}_{\mathrm{z}+1}$ is the ratio of the fourth to the third moment about the origin. This can be continued to higher moments, but more than four are seldom used in polymer analysis.

Note that these are moments about the origin, but the best description of a distribution is by moments about the mean. The first moment about the origin is the mean of a number distribution. Therefore, the first moment about the mean, $\sigma_{1}$, for a number distribution is zero by definition. Higher moments about the mean can be calculated by translation of the values of $M_{i}$ (use $M_{i}-M_{n}$ ) 
or by known relations between the moments about the origin and moments about the mean. These are:

$$
\begin{aligned}
& \sigma_{1} \equiv 0 \\
& \sigma_{2}=M_{n}\left(M_{w}-M_{n}\right) \\
& \sigma_{2}=M_{z} M_{w} M_{n}-3 M_{w} M_{n}+2 M_{n}^{3} \\
& \text { etc. }
\end{aligned}
$$

Returning to the lignin chromatograms, we calculated $M_{n}$ and $M_{W}$ from each chromatogram and compared these values to values of $M_{n}$ and $M_{W}$ obtained by VPO and LALLS for each lignin. The residuals, the difference between values from the chromatogram and values from first principles, were randomly distributed with respect to $M_{w}$. The largest residual for $M_{w}$ was $30 \%$, but most were 2 to $20 \%$ in absolute magnitude. Residuals for $M_{n}$, as expected, were not as good. While random, most ranged from 2 to $30 \%$ in absolute magnitude with two outliers in the range of $70-80 \%$.

Comparison with results reported in Table 4.3.1 shows a dramatic improvement in agreement. The difference in $\mathrm{M}_{\mathrm{W}}$ by chromatography and $\mathrm{M}_{\mathrm{W}}$ by LALLS ranged conservatively from 67 to $95 \%$. Using the new values of $\mathrm{M}_{\mathrm{W}}$ calculated from the chromatograms, we can reevaluate the ratio of $M_{w_{L S}} / M_{W}$. The ratios for the old values (polysaccharide standard) and for then new values (derived calibration) are given in Table 4.5.1 for comparison.

Values for $M_{n}, M_{W}, M_{z}$ and $M_{z+1}$ calculated from the chromatograms for the lignins from the circulation digester pulping liquors are given in Table 4.5.2.

A typical chromatogram is shown in Figure 4.5.1, which is the chromatogram for lignin from the liquor for circulation digester experimental condition no. 13. The molecular weight 
TABLE $\quad 4.5 .1$

Comparison of Ratio of Molecular Weights by HTHPLC $\left(\mathrm{M}_{\mathrm{w}_{1}}, \mathrm{M}_{\mathrm{w}_{2}}\right)$ to Molecular Weights by LALLS for $\left(M_{w_{L S}}\right)$ for Kraft Circulation

Digester Lignins

\begin{tabular}{|c|c|c|}
\hline $\begin{array}{c}\text { Circulation Digester } \\
\text { Expt. No. }\end{array}$ & $\mathbf{M}_{\mathbf{w}_{\mathbf{1}}} / \mathbf{M}_{\mathbf{w}_{\mathbf{L S}}}$ & $\mathbf{M}_{\mathbf{w}_{\mathbf{2}}} / \mathbf{M}_{\mathbf{w}_{\mathbf{L S}}}$ \\
\hline \hline 1 & 3.06 & 1.13 \\
\hline 3 & 9.55 & 1.07 \\
\hline 9 & 2.76 & 1.30 \\
\hline 14 & 3.39 & 0.972 \\
\hline 17 & 4.44 & 0.813 \\
\hline
\end{tabular}

$\mathrm{M}_{\mathrm{w}_{1}}=\mathrm{M}_{\mathrm{W}}$ calculated from chromatograph using polysaccharide standards

$\mathrm{M}_{\mathrm{W}_{2}}=\mathrm{M}_{\mathrm{W}}$ calculated from chromatograph using the derived calibration 
TABLE $\quad 4.5 .2$

Molecular Weights for Lignins from the

Circulation Digester Experiment Calculated from HTHPLC Chromatograms

\begin{tabular}{|c|c|c|c|c|}
\hline \multirow[b]{2}{*}{$\begin{array}{c}\text { Digester } \\
\text { Experiment } \\
\text { No. } \\
\end{array}$} & \multicolumn{4}{|c|}{ Molecular Weights, gm/mol } \\
\hline & $M_{n} \times 1^{-3}$ & $\mathbf{M}_{\mathbf{w}} \times 10^{-3}$ & $\mathbf{M}_{\mathrm{z}} \times \mathbf{1 0}^{-4}$ & $\mathbf{M}_{\mathrm{z}+1} \times 10^{-5}$ \\
\hline 1 & 2.209 & 22.265 & 9.9665 & 1.8162 \\
\hline 2 & 2.406 & 25.197 & 12.123 & 2.4420 \\
\hline 3 & 2.485 & 30.729 & 14.219 & 2.4334 \\
\hline \multicolumn{5}{|l|}{4} \\
\hline 5 & 2.217 & 24.425 & 12.982 & 2.4490 \\
\hline 6 & 2.320 & 26.211 & 13.814 & 2.5851 \\
\hline 7 & 2.378 & 29.234 & 16.018 & 2.9362 \\
\hline 8 & 1.844 & 12.038 & 6.435 & 1.8170 \\
\hline 9 & 2.533 & 28.416 & 13.259 & 2.4388 \\
\hline 10 & 2.864 & 37.892 & 16.624 & 2.8226 \\
\hline 11 & 2.086 & 18.388 & 9.5901 & 2.1044 \\
\hline 12 & 2.401 & 23.265 & 10.116 & 1.9684 \\
\hline 13 & 2.138 & 23.429 & 14.964 & 3.2213 \\
\hline 14 & 1.980 & 18.392 & 10.379 & 2.0530 \\
\hline 15 & 2.464 & 29.095 & 15.410 & 3.1624 \\
\hline 16 & 2.236 & 21.589 & 11.835 & 2.4479 \\
\hline 17 & 2.476 & 34.902 & 15.807 & 2.5876 \\
\hline 18 & 2.236 & 21.589 & 11.835 & 2.4479 \\
\hline 19 & 2.548 & 27.644 & 13.598 & 2.5046 \\
\hline 20 & 2.711 & 24.684 & 9.887 & 1.9090 \\
\hline 21 & 2.346 & 17.903 & 9.1648 & 2.0948 \\
\hline 22 & 2.067 & 20.368 & 12.174 & 2.6494 \\
\hline 23 & 1.873 & 16.260 & 10.752 & 2.3854 \\
\hline 24 & 1.998 & 22.805 & 15.380 & 3.0559 \\
\hline 25 & 2.000 & 20.381 & 13.520 & 2.6611 \\
\hline
\end{tabular}




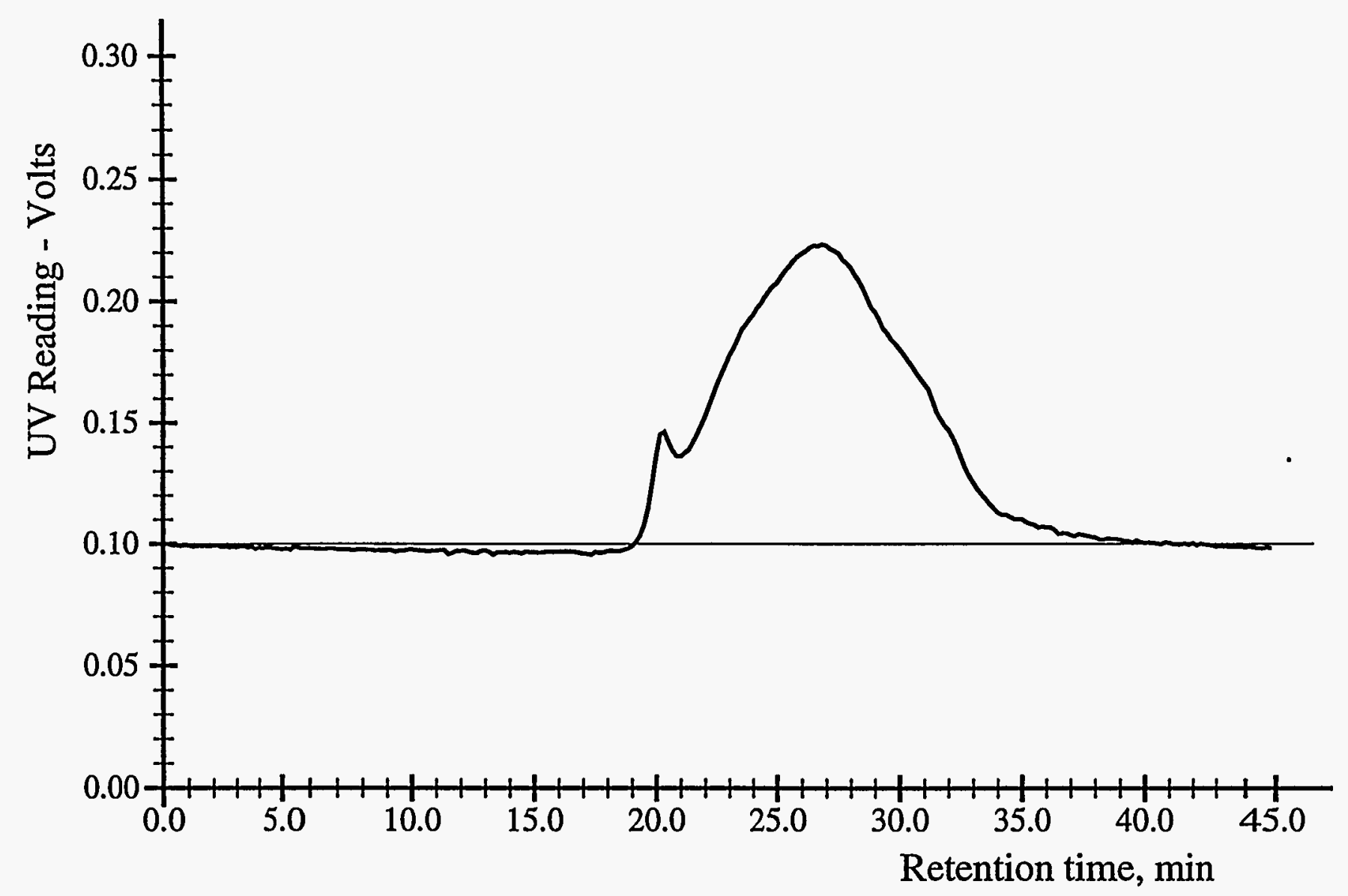

Figure 4.5.1 Typical Chromatographic Curve for SEC for lignin in DMSO + $0.1 \mathrm{M} \mathrm{LiBr}$ at $85^{\circ} \mathrm{C}$ Using Jordi Gel Column Digester Pulping Condition 17 
distribution derived from this chromatograph is shown in Figure 4.5.2. Molecular weight distributions for the lignins for some of the other 24 circulation digester experiments are given in Figures 4.5.2 through 4.5.3, and 4.5.4. The differences in distributions resulting from different pulping conditions are clearly evident; much more so than from the original chromatograms. 


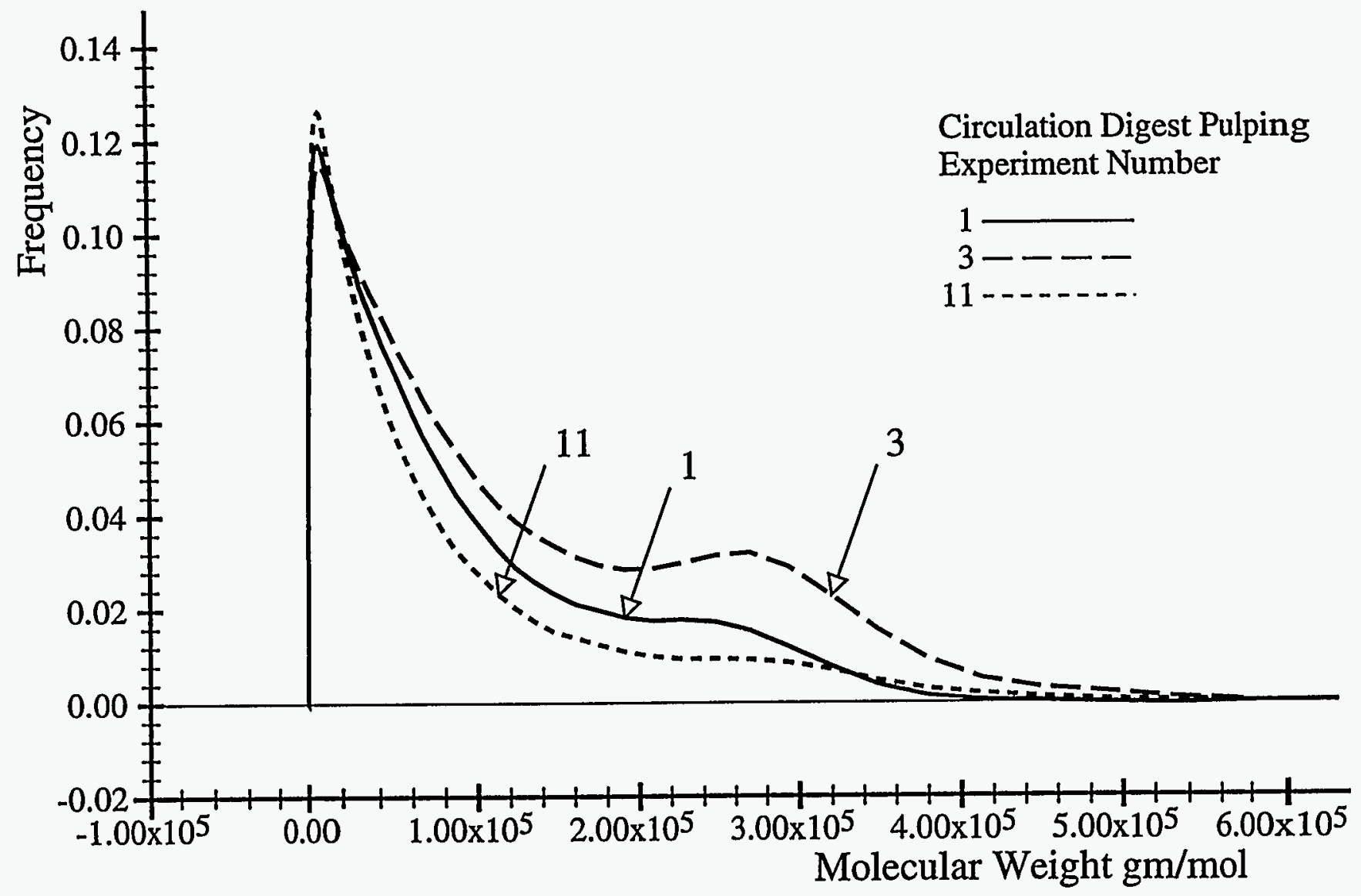

Figure 4.5.2 Molecular Weight distribution for lignins from Circulation Digestor Pulping Experimental Liquors 


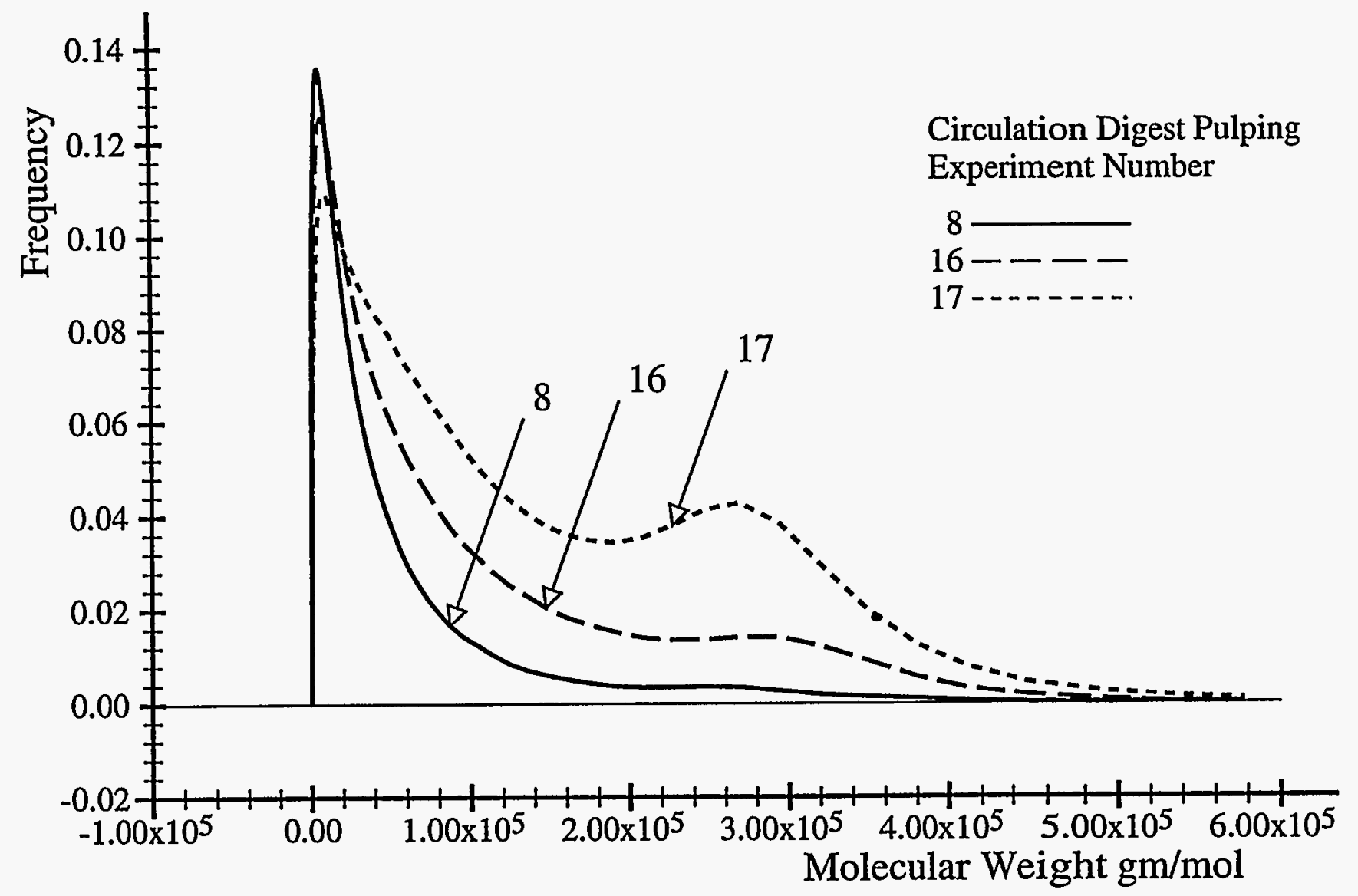

Figure 4.5.3 Molecular Weight distribution for lignins from Circulation Digestor Pulping Experimental Liquors 


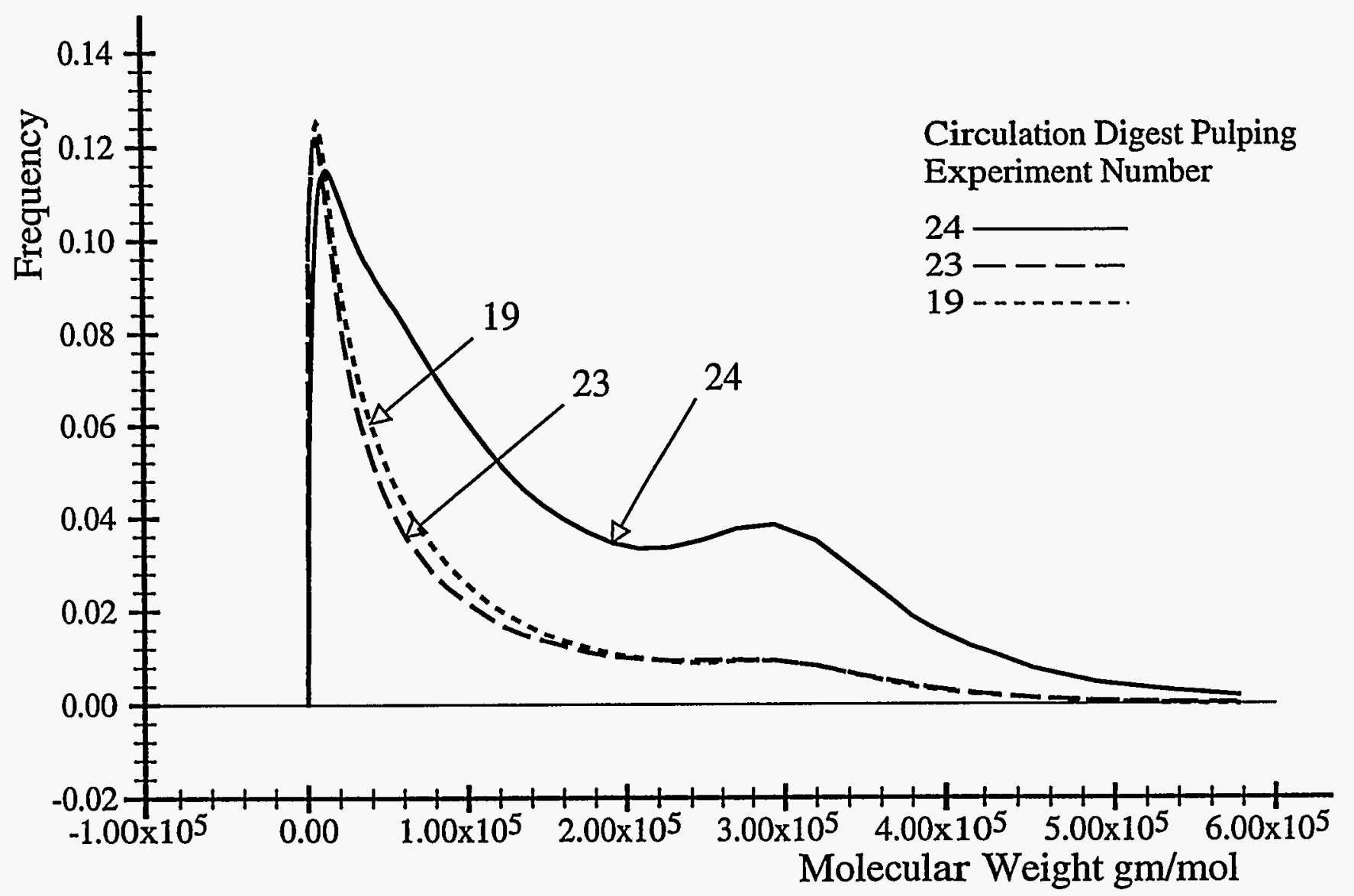

Figure 4.5.4 Molecular Weight distribution for lignins from Circulation Digestor Pulping Experimental Liquors 


\subsection{PULPING AND LIGNIN MOLECULAR WEIGHT}

It is clear that pulping conditions have significant effects on the molecular weights and molecular weight distributions of lignins in the black liquors produced. Due to the complexity of black liquor solutions, the molecular weights and molecular weight distribution of all of the lignin in a black liquor cannot be determined by experimental methods currently available.

We can consider lignin in a black liquor to be composed of three fractions. These are the lignin components that are soluble in an acid solution at $\mathrm{pH}=1.0$. This fraction is undoubtedly composed of very low molecular weight fragments and constitutes from 15 to almost $30 \mathrm{wt} \%$ of the lignin present in a black liquor. The second fraction is the lignin lost in purifying the higher molecular weight fraction for molecular weight characterization of the higher molecular weight fraction. This second fraction constitutes about 8 to $20 \mathrm{wt} \%$ of the lignin present in black liquor. Although undoubtedly higher in molecular weight than the fraction that is completely acid soluble, it is also undoubtedly lower in molecular weight than the fraction that is recovered as purified lignin. The third fraction, the high molecular weight purified lignin, constitutes more than $60 \mathrm{wt} \%$ of the lignin in black liquor.

In summary, lignin in black liquor can be considered to consist of three fractions which are:

1. Completely acid soluble -15 to $30 \mathrm{wt} \%$ of lignin present - very low molecular weights

2. Partially soluble -8 to $20 \mathrm{wt} \%$ of lignin present - low to moderate molecular weights

3. Purified acid insoluble lignin $->60 \mathrm{wt} \%$ of lignin present - high molecular weights

We believe that the high molecular weight fraction dominates the polymeric behavior of lignin in solution in its effects on properties. Indeed, the first two fractions, because of their close chemical similarity to the high molecular weight fraction, probably act as "plasticizers." This is apparent from such studies as measurement of glass transition. The glass transition of a precipitated lignin increases from about $120-130^{\circ} \mathrm{C}$ to $143-165^{\circ} \mathrm{C}$ with increasing purification. Obviously, the second fraction has a plasticizing effect. While measurements on black liquor 
solids include the effects of cellulosic fragments and salts as well as the effects of the first and second lignin fractions, the depression of the glass transition is very large; glass transition for $100 \%$ solids of kraft lignins are in the range of $25-45^{\circ} \mathrm{C}$. The depression of more than $100^{\circ} \mathrm{C}$ of the glass transition indicates a high plasticizing effect that is similar to the depression for such polymers as PVC with 30-40 volume\% of a good solvent for PVC.

Since the high molecular weight fraction is more than $60 \mathrm{wt} \%$ of the total lignin present in black liquor solids and since lignin constitutes $35-44$ wt\% of black liquor solids, the molecular weights of the high molecular weight fraction should affect a number of black liquor properties, particularly rheological properties. Therefore, we developed correlations relating $\mathbf{M}_{\mathbf{n}}, \mathbf{M}_{\mathrm{W}}$, and polydispersity index, P.I. $=M_{W} / M_{n}$ to pulping conditions. This is fully described in the publication: Dong, D.J. and A.L. Fricke, "Effects of Multiple Pulping Variables on the Molecular Weight and Molecular Weight Distribution of Kraft Lignin," Journal of Wood Chemistry and Technology, 15 (3), 369-393 (1995) that is included as part of this report re print re mo red. As with other responses, we applied response surface analysis techniques to determine the effects of pulping conditions on $M_{n}, M_{W}$, and P.I. $=M_{w} / M_{n}$ determined by VPO and LALLS for purified lignins from each of the circulation digester experiments. The general equation used was a quadratic model with interactions:

$$
Y=a_{o}+\sum_{i=1}^{k} a_{i} X_{i}+\sum_{i=1}^{k} a_{i i} X_{i}^{2}+\sum_{i<j}^{k} a_{i j} X_{i} X_{j}
$$

where:

$$
\begin{aligned}
& Y=\text { response }\left(M_{n}, M_{W} \text {, or P.I. }\right) \\
& X_{i}=\text { independent pulping variable } \\
& a_{0}, a_{i}, a_{i i}, a_{i j}=\text { correlation constants }
\end{aligned}
$$


The functions proved to be quite complex; all fifteen parameters (correlation coefficients) are statistically significant. Values for the coefficients for each response are given in the publication and in Table 5.0.1. The correlation coefficient for $\mathrm{M}_{\mathrm{n}}$ is 0.912 , but the correlation coefficients for $\mathrm{M}_{\mathrm{W}}$ and P.I. are 0.71 and 0.75 , respectively. These are lower than we should like, but can only be reduced by introduction of three factor interactions. We did not view this as justified.

Contour plots can be constructed with these equations to study the effects of pulping variables two-at-a-time. Examples of these are given in the publication. These are quite informative in examining the complex effects of pulping conditions on the molecular weight and polydispersity index of the high molecular weight fraction of lignin in black liquor. 
TABLE 5.0.1

Constants for Equations for $M_{W}, M_{n}$, and P.I. $=M_{w} / M_{n}$ of High Molecular Weight Lignin in Black Liquors from Circulation Digester Pulping Experiments (Equation 5.0.1)

\begin{tabular}{|c|c|c|c|}
\hline$Y=$ & $\mathrm{M}_{\mathrm{w}}$ & $M_{n}$ & P.I. $=\mathrm{M}_{\mathrm{w}} / \mathrm{M}_{\mathrm{n}}$ \\
\hline Variable & \multicolumn{3}{|c|}{ Parameters } \\
\hline INTERCEPT & $-1.95 E+06$ & $3.01 E+05$ & $-2.14 E+03$ \\
\hline $\mathrm{EA}$ & $4.09 \mathrm{E}+04$ & $4.01 E+03$ & $-1.82 E+01$ \\
\hline$S$ & $-9.90 \mathrm{E}+03$ & $7.55 E+02$ & $-1.27 E+01$ \\
\hline $\mathrm{T}$ & $9.71 E+03$ & $-2.00 \mathrm{E}+03$ & $1.42 \mathrm{E}+01$ \\
\hline $\mathbf{t}$ & $2.77 E+03$ & $3.04 \mathrm{E}+01$ & $2.27 \mathrm{E}-02$ \\
\hline $\mathrm{EA} * \mathrm{EA}$ & $-2.44 \mathrm{E}+03$ & $-6.89 \mathrm{E}+01$ & $-7.34 \mathrm{E}-01$ \\
\hline$S * S$ & $-8.21 E+01$ & $-3.71 E+00$ & $-6.77 E-03$ \\
\hline $\mathrm{T} * \mathrm{~T}$ & $-1.41 E+01$ & $3.09 \mathrm{E}+00$ & $-2.27 \mathrm{E}-02$ \\
\hline $\mathrm{t}^{*} \mathrm{t}$ & $-6.04 E+00$ & $-1.06 \mathrm{E}-01$ & $-2.74 \mathrm{E}-03$ \\
\hline $\mathrm{EA} * \mathrm{~S}$ & $7.10 \mathrm{E}+02$ & $-1.18 E+01$ & 4.70E-01 \\
\hline $\mathrm{EA} * \mathrm{~T}$ & $2.68 \mathrm{E}+01$ & $-4.91 E+00$ & $7.28 \mathrm{E}-02$ \\
\hline $\mathrm{EA}^{*} \mathrm{t}$ & $6.27 E+01$ & 5.81E-01 & $4.78 \mathrm{E}-02$ \\
\hline $\mathrm{S} * \mathrm{~T}$ & $1.30 \mathrm{E}+01$ & $-9.63 \mathrm{E}-01$ & $1.76 \mathrm{E}-02$ \\
\hline$S *_{\mathrm{t}}$ & $1.74 E+00$ & $-9.65 \mathrm{E}-01$ & $1.00 \mathrm{E}-02$ \\
\hline $\mathrm{T}^{*} \mathrm{t}$ & $-8.34 \mathrm{E}+00$ & $1.03 \mathrm{E}-02$ & $-1.76 \mathrm{E}-03$ \\
\hline
\end{tabular}

EA $=$ Effective Alkali, \%

$\mathrm{S}=$ Sulfidity, $\%$

$\mathrm{T}=$ Temperature, ${ }^{\circ} \mathrm{F}$

$\mathrm{t}=$ time at temperature, $\min$. 


\subsection{SIGNIFICANT OBSERVATIONS OF LIQUOR THERMAL BEHAVIOR}

The behavior of liquors at different concentrations of total solids with respect to freezing, drying, glass transition, and other transitions has led to some significant observations that have proven to be extremely useful in directing our analyses of results of our studies. These are sufficiently important to deserve description and comment.

Irreversible association of components of black liquor solids occurs when concentrating black liquors above about $85 \%$ solids, whether this is done by evaporation at moderate pressures (above $0.2 \mathrm{~atm}$ ) or by drying at moderate pressures. Completely dry black liquor solids that have been obtained by drying at temperatures above $90^{\circ} \mathrm{C}$ can seldom be dissolved completely, even in $0.1 \mathrm{~N} \mathrm{NaOH}$ solutions. Furthermore, these materials usually exhibit different physical properties than the original black liquor at the same concentration after dissolution and dilution. Black liquor solids dry very slowly at high solids. Long exposure to high temperatures for long periods of time leads to chemical changes that make it difficult to even reach a constant weight when drying a large quantity (more than several grams) of the liquor solids. Reversibility problems have also been observed when concentrating liquors above about $75 \%$ solids by evaporation. Liquors concentrated to above about $75 \%$ solids exhibit different properties than the original liquor when diluted after concentration by evaporation.

The problems presented by changes due to concentration to high solids levels by evaporation or drying led to several important procedural changes. The experimental liquors were concentrated and soap skimmed in two evaporation steps involving very short exposure times at evaporation temperatures to a concentration of $42-47 \%$ and then the liquors were stored in sealed containers at $4^{\circ} \mathrm{C}$. This minimized liquor volume while insuring no changes in the nature of the black liquor solids. Liquor samples for properties studies at higher solids concentrations were prepared by one step evaporation to the concentration desired while maintaining the evaporation temperature at a low level (usually below $92^{\circ} \mathrm{C}$ ). Measurements were then made on the liquor at the final concentration. Samples for study at concentrations above about $80-84 \%$ solids were 
prepared by freeze drying, as is described later. These procedures for concentrating samples yielded consistent and reproducible properties measurements.

It is highly desirable to determine liquor properties at solids concentrations from $\mathbf{7 5}$ to $100 \%$ solids. Also, it is imperative that purified lignins be prepared that are completely dried with no association of the lignin. This is not an uncommon problem; it plagues researchers in the biochemical and pigment industries. There are two potential solutions. The first is a total solvent exchange. This is routinely done with pigments where water is completely displaced by oil or varnish without change in the particle size characteristics of the pigment. The second is freeze drying in which an aqueous or non-polar solution is transformed to the solid state by freezing and the solvent then removed by sublimation at very low pressures. While slow, this procedure usually results in materials that are completely dry, but that have undergone no chemical or association changes during the process.

Freeze drying was adapted successfully for our work, and it was used for preparing all samples at concentrations above about $83 \%$, except for extremely small samples. For extremely small samples $(<25 \mathrm{mg})$ that were used for some thermal studies, such as DSC to determine heat capacity, a sample at a concentration of about $45 \%$ solids was placed in the experimental container to be used, the container was placed in a vacuum oven, and drying to the desired final concentration was conducted at temperatures below $50^{\circ} \mathrm{C}$. Normally, samples for study at very high solids concentrations and purified lignin samples were freeze dried.

The procedure for freeze drying is important. Black liquor at 22-30\% solids was frozen and the temperature lowered to below $-20^{\circ} \mathrm{C}$. The frozen liquor was ground to a coarse powder in a dry box at this low temperature (or below) by adding a small amount of liquid nitrogen while grinding. The frozen, ground sample was then placed in a freeze drier and dried to the final solids concentration by sublimation of the solvent at a pressure of about 3 microns. The dried sample was then ground to a powder in a dry box and placed in a sealed container until used. All 100\% black liquor solids were prepared in this manner. 
In preparing purified lignin, two freeze drying steps were involved. After the second acid precipitation and washing, the lignin slurry was frozen, ground at low temperature, and then freeze dried to constant weight and ground to a fine powder. This powder was solvent extracted, filtered, washed with solvent, and the slurry frozen and ground. The frozen, ground slurry was then freeze dried to constant weight and transferred to a sealed container until used.

During the original work on liquor properties, it was discovered that liquors would not freeze at concentrations above about $43-46$ wt\% solids; at high concentrations, a liquor undergoes a glass transition rather than freezing (Massee, 1983, Massee et al., 1986, Fricke, 1985). Further investigation with polar and non-polar amorphous polymers demonstrated that this was not unique with black liquors, but was expected behavior for amorphous polymer-solvent solutions. This is clearly illustrated in Figures 6.0.1 and 6.0.2. From these illustrations, one can see that there is a sharp transition from freezing to glass transition behavior.

The transition is interpreted as being the result of a transition in solution behavior from black liquor solids acting as solute in water as the solvent to water acting as solute in black liquor solids acting as solvent. In the former state (water as solvent), the solution can be treated as a dilute polymer solution or as a non-ideal fluid with regard to correlations. In the latter state (black liquor solids as solvent), the solution must be treated as a concentrated polymer solution or as a plasticized polymer (rubber state). This approach has been successful.

One should expect the concentration at which the solution transition occurs to increase with increasing temperature. Since the transition is a change in short range order, the concentration at which this occurs at a higher temperature should be apparent from measurement of a thermodynamic property from which a second order thermodynamic property can be determined. This was done with density studies. Density was measured as a function of solids concentration from zero to $100 \%$ solids and at a constant temperature of $25^{\circ} \mathrm{C}$. Density (the reciprocal of specific volume) is a first order thermodynamic property. The derivative of density with respect to an independent thermodynamic quantity, such as concentration, is a second order thermodynamic 


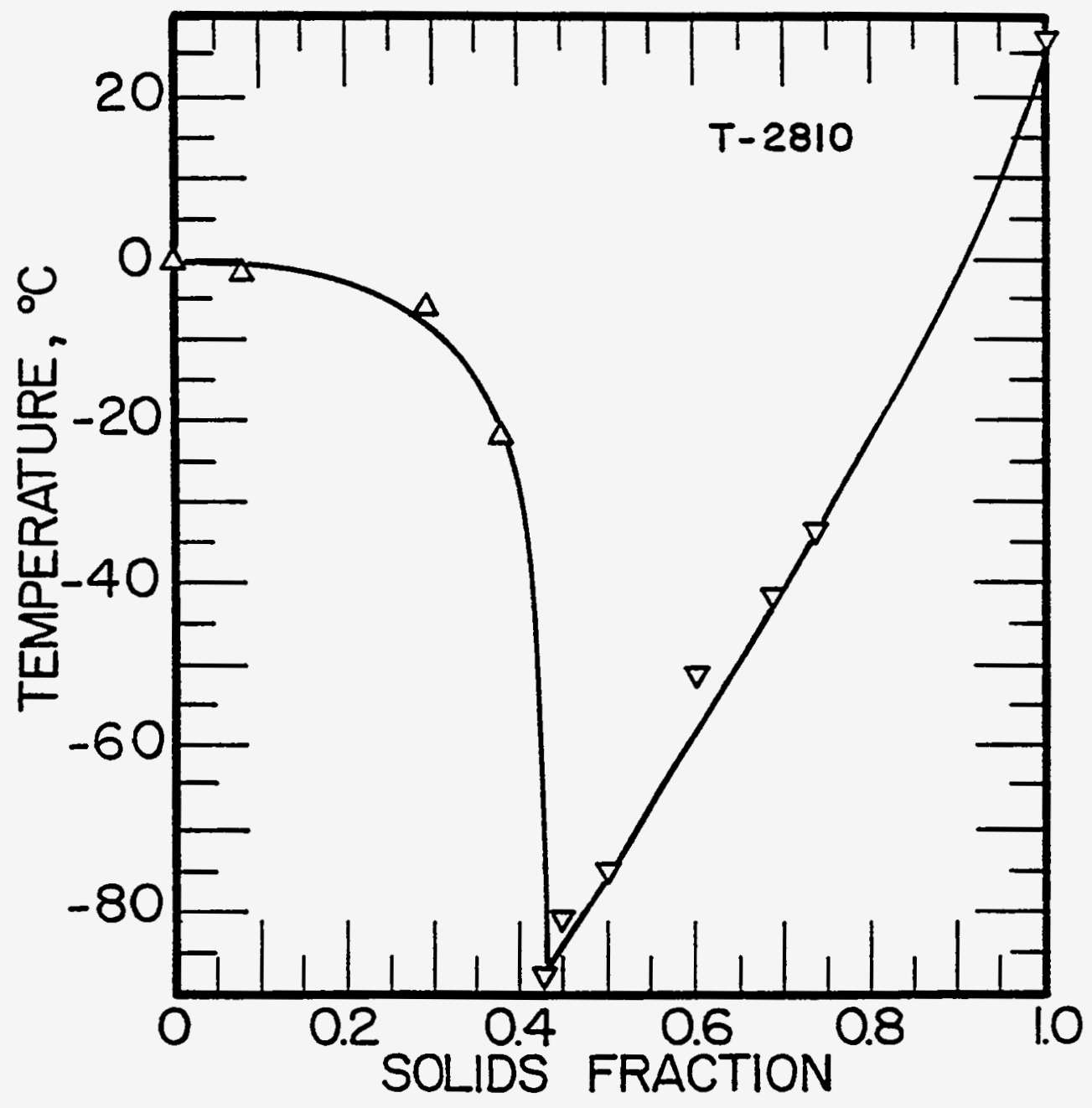

Figure 6.0 .1

Typical Freezing-Glass Transition Behavior for a Kraft Black Liquor 


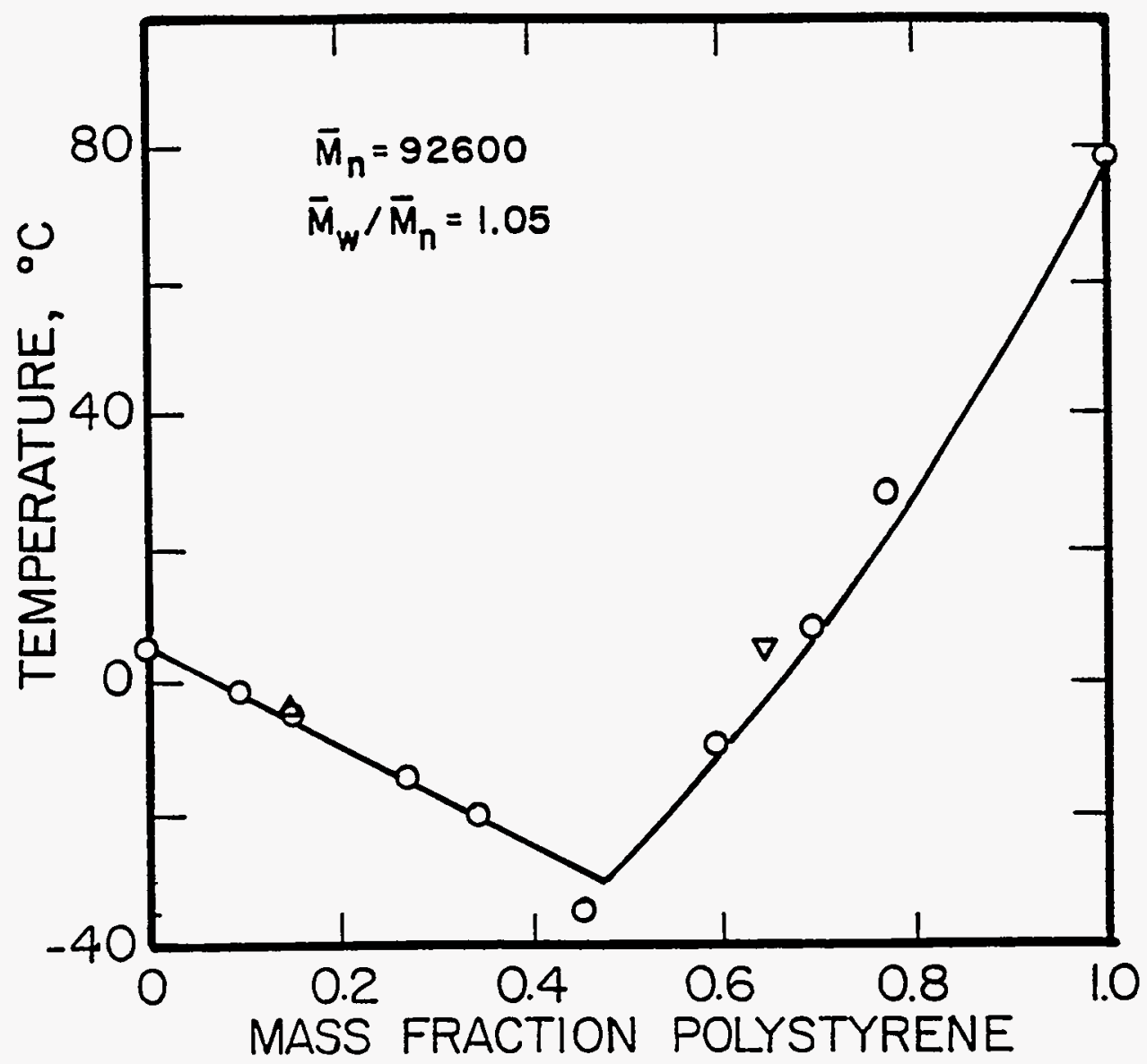

Figure 6.0 .2

Typical Freezing-Glass Transition Behavior for an Amorphous Polymer Solution 
quantity. Thus:

$$
\begin{aligned}
& (\rho)_{T, P . C}=\text { first order property } \\
& \left(\frac{\partial \rho}{\partial C}\right)_{T, P}=\text { second order property }
\end{aligned}
$$

where:

$$
\begin{aligned}
& \rho=\text { density } \\
& T=\text { temperature } \\
& \mathrm{P}=\text { pressure } \\
& \mathrm{C}=\text { concentration }
\end{aligned}
$$

If there is a change in order that is isenthalpic, the first order property will be continuous, but the second order property will be discontinuous.

Figure 6.0.3 shows the density of one of the circulation digester experimental black liquors as a function of concentration at a constant temperature of $25^{\circ} \mathrm{C}$. Density is a continuous function of concentration, but the derivative of density with respect to concentration exhibits two discontinuities. The first can be interpreted as due to the phase inversion discussed previously. The second is interpreted as being due to a change to a plasticized glass state. In this state, the liquor will be viscoelastic and probably cannot sustain infinite strain. That is, it probably cannot exhibit completely fluid behavior.

As the temperature is increased, one can expect the concentrations at which these transitions occur to increase. At this time, the transition concentrations vs. temperature are not defined.

The behavior appears to be general for kraft black liquors. The effect on properties is noticeable. The maximum in excess heat capacity occurs in the region of the second transition. Boiling behavior exhibits a change in the region between transitions as does viscosity behavior. 


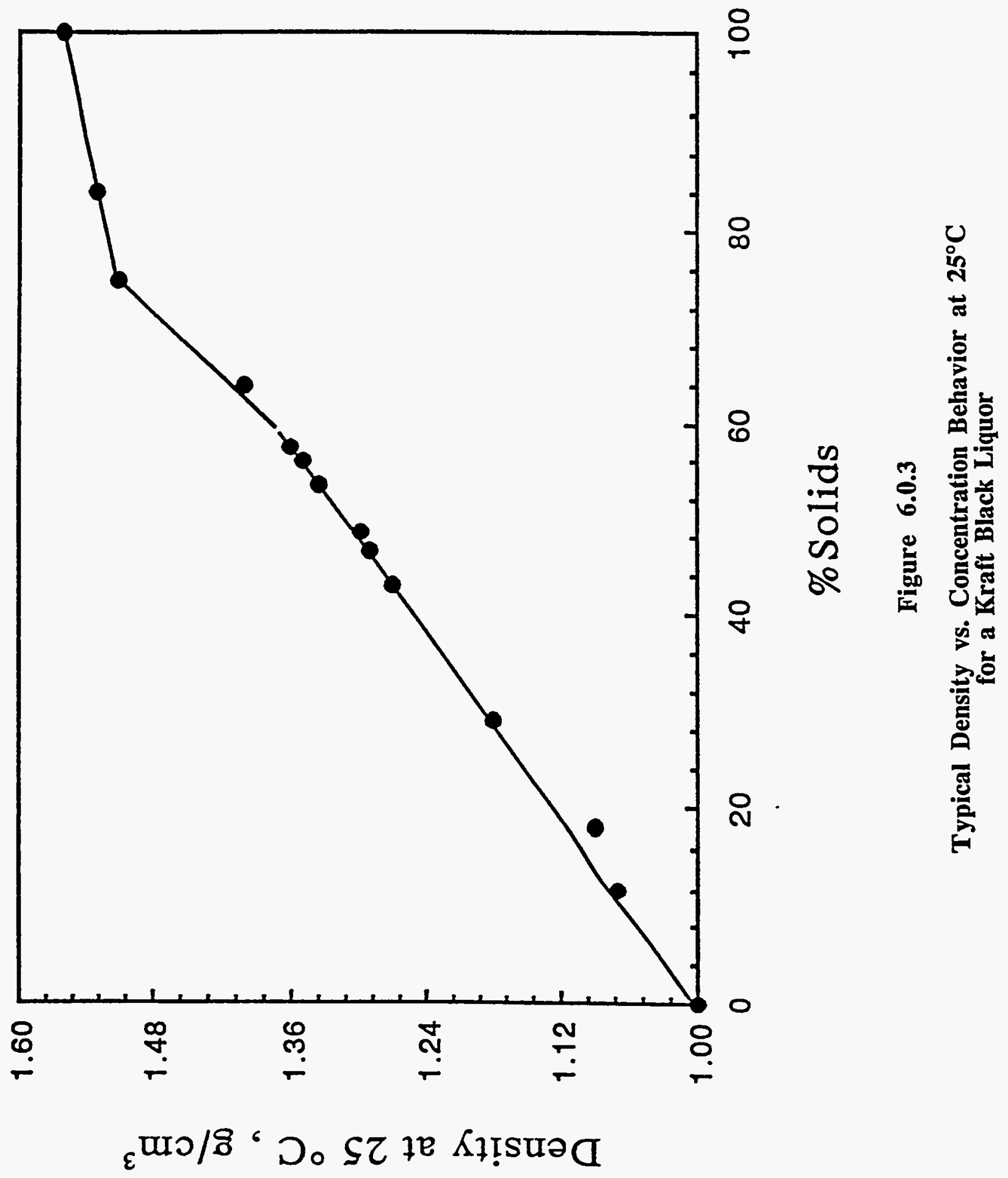


Viscoelasticity becomes increasingly significant with concentration as the second transition is approached.

Overall, these observations have been extremely helpful in directing experimental work, selecting methods for data reduction and data treatment, and in guiding efforts for correlation of results. 


\subsection{HEAT OF COMBUSTION}

Heat of combustion of black liquor is an important quantity affecting performance of recovery systems. Heat of combustion was correlated with pulping conditions and liquor composition for liquors produced in the circulation digester pulping experiments. The results are presented in this section.

Heats of combustion were determined by bomb calorimetry with standard states that equate heat of combustion to the so-called higher heating value (HHV) for many liquors. For a number of liquors, the heat of combustion was determined as a function of solids from $55-69 \%$ (the lower limit for ensuring complete combustion) to $100 \%$ solids. In every case, the heat of combustion decreased linearly with decrease in solids concentration with only minor variations in the rate of decrease. Therefore, the heat of combustion determined at $100 \%$ solids can be used to predict the heat of combustion at other solids concentrations with only slight error. Heats of combustion at $100 \%$ solids were determined by multiple measurements on black liquor solids for each of the 25 separate pulping conditions used in the circulation digester designed experiment. Results have been published in the publication: Zaman, A.A. and A.L. Fricke, "Effects of Pulping Conditions and Black Liquor Composition on the Heat of Combustion of Slash Pine Black Liquor," AIChE Symposium Series, Advances in Pulp and Papermaking, 21,(307), 154-159 (1995), which is included as part of this report. This is the first report of a systematic study of the variation in heating value with variation in pulping conditions for even a limited number of pulping variables.

Response surface methodology was used for fitting quadratic models with interactions as has been done with other responses. Different statistical evaluation methods, as explained in the publication, were used to select the simplest, statistically significant model that exhibited no bias. This was determined to be a 12 parameter model that is:

$$
\begin{aligned}
& 2 \text { parameter model that is: repript } \\
& \begin{array}{l}
\Delta \mathrm{H}_{\mathrm{c}}=11,481+968.84 * \mathrm{~S}-4469.96 * \mathrm{EA} \\
\text { removed, } \\
-2224.13 * \mathrm{t}-2.56{ }^{*} \mathrm{~S}{ }^{*} \mathrm{~T}+173.92 \mathrm{EA} * \mathrm{t} \\
+8.53 * \mathrm{EA}^{*} \mathrm{~T}+0.0316 * \mathrm{~S} * \mathrm{EA} * \mathrm{~T}
\end{array}
\end{aligned}
$$




$$
\begin{aligned}
& -0.00083 * \mathrm{~S} * \mathrm{~T} * \mathrm{t}-0.399 * \mathrm{EA} * \mathrm{t} * \mathrm{~T} \\
& +16.51 * \mathrm{EA} * \mathrm{EA}+5.14 * \mathrm{~T} * \mathrm{t}
\end{aligned}
$$

where:

$$
\begin{aligned}
& \Delta \mathrm{H}_{\mathrm{C}}=\text { heat of combustion of black liquor solids (Btu/lb) } \\
& \mathrm{EA}=\text { Effective Alkali, \% } \\
& \mathrm{S}=\text { Sulfidity, } \% \\
& \mathrm{t}=\text { time at temperature, } \min \\
& \mathrm{T}=\text { Temperature, }{ }^{\circ} \mathrm{K}
\end{aligned}
$$

This relation can be used to construct response surfaces so that the effects of pulping variables on heat of combustion can be examined two-at-a-time, as before. Examples of this are presented in the publication.

The results, of course, apply only to the skimmed liquors made from slash pine. However, corrections for soap concentrations greater than the equilibrium soap concentration at $28-30 \%$ solids (0.26-0.29 wt\% of solids) or for differences in "dead load" (carbonates, sulfates, and chlorides), can be made, assuming the effects are additive. Examples are given in the publication.

It was expected that the correlation of heat of combustion with liquor solids composition would be simpler, and that the most significant compositional variables affecting the heat of combustion would be lignin concentration, other organics concentration, sodium concentration, and other inorganic concentrations. Surprisingly, this also resulted in a 12 parameter model and the correlation was not as good as that for correlation with pulping conditions. The correlation equation is given in the publication included as part of this report. 
From a comprehensive study of response surfaces, we were led to exploring a number of non-linear models that could lead to simpler correlations. The results are an excellent example of the application of response surface analysis.

One relation developed that is extremely simple is a relation between heat of combustion and pulp yield, which is:

$$
\Delta \mathrm{H}_{\mathrm{c}}=0.36 \mathrm{Y}^{3.35} \exp [-0.066 \mathrm{Y}]
$$

where:

$$
\begin{aligned}
& \Delta \mathrm{H}_{\mathrm{C}}=\text { heat of combustion of solids, Btu/lb } \\
& \mathrm{Y}=\text { pulp yield, \% oven dry wood }
\end{aligned}
$$

This applies strictly only to the experimental liquors and would be difficult to adjust for variations in dead load or soap concentration. However, the form of the relation could be used in correlating mill data where soap concentrations, dead load, and sulfur oxidation are fairly constant.

Non-linear relations between heat of combustion and pulping variables or solids composition involving only 5 parameters each (as opposed to 12) were developed with correlation coefficients greater than 0.99 for each. These are the recommended correlations. These are:

$$
\Delta \mathrm{H}_{\mathrm{c}}=0.49 \mathrm{EA}^{-0.13} \mathrm{~S}^{0.075} \mathrm{~T}^{1.57} \mathrm{t}^{-0.011}
$$

and

$$
\Delta \mathrm{H}_{\mathrm{c}}=11947.5 \mathrm{~L}^{0.63} \mathrm{I}^{-0.06} \mathrm{O}^{0.024} \mathrm{SO}^{0.096}
$$

where: 


$$
\begin{aligned}
& \Delta \mathrm{H}_{\mathrm{c}}=\text { heat of combustion of solids, Btu/lb } \\
& \text { EA = Effective alkali, \% } \\
& \mathrm{S}=\text { Sulfidity, } \% \\
& \mathrm{~T}=\text { Temperature, }{ }^{\circ} \mathrm{K} \\
& \mathrm{t}=\text { Time at temperature, } \mathrm{min} . \\
& \mathrm{L}=\text { lignin concentration, } \mathrm{gm} / \mathrm{gm} \\
& \mathrm{O}=\text { Other organics, gm/gm } \\
& \mathrm{SO}=\text { sodium, gm/gm } \\
& \mathrm{I}=\text { other inorganics, } \mathrm{gm} / \mathrm{gm}
\end{aligned}
$$

These relations indicate that cooking temperature has the greatest effect on heat of combustion and that lignin is the largest contributor to the heat of combustion. 


\subsection{DENSITY}

Density and thermal expansion studies were included in this program for several reasons. Firstly, volumetric flow rates are normally measured in plant operations, but mass flow rates are necessary for material and energy balances. Secondly, density appears in many engineering relations used for design that are based on similitude, and lack of precise knowledge of density introduces uncertainty. Thirdly, specific volume (the reciprocal of density) is a basic thermodynamic property, and behavior of this property can aid in understanding a material.

Density of black liquors at solids concentrations below $55 \%$ has been determined in a number of reported studies, but no measurements at higher solids concentrations had been reported prior to this study. In our previous work (Wight, 1985, Fricke, 1985), we had provided the most detailed study and had included thermal expansion studies of liquors at solids concentrations up to 50\%. All studies showed that density is a linear function of solids concentration at constant temperature. The density at $25^{\circ} \mathrm{C}$ can be expressed as:

$$
\rho_{25}=0.99707+\mathrm{aX}
$$

where:

$$
\begin{aligned}
& \rho_{25}=\text { density at } 25^{\circ} \mathrm{C}, \mathrm{gm} / \mathrm{ml} \\
& \mathrm{X}=\text { solids concentration, } \% \\
& \mathrm{a}=\text { constant }
\end{aligned}
$$

The constant, a, varies with liquor solids composition. Wight (1985) demonstrated that, for a limited number of softwood kraft liquors, the organic/inorganic ratio had a dominating effect on a.

From our thermal studies, it was clear that black liquor at low concentrations behaved as a dilute polymer solution, which suggested that the principle of corresponding states could be applied. We arbitrarily chose $25^{\circ} \mathrm{C}$ and the same solids concentration as the reference state. The 
ratio of density at any solids concentration to the reference density, the reduced density, should be constant if the thermodynamic state is the same. This was done successfully for a number of liquors and:

$$
\rho_{R}=1.0-A(T-25)-B(T-25)^{2}
$$

where:

$$
\begin{aligned}
& \rho_{R}=\text { reduced viscosity }=\rho / \rho_{R} \\
& T=\text { Temperature, }{ }^{\circ} \mathrm{C} \\
& \mathrm{A}, \mathrm{B}=\text { constants }
\end{aligned}
$$

reduced all thermal expansion curves to a single curve for any one liquor. This was applied successfully to a number of different types of black liquor (Wight, 1985, Fricke, 1985). Our work was reported by Adams and Frederick (9). Adams and Frederick (9), in reporting our results, overlooked the lack of complete correlation with organic/inorganic ratio and ignored the caveat concerning extrapolation due to uncertainty of the thermodynamic state and recommended extrapolation. On fundamental grounds, this had to be in error.

In the present work, we used gas comparison pycnometry to measure densities of black liquors at solids concentrations from 55 to $100 \%$, and we used dilatometry for thermal expansion measurements. The instruments and procedures have been reported in detail in an earlier report (Fricke, 1997). The description of development and interpretation have been published in: Zaman, A., M.O. Wight, and A.L. Fricke, "Density and Thermal Expansion of Black Liquors," TAPPI Journal, 77(8), 175-181 (1994), which is included as part of this report. Results clearly indicate that two second order thermodynamic transitions occur at $25^{\circ} \mathrm{C}$. At concentrations higher than that at which the second occurs, the change in density with concentration is what would be expected for a plasticized glassy polymer. Other conclusions are given in detail in the publication.

$$
\begin{aligned}
& \text { reprint } \\
& \text { removed }
\end{aligned}
$$


Subsequently, measurements of density and thermal expansion were made for many liquors over the entire solids concentration range for temperatures up to $100^{\circ} \mathrm{C}$ or higher, when possible. All liquors exhibited similar behavior, including liquors derived from sulfite, carbonate, and semi-chemical pulping. However, the solids concentrations at which the second order transitions occurred varied with species, pulping conditions, and pulping process. Generally, the first second order transition occurred at solids concentrations between 60 and $70 \%$ for kraft liquors, but it occurred at 28-33\% for semi-chemical liquors.

Density and thermal expansion measurements were made for all of the liquors from the circulation digester pulping experiment for slash pine. These data were then treated extensively to develop quantitative correlations for density, and results have been published in: Zaman, A.A., J.S. Deery, T.W. McNally, and A.L. Fricke, "Effect of Pulping Variables on Density of Slash Pine Kraft Black Liquors: Predictive Models," TAPPI Journal, 80(9), 199-207, (1997), which is included as part of this report. A detailed description is given in the publication. reprint red.

Since density is a piece-wise continuous function with respect to concentration at constant temperature, three linear segments involving a minimum of four constants for each liquor at constant temperature (assuming that the density at $100 \%$ solids is an additive property as shown earlier (Wight et al., 1994) would have to be correlated. In addition, because it has been shown that the thermal expansion is different in each thermodynamic state, six additional constants for a total minimum of ten would have to be correlated to completely quantify the effect of pulping conditions or composition on density. This proved to be essentially impossible and was viewed as not worth the effort. Instead, we concentrated upon correlating density with pulping conditions and composition for the lower thermodynamic state. This is tractable and of the greatest interest.

Correlation of density for the lower thermodynamic state should be accurate up to about $70 \%$ solids concentration at liquor firing temperatures, and it will give conservative predictions of density from the first transition to concentrations somewhat above that for the second transition. Since firing by present technology is not possible at concentrations above that of the second 
transition (the liquor is a plasticized rubbery glass), the correlations developed should be adequate for engineering purposes.

The constants a, A, and B in equations 9.0.1 and 9.0.2 were determined for each liquor derived from the circulation digester pulping experiment. As before, response surface methodology was used to determine the simplest, statistically significant, linear regression model with interaction terms as:

$$
\begin{aligned}
Y= & \beta_{o}+\sum_{i=1}^{4} \beta_{i} X_{i}+\sum_{i=1}^{4} \beta_{i j} X_{i} X_{j}+\sum_{i=1}^{4} \beta_{i i} X_{i}^{2} \\
& +\sum_{i<j<k}^{4} \beta_{i j k} X_{i} X_{j} X_{k}+\sum_{i<j<k<1}^{4} \beta_{i j l l} X_{i} X_{j} X_{k} X_{1}
\end{aligned}
$$

where:

$$
\begin{aligned}
& Y=a \text { response constant }=a, A \text {, and } B \\
& \beta_{0}, \beta_{i}, \beta_{i i}, \beta_{i j}, \beta_{i j k}, \beta_{i j k l}=\text { regression parameters } \\
& X_{i}=\text { pulping variable }
\end{aligned}
$$

Responses of a, A, and B are highly non-linear. The complete model (20 parameters with 5 degrees of freedom) gives correlation coefficients of $0.994,0.999$, and 0.997 , respectively, for a, A, and B. Parameters for the complete model are given in Table 2 of the publication. This model can be used to explore the effect of two pulping variables at a time at constant values of the other two pulping variables and constant temperature and solids concentration. From inspection of such surfaces and from statistical methods, simpler (but less precise) models can be developed.

The simpler models selected and recommended for $\mathrm{a}, \mathrm{A}$, and $\mathrm{B}$ are:

$$
\mathrm{a}=4.6 \times 10^{-3}-1.67 \times 10^{-4} * \mathrm{t}+8.66 \times 10^{-4} * \mathrm{EA}
$$




$$
\begin{aligned}
& -1.8 \times 10^{-4} * \mathrm{~S}+8.51 \times 10^{-6} * \mathrm{t} * \mathrm{EA} \\
& +4.21 \times 10^{-6} * \mathrm{t} * \mathrm{~S}-7.99 \times 10^{-7} * \mathrm{~T} * \mathrm{EA} \\
& +1.21 \times 10^{-5} * \mathrm{EA} * \mathrm{~S}+3.48 \times 10^{-7} * \mathrm{t} * \mathrm{t} \\
& -3.52 \times 10^{-5} * \mathrm{EA} * \mathrm{EA}-2.85 \times 10^{-7} * \mathrm{EA} * \mathrm{~S} * \mathrm{t}
\end{aligned}
$$

with correlation coefficient $=0.93$

$$
\begin{aligned}
\mathrm{A}= & 1.67 \times 10^{-2}-1.1 \times 10^{-6} * \mathrm{t}-2.0 \times 10^{-4} * \mathrm{~T}-4.11 \times 10^{-4} * \mathrm{~S} \\
& +6.25 \times 10^{-6} * \mathrm{t} * \mathrm{~S}+2.4 \times 10^{-6} * \mathrm{~T} * \mathrm{~S} \\
& +2.58 \times 10^{-5} * \mathrm{EA} * \mathrm{~S}+5.83 \times 10^{-7} * \mathrm{~T} * \mathrm{~T} \\
& +2.26 \times 10^{-9} * \mathrm{t} * \mathrm{~T} * \mathrm{EA} * \mathrm{~S}-1.51 \times 10^{-7} * \mathrm{EA} * \mathrm{~S} * \mathrm{~T} \\
& -3.85 \times 10^{-7} * \mathrm{EA} * \mathrm{~S} * \mathrm{t}-3.64 \times 10^{-8} * \mathrm{~S} * \mathrm{~T} * \mathrm{t}
\end{aligned}
$$

with correlation coefficient $=0.91$

$$
\begin{aligned}
\mathrm{B}= & -1.269 \times 10^{-5}-3.857 \times 10^{-6} * \mathrm{t} \\
& +8.398 \times 10^{-6} * \mathrm{~S}+2.41 \times 10^{-8} * \mathrm{~T} * \mathrm{t} \\
& +2.59 \times 10^{-7} * \mathrm{t} * \mathrm{EA}-8.316 \times 10^{-9} * \mathrm{t} * \mathrm{~S} \\
& +3.812 \times 10^{-9} * \mathrm{~T} * \mathrm{EA}-4.723 \times 10^{-8} * \mathrm{~T} * \mathrm{~S} \\
& -5.15 \times 10^{-7} * \mathrm{EA} * \mathrm{~S}+2.846 \times 10^{-12} * \mathrm{t} * \mathrm{~T} * \mathrm{EA} * \mathrm{~S} \\
& +2.906 \times 10^{-9} * \mathrm{EA} * \mathrm{~S} * \mathrm{~T}-1.604 \times 10^{-9} * \mathrm{EA} * \mathrm{~T} * \mathrm{t}
\end{aligned}
$$

with correlation coefficient $=0.96$

where:

$\mathrm{EA}=$ Effective alkali, $\%$ 


$$
\begin{aligned}
& \mathrm{S}=\text { Sulfidity }, \% \\
& \mathrm{~T}=\text { Temperature },{ }^{\circ} \mathrm{C} \\
& \mathrm{t}=\text { Time at temperature, } \mathrm{min} .
\end{aligned}
$$

The recommended equations for a, $\mathrm{A}$, and $\mathrm{B}$ involve 11, 12, and 12 regression constants and 10, 11 , and 11 variables or interaction terms, respectively.

The responses are very non-linear and identical variables or interactions do not appear in each recommended equation. Inspection of response surfaces to suggest possible non-linear models could have been pursued, but was not deemed to be worth the effort vis-a-vis other needs. Instead, response surfaces were used to explore example responses that are detailed in the publication.

Examples of the fit of the model to experimental data are shown in the publication. In cases where the lignin concentration and the organic/inorganic ratio are low, the first transition occurs at nearly $70 \%$ solids and the agreement of experimental and predicted values at up to $76 \%$ solids for temperatures above $40^{\circ} \mathrm{C}$ is excellent. In cases where the lignin concentration and the organic/inorganic ratio is high, the experimental and predicted values are markedly different at $75 \%$ solids; the predicted values are considerably less than the experimental values. 


\subsection{HEAT CAPACITY}

Heat capacity is a fundamental property appearing in many engineering relations used for design, and heat capacities must be known for accurate energy balances. Heat capacities of liquors have been reported from other studies (Harvin and Brown, 1953, Hunter et al., 1953, Koorse et al., 1977) for concentrations up to $50 \%$ solids. The most extensive studies have been reported by (Massee, 1984), (Massee et al., 1987) and (Fricke, 1985, 1987) that included measurements at very high solids (almost 100\%). Massee (1984) developed a model for excess heat capacity of black liquor based upon treatment of black liquor as a binary of water and solids. A theoretically sound basis for the model was developed and reported (Massee, M.A., E. Kiran, and A.L. Fricke, 1987). Results of this and extensions of work have been reported (Fricke, 1985, Fricke, 1987, Fricke, 1990, Fricke, 1993).

As part of his Ph.D. studies, Stoy (1992) collected data on heat capacities of liquors in this program and supervised data collection for all liquors produced in the circulation digester pulping experiments as well as for a number of mill liquors up to and including $100 \%$ solids. Detailed description of experimental procedures used has been reported (Fricke, 1997). In every case, the fundamentally sound model developed by Massee with the able guidance of Professor E. Kiran proved to be valid for correlation.

Correlation of these results required considerable time and effort, and modification of the fundamentally sound model developed by Massee, based on observations of the overall results. The first publication on this work: Zaman, A.A., S.A. Tavares, and A.L. Fricke, "Studies on the Heat Capacity of Slash Pine Kraft Black Liquors: Effects of Temperature and Solids Concentrations," Journal of Chemical and Engineering Data, 41 (2), 266-271, (1996) is included as part of this report. The model developed by Massee correlates the data for any one liquor very well. Moreover, correlation and analysis of results showed that heat capacity decreases almost linearly with solids concentration up to about $45 \%$ solids at most. At higher solids, behavior is non-ideal. This is in agreement with observations for other thermodynamic properties with respect to change in the system. Moreover, the excess heat capacity determined from the model always

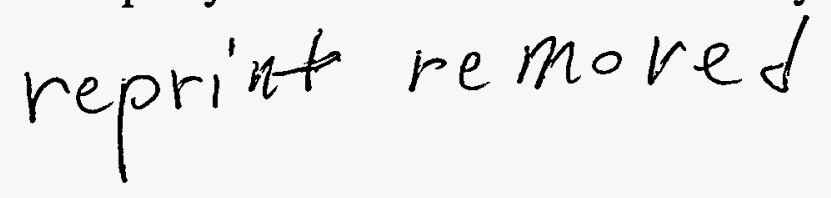


exhibited a maximum in the 70-80\% solids concentration range which is in the range for the higher second order transition defined by density measurements. One should note that this excess heat capacity decreased markedly with increasing temperature.

Massee's model involves four constants for each liquor. We sought an alternative that, although not as sound, involved fewer constants. Review of prior work and qualitative data analysis led us to use the following equation to fit the data for a black liquor:

$$
C_{p}=(A+B T) S+C T+D
$$

where:

$$
\begin{aligned}
& \mathrm{C}_{\mathrm{p}}=\text { Heat capacity, } \mathrm{kJ} / \mathrm{kg}{ }^{\circ} \mathrm{K} \\
& \mathrm{T}=\text { Temperature, }{ }^{\circ} \mathrm{K} \\
& \mathrm{S}=\text { Solids mass fraction, } \mathrm{kg} / \mathrm{kg}
\end{aligned}
$$$$
\text { A, B, C, D = constants }
$$

This appears to have four adjustable constants, but there are only two. At a solids mass fraction of zero, the equation becomes:

$$
C_{p}=C T+D
$$

and this, by definition, must be the heat capacity of water. Therefore, $C$ and $D$ are determined independently and are fixed. Values for $\mathrm{C}$ and $\mathrm{D}$ were determined from literature values for the heat capacity of water (Waest and Astle, 1979). One should note that this model (equation 9.0.1) assumes a linear dependence of heat capacity on solids concentration at constant temperature. This reduces precision, but greatly simplifies the correlation effort. 
Results of correlations showed that equation 9.0.1 could represent the data for all liquors from circulation digester pulping with correlation coefficients of 0.99 or better. The results were viewed as justification for the simplification used.

The recommended model is:

$$
C_{p}=(A+B T) S+C T+D
$$

with $\mathrm{C}=6.19 \times 10^{-4} \mathrm{~kJ} / \mathrm{kg}^{\circ} \mathrm{K}^{-2}$ and $\mathrm{D}=3.98 \mathrm{~kJ} / \mathrm{kg}{ }^{\circ} \mathrm{K}$. Values for $\mathrm{A}$ and $\mathrm{B}$ for each of the experimental liquors are given in Table 9.0.1. 
Table 9.0.1

Model Parameters for the Heat Capacity of Black Liquors for Equation (9.0.1)

\begin{tabular}{|c|c|c|c|}
\hline $\begin{array}{l}\text { Circulation Digester } \\
\text { Pulping Liquor No. }\end{array}$ & $\mathrm{A},\left(\frac{\mathrm{kJ}}{\mathrm{kg}^{\circ} \mathrm{K}}\right)$ & $\mathrm{B},\left(\frac{\mathrm{kJ}}{\mathrm{kg}^{\circ} \mathrm{K}^{2}}\right)$ & $\mathrm{R}^{2}$ \\
\hline 1 & -2.65 & 0.0018672 & 0.99 \\
\hline 2 & -2.66 & 0.0018985 & 0.99 \\
\hline 3 & -2.87 & 0.0026567 & 0.99 \\
\hline 4 & -2.63 & 0.0015713 & 0.99 \\
\hline 5 & -2.67 & 0.0016320 & 0.99 \\
\hline 6 & -2.75 & 0.0018386 & 0.99 \\
\hline 7 & -2.59 & 0.0017911 & 0.99 \\
\hline 8 & -2.41 & 0.0012024 & 0.99 \\
\hline 9 & -2.39 & 0.0013667 & 0.99 \\
\hline 10 & -2.59 & 0.0017180 & 0.99 \\
\hline 11 & -2.71 & 0.0021244 & 0.99 \\
\hline 12 & -2.39 & 0.0012727 & 0.99 \\
\hline 13 & -2.67 & 0.0021099 & 0.99 \\
\hline 14 & -3.26 & 0.0032104 & 0.99 \\
\hline 15 & -2.85 & 0.0025366 & 0.99 \\
\hline 16 & -2.73 & 0.0021905 & 0.99 \\
\hline 17 & -2.68 & 0.0019773 & 0.99 \\
\hline 18 & -2.48 & 0.0013868 & 0.99 \\
\hline 19 & -2.67 & 0.0020873 & 0.99 \\
\hline 20 & -2.28 & 0.0009386 & 0.99 \\
\hline 21 & -2.80 & 0.0021483 & 0.99 \\
\hline 22 & -2.72 & 0.0018418 & 0.99 \\
\hline 23 & -2.52 & 0.0014982 & 0.99 \\
\hline 24 & -2.45 & 0.0013102 & 0.99 \\
\hline 25 & -2.41 & 0.0013255 & 0.99 \\
\hline
\end{tabular}




\subsection{HEAT OF DILUTION AND ENTHALPY-CONCENTRATION RELATIONS}

Accurate enthalpies are necessary for accurate energy balances. The quantitative evaluation of heat capacity described earlier will assist in improving the accuracy of enthalpy relations for Slash Pine kraft black liquors (these can also be used for liquors derived from other Southern softwoods with little error), but black liquors have been shown to be non-ideal at higher solids for every property investigation. One should expect, therefore, that black liquors would exhibit a significant heat of dilution (or heat of solution). Until now this has been ignored in enthalpy calculations for black liquor. In fact, only two single point measurements of the heat of mixing for a black liquor have been reported previously (Grace, T.M. and M.S. Funk, 1981).

\subsection{Development of Experimental Method}

As part of this program, research has been conducted to develop a method for accurately measuring the heat of dilution of black liquor by using absolute microcalorimetry. Development of the method constituted part of M.A. Stoy's Ph.D. research (Stoy, 1992). The experimental method has been described in detail in previous reports to DOE (Fricke, 1993, Fricke, 1997) as well as in the Ph.D. thesis (Stoy, 1992). Details of the method and description of the method for calculating the heat of dilution at $80^{\circ} \mathrm{C}$ as a function of solids concentration for reference states of liquid water at $0^{\circ} \mathrm{C}$ and liquor solids at an extrapolated state of infinite dilution at $80^{\circ} \mathrm{C}$ have been published in Stoy, M.A. and A.L. Fricke, "Development of a Method for Measuring the Heat of Dilution of Kraft Black Liquor and Water," TAPPI Journal, 77, 8, 169-174 (1994), which is included as part of this report.

$$
\begin{aligned}
& \text { reprint } \\
& \text { removed, }
\end{aligned}
$$

\subsection{Enthalpy Concentration}

With accurate heat capacity and heat of dilution data, an enthalpy-concentration relation for a black liquor can be developed. This has been done by Stoy (Stoy, 1992). The method of calculation and several example enthalpy-concentration charts for kraft black liquors are given in the publication: Stoy, M.A. and A.L. Fricke, "Enthalpy Concentration Relations for Black 
Liquor," TAPPI Journal, 77, 9, 103-110 (1994), which is included as part of this report. The method of calculation is presented clearly and concisely in the publication. More detailed development is given by Stoy (Stoy, 1992).

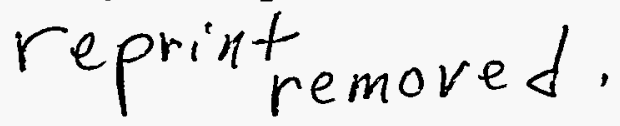

A number of things are apparent. The effects of heat of dilution on enthalpy are not negligible, even at moderate solids concentrations (see Figure 2 and Figure 3 of the publication in which the enthalpy vs. concentration for zero heat of dilution is represented by a straight, dotted line). These same Figures show that variations for the four liquors tested are minor below about $50 \%$ solids, but that variations become larger as concentration increases. The heat of dilution at $80^{\circ} \mathrm{C}$ and $80 \%$ solids has an average value for the four liquors of $190 \mathrm{~kJ} / \mathrm{kg}$ of solution, which is certainly significant.

Enthalpy-concentration relations for the four liquors, calculated by standard thermodynamic methods using the heat of dilution curves at $80^{\circ} \mathrm{C}$ and non-ideal heat capacity relations developed using Massee's model for the four liquors are presented in tabular form in Tables II, III, IV and V and in graphical form in Figures 4, 5, 6, and 7 in the publication show that none of the liquors behaves ideally. These are the first accurate enthalpy-concentration relations to be published for any black liquor.

The heat of dilution data used was precise and reproducible. The heat capacity data was reasonably accurate and modeled on a sound theoretical basis. In both cases, a single liquor was treated as a pseudo-binary consisting of black liquor solids and water. If the assumption of a pseudo-binary is valid, there should be thermodynamic consistency between enthalpy and fugacity.

Accurate equilibrium vapor pressure data had been collected for these liquors as a function of solids concentrations. We assumed that the vapor consisted only of water (a valid assumption for equilibrium vapor pressure for a skimmed liquor). Second viral coefficient values for water vapor (O'Connell, J.P. and J.M. Prausnitz, 1970) and known properties of water (Keenan, J.H. and F.G. Keyes, 1952) were used to convert vapor pressure to fugacity for water. One equilibrium vapor pressure value and the liquid enthalpy at constant solids were used to calculate the water fugacity of the liquid as a function of temperature by standard thermodynamic procedures 
(Stoy, 1992). The fugacities of water in the black liquor were then used to calculate the vapor pressure as a function of temperature and the results compared. It should be noted that this is a quite sensitive test of thermodynamic consistency. This was done for all four liquors at different solids levels. The worst case is presented in Figure 8. It is quite obvious that Massee's model for heat capacity, the heats of dilution, and equilibrium vapor pressure data are quite consistent thermodynamically with the assumption that a black liquor of constant solids composition behaves as a binary system.

\subsection{Enthalpy-Concentration Model}

Once the experimental method for experimentally determining the heat of dilution had been established and enthalpy-concentration relations were shown to be thermodynamically consistent with treatment of a black liquor of constant solids composition as a binary, heat of dilution was determined experimentally for all of the black liquors derived from the circulation digester pulping experiments. One can appreciate that this experimental work, along with the experimental work necessary to determine heat capacities for all of these liquors took considerable time and effort.

The data were used to develop enthalpy-concentration relations for the liquors derived from the circulation digester pulping experiments as reported in: Zaman, A.A. and A.L. Fricke, "Heat of Dilution and Enthalpy-Concentration Relations for Slash Pine Kraft Black Liquors," Chem. Eng.Comm., 155, 197-216 (1996), which is included as part of this report. reprint re mo ved.

Heats of dilution as a function of solids concentration at $80^{\circ} \mathrm{C}$ with the same reference states for water and black liquor solids were determined by the method developed by Stoy (Stoy, 1992, Fricke, 1993, Stoy and Fricke, 1994). These were used, following Stoy, to calculate "base isotherms" at $80^{\circ} \mathrm{C}$ for each, which are really the enthalpy-concentration relations as a function of solids at a constant temperature of $80^{\circ} \mathrm{C}$.

These "base isotherms" all exhibit exponential type decay with increasing solids concentration. Evaluation of a number of correlating functions led to the following as a satisfactory correlating function: 


$$
\mathrm{H}_{80}=\mathrm{H}_{\mathrm{w}}+\mathrm{b}\left[-1+\exp \left(\frac{-\mathrm{X}}{\mathrm{c}}\right)\right]
$$

where:

$\mathrm{H}_{80}=$ liquor enthalpy at $80^{\circ} \mathrm{C}$ and solids mass fraction, $\mathrm{X}, \mathrm{Btu} / \mathrm{lb}$ solutions

$\mathrm{X}=$ solids mass fraction

$\mathrm{H}_{\mathrm{W}}=$ enthalpy of water at $80^{\circ} \mathrm{C},=143.9 \mathrm{Btu} / \mathrm{lb}$

$\mathrm{b}, \mathrm{c}=$ adjustable constants

Values determined for $\mathrm{b}$ and $\mathrm{c}$ for liquors at all of the pulping conditions, except two, are given in Table 10.3.1. The correlation coefficients are $0.99+$ in all cases.

Once the enthalpy at $80^{\circ} \mathrm{C}$ is determined for a liquor at a given concentration, the enthalpy at any other temperature is simply:

$$
\mathrm{H}_{\mathrm{T}}=\mathrm{H}_{80}+\int_{80}^{\mathrm{T}} \mathrm{C}_{\mathrm{p}} \mathrm{dT}
$$

where:

$\mathrm{H}_{80}=$ enthalpy of the liquor at the given concentration and $80^{\circ} \mathrm{C}$

$\mathrm{Cp}=$ heat capacity of the liquor at the given concentration

$\mathrm{T}=$ Temperature, ${ }^{\circ} \mathrm{C}$

$\mathrm{H}_{\mathrm{T}}=$ enthalpy of the liquor at the given concentration and temperature, $\mathrm{T}$

Heat capacities, as determined by using the model: 
Figure 10.3.1

Model Parameters for Equation 10.3.1 for

Calculation of "Base Isotherms" (Enthaply of Black Liquor at $80^{\circ} \mathrm{C}$ ) and Values of Enthalpy of Slash Pine Black Liquors at $80^{\circ} \mathrm{C}$ and at the Solids Concentration Given

\begin{tabular}{|l|l|l|l|l|l|}
\hline $\begin{array}{c}\text { Circulation } \\
\text { Pulping } \\
\text { Liquor No. 1 }\end{array}$ & \multicolumn{1}{|c|}{ \% Solids } & $\begin{array}{c}\mathrm{H}_{80}(\mathrm{~kJ} / \mathrm{kg} \\
\text { solids) }\end{array}$ & \multicolumn{1}{|c|}{$\mathrm{b}$} & \multicolumn{1}{c|}{$\mathbf{c}$} & $\mathbf{R}^{2}$ \\
\hline 1 & 0.81 & 264.8 & 83.9 & 0.243 & $0.99+$ \\
\hline 2 & 0.79 & 225.7 & 116.54 & 0.327 & $0.99+$ \\
\hline 3 & 0.77 & 247.0 & 103.52 & 0.283 & $0.99+$ \\
\hline 4 & 0.80 & 236.4 & 107.5 & 0.305 & $0.99+$ \\
\hline 5 & 0.79 & 259.6 & 97.06 & 0.289 & $0.99+$ \\
\hline 6 & 0.79 & 258.0 & 106.25 & 0.300 & $0.99+$ \\
\hline 7 & 0.77 & 260.8 & 103.01 & 0.294 & $0.99+$ \\
\hline 8 & ---- & --- & 107.31 & 0.314 & $0.99+$ \\
\hline 9 & 0.73 & 240.0 & 97.02 & 0.268 & $0.99+$ \\
\hline 10 & 0.78 & 239.4 & 98.16 & 0.271 & $0.99+$ \\
\hline 11 & 0.86 & 231.0 & 95.16 & 0.265 & $0.99+$ \\
\hline 12 & 0.73 & 241.0 & 112.45 & 0.293 & $0.99+$ \\
\hline 13 & 0.80 & 233.2 & 92.53 & 0.272 & $0.99+$ \\
\hline 14 & 0.80 & 224.0 & 124.08 & 0.348 & $0.99+$ \\
\hline 15 & 0.76 & 236.6 & 102.02 & 0.304 & $0.99+$ \\
\hline 16 & 0.78 & 222.0 & 109.25 & 0.334 & $0.99+$ \\
\hline 17 & 0.80 & 253.1 & 90.02 & 0.290 & $0.99+$ \\
\hline 18 & 0.73 & 244.3 & 111.77 & 0.305 & $0.99+$ \\
\hline 19 & 0.73 & 229.0 & 120.60 & 0.358 & $0.99+$ \\
\hline 20 & 0.73 & 243.0 & ---- & ---- & $--\ldots$ \\
\hline 21 & 0.73 & 244.6 & 103.05 & 0.308 & $0.99+$ \\
\hline 22 & 0.73 & 245.2 & 103.88 & 0.300 & $0.99+$ \\
\hline 23 & 0.73 & 244.7 & ---- & --- & --- \\
\hline 24 & 0.79 & 238.0 & 105.40 & 0.282 & $0.99+$ \\
\hline 25 & 0.80 & 247.0 & 101.97 & 0.337 & $0.99+$ \\
\hline
\end{tabular}




$$
C_{p}=(A+B T) S+6.19 \times 10^{-4} T+3.98
$$

where:

$$
\begin{aligned}
& \mathrm{T}=\text { Temperature, }{ }^{\circ} \mathrm{K} \\
& \mathrm{S}=\text { solids mass fraction } \\
& \mathrm{C}_{\mathrm{p}}=\text { heat capacity, } \mathrm{kJ} / \mathrm{kg}{ }^{\circ} \mathrm{K}
\end{aligned}
$$

were used with the constants A and B as given in Table 9.0.1, rather than Massee's more fundamental relation, since it had been shown that this could be used with only slight sacrifice in accuracy.

The values of $b$ and $c$ for equation (10.3.1) and $A$ and $B$ for equation (10.3.3) permit the enthalpy-concentration relation to be calculated for the liquor. A number of examples are presented graphically in the publication. Enthalpies at $80^{\circ} \mathrm{C}$ for all but one liquor have been calculated for 73 86\% solids (note error in Table II of the publication: values of solids concentration are mass fraction, not wt\%). These range from 220 to $260 \mathrm{~kJ} / \mathrm{kg}$ solids, which is certainly not negligible compared to the ideal mixture enthalpy of about $75 \mathrm{~kJ} / \mathrm{kg}$ solids.

Since the variation in enthalpy from liquor to liquor of the same species and at the same temperature and composition varied less than about $15 \%$ of the change due to dilution from about $75 \%$ solids, correlation of the adjustable constants with pulping conditions was not pursued; values at intermediate conditions can be estimated quite well by interpolation.

Correlation of the adjustable constants with liquor composition was not done due to higher priorities for other studies. 


\subsection{VAPOR-LIQUID EQUILIBRIA}

Vapor-liquid equilibria (or at least the boiling point rise) of black liquors with respect to concentration are very important data for design of liquor concentration systems, especially for multiple effect systems that are used in the pulping industry to decrease energy requirements for concentration. These relations are also important in liquor firing and in droplet drying in the furnace. The vapor pressure at firing concentrations sets an upper limit on the liquid temperature for firing. The driving force for initial drying of droplets in the furnace is determined by the difference between the liquor vapor pressure and the water vapor pressure in the furnace. Also, it has already been shown earlier in this report that these data can be used to test thermodynamic consistency of enthalpy data. If enthalpy data are thermodynamically consistent, enthalpy data and vapor-liquid equilibria at one pressure vs. solids concentration can be used to calculate fugacity (and vapor pressure) at other temperatures as shown earlier. Details for the standard thermodynamic calculations specifically for black liquors are given by Stoy (Stoy, 1992). This has been tested numerous times. We have applied this to mill liquors where vapor-pressure equilibria were determined at pressures of 0.2 to $1.0 \mathrm{~atm}$ absolute pressure for the firing solids concentration with extrapolation of the data to as much as $4.0 \mathrm{~atm}$ for determining the maximum firing temperature for the particular mill condition. The extrapolated estimates and mill experience were never in disagreement.

Vapor-liquid equilibria data as a function of solids concentration were collected for each of the liquors derived from the circulation digester experimental pulping of Slash Pine as well as for mill liquors and other experimental liquors. The quantitative analysis of the effect of pulping conditions on vapor-liquid equilibria results was performed on the liquors derived from the circulation digester experimental pulping.

\subsection{Experimental Method and Initial Results}

Equilibrium vapor pressure or boiling point elevation has long been recognized as being important for black liquor processes; the earliest work was reported in 1939 (Kobe, K.A. and R.J. 
Sorenson, 1939). Two good summaries of results available up to 1986 have been published (Adams, T.N. and J. Frederick, 1986, Robinson, M.L. and D.T. Clay, 1986).

As part of his Ph.D. thesis, Stoy (Stoy, 1992) thoroughly reviewed all reported measurements and critically reviewed the methods used in order to develop an accurate method for this work. Basically, four methods have been used in the past. These are:

1. Measurement of pressure and temperature in a stirred vessel while operating at total reflux.

2. Measurement of pressure and temperature in a stirred vessel containing black liquor dispersed in a non-volatile oil while operating at total reflux.

3. Measurements of boiling point elevation in multiple effect evaporator systems in mills or in pilot scale evaporators.

4. Gravimetric determination of liquor concentration for a liquor in contact with water vapor at constant pressure.

Results reported from using stirred vessels at total reflux (Method 1) have been limited to liquor concentrations below about 65\% solids; however, the most extensive work reported was for sulfite liquors (Han, 1957). Method 2 has been used to determine vapor-liquid equilibria at solids concentrations up to almost $100 \%$ solids by several investigators. Results are highly questionable. The oils were added to lower the viscosity, and it was assumed that the black liquor droplets were completely dispersed, did not interact with the oil, and that there was no superheating. Using calorimetric methods, Stoy (Stoy, 1992) found that there was significant solubility of some kraft black liquor components in every hydrocarbon oil he tested. Also, heat transfer calculations indicated that there has to be significant superheat in the liquid. Results determined by this technique must be in error. Results reported from Method 3 suffer from the fact that vapor and liquid may not be in equilibrium, which would give results for boiling point elevation that are consistently lower than the true value. Theoretically, Method 4 is excellent. Experimentally, it is 
difficult to conduct and the time to establish equilibrium can be very long, unless the liquor sample is small and distributed so as to have a large surface to volume ratio. Stoy (Stoy, 1992) discusses the problem inherent in this method in detail.

After this extensive review, Stoy recommended that the stirred vessel method be used for our work. The design and development was done with critical attention given to pressure control and measurement, temperature measurement, control of heat flux, and control of mixing. Later, an automatic mass balance system was added.

The basic vessel was a straight sided five liter vessel with a three liter straight sided glass section at the top and a two liter conical stainless steel section at the bottom. This permitted foaming to be monitored and permitted mixing to be visually evaluated while providing good uniform heat flux at the bottom where the stainless steel bottom of the vessel was encased in an electrical heating jacket with voltage control to control heat flux.

Stoy designed a baffle and opposed turbine system to maximize mixing in the vessel for fluids with viscosities up to $500 \mathrm{cp}$. The agitator is driven by a DC variable speed motor and is sealed by a tapered stuffing box filled with Teflon coated fibers. This proved, as will be pointed out later, to be a successful system; however, the stuffing box proved to be the weak point. Measures were adopted to ensure elimination or minimization of air leakages into the system by periodic monitoring and adjustment.

The vessel was mounted at the top to a flat plate rigidly connected to a supporting frame. The agitator was mounted in a step block in the bottom of the vessel and through two roller bearings in pillow blocks above the vessel. The motor was connected by a flexible belt drive to a drive shaft that passed through two roller bearings in pillow blocks. The drive shaft and agitator shaft were connected by a flexible coupling. The bearings for the drive system were rigidly connected to the same frame that supported the vessel. Extreme care was taken to align the vessel axis and shafts to minimize wear on the sealant contained in the stuffing box.

Two condensers were connected to the vessel in series. The first was a $300 \mathrm{~mm}$ glass Graham condenser and the second was a 1-1 shell and tube metal exchanger containing 14-0.25 
inch OD x 18 inch long tubes that was also mounted vertically. The condensate line was connected via a flexible tube to a glass flask that served as a condensate receiver. The receiver was mounted on a platform beam balance so that its mass could be measured continuously.

The system can be operated in two fashions. When the Graham condenser is used, the condensate is returned to the vessel. This permits total reflux operation so that equilibrium data could be taken at conditions of constant solids concentration. With the Graham condenser drained, the condensate is collected in the receiver and the receiver mass recorded continuously. If the rate of evaporation is sufficiently low, equilibrium data as a function of solids concentration at constant pressure could be collected.

Measurement and control received particular attention. A diaphragm strain gage type of pressure transducer that was resistant to corrosion by black liquor and had minimal hysteresis and very rapid response time was selected. This was first calibrated over nearly the entire range against a mercury manometer read by cathetometer. It was mounted directly into the vapor space of the vessel. The system pressure was controlled by controlling the rate of air bled into the exhaust line from the receiver that was connected to a vacuum pump. The transducer was connected to a controller and the control system calibrated as a unit. Pressure could be controlled to within \pm 0.5 $\mathrm{mm} \mathrm{Hg}$ with cycling of $\pm 1 \mathrm{~mm} \mathrm{Hg}$ or less from $50 \mathrm{~mm} \mathrm{Hg}$ to atmospheric pressure. Temperature of the liquid was measured by a rapid response resistance thermometer connected to a bridge system. The thermometer and bridge were supplied with calibration traceable to NIST, but it was checked before use using freezing point standards and boiling point standards. The receiver balance was connected to an electronic system that gave readings in a series of steps of $100 \mathrm{mv}$ with a linear response of about $4 \mathrm{gms} / \mathrm{mv}$. It was calibrated over the entire range with dead weights and found to be linear within $\pm 0.5 \mathrm{gms}$. The system control was tested with water at total reflux. The pressure was found to cycle about the set point with an amplitude of $\pm 0.5 \mathrm{~mm} \mathrm{Hg}$ and frequency of 30-40 seconds. This cycling produced a similar cycling of the temperature with an amplitude of $\pm 0.05^{\circ} \mathrm{C}$ or less. It was determined to use mid-point readings for both temperature and pressure. 
Several fluids and solutions for which accurate vapor-liquid equilibria data are available were used to test the system accuracy at total reflux and to determine the maximum rate of evaporation for which equilibrium could exist. The latter was determined to be $6 \mathrm{gm} / \mathrm{min}$ or less. Tests showed that the rate of evaporation was constant and could be controlled by controlling the heat flux. Tests with water and $\mathrm{NaCl}, \mathrm{NaOH}$, and sucrose solutions were conducted. Sucrose solutions, up to $65 \mathrm{wt} \%$ were used to determine the effect of viscosity. Boiling points measured agreed with literature values within $\pm 0.15^{\circ} \mathrm{C}$ or less in all cases.

At total reflux, the evaporation rate was set at $1-1.5 \mathrm{gm} / \mathrm{min}$. It normally required about 15 minutes to guarantee steady-state had been attained. When run as a concentrator, the evaporation rate was set at a maximum of $4 \mathrm{gms} / \mathrm{min}$ and maintained at a constant rate. At the end of a concentrator run, validity of results was checked by making a material balance. Further details are given by Stoy (Stoy, 1992).

A summary of the unit with initial results for both an experimental and a mill liquor have been published in: Stoy, M.A., A.A. Zaman, and A.L. Fricke, "Vapor-Liquid Equilibria for Black Liquors," 1992 International Chemical Recovery Conference, 495-511 (1992) that is included as part of this report.

$$
\text { reprint removed, }
$$

The system was used routinely for liquors (except carbonate and semi-chemical liquors) at concentrations up to $75 \%$ solids. If the liquor viscosity is within limits, measurements are made at up to $85 \%$ solids. If there is no solids precipitation during concentration, all liquors exhibit similar response with no discontinuity or sudden changes in slope of the boiling point vs. solids concentration curve. In all cases, the vapor pressure at constant solids was a logarithmic function of reciprocal absolute temperature with a coefficient for the $1 / \mathrm{T}^{2}$ term that was relatively insignificant. For skimmed liquors, the relations for different solids concentrations from 12 to above $75 \%$ solids were very nearly parallel, indicating that the heat of vaporization is nearly constant over the range of solids concentration. This is clearly illustrated with the data presented in the publication. 
Boiling point elevations at constant pressure as a function of solids concentration can be obtained from a cross plot of the vapor pressure data or determined by direct experiment. Figures 4 and 7 in the publication are illustrations of such cross plots and Figure 10 is an illustration of results determined by direct experiment.

Several points are evident. BPE increases with increasing pressure and the effect of pressure generally increases with increasing solids concentration. Boiling point elevation, or rise, increases at nearly a linear rate to $15-25 \%$ solids, depending upon the liquor, after which the rate of change increases with increasing solids concentration to $55-70 \%$ solids, depending upon the liquor. At higher concentrations, the rate of change of boiling point rise decreases with increasing solids concentration. We infer that the behavior with respect to rate of change of boiling point rise at high solids is caused by the same behavior shown to affect density and viscosity behavior.

Data can also be treated in terms of reference plots. Figure 5 in the publication is a Dübring plot for one of the liquors. It is worth noting the abrupt change in slope of the lines between 50 and $57 \%$ solids.

Different liquors are compared in the publication. Particularly, the difference in results between softwood liquors and a hardwood liquor are discussed. Finally, the ranges of boiling point rise at a number of solids concentrations determined in this work for these few liquors are compared with those determined in past work. The agreement is generally poor, except for the mid-range (50-60\%) of solids concentration. We believe the disagreement at high solids is due to superheating in the experiments of past workers. We can arrive at no justifiable reasons for the differences observed at low concentrations.

As describe earlier, vapor-liquid equilibria determined experimentally with this system are thermodynamically consistent with enthalpy determined by calorimetry measurements. Also, the system has been shown to give accurate vapor-liquid equilibrium data for known systems, either when operated at total reflux or as a concentrator at a low rate of evaporation. The weak point is the stuffing box; it is difficult to eliminate the effect of air leakage. If the system were to be modified or if a new system were to be constructed, two changes should be made. A magnetic 
coupling should be used for the drive in order to eliminate the need for a shaft seal; the small sacrifice in torque limit for agitation would be more than compensated for by the elimination of this source of air leakage. The vessel should be constructed entirely of metal with viewing ports so that data could be taken at pressures well above atmospheric.

This unit is highly recommended for those interested in boiling behavior. It has been shown to operate as a Rayleigh differential still for these systems. We have been able to observe first order thermodynamic changes in the liquid (such as solids precipitation) as evidenced by discontinuities in the rate of change of boiling point with increase in solids concentration measured at constant pressure, and stripping of organics or other volatiles can be determined for incremental changes in solids concentration by analysis of the condensate collected. These latter two uses have been demonstrated in experiments conducted with our unit on some liquors.

\subsection{Vapor-Liquid Equilibria Correlation}

Vapor-Liquid Equilibria data have been collected for all black liquors derived from the circulation digester experiment using skimmed liquors. Data were taken under conditions of total reflux (constant solids concentration) at pressures ranging from about 0.2 to 1.0 atmospheres at constant solids concentrations ranging from about 23 to as high as $85 \%$ solids concentrations. Typically, data were collected at seven to nine concentrations for each liquor. In addition, the boiling point of these liquors was determined as a function of solids concentration at constant pressure during experiments run to prepare concentrated liquor samples for other properties studies. These experiments were normally conducted at reduced pressures in the range of 0.35 to $0.65 \mathrm{~atm}$. Experimental results were very reproducible, and results from experiments run to determine the boiling point of a black liquor as a function of solids concentration at constant pressure were always in excellent agreement with vapor-pressure data taken at constant solids composition for the same liquor.

It must be emphasized that these data for the experimental liquors were for liquors that had previously been evaporated to about $25-30 \%$ solids concentration and the soap skimmed. 
Therefore, volatile organics and soap had been nearly all removed. During the evaporation and skimming that was conducted in the pilot scale evaporator described previously, the condensate was white, but often "milky" in appearance. A number of analyses on the condensate collected showed the condensate contained no lignin components, barely detectable traces of positive ion metals, but fairly high organic carbon that was principally due to methanol and to soap components stripped from the liquor during concentration. Vapor-liquid equilibria experiments run with the previously evaporated and skimmed liquors produced condensates that were clear and water white with barely detectable levels of organic carbon in a few cases. Therefore, the condensates from experiments run using the preevaporated and skimmed experimental liquors were essentially only water.

A compete summary of results of vapor-liquid equilibria studies conducted with the black liquors derived from the circulation digester experiment and correlation of these results has been published in: Zaman, A.A., T.W. McNally, and A.L. Fricke, "Vapor Pressure and Boiling Point Elevation of Slash Pine Black Liquors: Predictive Models with Statistical Approach," Ind. \& Eng. Chem. Res., 1998(37), 275-283 (1998) that is included as part of this report. reprint' reved.

Results demonstrate that the condensate is essentially water and that the vapor pressure at any solids concentration is given by:

$$
\ln P=A-B / T+C / T^{2}
$$

where:

$$
\begin{aligned}
& \mathrm{P}=\text { vapor pressure, } \text { atm } \\
& \mathrm{T}=\text { Temperature, }{ }^{\circ} \mathrm{K}
\end{aligned}
$$

$$
\mathrm{A}, \mathrm{B}, \mathrm{C}=\text { experimental constants }
$$


However, $\mathrm{C}$ is extremely small; therefore, the third term can be neglected with very little loss of accuracy. Thus, the vapor pressure is given by:

$$
\ln \mathrm{P}=\mathrm{A}-\mathrm{B} / \mathrm{T}
$$

with nearly the same accuracy.

If black liquor is treated as a binary of water and black liquor solids and if we assume water vapor behaves as an ideal gas, integration of the Clausius-Clapyron equation leads to equation (11.2.2). If the heat of vaporization were constant with respect to solids concentration, $B$ should not vary with respect to concentration for a given black liquor. However, both $A$ and $B$ vary with concentration for a given liquor, as illustrated for selected liquors as shown in Table 2 of the publication. This is not unexpected. Enthalpy studies have shown clearly that black liquor is a non-ideal solution, even though its treatment as a binary is thermodynamically consistent. It is important to note that it has been shown that complete vapor-liquid equilibria can be accurately predicted from enthalpy and one equilibrium boiling point vs. solids concentration curve at constant pressure.

Boiling point elevation or boiling point rise (BPR) is generally a function of pressure above about $20 \%$ solids and the BPR vs. solids concentration varies with variations in the liquor solids, as is illustrated for selected liquors in Figures 2 and 3 of the publication. Our method for handling this is described later.

Vapor-liquid equilibria for a binary consisting of a volatile and non-volatile component have been treated successfully in terms of molality:

$$
\mathrm{BPR}=\mathrm{K}_{\mathrm{B}} \mathrm{m}
$$

where: 


$$
\begin{aligned}
\mathrm{BPR} & =\text { boiling point rise } \\
\mathrm{m} & =\text { molality } \\
& =\text { mols non-volatile component/mol volatile component } \\
\mathrm{K}_{\mathrm{B}} & =\text { constant }
\end{aligned}
$$

Black liquor solids (the non-volatile component) is a mixture of many components and the appropriate molecular weight is unknown; however, the composition of the liquor solids does not change during concentration. Realizing that, in this case, molar concentration of solids is proportional to mass concentration, Frederick (Frederick et al., 1980) suggested modifying equation (10.2.3) by substituting mass fractions for molality to give:

$$
\mathrm{BPR}=\mathrm{K}\left[\frac{\mathrm{S}}{1-\mathrm{S}}\right]
$$

where:

$$
\begin{aligned}
& \text { BPR = boiling point rise } \\
& S=\text { mass fraction of liquor solids } \\
& 1-S=\text { mass fraction of water } \\
& K=\text { constant }
\end{aligned}
$$

which both he (Frederick et al., 1980) and Wennberg (Wennberg, 1985) used successfully to correlate BPR vs. solids for concentrations up to about $50 \%$ solids. Above that concentration, both Frederick and Wennberg observed a change in slope (change in $\mathrm{K}$ ) when BPR was plotted vs. (S/1-S). Frederick concluded that this was due to precipitation of $\mathrm{Na}_{2} \mathrm{SO}_{4}$ and $\mathrm{Na}_{2} \mathrm{CO}_{3}$ from the liquor. $\mathrm{He}$ added $\mathrm{Na}_{2} \mathrm{CO}_{3}$ and observed that $\mathrm{BPR}$ did not change with addition of $\mathrm{Na}_{2} \mathrm{CO}_{3}$ at concentrations above $50 \%$. 
Our results also show a change in slope (change in $\mathrm{K}$ ) when BPR is plotted vs. (S/S-1), as is illustrated in Figures 4 and 5 of the publication; however, this change occurs at about $65 \%$ solids for the slash pine liquors that were extensively studied in this work. While Frederick may be correct in attributing this to precipitation of salts from the liquor solids, there are reasons to question his interpretation and to consider alternatives. Solids precipitation is a first order thermodynamic transition, and detailed and accurate enthalpy studies have shown no evidence of a first order transition occurring at high solids that cannot be attributed to heat of dilution if concentration in solution is changed. There was no visual evidence of salt precipitation in our liquors, even when the liquors were held at constant elevated temperature and constant concentration for extended periods. It is worth noting that solids precipitation was visually observed in some mill liquors with a concomitant change in slope of the line when BPR was plotted vs. (S/1-S) for those cases.

An alternative and possibly much more valid explanation may be that the change in liquor BPR behavior is due to the second order transition in the liquor has been shown to occur for these liquors at concentrations of about $65 \%$ solids and $25^{\circ} \mathrm{C}$. This would certainly affect the assumption that mass fraction is proportional to molality, or at least it would change the proportionality constant. The change could be accounted for from experimental data by modifying (S/1-S) appropriately or by changing $\mathrm{K}$ in equation (10.2.4). The latter course proved to be successful and more tractable. Our data were divided into two concentration regions, $S<0.65$ and $S>0.65$, and separate equations used for each, which are:

$$
\mathrm{BPR}=\mathrm{a}\left[\frac{\mathrm{S}}{1-\mathrm{S}}\right], \mathrm{S}<0.65
$$

and:

$$
\mathrm{BPR}=\mathrm{a}^{\prime}+\mathrm{b}^{\prime}\left[\frac{\mathrm{s}}{1-\mathrm{S}}\right], \mathrm{S}>0.65
$$


where $\mathrm{a}, \mathrm{a}^{\prime}$, and $\mathrm{b}^{\prime}$ are constants for a liquor.

The constants, $a, a^{\prime}$, and $b^{\prime}$, are pressure dependent, but all are linear with respect to pressure, as illustrated in Figures 6 and 7 of the publication. Although described in the publication as unique, it is really related to the reasoning used to develop Dübring relations and only depends upon the Diubring relations being linear with pressure at constant concentration, and this had been demonstrated in our earlier work described in section 12.1 of this report.

Since the boiling point rise relations vary from liquor to liquor, the values of $a, a^{\prime}$, and $b^{\prime}$ for equations (11.2.5) and (11.2.6) are dependent upon the liquor composition. This leads to defining $a, a^{\prime}$, and $b^{\prime}$ as:

$$
\begin{aligned}
& a=a_{1}+b_{1} P \\
& a^{\prime}=a_{2}+b_{2} P \\
& b^{\prime}=a_{3}+b_{3} P
\end{aligned}
$$

The final development leads to six constants that are true constants and that can define the complete BPR behavior of the slash pine liquors up to $80-85 \%$ solids concentrations. Substitution of these relations into equations (11.2.5) and (11.2.6) leads to:

$$
\begin{aligned}
& \text { BPR }=\left(a_{1}+b_{1} P\right)\left[\frac{S}{1-S}\right], S<0.65 \\
& \text { BPR }=\left(a_{2}+b_{2} P\right)+\left(a_{3}+b_{3} P\right)\left[\frac{S}{1-S}\right], S \geq 0.65
\end{aligned}
$$

as the final test relations. 
Values for the constants for equations (11.2.10) and (11.2.11) were determined from the experimental data for 21 of the experimental liquors, and these are given in Table 11.2.1. The correlation coefficients are good, but not excellent; two are 0.91-0.92 and the remainder are 0.95$0.99+$ with nearly all at $0.98-0.99+$. The great advantage, in spite of the lower than desirable correlation coefficients in a few cases, of using these constants is the vast reduction in volume of data that it affords.

Once the set of six constants for each liquor necessary to completely define BPR up to 80$85 \%$ solids were determined, we proceeded to search for correlations of these constants with pulping conditions. Linear quadratic models with two variable, three variable, and four variable interactions were evaluated by statistical methods. The complete linear quadratic regression equations ( 16 constants with five degrees of freedom) yielded regression coefficients of 0.99 or better for the equations for the six constants in the BPR relations, equations (11.2.10 and 11.2.11). Values for the constant for each term in the relation of each constant for equations (11.2.10) each constant for equations (11.2.10) and (11.2.11) that relates the constant for equation (11.2.10) or (11.2.11) are given in Table 4 of the publication. The complete regression equation is given by equation (12) in the publication. 
Table 11.2.1

Values of Constants for Equations for Boiling Point Rise of

Circulation Digester Pulping Liquors

\begin{tabular}{|c|c|c|c|c|c|c|c|c|c|}
\hline $\begin{array}{c}\text { Circulation } \\
\text { Digester } \\
\text { Pulping } \\
\text { Experiment } \\
\text { No. } \\
\end{array}$ & $a_{1}$ & $b_{1}$ & $\mathrm{R}^{2}$ & $a_{2}$ & $b_{2}$ & $\mathrm{R}^{2}$ & a3 & $b_{3}$ & $\mathrm{R}^{2}$ \\
\hline$\overline{1}$ & 6.4779 & 0.0027 & 0.99 & 6.4100 & 0.0039 & $\overline{0.98}$ & $\overline{2.4198}$ & 0.0001 & $\overline{0.95}$ \\
\hline 2 & 4.5268 & 0.0036 & 0.95 & 1.9760 & 0.0037 & 0.99 & 2.9903 & 0.0005 & 0.99 \\
\hline 3 & 4.8986 & 0.0058 & 0.99 & 4.9615 & 0.0030 & 0.99 & 2.9424 & 0.0012 & 0.97 \\
\hline 4 & 7.5048 & 0.0033 & 0.98 & 3.2589 & 0.0032 & 0.99 & 4.1303 & 0.0006 & 0.98 \\
\hline 5 & 4.0383 & 0.0039 & 0.98 & 4.9886 & 0.0020 & 0.99 & 2.5190 & 0.0011 & 0.97 \\
\hline 6 & 2.9704 & 0.0052 & 0.97 & 1.0695 & 0.0032 & 0.99 & 3.8406 & 0.0006 & 0.92 \\
\hline 7 & 5.4163 & 0.0048 & 0.99 & 3.3479 & 0.0027 & 0.99 & 4.4275 & 0.0010 & 0.98 \\
\hline 8 & 4.7320 & 0.0040 & 0.98 & 2.5867 & 0.0061 & 0.98 & 3.6788 & 0.0003 & 0.91 \\
\hline 10 & 3.3071 & 0.0046 & 0.98 & 1.9893 & 0.0023 & 0.99 & 3.0659 & 0.0016 & 0.97 \\
\hline 11 & 5.5057 & 0.0037 & 0.98 & 9.1854 & 0.0032 & 0.96 & 1.6429 & 0.0012 & 0.99 \\
\hline 12 & 3.9646 & 0.0050 & 0.99 & 1.9807 & 0.0027 & 0.99 & 4.6920 & 0.0003 & 0.99 \\
\hline$\overline{14}$ & 3.7780 & 0.0033 & 0.98 & 3.2908 & 0.0047 & 0.98 & 2.6992 & 0.0007 & 0.99 \\
\hline 15 & 3.9872 & 0.0050 & 0.98 & 2.0465 & 0.0037 & 0.98 & 3.4490 & 0.0013 & 0.97 \\
\hline 17 & 4.8785 & 0.0038 & 0.98 & 3.8232 & 0.0042 & 0.96 & 3.3749 & 0.0009 & 0.96 \\
\hline 18 & 6.1824 & 0.0022 & 0.98 & 0.3336 & 0.0032 & 0.99 & 5.7703 & 0.0006 & 0.98 \\
\hline 20 & 7.5405 & 0.0039 & 0.98 & 8.2448 & 0.0027 & 0.97 & 3.4371 & 0.0004 & 0.99 \\
\hline 21 & 5.4164 & 0.0036 & 0.98 & 3.3423 & 0.0034 & 0.98 & 2.6084 & 0.0007 & 0.98 \\
\hline 22 & 4.0645 & 0.0033 & 0.98 & 4.4454 & 0.0017 & 0.98 & 2.9695 & 0.0007 & 0.98 \\
\hline 23 & 4.7771 & 0.0042 & 0.99 & 4.9451 & 0.0017 & 0.98 & 3.2131 & 0.0017 & 0.98 \\
\hline 24 & 6.6487 & 0.0024 & 0.97 & 4.3682 & 0.0034 & 0.98 & 3.2226 & 0.0002 & 0.99 \\
\hline 25 & 3.7005 & 0.0050 & 0.98 & 1.6317 & 0.0047 & 0.99 & 3.8420 & 0.0006 & 0.99 \\
\hline
\end{tabular}


The best fits without bias contained 11 variables (twelve terms). These are the recommended equations. The recommended equations relating the six constants of equations (11.2.10) and (11.2.11) to pulping conditions are:

$$
\begin{aligned}
& \mathrm{a}_{1}=3.955 \times 10^{3}+2.941 \mathrm{t}-15.278 \mathrm{~T}-77.690 \mathrm{EA} \\
&-5.470 \times 10^{-3} \mathrm{Tt}-3.488 \times 10^{-2} \mathrm{tEA}-0.397 \mathrm{tS} \\
&+0.178 \mathrm{TEA}+1.428 \times 10^{-2} \mathrm{~T}^{2}-5.0 \times 10^{-5} \mathrm{tTEAS} \\
&+2.260 \times 10^{-2} \mathrm{tEAS}+8.750 \times 10^{-4} \mathrm{tTS} \\
& \text { with } \mathrm{R}^{2}=0.93, \text { adjusted } \mathrm{R}^{2}=0.84 \\
& \mathrm{~b}_{1}=5.772 \times 10^{-1}+1.288 \times 10^{-3} \mathrm{t}-3.260 \\
& \times 10^{-3} \mathrm{~T}+1.625 \times 10^{-2} \mathrm{EA}+1.110 \times 10^{-4} \mathrm{~S} \\
&-3.198 \times 10^{-6} \mathrm{tT}-1.655 \times 10^{-6} \mathrm{tS}-3.936 \\
& \times 10^{-5} \mathrm{TEA}+1.50 \times 10^{-7} \mathrm{t}^{2}+4.480 \times 10^{-6} \mathrm{~T}^{2} \\
& 2.255 \times 10^{-5} \mathrm{EA} \mathrm{A}^{2}+2.734 \times 10^{-8} \mathrm{tTEA} \\
& \mathrm{R}^{2}=0.98, \text { adjusted } \mathrm{R}^{2}=0.96 \\
& \\
& \mathrm{a}_{2}=3.778 \times 10^{3}-17.7 \mathrm{~T}+38.72 \mathrm{EA}+2.861 \\
& \times 10^{-1} \mathrm{tS}-9.448 \times 10^{-2} \mathrm{TEA}-2.894 \times 10^{-2} \mathrm{EAS} \\
&-1.315 \times 10^{-3} \mathrm{t}^{2}+2.082 \times 10^{-2} \mathrm{~T}^{2}+1.633 \\
& \times 10^{-1} \mathrm{EA} \mathrm{A}^{2}+5.621 \times 10^{-5} \mathrm{tTEAS}-2.537 \\
& \times 10^{-2} \mathrm{tEAS}-6.190 \times 10^{-4} \mathrm{TtS} \\
& \mathrm{R}^{2}=0.97, \text { adjusted } \mathrm{R}^{2}=0.94 \\
& \mathrm{~b}_{2}=1.558+5.050 \times 10^{-4} \mathrm{t}+6.930 \times 10^{-3} \mathrm{~T} \\
& 9.266 \times 10^{-3} \mathrm{EA}-3.721 \times 10^{-5} \mathrm{tEA}-8.177 \\
& \mathrm{t}+2.113 \times 10^{-6} \mathrm{TS}-7.054 \times 10^{-5} \mathrm{EAS} \\
&
\end{aligned}
$$




$$
\begin{aligned}
& -8.079 \times 10^{-6} \mathrm{~T}^{2}-2.610 \times 10^{-4} \mathrm{EA}^{2}+1.514 \\
& \times 10^{-6} \mathrm{tEAS}+1.390 \times 10^{-7} \mathrm{tTS} \\
& \mathrm{R}^{2}=0.95, \text { adjusted } \mathrm{R}^{2}=0.88
\end{aligned}
$$

$$
\begin{aligned}
\mathrm{a}_{3} & =-6.745 \times 10^{2}+3.314 \mathrm{t}-15.790 \mathrm{EA}+3.905 \mathrm{~S} \\
& -2.990 \times 10^{-4} \mathrm{tT}-3.376 \times 10^{-3} \mathrm{tS}+3.812 \\
& \times 10^{-2} \mathrm{EAS}-8.249 \times 10^{-3} \mathrm{TS}+9.910 \times 10^{-4} \mathrm{t}^{2} \\
& -4.070 \times 10^{-3} \mathrm{~T}^{2}-4.873 \times 10^{-2} \mathrm{EA}^{2}+1.460 \\
& \times 10^{-5} \mathrm{tTEA} \\
& \mathrm{R}^{2}=0.81, \text { adjusted } \mathrm{R}^{2}=0.78 \\
\mathrm{~b}_{3} & =-8.334 \times 10^{-3}-1.736 \times 10^{-2} \mathrm{t}+2.161 \\
& \times 10^{-5} \mathrm{~T}+3.869 \times 10^{-5} \mathrm{tT}+1.120 \times 10^{-3} \mathrm{tEA} \\
& +4.640 \times 10^{-4} \mathrm{tS}-3.360 \times 10^{-7} \mathrm{t}^{2}-1.566 \\
& \times 10^{-6} \mathrm{~S}^{2}+6.405 \times 10^{-8} \mathrm{tTEAS}-2.876 \\
& \times 10^{-5} \mathrm{tEAS}-2.496 \times 10^{-6} \mathrm{tTEA}-1.029 \times 10^{-6} \mathrm{tTS} \\
& \mathrm{R}^{2}=0.80, \text { adjusted } \mathrm{R}^{2}=0.75
\end{aligned}
$$

where:

$$
\begin{aligned}
& \mathrm{EA}=\text { Effective alkali, } \% \\
& \mathrm{~S}=\text { Sulfidity, } \% \\
& \mathrm{~T}=\text { Temperature, }{ }^{\circ} \mathrm{K} \\
& \mathrm{t}=\text { Time at temperature, } \text { min. }
\end{aligned}
$$

The regression coefficients for $\mathrm{a}_{1}$ and $\mathrm{b}_{1}$ are very good, indicating very good prediction of the data for solids concentrations below $65 \%$. Regression coefficients for $a_{2}$ and $b_{2}$ are quite 
acceptable, indicating good prediction of the intercept for the second line. The regression coefficients for $\mathrm{a}_{3}$ and $\mathrm{b}_{3}$, which define the slope of the line relating BPR to (S/1-S) at solids concentrations above 65\%, are not as good. This is not an unreasonable result when one considers other results. There is reason to believe that a transition in solution behavior occurs around $65 \%$ solids and lignin characteristics should play a greater role above this concentration. It has been shown that the MWDs of the lignins in these liquors differ drastically. Even so, the correlations predict the data quite well. The maximum error in prediction of BPR rise for all of the data is about 4\%. The correlations predict data for slash pine liquors not included in the regression with the same accuracy or better.

The method for obtaining equilibrium vapor pressure vs. temperature at constant solids concentration is given in the publication, along with examples of fits of the predicted relations to experimental data (Figures 8 and 9 in the publication).

All liquors tested, which included Western softwood kraft, hardwood kraft, mixed hardwood and softwood kraft, sulfite, carbonate, and semi-chemical pulping liquors exhibited the same general behavior. However, there were differences. The region for validity of equation (11.2.5) was generally 0 to almost 75\% solids for hardwood kraft and 0 to about $35 \%$ solids for carbonate and semi-chemical liquors. These limits agreed with values of the first second order transition for these liquors, as determined by density measurements at $25^{\circ} \mathrm{C}$. In some cases with mill kraft liquors, both hardwood and softwood, the region for validity of equation (11.2.5) was limited to 0 to $45 \%$ solids to 0 to $55 \%$ solids. In every such case, there was a discontinuity in the rate of change of boiling point at constant pressure with increase in solids concentration, and there was yisual evidence of precipitation in the evaporator. Otherwise, kraft mill liquors behaved like the slash pine experimental liquors.

In summary, this phase of the program has resulted in a number of important developments. A flexible experimental apparatus has been developed for accurate determination of vapor-liquid equilibria of black liquors at up to $85 \%$ solids concentrations. Vapor-liquid equilibria for black liquors have been shown to be thermodynamically consistent with enthalpy and 
consistent with the first second order transition observed in other measurements. Precipitation from liquors during concentration, a real problem in mill operation, can be observed (if it occurs) from experiments using the apparatus. A data reduction scheme has been developed that can be applied to other liquors to reduce the experimental effort needed to completely describe the vaporliquid equilibria of the liquor. A quantitative model has been developed that relates vapor-liquid equilibria at up to $85 \%$ solids to pulping conditions for an important wood species (slash pine). Moreover, one can expect this model to qualitatively fit vapor-liquid equilibria for kraft pulping of other species. 


\subsection{VISCOSITY AND RHEOLOGICAL BEHAVIOR}

While other properties have been shown to be complex and to vary substantially over the concentration range experienced in black liquor processing as well as variations caused by different pulping conditions for liquors derived from kraft pulping of even one specific wood species, viscosity and rheological behavior are the most complex and exhibit the largest variations. In processing any specific kraft black liquor from about $15 \%$ solids concentration to $70 \%$ solids concentration, variations in all properties are substantial, but viscosity varies the most. Over the range cited, density will vary by about $25-28 \%$, BPR will be about $22^{\circ} \mathrm{C}$ at one atmosphere (a $22 \%$ increase in boiling point compared to water), heat capacity will vary by about $35 \%$, the enthalpy correction necessary to account for heat of dilution will be about equal to the sensible heat for the liquid (calculated using the heat capacity of the liquor at $70 \%$ solids referred to $0^{\circ} \mathrm{C}$ ), but the viscosity will vary by a factor of at least 50 and usually over $100(5,000$ to $10,000 \%)$ ! Also, viscosity shows the most complex response to pulping conditions and solids composition as well as the largest variations. It also exhibits the greatest differences with respect to wood species used. Accurate values for all of the properties investigated in this program are needed, but it is obvious that viscosity and rheological behavior must receive the most study.

The range of viscosity and the need to investigate the viscoelastic behavior of black liquors at high solids introduces a great deal of complexity. This complexity is increased by the need to make measurements on a material containing a volatile component over a wide range of temperature and shear rate, and measurements on a material whose rheological behavior has been shown to be time dependent at high solids and temperature due to changes in the liquor solids (Small, 1986, Soderhjelm, 1986, 1988). Obviously, no one instrument could be used for all measurements. Also, since most instruments were designed for polymer or polymer solution applications, the temperature control system of nearly every instrument has to be modified; the change of viscosity of black liquors (a polar solution) is five to ten times larger than that for most polymers or polymer solutions. Finally, many instruments are incapable of measurement of fluids exhibiting significant vapor pressure. 


\subsection{Instruments}

Eight different basic types of instruments with different tooling for many of the instruments were used in our studies to permit us to study rheological properties over the full range of concentration, temperature, and shear rate or frequency of interest. Many of these were modified or custom built to meet our needs. With these instruments, we could study the full range of variables. All instruments were calibrated carefully to provide the highest precision possible, and calibrations of various instruments were checked against each other to insure agreement of determinations within at least $\pm 10 \%$ and usually $\pm 5 \%$ or better.

The simplest system used was a set of glass capillary viscometers. These could be used to determine viscosity of Newtonian fluids ranging from 0.5 to about $600 \mathrm{cp}$ at temperatures from $10^{\circ} \mathrm{C}$ to within $10^{\circ} \mathrm{C}$ or less of the normal boiling point of the fluid. Temperature was controlled to within $\pm 0.1^{\circ} \mathrm{C}$ or better. These were used extensively for measurements of viscosity of black liquors at low solids concentrations ( $<50 \%$ solids).

A Cambridge Sliding Element Viscometer that had been modified for our applications and which incorporated our design for precise temperature control was used to measure Newtonian viscosities at low solids $(<50 \%)$ concentrations and zero shear rate viscosities at higher solids (50 to 70\%) concentrations at high temperatures. This is a pressurized viscometer. Measurements can be made at temperatures up to at least $160^{\circ} \mathrm{C}$ and pressures up to $500 \mathrm{psig}$. Using different elements, we can measure viscosities from 1.2 to $500 \mathrm{cp}$. Measurements with black liquor were normally made at temperatures ranging from 40 to $140^{\circ} \mathrm{C}$.

A completely equipped Rheometrics RMS-800 was used, particularly for studies of viscoelasticity and for determination of zero-shear rate viscosity at high solids. The instrument is equipped with two stress measuring devices to permit accurate measurement of shear and normal stresses over a range of at least $10^{5}$. Four sets of cone-and-plate and parallel plate tooling of different characteristics are available. Several environmental chambers with very precise temperature control are included. The instrument can be operated under conditions of constant controlled strain rate, oscillatory controlled strain rate at constant maximum total strain, or at 
programmed rates of strain. In our work, it was used for measurements at temperatures from $-30^{\circ} \mathrm{C}$ to within about $10^{\circ} \mathrm{C}$ of the normal boiling point of the fluid with parallel plate geometry. Measurements can be made with fluids having viscosities ranging from $1 \mathrm{cp}$ to $10^{7} \mathrm{cp}$ at shear rates up to about $15 \mathrm{sec}^{-1}$ or frequencies up to about $30 \mathrm{cps}$. It was used extensively for black liquors.

A Haake RV-12 system with modified or custom built tooling was used. This system is the same as the Haake RV-20 system now marketed, except that the instrument signals are now interfaced to a computer. The basic system is a rotational viscometer with speed control and torque measurement. Cup-and-bob and cone-and-plate or parallel plate geometries are available for tooling. Three drive heads with capability of measuring torque precisely from about 7 to $1500 \mathrm{gm}$ $\mathrm{cm}$ are available and used.

Several rotating bob geometries (a total of five) are available and most were used to determine viscosity of liquors at temperatures ranging from $10^{\circ} \mathrm{C}$ to within $10^{\circ} \mathrm{C}$ of the normal boiling point of the liquor. Measurements could be made at shear rates ranging from about 50 to $800 \mathrm{sec}^{-1}$ for fluids with viscosities ranging from about $5 \mathrm{cp}$ to well above $2000 \mathrm{cp}$.

The parallel plates geometry was used for low shear rate measurements $\left(<10 \mathrm{sec}^{-1}\right)$ at temperatures ranging from $10^{\circ} \mathrm{C}$ to within $10^{\circ} \mathrm{C}$ of the normal boiling point of the fluid. With different drive heads and plates, this arrangement could be used for measurement of viscosities ranging from about $10 \mathrm{cp}$ to more than $10^{5} \mathrm{cp}$.

Custom designed and built pressurized cup-and-bob assemblies were also used (Fricke, $1985,1990,1993)$. The drive is magnetically coupled to the rotating bob contained in the pressurized cup assembly. The bob rotates on jeweled bearings to minimize friction. One assembly is completely jacketed and temperature controlled to within $\pm 0.1^{\circ} \mathrm{C}$ by circulating a temperature control fluid through the jacket at high velocity. The other assembly is completely immersed in an oil bath with temperature controlled within $\pm 0.1^{\circ} \mathrm{C}$ or better. Measurements can be made for fluids with viscosities ranging from about $10 \mathrm{cp}$ to more than $1000 \mathrm{cp}$ at shear rates from about 80 to $800 \mathrm{sec}^{-1}$. Measurements can be made at pressures up to $500 \mathrm{psig}$ and at temperatures 
from 40 to $230^{\circ} \mathrm{C}$. With black liquors, measurements were seldom made at temperatures above $140^{\circ} \mathrm{C}$.

In all of these arrangements, measurements could be begun within no more than seven minutes of loading the viscometer, and measurements at multiple shear rates could be made within one hour. Due to the problems with viscosity change with time at high solids and temperature, all measurements at these conditions were made within one hour of loading the sample.

The devices described have all been limited to Newtonian fluids or to non-Newtonian fluids at shear rates below about $800 \mathrm{sec}^{-1}$. Also, viscoelasticity could only be investigated at lower temperatures (temperatures less than about $10^{\circ} \mathrm{C}$ below the normal boiling point). Other devices were needed to make measurements for non-Newtonian fluids at higher shear rates.

An Instron 3200 capillary melt viscometer was used to measure viscosity up to about $10^{4}$ $\mathrm{sec}^{-1}$ for higher solids concentrations at temperatures from $30^{\circ} \mathrm{C}$ to within about $10^{\circ} \mathrm{C}$ of the normal boiling point. This instrument is a shear rate controlled device. Various gearings and sets of capillaries are available to permit measurement from about 40 to more than $10^{5} \mathrm{sec}^{-1}$; however, measurements much above $10^{4} \mathrm{sec}^{-1}$ are seldom valid due to viscous dissipation in the capillary. This device was used to measure viscosity of black liquors at high solids and shear rates, but lower temperatures.

A custom designed and built pressurized viscometer (Farrington, 1986, Fricke, 1985) was intended for extensive use to measure viscosity at high shear rates and temperature. The device was designed for operation at pressures up to at least 500 psig. It was tested and used for measurement of viscosities of some black liquors. Unfortunately, when the instrument was designed and built, we were not aware of the fact that the viscosity of black liquors decreased rather rapidly with time at high solids concentration and temperature. This prevented its extensive use in our work, since very large quantities of liquor at high solids concentrations would have been required. However, it is highly accurate, capable of measurements at up to $250^{\circ} \mathrm{C}$ and $500 \mathrm{psig}$ for viscosities from about 40 to more than $10,000 \mathrm{cp}$. It can be used for high shear rate measurements of mill liquors where availability of a large quantity of liquor is not a problem. 
A Brookfield rotating cup viscometer has been used. This device uses a stationary bob and a rotating cup that can be pressurized to pressures as high as $400 \mathrm{psig}$. Several cup and bob geometries and two torque ranges are available. Since the cup rotates, the shear rate range that can be used is not limited by the development of secondary flow patterns within the fluid. The instrument is immersed within an oil bath for temperature control. This device can be used to measure viscosities from 10 to more than $10^{4} \mathrm{cp}$ at shear rates ranging from 10 to above 1500 sec$^{-1}$, depending upon fluid viscosity and the tooling used. It has been used for measurements with black liquors at up to $140^{\circ} \mathrm{C}$ and at shear rates well above $1200 \mathrm{sec}^{-1}$. At high shear rates, care must be exercised to make measurements that are unaffected by viscous dissipation.

A Nametre vibrating ball viscometer was also used. This instrument is capable of making measurements at one frequency (or shear rate) over extremely large ranges of viscosity, temperature, and pressure. The fluid to be measured is contained in a jacketed pressure chamber suitable for measurements at up to $600 \mathrm{psig}$ and temperatures ranging from 40 to above $160^{\circ} \mathrm{C}$. Viscosities ranging from about 2 to more than $10^{5} \mathrm{cp}$ can be measured under these conditions. It is capable of yielding a viscoelastic measurement at a single frequency at high temperature and pressure. Its disadvantages are that more than one liter of fluid is required for a measurement and density must be known to determine absolute viscosity, because the product of viscosity and density is measured by the instrument.

Extreme care was exercised in maintaining calibration of the instruments used in the course of this program, and in use of corrections to correct determinations for instrument artifacts such as entry and exit effects, end effects, etc. to insure that measurements were true bulk fluid measurements of viscosity and storage modulus were determined. In many cases, measurements with different instruments were "overlapped" to insure that discontinuities due to measurements with different instruments were not a factor. The details for corrections are given in the publications on the work done in this program as well as in other reports (Fricke, 1983, 1985, 1987, 1990, 1997 and Zaman, 1992). 


\subsection{Viscosity Regimes}

Viscosities of black liquors at low solids concentrations ( $<50 \%$ solids) and at temperatures up to $100^{\circ} \mathrm{C}$ have been measured over many years (Morre, 1923, Kobe and McCormack, 1949, Hunter et al., 1953, Harvin, 1955, Han, 1957, Melcher, 1961, Bodenheimer, 1969, Lankenau and Flores, 1969, Polyakov et al., 1970, Wight, 1985, Fricke, 1985, Zaman and Fricke, 1993). The most extensive data are reported by Wight (1985), Fricke (1987) and Zaman and Fricke (1993). The latter have shown that kraft black liquors behave as Newtonian fluids at temperatures above $10^{\circ} \mathrm{C}$ and solids concentrations below $50 \%$. In this regime black liquor can be treated as a dilute polymer solution and methods developed for data reduction and correlation for dilute polymer solutions can be applied successfully (Wight, 1985, Fricke, 1985, Adams and Frederick, 1986).

Marton (1971), Ghalke and Veeramani (1977), Oye et al.(1977), Herrick et al. (1979), Kim (1980), Wight et al. (1981), Sanquist (1981, 1983), Steinuff and Agarwal (1981), Co et al. (1982), Small (1984, 1985), Wight (1985), Kim et al. (1981), Soderhjelm (1986, 1988, 1992), Stevens (1987), Janson and Soderhjelm (1988), and Milanova and Dorris (1989) have reported data on viscosity of black liquors at solids concentrations above $50 \%$ solids and temperatures up to $110^{\circ} \mathrm{C}$. In most cases, the characteristics of the black liquor solids are not reported nor the pulping conditions recorded. Many have shown that black liquor behavior is non-Newtonian in this region and that the behavior is pseudoplastic. The most extensive data has been reported by Wight (1985) and Fricke $(1983,1985,1987)$. The fact that behavior is non-Newtonian at these conditions is in agreement with the interpretation that a second order transition in the fluid occurs. In this regime, theories developed for concentrated polymer solutions apply and rheology becomes sensitive to the concentration and molecular weight of the lignin present (Wight, 1985, Fricke, 1985, Fricke, 1987, Wennberg, 1989).

At very high solids concentration and high temperature (the effects of temperature and concentration are related), liquors become viscoelastic (Co and Wight, 1982, Wight, 1985, Fricke, 1985). At some point, the liquor becomes unable to undergo infinite strain and acts as a semi- 
solid. This occurs at very high solids (above $85 \%$ ) or at lower solids and lower temperatures (about $-20^{\circ} \mathrm{C}$ ). Therefore, there is a third regime where the liquor behaves as a semi-solid rather than a fluid. It is of interest to attempt to define the lower limit of concentration where this behavior will occur, since it defines the upper limit in concentration for liquor firing with present technology.

The first two regimes have been thoroughly investigated in this program. Best efforts have been made to determine the limits for the third regime, but work is not as extensive.

\subsection{Low Solids $(<50 \%)$ Viscosity}

Fricke first suggested using theories developed for dilute polymer solutions that were based on colligative properties or corresponding states to reduce viscosity data at low solids concentrations after Massee (1984) investigated the freezing-glass transition behavior of black liquors. The solids concentration limit for correlation was set arbitrarily, based on research by Wight (1985). Wight (1985) correlated data for a large number of black liquor systems in an earlier study (Fricke, 1985). Adams and Frederick (1988) published these results with extensive claims for application to many systems without regard to variations due to changes in liquor solids composition.

The correlation proposed by Wight (1985) involves referring viscosity of the liquor to the viscosity of the solvent at the same temperature, which is called the reduced viscosity. In the case of black liquor, the reduced viscosity is defined as:

$$
\mu_{\mathrm{R}}=\frac{\mu}{\mu_{\mathrm{w}}}
$$

where:

$$
\begin{aligned}
& \mu=\text { liquor viscosity at temperature, } T \\
& \mu_{\mathrm{W}}=\text { viscosity of water at temperature, } T
\end{aligned}
$$




$$
\mu_{\mathrm{R}}=\text { reduced viscosity at temperature, } \mathrm{T}
$$

In most cases, the kinematic viscosity was measured rather than the absolute viscosity. The kinematic viscosity is defined as:

$$
v=\mu / \rho
$$

and the reduced kinematic viscosity is defined as:

$$
v_{\mathrm{R}}=(\mu / \rho) /\left(\mu_{\mathrm{w}} / \rho_{\mathrm{w}}\right)
$$

where:

$$
\begin{aligned}
& \rho=\text { liquor density at temperature, } T \\
& \rho_{W}=\text { density of water at temperature, } T \\
& v=\text { kinematic viscosity at temperature, } T \\
& v_{R}=\text { reduced kinematic viscosity at temperature, } T
\end{aligned}
$$

Both $\mu_{R}$ and $v_{R}$ were used in reducing data. Use of $v_{R}$ is successful, since the density of liquor increases linearly with concentration at constant temperature and the effect of temperature on density of both black liquor and water is small compared to the effect of temperature on viscosity. These factors are accounted for by adjustments in the constants of the data reduction equation discussed later.

Finally, it is known that viscosity is an exponential function of reciprocal absolute temperature, which led to use of $S / T$ as a reducing function where $S=$ solids mass fraction and $T=$ absolute temperature (Wight, 1985, Fricke, 1985, 1987, Adams and Frederick, 1988). Fricke and Zaman (Fricke, 1987, Zaman and Fricke, 1991) later suggested using a reference absolute 
temperature, $\mathrm{T}_{0}$, as a scaling factor to yield $\left(\mathrm{ST}_{0} / \mathrm{T}\right)$ as the reducing function. This reducing function leads to:

$$
\log \left(v_{R}\right)=\sum_{i=1}^{n} a_{i}\left(\frac{S}{T}\right)^{i}
$$

and

$$
\log \left(v_{R}\right)=\sum_{i=1}^{n} a_{i}^{\prime}\left(\frac{S T_{0}}{T}\right)^{i}
$$

where:

$$
\begin{aligned}
& v_{R}=\text { Reduced kinematic viscosity } \\
& S=\text { Solids mass fraction } \\
& T=\text { Absolute temperature } \\
& T_{0}=\text { Reference temperature } \\
& a_{i}, a_{i}^{\prime}=\text { Constants for a liquor }
\end{aligned}
$$

as the data reduction equation that can be used to fit all data for a single liquor to one curve. Extensive work by Wight (1985), Fricke $(1985,1987)$ and Zaman and Fricke (1991) show that two terms for either equations (12.3.4) or (12.3.5) are sufficient to correlate data for any one black liquor (constant composition of solids) with an adjusted correlation coefficient of 0.996 or better. It has also been shown by Wight $(1985)$ and Zaman $(1991,1992)$ that this function can be used universally for black liquors; however, correlations vary with liquor solids composition. Therefore, one should not use a single correlation of this type as recommended by Adams and Frederick (1988). The reference temperature used by Zaman and Fricke (1991) for equation (12.3.5) was $313.16^{\circ} \mathrm{K}$. 
A review of past work and presentation of some of the early work performed in this program, along with a review of viscosity at high solids ( $>50 \%)$ and high temperatures is described in the publication: Zaman, A.A. and A.L. Fricke, "Viscosity of Black Liquor Up to $130^{\circ} \mathrm{C}$ and $84 \%$ Solids," Forest Products Symposium, AIChE Proceedings, 59-77 (1991) that is included as part of this report. This publication, included here, will also be referred to extensively in later sections of this report. reprint removed.

Zaman and Fricke (1994) also performed an extensive evaluation of the use of theories for viscosities of liquids and for viscosities for dilute polymer solution. The publication on this work: Zaman, A.A. and A.L. Fricke, "Correlations for Viscosity of Kraft Black Liquors at Low Solids Concentrations," AIChE Journal, 40(1), 187-192 (1994) is included as part of this report. It is clearly shown that black liquor at low solids concentrations can be treated as a dilute polymer solutions. General correlation forms developed from absolute reaction rate and free volume theories that are applicable to dilute polymer solutions have to be shown to apply to black liquors at low solids concentrations. reprint remoref.

Absolute reaction rate theory leads to:

$$
\mu=A_{1} T^{0.5} \exp \left[B_{1} / T\right]
$$

and free volume theories lead to:

$$
\mu=\mathrm{A}_{2} \mathrm{~T}^{0.5} \exp \left[\frac{\mathrm{B}_{2} \mathrm{~T}_{\mathrm{o}}}{\mathrm{T}-\mathrm{T}_{\mathrm{o}}}\right]
$$

where:

$$
\begin{aligned}
& \mu=\text { Viscosity } \\
& T=\text { Temperature }
\end{aligned}
$$


$\mathrm{T}_{0}=$ Phase transition temperature

$A_{1}, A_{2}, B_{1}, B_{2}=$ Constants

Equation (12.3.6) is a two constant model and equation (12.3.7) is a three constant model; however, $T_{0}$ (the temperature at which the free volume is zero) can be fixed as a constant independent of solids. Using results of Massee's work (1985), we found that $T_{0}=220^{\circ} \mathrm{K}$ could be used as a constant independent of concentration. Use of both of these equations was tested. Both models could be used to fit viscosity data for black liquors with very high precision $\left(\mathrm{R}^{2}>\right.$ 0.99).

The constants, $A_{1}$ and $B_{1}$, for equation (12.3.6) were both found to be concentration dependent. $B_{1}$ increases with increasing solids concentration, but the rate of increase is not linear. However, the values for $\mathrm{B}_{1}$ which are slightly less than twice on "activation energy" are in the proper range for viscosity. $A_{1}$ proved to be uncorrelated with solids concentration. Thus, equation (12.3.6) proves to have little value for predicting the effects of both temperature and solids concentration on viscosity.

Equation (12.3.7) that is based on free volume theory is also a two constant model if $T_{0}$ is specified independent of concentration. That this is true has been shown for a number of liquors. One should also note that equation (12.3.7) is more widely accepted for correlating dilute polymer solution viscosity. The constants, $A_{2}$ and $B_{2}$, for equation (12.3.7) were evaluated for a number of different liquors with $\mathrm{T}_{0}=220^{\circ} \mathrm{K}$. As expected, the equation correlated data for a given liquor at any one solids concentration extremely well, and $A_{2}$ and $B_{2}$ were smooth functions of solids concentration. $A_{2}$ is a linear function of concentration and $B_{2}$ is a curvilinear function of concentration. It was found that $\mathrm{A}_{2}$ did not vary significantly from liquor to liquor for one species (this is expected from theoretical considerations) and can be expressed as an average linear function for all liquors from a single species. This was done and $\mathrm{B}_{2}$ reevaluated as a function of concentration for each liquor. $B_{2}$ proved again to be a curvilinear function of concentration with a 
different curve for each liquor. Typical results are given in the publication (Zaman and Fricke, 1994).

Summarizing, equation (12.3.6) is not useful for correlating viscosity with respect to temperature and concentration. Equation (12.3.7) can be used for high precision with a total of five constants, two that vary only with species, but three that vary from liquor to liquor for the same species. Even though this equation is very precise, it would be very difficult and complex to attempt to use it to develop relations between pulping conditions and viscosity.

Equations (12.3.4) and (12.3.5) and their alternate forms for absolute reduced viscosity combine the effects of temperature and concentration, and have long been applied successfully to dilute polymer solutions (Billmeyer). Using the same data as used in the evaluation of the activation energy and free volume theory models, we correlated the data using equations (12.3.4) and (12.3.5). It was found that a two constant equation:

$$
\ln \left(v_{R}\right)=a_{1}\left(\frac{S}{T}\right)+a_{2}\left(\frac{S}{T}\right)^{2}
$$

correlated all of the data for any one liquor with little loss of precision $\left(R^{2} \geq 0.997\right)$. Since this is simpler and combines the effects of temperature and solids using only two constants, it was chosen as the model to be used for correlation of viscosity with pulping conditions. It should be pointed out that both $\mathrm{a}_{1}$ and $\mathrm{a}_{2}$ varied significantly from liquor to liquor for the same species.

Viscosities at concentrations below 50\% solids were measured at temperatures ranging from 25 to $100^{\circ} \mathrm{C}$ for the black liquors derived from the circulation digester pulping experiments as well as for many other black liquors. With the exceptions of liquors derived from carbonate and semi-chemical pulping, equation (12.3.8) was always successfully used to reduce data for any one liquor over the entire range of temperature for concentrations up to $50 \%$ solids.

Constants for equation (12.3.8) determined for the liquors derived from the circulation digester pulping experiments were determined and analyzed with respect to pulping conditions and solids composition. The results were published in: Zaman, A.A. and A.L. Fricke, "Viscosity of 
Softwood Kraft Black Liquors at Low Solids Concentrations: Effects of Solids Content, Degree of Delignification and Liquor Composition," Journal Pulp and Paper Sci., 21(4), J119-J126 (1995), which is included as part of this report. Values of $a_{1}$ and $a_{2}$ for equation (12.3.8) were determined for the liquors made at each pulping condition. Values of the constants for each liquor are given in Table 12.3.1. As can be seen, the equation with both constants permitted to vary from liquor to liquor gave a correlation coefficient of 0.997 or better in every case. reprint $\mathrm{removed,}$

Examination of the plots of equation (12.3.8) for each liquor showed nearly no variation at values of $\mathrm{S} / \mathrm{T}$ below about $30 \times 10^{-3}$. This is a typical behavior for dilute polymer solutions and led us to attempt recorrelation with $\mathrm{a}_{1}$, which really nearly represents the initial slope, set at a constant value for all of the liquors, i.e., for all of the liquors made by pulping the same species at different conditions. The constant, $\mathrm{a}_{1}$, was set at an average value of $466.4^{\circ} \mathrm{K}$ for these liquors and $a_{2}$ reevaluated for each liquor. The assumption that $a_{1}$ is a universal constant for liquors from the same species appears valid, since little precision is lost; the lowest correlation coefficient was 0.992 and only three were below 0.995 . Thus, the variation from liquor to liquor of a single species is reduced to variations in one constant and one can concentrate upon relating this one constant to the effects of pulping conditions or composition of the liquor solids.

The black liquors derived from the circulation digester experiments are an excellent set to explore the effects of pulping conditions on the viscosity of black liquors at low solids. In addition to knowing the pulping conditions for each liquor, the H-factor, the Kappa number and yield of the pulp, and the quantities of many constituents of the liquor are known. These effects were explored semi-quantitatively in the study reported in the publication.

The Kappa number is an arbitrary measurement of the lignin remaining in the pulp (the lower the Kappa number, the greater the delignification). As shown in the publication, the reduced viscosity at a particular temperature and solids concentration tends to be a maximum at intermediate Kappa number. This is attributed to the presence of substantial amounts of higher molecular weight lignin in the liquor under these circumstances. It is worth noting that the reduced viscosity always is less as the sulfidity is increased and that reduced viscosity appears to continuously 
Table 12.3.1

Values of Constants for Equation (12.3.8) for Low Concentration Viscosity of Slash Pine Black Liquors, with and without a1 Fixed

\begin{tabular}{|c|c|c|c|c|c|}
\hline $\begin{array}{l}\text { Circulation Digester } \\
\text { Experiment Number }\end{array}$ & $\begin{array}{l}a_{1} \times 10^{-2} \\
(\mathrm{~K})\end{array}$ & $\begin{array}{c}a_{2} \times 10^{-4} \\
\left(\mathrm{~K}^{2}\right)\end{array}$ & $\mathrm{R}^{2}$ & $\begin{array}{c}\mathrm{a}_{2} \times 10^{4}\left(\mathrm{~K}^{2}\right) \text { with } \\
\mathrm{a}_{1}=466.4^{\circ} \mathrm{K}\end{array}$ & $\mathrm{R}^{2}$ \\
\hline 1 & 1.94 & 185 & 0.997 & 165 & 0.996 \\
\hline 2 & 6.15 & 176 & 0.999 & 190 & 0.994 \\
\hline 3 & 4.76 & 168 & 0.998 & 174 & 0.993 \\
\hline 4 & 5.33 & 160 & 0.999 & 165 & 0.997 \\
\hline 5 & 5.40 & 172 & 0.999 & 177 & 0.998 \\
\hline 6 & 4.17 & $\overline{199}$ & 0.998 & 191 & 0.996 \\
\hline 7 & 5.83 & 152 & 0.999 & 161 & 0.998 \\
\hline 8 & 3.51 & 136 & 0.999 & 126 & \begin{tabular}{|l|}
0.997 \\
\end{tabular} \\
\hline 9 & 5.59 & 164 & 0.999 & 171 & 0.998 \\
\hline 10 & 7.10 & 161 & 0.999 & 184 & 0.998 \\
\hline 11 & 5.49 & 146 & 0.998 & 154 & 0.992 \\
\hline 12 & 3.62 & 172 & 0.998 & 163 & 0.997 \\
\hline 13 & 5.30 & 144 & 0.998 & 151 & 0.996 \\
\hline 14 & 4.03 & 168 & 0.999 & 163 & 0.998 \\
\hline 15 & 4.63 & 164 & 0.999 & 163 & 0.997 \\
\hline 16 & 3.84 & 167 & 0.999 & 160 & 0.998 \\
\hline 17 & 6.10 & 160 & 0.998 & 174 & 0.995 \\
\hline 18 & 3.12 & 186 & 0.998 & 173 & 0.997 \\
\hline 19 & 1.55 & 178 & 0.998 & 154 & 0.995 \\
\hline 20 & 6.28 & 130 & 0.999 & 145 & 0.995 \\
\hline 21 & 1.58 & 163 & 0.999 & 141 & 0.996 \\
\hline 22 & 5.23 & 175 & 0.999 & 180 & 0.998 \\
\hline 23 & 4.97 & $\overline{171}$ & 0.999 & 170 & 0.996 \\
\hline 24 & 7.82 & 146 & 0.997 & 183 & 0.995 \\
\hline 25 & 3.22 & 174 & 0.999 & 161 & 0.997 \\
\hline
\end{tabular}


increase with decreasing Kappa number at low sulfidity and effective alkali. This is in qualitative agreement with earlier work.

If it is assumed that delignification is a first order reaction, the H-factor (Vroom, 1957) can be used to characterize delignification. The trends in reduced viscosity with $\mathrm{H}$-factor are discussed in the publication. It is clear that viscosity is a maximum at intermediate $\mathrm{H}$-factors where the solids fraction contains the highest concentration of lignin and where the lignin molecular weight is highest. Since there is a linear relationship between pulp yield and Kappa number, the reduced viscosity also passes through a maximum with respect to pulp yield.

The effects of lignin weight average molecular weight and lignin fraction of the liquor solids are examined independently. As discussed in the publication, reduced viscosity at higher solids generally increases linearly with increase in both characteristics of the liquor solids.

The effects of concentration of sodium, carbonates, other inorganics, and $\mathrm{pH}$ (measured at approximately $10 \%$ solids and $25^{\circ} \mathrm{C}$ ) were also explored. Viscosity decreased with sodium content and $\mathrm{pH}$, and there are also slight decreases in viscosity with increases in carbonates or other inorganics. A more complete discussion is given in the publication.

After completing this initial analysis and after the choice of the most suitable model for viscosity correlation for a single liquor, we proceeded to modeling the constants for the viscosity correlations with respect to pulping conditions and liquor solids composition by statistical methods and response surface analysis of the data for low solids concentration viscosity of the liquors derived from the circulation digester pulping experiments. These efforts were successful and the results have been published in: Zaman, A.A. and A.L. Fricke, "Effects of Pulping Conditions and Black Liquor Composition of Softwood Kraft Black Liquors: Predictive Models," TAPPI Journal, 78(10), 107-119 (1995), which is included as part of this report. In general, correlations were performed using $a_{2}$ of equation (12.3.8) with $a_{1}$ of equation (12.3.8) fixed at a value of $466.4^{\circ} \mathrm{K}$ as the response variable. heprint removed.

The responses of a2 to pulping variables $(E A, S, t, T)$ to combined pulping variables (EA, $\mathrm{S}, \mathrm{H}$-factor), and to liquor solids composition factors (lignin, sodium, inorganics, other organics, 
lignin molecular weight) were all developed using linear quadratic models with interactions and statistical significance tests to identify the statistically significant terms in the same manner as discussed previously for the correlation for other properties. Full details for this particular study are given in the publication along with example response surfaces developed using the final correlations. Pertinent data for composition of the solids is given in Table III of the publication and is also given with circulation digester pulping experiment numbers in Table 12.3.2. The weight average molecular weights used in this correlation are those determined by HTHPLC using polysaccharides as standards. These values are given in Tables III of the publication and Table 12.3.2. Now that corrected weight average molecular weights are available from HTHPLC and MWDs are available, the response with respect to lignin molecular weight should be redetermined. This will not change the general conclusions on trends; only the values of coefficients for parameters in the correlations developed.

Analysis of the significance levels of linear, quadratic, and interaction terms, along with response surface analysis, indicate that the response of viscosity to pulping conditions is highly non-linear, as can be seem from the examples of surfaces. Depending upon the statistical approach used, slightly different statistical models for a2 were developed, but all of the models relating a2 to pulping variables that were the best statistically, no matter the method of search used, involved nine parameters (ten constants) with adjusted regression coefficients of 0.79 and 0.75 , respectively, for models for four pulping variables $(E A, S, t, T)$ and for three pulping variables (EA, S, H-factor), respectively.

The recommended relations are:

$$
\begin{aligned}
\mathrm{a}_{2} & =-490926526.0+(13826.0 \times \mathrm{t}) \\
& +(2180913.0 \times \mathrm{T})-(17315.0 \times \mathrm{S} \times \mathrm{t}) \\
& +(21.54 \times \mathrm{S} \times \mathrm{T})+(1795.15 \times \mathrm{S} \times \mathrm{EA} \times \mathrm{t}) \\
& +(39.15 \times \mathrm{S} \times \mathrm{t} \times \mathrm{T})-(4.1 \times \mathrm{S} \times \mathrm{EA} \times \mathrm{t} \times \mathrm{T})
\end{aligned}
$$


Table 12.3.2

\section{Composition of Solids of Circulation Digester Pulping \\ Experiment Black Liquors}

\begin{tabular}{|c|c|c|c|c|c|c|}
\hline $\begin{array}{c}\text { Circulation } \\
\text { Digester } \\
\text { Experiment } \\
\text { Number } \\
\end{array}$ & $\begin{array}{l}\text { Lignin, } \\
\text { g/g solids }\end{array}$ & $\overline{\mathbf{M}}_{\mathrm{w}}$ & $\begin{array}{l}\text { Sodium, } \\
\text { g/g solids }\end{array}$ & $\begin{array}{c}\text { Carbonates, } \\
\text { g/g solids }\end{array}$ & $\begin{array}{l}\text { Organics, } \\
\text { g/g solids }\end{array}$ & $\begin{array}{c}\text { Inorganics, } \\
\text { g/g solids }\end{array}$ \\
\hline$\overline{1}$ & 0.350 & 6411.0 & 0.152 & 0.0289 & 0.544 & 0.237 \\
\hline 2 & 0.435 & 6618.0 & 0.145 & 0.0537 & 0.613 & 0.243 \\
\hline 3 & 0.380 & 8687.0 & 0.177 & 0.0288 & 0.561 & 0.262 \\
\hline 4 & 0.409 & 6422.0 & 0.169 & 0.0612 & 0.587 & 0.281 \\
\hline 5 & 0.421 & 6544.0 & 0.162 & 0.0545 & 0.594 & 0.307 \\
\hline 6 & 0.417 & 6931.5 & 0.149 & 0.0558 & 0.627 & 0.280 \\
\hline 7 & 0.384 & 7528.5 & 0.188 & 0.0635 & 0.566 & 0.352 \\
\hline 8 & 0.393 & 3910.0 & 0.175 & 0.0656 & 0.619 & 0.334 \\
\hline 9 & 0.408 & 7960.0 & 0.142 & 0.0465 & 0.613 & 0.245 \\
\hline 10 & 0.427 & 9358.0 & 0.145 & 0.0617 & 0.628 & 0.262 \\
\hline 11 & 0.344 & 5046.5 & 0.166 & 0.0691 & 0.526 & 0.304 \\
\hline 12 & 0.440 & 6023.5 & 0.162 & 0.0454 & 0.607 & 0.269 \\
\hline 13 & 0.376 & 5995.5 & 0.189 & 0.0242 & 0.561 & 0.299 \\
\hline 14 & 0.423 & 5589.0 & 0.136 & 0.0154 & 0.557 & 0.202 \\
\hline 15 & 0.406 & 7571.5 & 0.168 & 0.0064 & 0.473 & 0.211 \\
\hline 16 & 0.404 & 5693.0 & 0.166 & 0.0226 & 0.554 & 0.283 \\
\hline 17 & 0.419 & 9672.0 & 0.163 & 0.0602 & 0.630 & 0.304 \\
\hline 18 & 0.365 & 6279.5 & 0.169 & 0.0592 & 0.440 & 0.290 \\
\hline 19 & 0.430 & 5002.5 & 0.173 & 0.0931 & 0.552 & 0.360 \\
\hline 20 & 0.339 & 4820,5 & 0.166 & 0.1280 & 0.485 & 0.420 \\
\hline 21 & 0.430 & 5181.0 & 0.150 & 0.0354 & 0.680 & 0.258 \\
\hline 22 & 0.417 & 7154.0 & 0.145 & 0.0546 & 0.581 & 0.265 \\
\hline 23 & 0.406 & 7149.0 & 0.167 & 0.0603 & 0.519 & 0.307 \\
\hline 24 & 0.397 & 9582.0 & 0.159 & 0.0642 & 0.565 & 0.268 \\
\hline 25 & 0.413 & 6470.0 & 0.158 & 0.0448 & 0.561 & 0.325 \\
\hline
\end{tabular}




$$
\begin{aligned}
& -(2415.04 \times \mathrm{T} \times \mathrm{T})-(60.99 \times \mathrm{t} \times \mathrm{t}) \\
& \text { where } \mathrm{r}^{2}=0.87, \text { adjusted } \mathrm{r}^{2}=0.79 \\
& \mathrm{a}_{2}=1603552.0+(1360.83 \times \mathrm{h})-(214.38 \times \mathrm{EA} \times \mathrm{h}) \\
& +(482.1 \times \mathrm{S} \times \mathrm{S})+(0.476 \times \mathrm{h} \times \mathrm{h}) \\
& -(0.224 \times \mathrm{S} \times \mathrm{S} \times \mathrm{H})-(84.53 \times \mathrm{EA} \times \mathrm{EA} \times \mathrm{S}) \\
& +(10.48 \times \mathrm{EA} \times \mathrm{EA} \times \mathrm{H})-(0.04 \times \mathrm{EA} \times \mathrm{h} \times \mathrm{h}) \\
& \text { where adjusted } \mathrm{r}^{2}=0.75
\end{aligned}
$$

where:

$$
\begin{aligned}
& \mathrm{EA}=\text { Effective alkali, } \% \\
& \mathrm{~S}=\text { Sulfidity }, \% \\
& \mathrm{t}=\text { Time at temperature, } \min . \\
& \mathrm{T}=\text { Temperature, }{ }^{\circ} \mathrm{K} \\
& \mathrm{h}=\mathrm{H} \text {-factor, hrs. }
\end{aligned}
$$

Calculated values for $\mathrm{a}_{2}$ and for viscosity should be accurate to within $\pm 6 \%$ and $\pm 13 \%$ or better for equation (12.3.8) and to within $\pm 10 \%$ and \pm about $17 \%$ or better for equation (12.3.8).

The same techniques were applied with respect to the liquor composition. The variables considered were lignin molecular weight, lignin concentration, inorganics concentration, and sodium concentration. Note that carbonate concentration, concentration of other organics, and $\mathrm{pH}$ are not included. Carbonate concentration is quite low for all of the liquors and tends to follow sodium, since carbonate was set at a level corresponding to $85 \%$ causticizing efficiency in the white liquor. $\mathrm{pH}$ tended to follow sodium. Other organics are not independent if lignin and inorganics or specified. 
The model developed for a2 response with respect to the four liquor composition variables also contains nine parameters (ten constants). The best correlation developed is:

$$
\begin{aligned}
a_{2} & =2331959.0-\left(1327.75 \times X_{1}\right) \\
& -\left(258143870.0 \times X_{2}\right)+\left(69528231.0 \times X_{3}\right) \\
& +\left(11663.0 \times X_{1} \times X_{3}\right)+\left(1569590311.0 \times X_{2} \times X_{3}\right) \\
& +\left(77236.0 \times X_{1} \times X_{2} \times X_{4}\right)-\left(469639 \times X_{1} \times X_{2} \times X_{3} \times X_{4}\right) \\
& -\left(0.036 \times X_{1} \times X_{1}\right)-\left(531279901.0 \times X_{3} \times X_{3}\right) \\
& \text { where } \mathrm{r}^{2}=0.85, \text { adjusted } \mathrm{r}^{2}=0.8
\end{aligned}
$$

where:

$$
\begin{aligned}
& \mathrm{X}_{1}=\text { Lignin molecular weight } \\
& \mathrm{X}_{2}=\text { Inorganics concentration, } \mathrm{g} / \mathrm{g} \\
& \mathrm{X}_{3}=\text { Sodium concentration, } \mathrm{g} / \mathrm{g} \\
& \mathrm{X}_{4}=\text { Lignin concentration, } \mathrm{g} / \mathrm{g}
\end{aligned}
$$

The equation can be used to predict $a_{2}$ with an accuracy of $\pm 7 \%$ or better.

Non-linear search procedures were then used to try to determine simpler non-linear models that would predict a2 with equal or greater accuracy. This was reasonably well accomplished and yielded the following recommended models:

$$
\begin{aligned}
& \mathrm{a}_{2}=0.272 \mathrm{~T}^{2.72} \mathrm{t}^{-0.0012} \mathrm{~S}^{-0.0712} \mathrm{EA}^{-0.2544} \\
& \mathrm{a}_{2}=1.91 \times 10^{6}-13.74\left(\log _{\mathrm{e}} \mathrm{H}\right) \mathrm{EA}^{2.02} \mathrm{~S}^{0.746}
\end{aligned}
$$


$\mathrm{a}_{2}=11.165\left(\mathrm{M}_{\mathrm{w}}\right)^{0.297} \mathrm{~L}^{0.054} \mathrm{I}^{-0.013} \mathrm{Na}^{-0.303}$

(excluding carbonates)

$$
\mathrm{a}_{2}=11.042\left(\mathrm{M}_{\mathrm{w}}\right)^{0.312} \mathrm{~L}^{0.056} \mathrm{I}^{0.019} \mathrm{Na}^{-0.34}
$$

(including carbonates)

with accuracies for $a_{2}$ of $\pm 8 \%, \pm 9 \%, \pm 8 \%$, and $\pm 8 \%$, for equations (12.3.12), (12.3.13), (12.3.14), and (12.3.15), respectively. These will predict viscosity within about $\pm 17 \%$ or better at all conditions.

\subsection{Rheological Behavior at High ( $>50 \%$ ) Solids Concentration}

The rheological behavior of black liquors at solids concentrations above $50 \%$ is a major factor affecting high solids concentration and firing of black liquors. This behavior is also highly complex. The complexity is to be expected due to the complex nature of the mixture and due to the changes that have been shown to take place in other liquor properties as the concentration is increased.

The first viscosity measurements at solids concentration above $50 \%$ were made by Marton (1971). Using a wide variety of viscometers (most of which were designed for study of polymeric fluids), Ghalke and Veeramani (1977), Oye et al. (1977), Herrick et al. (1979), Kim (1980), Wight et al. (1981), Sandquist (1981, 1983), Stenuff and Agarwal (1981), Co et al. (1982), Small (1984, 1985), Wight (1985), Kim et al. (1981), Soderhjelm (1986, 1988, 1992), Stevens (1987), Janson and Soderhjelm (1988), Wennberg (1985, 1989), and Milanova and Dorris (1989) have reported viscosity data at solids concentration up to $75 \%$ solids and at temperatures up to $120^{\circ} \mathrm{C}$. Results of most of this work are highly suspect, because black liquor viscosity is now known to be very dependent upon temperature and behavior is known to be non-Newtonian. Most past workers considered neither of the effects. 
Kim (1980) was the first to consider high solids concentration black liquor to be a nonNewtonian fluid. He found kraft softwood black liquors to be pseudoplastic. Following his work, other investigators began to consider the effects of shear rate on viscosity. Small (1984) and Wight (1985) made extensive studies of temperature control of a number of viscometers and recommended revisions for the controls of these instruments to permit precise measurements for black liquors. Small $(1984,1985)$ also demonstrated that black liquor viscosity decreases rapidly with time when the liquor is held at high temperature and high solids concentrations. Following Small, this effect was also reported for other liquors by Soderhjelm $(1986,1988)$. For these reasons, most of the data reported before 1988 is highly suspect. Exceptions probably are the results reported by Kim (1980), Small $(1984,1985)$, Wight (1985), and Stevens (1987).

In all cases, except three, the non-Newtonian behavior of black liquor was either ignored or the fluid was determined to be pseudoplastic. Soderhjelm $(1986,1988)$ and Wennberg $(1989)$ reported thixotropic behavior for highly viscous hardwood black liquors which was attributed to presence of higher molecular weight hemi-cellulose derivatives and their association with lignin. This has never been observed for softwood black liquors nor observed for hardwood black liquors in other studies.

The decrease of viscosity with time studied by Small $(1984,1985)$ and Soderhjelm $(1986$, 1988 ) is an irreversible change that Small attributed to degradation of the lignin. Estimates of the effects of such degradation, based on calculations of chain scission, were made by Fricke (1987).

The most extensive data had been reported by Kim (1980), Wight (1985), and Small $(1985,1986)$. The data and methods of data were also reported and summarized by Fricke (1983, 1985, 1987). Kim (1980) demonstrated that the lower limiting viscosity (zero shear rate viscosity) could be determined by proper extrapolation of capillary viscometer data. He also demonstrated that data taken with multiple length capillaries could be treated so as to determine viscosity free of end effects from capillary data. Finally, he was able to show that the zero shear rate viscosity nearly, but not quite, fitted an Arhennius relationship at solids concentrations from about 55 to $75 \%$ solids. 
Wight (1985) reported extensive data for direct measurement of viscosity at low shear rates using a parallel plate viscometer. (It is worth noting that Wight determined that cone-and-plate viscometers gave inconsistent and erroneous measurements of viscosity of black liquors). Wight combined measurements of viscosity from parallel plate and capillary instruments into one viscosity vs. shear rate curve to demonstrate that the measurements made with different geometries agreed. He then normalized the curve by dividing each viscosity, $\eta$, by the zero shear rate viscosity, $\eta_{0}$, to obtain the reduced viscosity, $\eta / \eta_{0}$. He then demonstrated that such curves for each temperature could be superimposed by superposition principles developed for polymers to yield one curve for a single liquor at fixed concentration that was valid for all temperatures and shear rates. Moreover, the shift factor function, aT, developed from superimposing the curves behaved as expected from polymer theory. This has two important consequences. It permits one to reduce the amount of data necessary to describe the liquor behavior and it confirms that black liquors behave as polymer solutions in this concentration range. These results were reported by Wight (1985) and by Fricke $(1983,1985)$.

Wight (1985) was also the first to conduct viscoelastic studies of black liquors. He studied two black liquors, and applied principles developed for polymers to superimpose data for constant concentrations for storage modulus and the real component of the complex viscosity. These results were also reported by Fricke $(1983,1985,1987)$.

The high solids concentration steady shear behavior of three kraft black liquors selected from a pulping study of Slash Pine was thoroughly investigated by Stevens (1987). In all cases, the temperature superposition of data for a liquor at constant solids was successful. Stevens then successfully superimposed these curves for a liquor to a single curve for a liquor, demonstrating that effects of concentration were a smooth function. Even though the shift factor for this second superposition was purely empirical, it was an important step forward that led to further developments. This development was reported by Fricke (1987).

The most extensive and precise studies of rheological behavior have been made in this present program [Small (1983), Stevens (1987), Zaman (1992), Zaman and Fricke (1991, 1994, 
1995, 1995, 1995, 1996), Fricke (1990, 1993, 1997)] and in its predecessor [Wight (1985), Co et al. (1982), Small (1984), Kim (1982), Fricke $(1983,1985,1987)]$. These were the first to show non-Newtonian behavior, investigate viscosity at high temperatures, study viscoelastic behavior, define instrument requirements for precise data collection, successfully measure viscosity over a broad range of shear rates, and successfully apply data reduction and superposition principles developed for polymers to the rheology of black liquors. Other investigators quickly adapted these developments to their studies. A review of these developments and their consequences is given in the publication by Zaman and Fricke (1991) that is included in section 12.3 of this report and in even more detail elsewhere (Zaman, 1992).

The results show that the study of rheology of black liquors can be divided into four parts. These are:

1. Determination and correlation of zero shear rate viscosity

2. Superposition of steady shear rate viscosity for temperature and concentration

3. Simplification of superposition of steady shear rate viscosity by proper application of polymeric theories

4. Viscoelastic studies

This has been accomplished in a systematic fashion in this program for extensive data for the kraft black liquors derived from the circulation digester pulping experiment as well as for a number of mill liquors. All kraft liquors studied have behaved quantitatively in exactly the same manner, except for those in which significant precipitation or separation of a second phase occurred. If this happened, it always occurred at $47-55 \%$ solids. Except for liquors from carbonate or semichemical pulping, liquors from other pulping processes behaved very much like kraft liquors. Both carbonate and semi-chemical pulps exhibited the onset of non-Newtonian behavior at lower solids as expected, since the first second order thermodynamic transition for these liquors occurred at much lower solids concentrations. 


\subsubsection{Zero Shear Rate Viscosity}

Determination and data reduction of zero shear rate viscosity measurements at high solids is important for a number of reasons. The shear rate limits below which a black liquor behaves as a Newtonian fluid (the zero shear rate region) decreases with increase in solids concentration and with decrease in temperature. Viscosities for most black liquors at normal processing temperature $\left(100-130^{\circ} \mathrm{C}\right)$ and present processing solids concentrations (up to $75 \%$ solids) have been shown to exhibit little or no non-Newtonian effects at shear rates below about $800 \mathrm{sec}^{-1}$. Therefore, at present processing conditions for most mills, zero shear rate viscosity is adequate to describe operating expectations. The zero shear rate viscosity is a fundamental parameter that should be the simplest to relate to the liquor solids composition. Finally, the zero shear rate viscosity is a normalizing factor for models for non-Newtonian behavior that can be used to simplify description of non-Newtonian behavior.

Although this should be the simplest of the parameters to correlate for high solids rheology of black liquors, behavior is still complex as will be described. Also, full exploration of the zero shear rate viscosity of a black liquor from about 55 to $85 \%$ solids and temperatures ranging from 60 to $130-140^{\circ} \mathrm{C}$ requires from 400 to 800 individual tests! Our first objective, therefore, was to determine zero shear rate experimentally over broad ranges for one of our liquors derived from the circulation digester pulping experiments and for a softwood mill liquor for comparison. This was done using data taken with multiple instruments as described by Wight (1985). Full details are given by Zaman (1992). The results of this initial study are presented in the publication: Zaman, A.A. and A.L. Fricke, "Viscosity of Black Liquor up to $130^{\circ} \mathrm{C}$ and $84 \%$ Solids," Forest Products Symposium, AIChE Proceedings, 59-77 (1991) that is included in section 12.3 as part of this report.

The behavior of these liquors, and their similarities, are clearly shown by the data presented in the publication. An extensive search was made for a correlation for combined reduction of the effects of temperature and solids concentration on the zero shear rate viscosity of a black liquor. One should note that the correlation for low solids viscosity does not apply, since the liquor can no 
longer be considered to be a water solution. There was essentially no guidance from past work with these or other complex fluids. Generally, the search was conducted by examining functions that could bear some relationship to the ratio of liquor solids to water. This search led to the development of:

$$
X=\left(\frac{S}{S+1}\right) \frac{1}{T}
$$

where:

$$
\begin{aligned}
& \mathrm{S}=\text { Solids mass fraction } \\
& \mathrm{T}=\text { Absolute temperature } \\
& \mathrm{X}=\text { Correlating function }
\end{aligned}
$$

as the most satisfactory function. It must be emphasized that this is empirical, but it has since proven to be successful when applied to many liquors. Later, more fundamental approaches will be discussed. Using the empirical function for correlation, we found that a power series of $\mathrm{X}$ :

$$
\log \eta_{0}=\sum_{i=0}^{n} a_{i}\left[\left(\frac{S}{S+1}\right) \frac{1}{T}\right]^{i}=\sum_{i=0}^{n} a_{i} X^{i}
$$

where:

$\eta_{\mathrm{o}}=$ Zero shear rate viscosity

$\mathrm{X}=$ Correlating function

$\mathbf{a}_{\mathbf{i}}=$ Constants 
with $\mathbf{n}=2$ (three constants) could be used to correlate zero shear rate viscosities for these liquors with correlation coefficients of 0.994 or better. As shown in the publication, this correlated zero shear rate viscosity data for a liquor at all solids concentrations and temperatures over a range of viscosity of six orders of magnitude or more. However, the constants for equation (12.4.1.2) all varied from liquor to liquor. This means that, for a universal correlation of zero shear rate viscosity with temperature, solids concentration, and pulping conditions, correlations for three constants would have to be developed (rather than for one as required for low solids concentration viscosity).

Further experimental and correlating efforts are described in the publication: Zaman, A.A. and A.L. Fricke, "Newtonian Viscosity of High Solids Kraft Black Liquors: Effects of Temperature and Solids Concentrations," I\&EC Research, 33(2), 428-435 (1994). Equation (12.4.1.2) was used successfully as a reduction correlating function for four additional liquors. The correlation plots for these liquors are presented (see Figure 11 of the publication) for comparison. Obviously, there is a large variation due to pulping conditions (liquor solids composition). Comparison of experimental values of $\eta_{0}$ with calculated values based on correlation with equation (12.4.1.2) is made in Table 6 of the publication. The correlations were used to estimate $\eta_{0}$ with maximum error of about $\pm 20 \%$. When one considers that the correlation

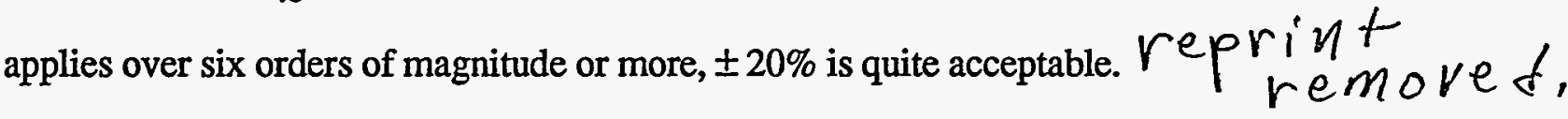

Data presented in both publications indicate that the zero shear rate viscosity does not follow an Arhennius relation over broad temperature ranges and that this departure becomes larger with increasing solids concentration. Also, the activation energy for viscosity increased markedly with increasing solids. Finally, the effect of solids concentration on zero shear rate viscosity is very large at lower temperatures.

Even though the reducing correlation expressed by equation (12.4.1.2) proved to be successful, a more fundamentally based correlation was sought. Free volume theory has been used successfully for polymers and polymer solutions. Wennberg (1985) used free volume theory 
to model liquor viscosity. With this theory, Newtonian viscosity of liquids and polymers can be described by:

$$
\eta_{0}=A \exp \left[\frac{\mathrm{BT}_{\mathrm{o}}}{\mathrm{T}-\mathrm{T}_{\mathrm{o}}}\right]
$$

where:

$\eta_{0}=$ Zero shear rate viscosity

$\mathrm{T}=$ Absolute temperature

$\mathrm{T}_{0}=$ Temperature at which free volume is zero

$\mathrm{A}=$ Constant

$\mathrm{B}=$ Constant related to the barrier to rotation of chain bonds

The theory of reaction rates leads to:

$$
\eta_{\mathrm{o}}=\mathrm{A} \exp [\mathrm{E} / \mathrm{RT}]
$$

where:

$$
\begin{aligned}
& \eta_{0}=\text { Zero shear rate viscosity } \\
& T=\text { Absolute temperature } \\
& A=\text { Constant } \\
& R=\text { Gas constant } \\
& E=\text { Activation energy for flow }
\end{aligned}
$$


Wight et al. (1981) and Fricke $(1985,1987)$ used equation (12.4.1.4) successfully for liquor viscosities for narrow ranges of temperature. Wennberg (1985) and Soderhjelm (1986) used equation (12.4.1.4) for black liquors for broader temperature ranges by substituting $T^{x}$ for $T$ in equation (12.4.1.4) where $\mathrm{x}$ was an adjustable constant with no theoretical basis.

When plots of $\log \eta_{0}$ versus $1 / T$ are non-linear, many workers have used a combination of activation energy and free volume models with success for polymers. The expression used with the most success has been:

$$
\eta_{0}=\mathrm{AT}^{0.5} \exp \left[\frac{\mathrm{B}}{\mathrm{T}}+\frac{\mathrm{CT}_{\mathrm{o}}}{\mathrm{T}-\mathrm{T}_{\mathrm{o}}}\right]
$$

where:

$$
\begin{aligned}
& B=E_{V} / R \\
& E_{V}=\text { Activation energy for flow at constant volume }
\end{aligned}
$$

and other quantities are defined as before. $T_{0}$ is an adjustable parameter and is related to the glass transition temperature (Ferry, 1980).

Glass transition phenomena had been studied by Massee $(1984,1986)$ and Fricke $(1985)$ using differential scanning calorimetry (DSC) methods. Additional work with lignins and liquors was done in this program (Schmidl, 1992). The glass transition temperature, $\mathrm{T}_{\mathrm{G}}$, was measured as a function of solids concentration for the four liquors used for model development. There is some difference in $T_{G}$ for these liquors at any given solids concentration, but the difference is not large considering the substantial differences in solids characteristics represented by these four liquors. However, at this point, it was best to use the $T_{G}$ versus solids concentration relation determined for each liquor to define $\mathrm{T}_{\mathrm{G}}$. The value of $\mathrm{T}_{0}$ normally used in polymer work is 
usually 1.3 $\mathrm{T}_{\mathrm{G}}<\mathrm{T}_{\mathrm{o}}<1.4 \mathrm{~T}_{\mathrm{G}}$. $\mathrm{T}_{\mathrm{o}}$ was permitted to vary, proportional to $\mathrm{T}_{\mathrm{G}}$, in our work. Best results were obtained with $T_{0} \cong 1.3$, which agrees with polymer work.

Zero shear rate viscosity data for the four liquors with very different liquor solids characteristics were correlated with equation (12.4.1.5) using non-linear regression methods. The resulting correlations reproduced the data with correlation coefficients of 0.999 or better. The constant B in equation (12.4.1.5) must be positive and should increase with increasing solids concentration. The constants A and B can be functions of concentration, but should not vary from liquor to liquor from the same species and pulping process, since these should be dependent only on the type and concentration of polymer. The constant $\mathrm{C}$ (the constant related to barriers to rotation of the polymer) can be markedly affected by the other components in the liquor solids.

Every parameter of this model behaved as predicted. $\mathrm{T}_{0}$ was approximately $1.3 \mathrm{~T}_{\mathrm{G}}$. The constant $\mathrm{A}$ was determined to be of the form:

$$
A=\exp \left[a_{1}+b_{1}, S\right]
$$

and the equation for $\mathrm{A}$ for the Slash Pine liquors was determined to be:

$$
A=\exp [11.824-52.856 \mathrm{~S}]
$$

When the data were recorrelated with $\mathrm{A}$ fixed as given by equation (12.4.1.7) to determine new values for $B$ and $C$ as a function of concentration for each liquor, the relation for $B$ that was found to be best was:

$$
B=a_{2} b_{2} S
$$


Tests with four very diverse liquors showed that differences in B from liquor to liquor at any given solids concentration were small, and one could assume that these differences were negligible as expected from the theory.

The constant $\mathrm{C}$ varies markedly from liquor to liquor as expected. Also, its relationship to concentration is non-linear and a maximum occurs between about 60 and $70 \%$ solids. This very well may be related to the same changes causing abrupt changes in boiling point rise and density and maxima in heat capacity at constant solids. It is suggested that the constant $\mathbf{C}$ could be fitted with a parabola for each liquor. It is also worth noting that $\mathrm{C}$ is low and nearly constant for the liquor having the lowest concentration of lignin and the highest concentration of inorganics in the liquor solids.

The model represented by equation (12.4.1.5) includes the effects of both solids and temperature implicitly. $T_{0}, B$ and $A$ all vary with solids concentration. We believe that $T_{0}, B$, and A can be considered to be independent of pulping conditions for liquors made from the same wood with very little loss of precision. To evaluate these three parameters that vary with solids concentration, $T_{G}$ must be determined as a function of concentration and four constants must be determined to define A and B. Then, for each individual liquor, a total of three constants must be determined to define $\mathrm{C}$. Overall, this is a nine constant model. However, as has been pointed out, six are dependent only on species and type of pulping process. Once these are determined, it is conceivable that the constants for $\mathrm{C}$ can be defined for a specific liquor from measurements at five to six conditions.

Both models [equation (12.4.1.2) and equation (12.4.1.5)] can be used to estimate zero shear rate viscosity to within $\pm 20 \%$ or better. When the model given by equation (12.4.1.5) is used with specific data for $T_{G}$ and with adjustable values for $a_{2}$ and $b_{2}$ in equation (12.4.1.8). Viscosity can be estimated to within $\pm 5 \%$ for the liquor.

In summary, the empirical model [equation (12.4.1.2)] is more practical, less time consuming, and easier to use for correlation for a single liquor. The fundamental model [equation (12.4.1.5)] is undoubtedly better for developing a generalized correlation for a family of liquors 
originating from one species and a given pulping process. However, it would still require generalized correlation of three constants to define $\mathrm{C}$ in equation (12.1.4.5).

A further study of zero shear rate viscosity at high solids concentrations was conducted with the liquors derived from the circulation digester pulping experiment to try to determine the effects of different characteristics of the liquor solids on zero shear rate viscosity. Effects examined were degree of delignification, $\mathrm{H}$-factor, lignin concentration and molecular weight, sodium, chloride, and carbonate concentrations, organic/inorganic ratio, and $\mathrm{pH}$ (measured at about $10 \%$ solids). The results of this work have been published in: Zaman, A.A. and A.L. Fricke, "Effect of Pulping Conditions and Black Liquor Composition on Newtonian Viscosity of High Solids Kraft Black Liquors," I\&EC Research, 35(2), 590-597 (1996), which is included as part of this report. reprint removed.

There has been other recent work reported on aspects of compositional effects on viscosity. These include work by Soderhjelm et al. (1992), Soderhjelm and Sagfors (1992), Tiu et al. (1993), and Li (1991). In general, these works qualitatively show polysaccharides (if present) can increase viscosity rapidly with increasing solids concentration and that viscosity is affected by degree of delignification, lignin molecular weight and concentration, is higher for liquors from high yield pulping at low sulfidity, and is affected by carbonate concentration.

The Newtonian viscosities of 25 different liquors were determined as a function of solids and temperature at high solids concentrations from 50 to $85 \%$ solids and 40 to $140^{\circ} \mathrm{C}$ using a minimum of data for each liquor and correlating data for each liquor using equation (12.4.1.5). The pulping conditions, cook code number, H-factor, Kappa number, lignin concentration, and molecular weight determined by HTHPLC using polysaccharide standards are given in Table 1 of the publication. Other analyses are given elsewhere in the report and can be determined by comparing pulping conditions. Examples of the results of the correlations are given in the publication. Figures 1 and 2 demonstrate typical behavior for the effect of solids concentration at different temperatures for two distinctly different liquors. It is obvious that zero shear rate viscosity in the region of 55 to $80 \%$ solids concentration is a linear function of solids at constant 
temperature over a wide temperature range. As can be seen, zero shear rate viscosity varies about 1.5 orders of magnitude at $120^{\circ} \mathrm{C}$ for an increase in solids concentration from 55 to $80 \%$ ! Figure 3 in the publication illustrates the range of correlations for the different Slash Pine black liquors. At $80 \%$ solids concentration and $120^{\circ} \mathrm{C}\left[(\mathrm{S} / \mathrm{S}+1) \times \frac{1}{\mathrm{~T}}=1.13 \times 10^{-3}\right]$, viscosities can range from 0.95 to $13 \mathrm{~Pa}-\mathrm{sec}(950$ to $13,000 \mathrm{cp}$ ). Obviously, variations in liquors have significant effects on zero shear rate viscosity.

For comparison of effects, zero shear rate viscosities were estimated from the correlations for each liquor at. $80 \%$ solids and $120^{\circ} \mathrm{C}$. The effects of various factors were evaluated from these estimates. Most of the responses are quite complex. Details are given in the publication.

In general, viscosity was always a maximum at intermediate Kappa numbers. The location of the maxima varies with effective alkali and sulfidity. At fixed sulfidity, viscosity decreases with effective alkali. At low Kappa number, viscosity decreases with sulfidity at constant effective alkali. At high Kappa number, it increases with increased sulfidity at constant effective alkali. This, in general, agrees with observations of the effects of pulping conditions on lignin molecular weight and concentration.

Variations with $\mathrm{H}$-factor were examined. Figure 5 in the publication shows the result. At high effective alkali and sulfidity, viscosity decreases rapidly with $\mathrm{H}$-factor, but increases at low effective alkali and high sulfidity. At low sulfidity, viscosity is a maximum at intermediate Kappa numbers. Explanations for this behavior are given in the publication.

In general, viscosity was always a maximum at intermediate Kappa numbers. The location of the maxima varies with effective alkali and sulfidity. At fixed sulfidity, viscosity decreases with effective alkali. At low Kappa number, viscosity decreases with sulfidity at constant effective alkali. At high Kappa number, it increases with increased sulfidity at constant effective alkali. This, in general, agrees with observations of the effects of pulping conditions on lignin molecular weight and concentration.

Variations with $\mathrm{H}$-factor were examined. Figure 5 in the publication shows the result. At high effective alkali and sulfidity, viscosity decreases rapidly with $\mathrm{H}$-factor, but increases at low 
effective alkali and high sulfidity. At low sulfidity, viscosity is a maximum at intermediate Kappa numbers. Explanations for this behavior are given in the publication.

Liquor compositional factors were also examined. Liquor viscosity always increased monotonically with lignin concentration and lignin molecular weight, as expected, but the rate of increase at fixed sulfidity and effective alkali varied from combination to combination of the variables. Reasons for the differences are discussed in the publication.

The influences of organic/inorganic ratio, sodium, chloride, sulfite, and carbonate ions, and $\mathrm{pH}$ were examined. Responses are complex, but all of these are shown to affect viscosity. Sodium ion concentration always decreases viscosity, usually substantially. Although the concentration range is very limited, viscosity generally decreases with increasing chloride ion concentration. The response for sulfite ion concentration is complex and the concentration range is limited, but viscosity generally increases with increasing sulfite ion concentration. Carbonates appear to decrease viscosity, except at low pulping chemical levels. Generally, viscosity decreases with increasing $\mathrm{pH}$ and decreases dramatically with increasing $\mathrm{pH}$ at high levels of cooking chemicals.

Obviously, even zero shear rate viscosity behavior at high solids concentrations is extremely complex. We have been successful in developing data reduction correlations, one of which is soundly based on polymer theory and practice, that can be used to correlate data for a liquor over more than six orders of magnitude. We have used these to reduce viscosity data for a system of liquors for which pulping conditions and solids composition are known. Using calculated values at fixed conditions for each liquor, we have examined the effects of a number of pulping responses and solids composition factors. These responses are in general agreement with other work and with our other analyses. However, the complexity of the overall response is so great that we have been unable to develop the same types of generalized correlations that have been developed for other properties. 


\subsubsection{Non-Newtonian Viscosity}

Kim (1980, 1981), Wight (1985), Stevens (1987), and Fricke $(1985,1987)$ had previously shown that superposition principles developed for polymers can be applied successfully to black liquors at constant solids composition. This procedure is applied to normalized viscosity $\left(\eta / \eta_{0}\right)$ to superimpose data at different temperatures according to:

$$
\log \left[\eta / \eta_{0}\right]=\sum_{i=0}^{n} a_{i}\left[\log a_{T} \dot{\gamma}\right]^{i}
$$

where:

$$
\begin{aligned}
& \eta=\text { Viscosity } \\
& \eta_{0}=\text { Zero shear rate viscosity at the same temperature } \\
& \dot{\gamma} \text { Shear rate } \\
& a_{T}=\text { Shift factor }=f(T, \rho) \\
& T=\text { Temperature } \\
& \rho=\text { Density } \\
& a_{i}=\text { Constants }
\end{aligned}
$$

and the shift factor is defined as:

$$
a_{T}=\frac{\eta_{0} T^{0} \rho^{\circ}}{\eta_{0}^{\circ} T \rho}
$$

where:

$\mathrm{T}_{0}=$ Reference temperature

$\eta_{0}^{\circ}, \rho^{\circ}=$ Zero shear rate viscosity and density at the reference temperature 
For polymer melts, $T_{0}$ is a constant and $\rho^{\circ} \approx \rho$. With these assumptions, the shift factor reduces to:

$$
\mathrm{a}_{\mathrm{T}}=\frac{\eta_{\mathrm{o}} \mathrm{T}^{\mathrm{o}}}{\eta_{\mathrm{o}}^{0} \mathrm{~T}}
$$

This has been applied successfully to experimental and mill liquors. As described in the publication entitled: "Viscosity of Black Liquors up to $130^{\circ} \mathrm{C}$ and $84 \%$ Solids" that is included in section 12.2, the shift factor, $\mathrm{a}_{\mathrm{T}}$, is a non-linear function of temperature and varies with solids concentration. Examples of the success of temperature superposition for a liquor at constant solids concentration are given in the publication (Figures 24 and 25). The shift factor is different for each solids concentration. Typical results are shown in Figure 26 of the publication. Stevens (1987) and Fricke (1987) proposed that curves that had been superimposed with respect to temperature at constant solids could be superimposed by using a shift factor for solids. This was done successfully. We have used this procedure for experimental and mill liquors successfully. Examples for a mill and an experimental liquor are shown in Figures 27 and 28 of the publication. In these cases, all normalized viscosity data for a liquor are superimposed to one curve. To calculate a viscosity at a particular set of conditions ( $T, \dot{\gamma}, \%$ solids), the process is reversed as explained in the publication. For black liquors, three constant polynomials are necessary for the shift factors as:

$$
a_{t}=A+B / T+C / T^{2}
$$

and

$$
a_{s}=a+b / S+c / s^{2}
$$


where:

$\mathrm{a}_{\mathrm{T}}=$ Temperature shift factor

as $=$ Solids concentration shift factor

$\mathrm{T}=$ Absolute temperature

$\mathrm{S}=$ solids mass fraction

This leads to:

$$
\log \left[\eta / \eta_{0}\right]=\sum_{i=0}^{n} a_{i}\left[\log \left(a_{T} a_{s} \dot{\gamma}\right)\right]^{i}
$$

as the final correlating equation with $\mathrm{n}=2$ (three constants).

A number of models have been used to relate viscosity to shear rate for pseudoplastic (shear thinning) fluids. The simplest is the so called Power Law model which is:

$$
\eta=m \dot{\gamma}^{(n-1)}
$$

where:

$$
\begin{aligned}
& \eta=\text { Viscosity } \\
& \dot{\gamma}=\text { Shear rate } \\
& \mathrm{m}, \mathrm{n}=\text { Constants }
\end{aligned}
$$

and $m$ is a measure of the consistency of the fluid and $n$ is a measure of the degree of nonNewtonian behavior. This was used by $\operatorname{Kim}(1980,1981)$ for black liquors at higher shear rates. It is useful only in describing the linear region of a plot of $\log \eta$ versus $\log \dot{\gamma}$. 
Other models have been proposed as generalized power law models capable of fitting the shape of viscosity-shear rate curves over the entire range of shear rate. Two models that have been successfully used are the Cross (1965) model and the Carreau-Yaseda (1972, 1979) model. The Cross model is expressed as:

$$
\frac{\eta-\eta_{\infty}}{\eta_{0}-\eta_{\infty}}=\frac{1}{\left[1+(\lambda \dot{\gamma})^{\mathrm{m}}\right]}
$$

where:

$$
\begin{aligned}
& \eta=\text { Viscosity } \\
& \eta_{0}=\text { Zero shear rate viscosity } \\
& \eta_{\infty}=\text { Asymptotic value of viscosity at very high shear rates } \\
& \dot{\gamma}=\text { Shear rate } \\
& \lambda=\text { Parameter with dimension of time } \\
& \mathrm{m}=\text { Constant related to the flow index }
\end{aligned}
$$

If $\eta_{\infty}$ is assumed to be (or is) negligibly small, this reduces to:

$$
\frac{\eta}{\eta_{\mathrm{o}}}=\frac{1}{\left[1+(\lambda \dot{\gamma})^{\mathrm{m}}\right]}
$$

The Carreau-Yaseda model is expressed as:

$$
\frac{\eta-\eta_{\infty}}{\eta_{0}-\eta_{\infty}}=\left[1+(\lambda \dot{\gamma})^{a}\right]^{\frac{n-1}{a}}
$$

which reduces to: 


$$
\eta_{0}=\left[1+(\lambda \dot{\gamma})^{2}\right]^{\frac{n-1}{2}}
$$

when $\eta_{\infty}$ is negligibly small. This is a three constant model while the Cross model is a two constant model; however, the constants are more closely identified with characteristics of the curve. $1 / \lambda$ is equal to the shear rate at which viscosity begins to decrease (the limit of the zero shear rate viscosity region) and (n-1) is the slope of the power law region. The constant a permits adjustment of the breadth of the region between zero shear rate viscosity and power law viscosity regions. This flexibility can be sacrificed by setting $a=2$ to reduce the model to a two constant model, and this is successful in many cases. One should note that $\eta_{0}$ must also be determined.

These models can be applied to the universal curves developed by superposition as well as to individual curves of reduced viscosity versus shear rate. These models have been applied to data for black liquors in this program and results of the work have been published in: Zaman, A.A. and A.L. Fricke, "Steady Shear Flow Properties of High Solids Softwood Kraft Black Liquors: Effects of Temperature, Solids Concentration, Lignin Molecular Weight, and Shear Rate," Chem. Eng. Comm., 139, 201-221 (1995), which is included as part of this report, and in that summary publication: Zaman, A.A. and A.L. Fricke, "Kraft Black Liquor Rheological Behavior with Respect to Solids Concentration, Temperature, and Shear Rate," AIChE Symp. Series, Advances in Pulp and Papermaking, 91(307), 162-171 (1995) that is also included as part of this report. reprints temored.

All three models for pseudoplastic behavior were applied successfully to reduced viscosity data over appropriate ranges of shear rate for black liquors derived from the circulation digester pulping experiments. Examples of results for three selected liquors are given in detail in the publication. Zero shear rate viscosity data were correlated successfully by both the empirical and the combined activation energy-free volume models discussed earlier. Letting $\eta_{\mathrm{o}}$ be an adjustable constant, we also correlated all of the viscosity data for a number of liquors. The values of $\eta_{0}$ determined directly from the Cross and Carreau-yaseda models were in very close agreement with 
values of $\eta_{0}$ for these liquors that were determined by using the models for $\eta_{0}$ discussed earlier. This demonstrates that the Newtonian behavior at conditions of low shear rate and the nonNewtonian behavior at high shear rate can be correlated separately and the results can then be combined.

The cumbersome two step superposition process (superimpose curves at constant solids concentration and different temperatures to obtain curves universal in temperature, then superimpose universal temperature curves at different solids concentrations to obtain one curve universal in temperature and solids concentrations with two concomitant shifting functions) originally developed by Stevens $(1987)$ and reported by Fricke $(1990,1993)$ was shown to apply to these liquors, but a simpler and less empirical superposition method was sought.

We are essentially dealing with a polymer-diluent system at high solids concentrations. Williams et al. (1955) had shown that superposition could incorporate the effects of concentration if the reference temperature, $T_{0}$, in the shift factor relation:

$$
a_{T}=\frac{\eta_{0} T_{0} \rho_{0}}{\eta_{0}^{0} T \rho}
$$

were permitted to vary with concentration. Theoretically, $T_{0}$ should be the glass transition temperature. However, if $T_{G}$ is used for $T_{0}$, a value for zero shear rate viscosity at that temperature, $\eta_{0}^{\circ}$, must be determined. This is virtually impossible. To remedy this, Williams proposed setting To at a value that is a constant difference above the $T_{G}$ and denoted this temperature as TS. Thus:

$$
\mathrm{T}_{\mathrm{s}}=\mathrm{T}_{\mathrm{G}}+\mathrm{d}
$$

where:

$\mathrm{T}_{S}=$ Reference temperature for superposition 
$\mathrm{T}_{\mathrm{G}}=$ Glass transition temperature, $\left[\mathrm{T}_{\mathrm{G}}=\mathrm{f}(\right.$ concentration $\left.)\right]$

$\mathrm{d}=$ Constant

Williams found, that if $\mathrm{T}_{\mathrm{S}}$ were set such that:

\section{$1.3 \mathrm{~T}_{\mathrm{G}} \leq \mathrm{T}_{\mathrm{S}} \leq 1.4 \mathrm{~T}_{\mathrm{G}}$}

and if $\mathrm{T}_{\mathrm{G}}$ were determined as a function of concentration, viscosity data for a concentrated polymer solution could be superimposed in one step to yield a universal curve for reduced viscosity versus shear rate.

A given liquor is a concentrated polymer solution at high solids concentration and $T_{G}$ can be determined as a function of solids concentration for the liquor. Using the approach of Williams et al., we developed universal curves successfully for a number of liquors by a one-step shifting process that combines the effects of temperature and solids concentration. In agreement with Williams, we found $1.3 \mathrm{~T}_{\mathrm{G}} \leq \mathrm{T}_{\mathrm{S}} \leq 1.4 \mathrm{~T}_{\mathrm{G}}$ to be the most appropriate choice for the reference temperature. $I t$ is worth noting that the factor added to $T_{G}$ to define $T_{S}$ only varied from about 75 to about $85^{\circ} \mathrm{K}$. At $60 \%$ solids concentration, $\mathrm{T}_{\mathrm{G}}$ ranges from about $205^{\circ} \mathrm{K}$ to $218^{\circ} \mathrm{K}$ for liquors from pulping the same species at different conditions. The average of the added factor $\left(80^{\circ} \mathrm{K}\right)$ would define $\mathrm{T}_{\mathrm{S}}$ within about $\pm 1.7 \%$ at worst.

Using $T_{S}$, equation (12.4.2.11) is redefined as:

$$
a_{S T}=\frac{\eta_{o} T_{S} \rho_{S}}{\eta_{S}^{\circ} T \rho}
$$

where we have denoted the shift factor as asT to indicate that it is derived from a one step superposition for temperature and solids concentration. Although extensive density data are available for the liquors used in this program, one cannot expect extensive density data to be available for any liquor of interest. Also, black liquor viscosity has been shown to vary an average 
of four orders of magnitude for the temperature ranges studied at high solids concentrations and by an average of about three orders of magnitude with concentration changes from about 55 to $85 \%$ solids. While density of black liquor does vary, it varies by only a fraction of $\rho s$. Thus, little accuracy is sacrificed by assuming $\rho \approx \rho_{\mathrm{s}}$. Equation (12.4.2.13) then becomes:

$$
\mathrm{a}_{\mathrm{ST}}=\frac{\eta_{0} \mathrm{~T}_{S}}{\eta_{S}^{\circ} \mathrm{T}}
$$

Typical results for applying equation (12.4.2.14) to different black liquors are shown in Figures 9-12 of the Chem. Eng. Comm. publication. Obviously, the one step superposition process can be used with black liquors.

Extensive analysis by many researchers of the shift factor results for concentrated polymer solutions have shown that the shift factor equation can be generalized in terms of glass transition and free volume behavior. The result is the Williams-Landau-Ferry (WLF) relation that can be expressed in the form:

$$
\ln \left[\mathrm{a}_{\mathrm{ST}}\right]=\frac{-\mathrm{C}_{1}\left(\mathrm{~T}-\mathrm{T}_{\mathrm{S}}\right)}{\left(\mathrm{C}_{2}+\mathrm{T}-\mathrm{T}_{\mathrm{S}}\right)}
$$

where $C_{1}$ is affected by the specific volume and free volume at $T_{G}$ and $C_{2}$ is affected by the thermal expansion effects on free volume. $C_{1}$ and $C_{2}$ values of 8.86 and 101.6 have been reported for many polymer solutions.

Equation (12.4.2.15) was applied to the shift factors determined from superposition of reduced viscosity curves for the black liquors and values of $C_{1}$ and $C_{2}$ determined. These values are given for four liquors with very different characteristics in the first publication included in this subsection of the report. A typical test of the fit of equation (12.4.2.15) is shown in Figure 13 of the publication. Values determined for $C_{1}$ for black liquors are about four times the value of $C_{1}$ 
determined for concentrated synthetic polymer solutions while values for $\mathrm{C}_{2}$ are in closer agreement.

$\mathrm{C}_{1}$ and $\mathrm{C}_{2}$ were set at values of 26.77 and $104.16^{\circ} \mathrm{K}$ and the data for the liquors reevaluated by allowing $\mathrm{T}_{S}$ to be adjusted for each liquor. The result is a general shift factor with one adjustable parameter, $\mathrm{T}_{\mathrm{S}}$, that correlates the data for a number of liquors of the same species that can be used to estimate the reduced viscosity of a liquor for any concentration, temperature, and shear rate within about $\pm 20 \%$. Application of these methods can greatly reduce the quantity of experimental effort necessary to completely describe viscosity behavior of a liquor at high solids concentration. The second publication included in this subsection of the report, AIChE Symposium Series Advances in Pulp and Papermaking, presents a good summary of our treatments of black liquor rheology.

$$
\text { reprint removed, }
$$

\subsubsection{Viscoelasticity}

Firing at very high solids could be affected by viscoelasticity. Previously, only two prior studies (Wight and Co, 1982, Wight (1985) refer specifically to linear viscoelasticity functions determined for two softwood kraft black liquors. They determined, based on droplet formation studies with viscoelastic fluids, that viscoelastic effects should not affect droplet formation at firing temperatures for liquors with solids concentrations below $75 \%$.

We studied linear viscoelasticity behavior for three liquors derived from the circulation digester pulping experiment. These liquors were chosen as having different steady shear behavior at high solids concentration. The results have been published in: Zaman, A.A. and A.L. Fricke, "Viscoelastic Properties of High Solids Softwood Kraft Black Liquors," I\&EC Research, 34(1), 382-391 (1995) that is included as part of this report. Full details for measurement are given in the

publication and by zaman (1992). reprint removed.
Direct measurements at firing conditions cahnot be made, because the water in the liquor is very volatile at these temperatures. Instead, measurements were made at temperatures below $85^{\circ} \mathrm{C}$ for solids concentrations ranging from 61 to $81 \%$ solids. Oscillatory methods were used with a 
parallel plate geometry, and the maximum strain amplitude was set so that linear viscoelastic response was obtained.

Models for viscoelastic fluids were successfully applied to the data for three liquors. Results are given in the publication. Also, frequency-temperature superposition based on molecular theories was successful in superimposing curves for different temperatures and constant solids concentration to yield one curve. The curve as developed can be used to estimate the storage modulus and the dynamic viscosity at higher temperatures by extrapolation.

A combined shift factor for one step superposition of all curves for one liquor that had been applied successfully for non-Newtonian steady shear viscosity was not successful, but a two step process involving superposition for temperature followed by superposition for solids concentration that is analogous to the method used successfully for non-Newtonian steady shear viscosity was successfully applied to the data. Although empirical, it permits accurate interpolation and extrapolation to high temperatures and frequencies (shear rates). Details and results are presented in the publication.

Often, there is agreement between the values of viscosity determined by steady shear and oscillatory shear methods. This is the Cox-Merz principle (Cox and Merz, 1958). This principle was tested for the liquors studied. It was found to be applicable for all three liquors at low shear rates $\left(1 \mathrm{sec}^{-1}\right)$ and low frequencies $(1 \mathrm{rad} / \mathrm{sec})$ for all temperatures between 40 and $85^{\circ} \mathrm{C}$ and applicable over a very wide shear rate or frequency range for all three liquors above about $70^{\circ} \mathrm{C}$. This confirms that the results can be used to predict steady shear data at higher shear rates, and that oscillatory methods can be used to determine zero shear rate viscosities for steady shear.

Following the methods described by Wight (1985) and Fricke (1987), we estimated the relative importance of energy storage to viscous dissipation on recovery furnace operation (droplet formation) at $120^{\circ} \mathrm{C}$. On the basis of work done with these liquors, it is clear that viscoelastic effects are too small to affect droplet formation at $120^{\circ} \mathrm{C}$ and up to at least $81 \%$ solids for a Southern Softwood liquor with present firing techniques. 
Since a second order transaction is known to occur at about $85 \%$ solids that can be expected to so drastically change the liquor behavior that present firing techniques will be very unlikely to work, there was no reason to continue viscoelastic studies. 


\subsection{OVERVIEW AND GENERAL SUMMARY}

This program and its predecessor, "Physical Properties of Kraft Black Liquor," that was conducted at the University of Maine and the University of Florida have led to a fundamentally sound rationalization of black liquor behavior over the entire range of solids concentration. An overview of the developments and advances made in the course of research was prepared and presented at the International Energy Conference held in Houston, Texas in 1994. The paper: Fricke, A.L. and A.A. Zaman, "Black Liquor Properties," International Energy Conference, Houston, Texas, (1994), is included as part of this report. The basic principles for research studies, the effects of phase regimes on properties, generalized data reduction methods developed, summaries of experimental methods and ranges of applications and examples of applications to specific liquors are all presented in this publication. Developments have been reported in a timely fashion in four interim reports to the Department of Energy, in many papers presented at international and national technical meetings, and in reviewed publications in a wide range of research journals. Twenty-five of the latter are included in toto in this report. For these, written copyright releases have been obtained for inclusion in this report.

Extensive kraft pulping experiments with one species have been conducted, with and without control of uniformity of source or time of harvesting of the species. It has been shown that the effect of lack of control of source or harvest time for the softwood species used introduces an estimated 4-5\% variation in Kappa number and yield. Correlations relating Kappa number and yield to pulping conditions for Slash Pine were developed and reported. Black liquors produced in the pulping experiments were used as the basis for detailed analysis, composition characterization, and properties studies.

Liquor analyses were performed that were used to quantitatively identify more than $80 \%$ of the constituents of black liquors. In addition, $\mathrm{pH}$ at about $10 \%$ solids, sulfated ash, the fraction of lignin that could be isolated by acid precipitation and purification, residual active alkali, and organic/inorganic ratio were determined for each liquor. The molecular weight and molecular 
weight distribution of acid precipitated liquors, to be discussed later, were also determined. All of these results are reported for the liquors used in this program for properties studies.

Attempts to correlate the concentration of many minor constituents of the liquors with pulping conditions were unsuccessful. However, these variations in the individual constituents proved not to have strong effects on properties. In general, solids concentration, lignin concentration, organic/inorganic ratio were always important. In addition, organics other than lignin were sometimes important. For rheology, the effects of $\mathrm{pH}$, carbonate concentration, sulfite concentration, and residual active alkali were also important as well as lignin concentration and lignin molecular weight.

Extensive studies of lignin concentration and characterization of acid precipitated high molecular weight lignins were conducted. Factors that could affect analysis of lignin concentration in black liquor were quantitatively evaluated and the method developed was used to determine lignin concentration of all liquors. Results for the Slash Pine liquors were successfully correlated with pulping conditions.

Molecular weight and molecular weight studies of lignins in black liquor were a significant part of this program. Methods for determining number average molecular weights with corrections for impurities by VPO were refined and used in this program. Correct methods for determining weight average molecular weight were refined and determinations made in different solvents were used to demonstrate conclusively that true weight average molecular weights were determined for lignins. Methods for size exclusion chromatography to determine molecular weights and molecular weight distributions were explored extensively, and a reliable and reproducible method was developed. Disagreement between true weight average molecular weights determined by light scattering and weight average molecular weights determined from chromatographs using various monodisperse polymer standards led to studies of intrinsic viscosity as a possible means of developing a universal standard calibration. These intrinsic viscosity studies demonstrated that lignins are nearly spherical and not highly solvated in solution; therefore, intrinsic viscosity is not a 
good candidate for characterization of molecular weight nor is a universal calibration for size exclusion likely to be developed for lignins.

A calibration for lignins for a specific system was developed by recalculation of chromatograms by moment resolution. Molecular weights determined by size exclusion chromatography were then in agreement with molecular weights determined by VPO and by light scattering. This is the first time that moment resolution has been used successfully to calibrate a size exclusion system for determination of molecular weights. Results showed that distributions of lignin molecular weights of lignins produced by pulping Slash Pine at different conditions were highly skewed and usually bimodal; however, the presence and relative position of the higher molecular weight mode varied markedly with pulping conditions.

Number average molecular weights of lignins produced by pulping Slash Pine were successfully correlated with pulping conditions with about the same precision as for correlation with yield and Kappa number. Weight average molecular weight was correlated with pulping conditions, but the correlation was not as good as that for number average molecular weight. This was puzzling until final work was completed with size exclusion research, because light scattering results were more precise that VPO measurements. The reasons for this became clearer when final size exclusion results were available. Different lignin solubilizing and degradation reactions occur in pulping, and the effects of these different reactions vary as pulping conditions vary. This leads to variations in molecular weight distributions and complex responses of weight average molecular weight to pulping conditions. Four molecular weight averages, number average, weight average, $\mathrm{z}$-average, and $\mathrm{z}+1$ - average molecular weights were determined for acid precipitated lignins from black liquors produced by pulping Slash Pine at 25 different pulping conditions.

The behavior of black liquors was rationalized in terms of solution characteristics from determination of phase transition behavior and from application of methods to identify first and second order thermodynamic transitions. At low solids concentrations, black liquors behave as dilute polymer solutions, and colligative and corresponding states methods can be used to reduce and correlate data. At very high solids concentrations, black liquors behave like plasticized glassy 
polymers. In this condition, it is extremely unlikely that black liquors will be processed successfully with present recovery technology.

All research results were found to agree with this rationalization of black liquor behavior. Abrupt changes in properties responses confirm this interpretation, and results of thermal studies were proven to be thermodynamically consistent. All liquors examined behaved as expected, based on this rationalization. Therefore, methods of data reduction can be expected to be generally applicable for all black liquors, and trends determined from quantitative correlations with respect to pulping conditions for Slash Pine pulping can be expected for pulping other species and so for other types of pulping. These similarities are discussed in the report where appropriate.

Thermal properties were studied extensively. In a number of cases, the first experimental measurements of specific thermal properties were made. Accurate enthalpy measurements were reported for the first time, and thermodynamic consistency of our vapor-liquid equilibria and enthalpic data was demonstrated.

Heats of combustion were determined for all liquors. Correlations were developed relating heat of combustion of the Slash Pine liquors to pulp yield, pulping conditions, and liquor solids composition. Very simple non-linear correlations were developed relating heat of combustion to pulping conditions and to liquor solids composition. Surprisingly, heat of combustion does not correlate as an additive function of solids constituents as has generally been assumed.

Density and thermal expansion measurements were made over the entire range of solids composition. These measurements provided invaluable insight into second order thermodynamic transitions, as well as providing density information. Methods for data reduction for density data at low solids concentrations were applied successfully to all black liquors. The densities of the Slash Pine black liquors were correlated with respect to pulping conditions successfully. Applications and limitations of the model developed in this program are discussed.

Complete heat capacity data were taken for all Slash Pine black liquors, and these data were reduced by using the excess heat capacity methods developed in earlier work. A more simplified data reduction was also developed and applied to these data. The reduced correlation coefficients 
were then correlated with pulping conditions successfully to yield a quantitative model for prediction of heat capacity of black liquors from the pulping conditions.

A method for measuring the heat of dilution of black liquors accurately was developed, and the first heats of dilution with concentration data for black liquors were taken. These measurements, together with the heat capacity measurements discussed earlier, were used to develop enthalpy-concentration relations and the first true enthalpy-concentration charts for black liquor.

Heats of dilution were determined for all of the Slash Pine black liquors. A satisfactory correlating function for these data was determined and applied to data for all Slash Pine black liquors. The results were correlated with pulping conditions successfully. Therefore, an overall correlation relating enthalpy-concentration to pulping conditions for Slash Pine has been developed successfully.

Vapor-liquid equilibria received extensive study. A precise and accurate Rayleigh still was developed and used to determine vapor pressure equilibria and to determine boiling point at constant pressure as a function of solids concentration at concentrations up to $85 \%$ solids in many cases. The precision and accuracy of the still were proven from experiments with solutions of known properties. Data for a black liquor were shown to be thermodynamically consistent with enthalpic data, considering black liquor to be a binary of water and non-volatile black liquor solids. Of course, vapor-liquid equilibria varied with pulping conditions. The still performance proved to be sufficiently sensitive to indicate occurrences of solid precipitation from a liquor during concentration. No solids precipitation was evident for the Slash Pine liquors. When it occurred in kraft liquors from mills, precipitation occurred in the $47-58 \%$ solids region.

Data reduction methods based on molality that were used by others to reduce boiling point elevation data for black liquors at concentrations up to $50 \%$ solids were modified and applied to data taken in this program for solids concentrations up to $85 \%$ solids by dividing the concentration range into two segments and fitting a straight line to each segment. The division between ranges occurred in the same region where a second order thermodynamic transition was found to occur 
from density data. The upper region exhibited a less rapid increase in boiling point elevation with increase in concentration. This behavior is in agreement with expectations from consideration that a maximum in heat capacity occurs in this region, that liquors behave increasingly as nonNewtonian fluids in this region, and that heat of dilution increases rapidly in this region.

The three constants developed by data reduction for the boiling point elevation of the Slash Pine black liquors were correlated with respect to pulping conditions successfully to yield a predictive model relating boiling point elevation of Slash Pine black liquors at all concentrations to pulping conditions. In general, the behavior of mill liquors from pulping different species by different pulping processes is similar to the behavior for Slash Pine liquors, if no solids precipitation occurs.

Rheological behavior proved to be very complex and received a great deal of attention. Kraft black liquors always behave as Newtonian fluids at solids concentrations below $50 \%$, as is expected for dilute polymer solutions. Data reduction models based upon colligative properties and corresponding states and models based upon activation energy and free volume theories were both successfully applied. Although less fundamental in nature, the model based upon colligative properties proved to be simpler to relate to pulping conditions and liquor solids composition. Both linear and simpler non-linear correlations were developed to relate low solids concentration viscosity of Slash Pine black liquors to pulping conditions and liquor solids composition. Low concentration viscosity was found to depend upon lignin concentration, lignin weight average of molecular weight, inorganic concentration, and sodium concentration. The influence of Kappa number, $\mathrm{H}$-factor, yield, organics other than lignin, carbonates, other inorganics, and $\mathrm{pH}$ at low solids concentrations on viscosity were also explored and are reported.

Results for high solids concentrations were divided into three studies. Newtonian behavior at low shear rates, non-Newtonian viscous behavior, and viscoelastic behavior. Rheological behavior of black liquors at concentrations greater than $50 \%$ is extremely complex. Complete correlation was possible only for Newtonian behavior; however, this correlation is adequate for description of liquor behavior at processing conditions for most liquors up to $75 \%$ solids. 
An empirical series model with a reducing function of $[(\mathrm{S} / \mathrm{S}+1) 1 / \mathrm{T}]$ was always successful in reducing data for Newtonian viscosity in this region, and the three constants derived from the reducing function equation behave in an orderly fashion with respect to changes in pulping conditions. This data reduction method is recommended for defining the behavior of a single liquor.

A fundamental model, based upon a combination of activation energy and free volume theories, was applied successfully to all Slash Pine liquor data. This model involves four constants that are functions of concentration or solids composition. Two of these functions for "constants" were found to be universal for all liquors derived from the same species when pulped in the same process. The third was found to vary slightly with solids composition, but was defined by the glass transition depression resulting from decrease in solids concentration, as predicted by theory. The fourth reflected the effects of solids composition as expected. If the universal functions were to be previously known and the glass transition depression known, the last functional relation for the last "constant" could be determined from an estimated five or six individual measurements. The completed model could then be used to predict Newtonian viscosity of the liquor at all temperatures and concentrations.

Either model, if used to develop a total model to estimate Newtonian viscosity at high solids concentrations of liquors derived from a single species would require correlation of three constants with respect to pulping conditions. This has not been done. However, the effects of pulping conditions, Kappa number, H-factor, lignin concentration, lignin molecular weight, organics/inorganic ratio, sodium, chloride, sulfite, and carbonate concentrations, and liquor $\mathrm{pH}$ have been quantitatively examined.

Non-Newtonian behavior has been extensively investigated. Models developed for pseudoplastic behavior of polymer melts and concentrated polymer solutions have been applied to black liquor data successfully. The models and methods used are described. Superposition principles and theories developed for polymers and polymer solutions were successfully applied to 
data for black liquors. A generalized superposition function was developed for black liquors and shown to apply to Slash Pine liquors. This development is thoroughly described in this report.

Viscoelastic measurements were made with selected liquors to define the solid concentration where this behavior would be important in liquor processing. Studies were made experimentally at temperatures below $85^{\circ} \mathrm{C}$ by oscillatory shear experiments. Results showed that data reduction and superposition methods developed for polymer melts applied equally well to black liquors at high solids concentrations. Results also showed that the Cox-Merz principle applied to these liquors at temperatures above $70^{\circ} \mathrm{C}$. This principle states that viscosity determined in oscillatory experiments and viscosity determined in steady shear experiments at a shear rate equal to the frequency are identical. This permitted us to estimate the relative importance of viscoelastic effects in steady shear from oscillatory data. Our results demonstrate that viscoelastic effects are insignificant at $120^{\circ} \mathrm{C}$ or above for Slash Pine black liquors at concentrations up to $85 \%$ solids. Since present process technology most likely cannot be used at higher concentrations because of the change in nature of the fluid, no further viscoelastic studies were made.

Overall, this has been a successful program, in our opinion, that has contributed significantly to the industry, even though all of the objectives in the original proposal were not accomplished. The most important development are general understanding of liquor behavior that is fundamentally sound and generally applicable, and development of methods for experimental determination of liquor properties and lignin characteristics. Generalized correlations have been developed for many quantities that vary with pulping conditions. Technology transfer has been actively pursued throughout the program. Four interim technical reports have been submitted to the Department of Energy, more than 25 reviewed research publications have appeared in research journals, more than 20 papers have been presented at international or national technical society meetings or at DOE review meetings, and numerous presentations and seminars have been conducted at industrial sites and at other universities. 


\subsection{TECHNOLOGY TRANSFER}

Technology transfer has been actively pursued throughout the course of this program. Five interim reports have been submitted to the US Department of Energy, four $\mathrm{PhD}$ theses available through the services of Dissertation Abstacts, and 29 reviewed research publications that are reportings of research findings having a direct bearing on black liquors have appeared in research journals. In addition, five ME reports are filed at the University of Florida.

The DOE reports, research publications, and titles of $\mathrm{PhD}$ theses concerning results from this program are:

1. Fricke, A. L., Physical Properties of Kraft Black Liquor: Summary Report-Phases I and II, DOE Report Nos. AC02-82CE50606 and FG02$85 \mathrm{CE} 40740$, University of Florida, Gainesville, FL and University of Maine, Orono, ME, 1987.

2. Fricke, A. L., A Comprehensive Program to Develop Correlations for the Physical Properties of Kraft Black Liquors-Interim Report No. 1, Doe Report No. DOE/CE/40740-T4, (DE 89016404), University of Florida, Gainesville, FL, 1989.

3. Fricke, A.L., A Comprehensive Program to Develop Correlations for Physical Properties of Kraft Black Liquors, Interim Report No. 2, DOE Report No. DOE/CE/40740-T7, (DE94014503), University of Florida, Gainesville, FL, 1990.

4. Fricke, A. L., A Comprehensive Program to Develop Correlations for Physical Properties of Kraft Black Liquors, Interim Report No. 3, DOE Report No. DOE/CE/40740-T8, (DE95005300), University of Florida, Gainesville, FL, 1993.

5. Fricke, A. L., A.A. Zaman, Mark O. Stoy, G. Wolfgang Schmidl, D.J. Dong, and B.Speck, A Comprehensive Program to Develop Correlations for Physical Properties of Kraft Black Liquors: Final Report-Part I, submitted to DOE, December, 1997.

6. Small, J.D., Jr. and A.L. Fricke, "A Dual Chamber Capillary Viscometer for Viscosity Measurements of Concentrated Polymer Solutions at Elevated Temperatures," J. Sci. Instru., 57(6), 1182-1184 (1986) .

7. Massee,M.A., E. Kiran, and A.L. Fricke, "A Thermodynamic Model of the Heat Capacity of Compositionally Complex Polymer Solutions: Kraft Black Liquor," Chem.Eng. Comm. 50, 81-91 (1987).

8. Dong, D.J., and Fricke, A.L., "UV-Visible Response of Kraft Lignin in Soft Wood Black Liquor," Materials Research Society Symposium Proceedings, 197, 77-86 (1991).

9. Schmidl,G.W.,D.J.Dong, and A.L. Fricke, "Molecular Weight and Molecular Weight Distribution of Kraft Lignins," Materials Research Society Symposium Proceedings, 197, 21-30, (1991).

10. Zaman,A.A., D.J.Dong, and A.L. Fricke, "Kraft Pulping of Slash Pine," $\underline{\text { AIChE }}$ 1991 Forest Products Symposium, 1991, 49-57 (1992). 
11. Zaman,A.A. and A.L. Fricke, "Viscosity of Black Liquor Up to $130^{\circ} \mathrm{C}$ and $84 \%$ Solids", AIChE 1991 Forest Products Symposium, 1991, 59-77 (1992).

12. Stoy,M.A., A.A. Zaman, and A.L. Fricke, "Vapor-Liquid Equilibria for Black Liquors,"1992 International Recovery Conference, 495-511 (1992).

13. Dong, D.J. and A. L. Fricke, "Investigation of Optical Effects of Lignin Solutions and Determination of $\mathrm{M}_{\mathrm{W}}$ of Kraft Lignin," J. Appl. Polymer Sci., $\underline{50}$, 1131-1140 (1993).

14. Stoy,M.A. and A.L. Fricke, Development of a Method for Measuring the Heat of Dilution of Kraft Black Liquor and Water," TAPPI Journal, 77(8), 169-174 (1994).

15. Stoy,M.A. and A.L. Fricke, "Enthalpy Concentration Relations for Black Liquor, "TAPPI Journal,77(9), 103-110 (1994).

16. Fricke,A.L. and A.A. Zaman, "Black Liquor Properties," International Industrial Energy Technology Conference, Houston, Texas (1994).

17. Zaman,A.A., M.O. Wight, and A.L. Fricke, "Density and Thermal Expansion of Black Liquors," TAPPI Journal,77(8), 175-181 (1994).

18. Zaman, A.A. and A.L. Fricke, "Correlations for Viscosity of Kraft Black Liquors at Low Solids Concentrations," AIChE Journal,40(1), 187-192 (1994).

19. Zaman,A.A. and A.L. Fricke, "Newtonian Viscosity of High Solids Kraft Black Liquors: Effects of Temperature and Solids Concentrations, " I\&EC

Research, 35(2),590-597 (1994).

20. Dong,D.J. and A.L. Fricke, "Intrinsic Viscosity and the Molecular Weight of Kraft Lignin," Polymer,36, 2075-2078 (1995).

21. Dong, D. J., and A. L. Fricke, "Effects of Pulping Conditions on the Composition of Black Liquor from Slash Pine," Holzforschuung. 50(1), 7584(1995).

22. Dong,D.J. and A.L. Fricke, "Effects of Multiple Pulping Variables on the Molecular Weight and Molecular Weight Distribution of Kraft Lignin," Journal of Wood Chemistry and Technology, 15(3), 369-393 (1995).

23. Zaman,A.A. and A.L. Fricke,"Effects of Pulping Conditions and Black Liquor Composition on the Heat of Combustion of Slash Pine Black Liquor," AIChE Syposium Series, Advances in Pulp and Papermaking,91(307), 154-159 (1995).

24. Zaman,A.A. and A.L. Fricke, "Viscosity of Softwood Kraft Black Liquors at Low Solids Concentrations: Effects of Solids Content, Degree of Delignification and Liquor Composition," Journal Pulp and Paper Sci.,21(4), J119-J126 (1995).

25. Zaman,A.A. and A.L. Fricke, Effects of Pulping Conditions and Black Liquor Composition on Viscosity of Softwood Kraft Black Liquors: Predictive Models," TAPPI Journal,78(10), 107-119 (1995).

26. Zaman,A.A. and A.L. Fricke, "Steady Shear Flow Properties of High Solids Softwood Kraft Black Liquors; Effects of Temperature, Solids Concentration, Lignin Molecular Weight, and Shear Rate," Chem. Eng. Comm.,139, 201-221 (1995). 
27. Zaman,A.A. and A.L. Fricke, "Kraft Black Liquor Rheological Behavior with Respect to Solids Concentration, Temperature, and Shear Rate," AIChE Symposium Series, Advances in Pulp and Papermaking,91(307),162-171 (1995).

28. Zaman,A.A. and A.L. Fricke, "Viscoelastic Properties of High Solids Softwood Kraft Black Liquors," I\&EC Research, 34(1), 382-391 (1995).

29. Dong, D. J. and A. L. Fricke, "Electrokinetic Study of Kraft Lignin", TAPPI Journal.79(7), 191-197 (1996).

30. Zaman,A.A. and A.L. Fricke, "Heat of Dilution and Enthalpy-Concentration Relations for Slash Pine Kraft Black Liquors," Chem. Eng. Comm.,155, 197216 (1996).

31. Zaman,A.A. and A.L. Fricke, "Effect of Pulping Conditions and Black Liquor Composition on Newtonian Viscosity of High Solids Kraft Black Liquors," I\&EC Research, 35 (2), 590-597 (1996).

32. Zaman,A.A., S.A. Tavares and A.L. Fricke, "Studies on the Heat Capacity of Slash Pine Kraft Black Liquors: Effects of Temperature and Solids Concentrations," Journal of Chemical and Engineering Data,41(2), 266-271 (1996).

33. Zaman,A.A., J.S. Deery, T.W. McNally and A.L. Fricke, "Effect of Pulping Variables on Density of Slash Pine Kraft Black Liquors: Predictive Models," TAPPI Journal, 80(9), 199-207 (1997).

34. Zaman,A.A., T.W.McNally and A.L. Fricke, "Vapor Pressure and Boiling Point Elevation of Slash Pine Black Liquors: Predictive Models with Statistical Approach," I\&EC Research, 39, 275-283 (1998).

35. Schmidl, G.W., "Molecular Weight Characterization and Rheology of Lignins for Carbon Fibers," PhD Thesis, University of Florida, Gainesville, FL (1992).

36. Stoy, M.A., "Dependence of the Enthalpy and Vapor Pressure of Kraft Black Liquor on Solids Content," PhD Thesis, University of Florida, Gainesville, FL (1992).

37. Dong, D.J., "Characterization of Kraft Lignin and Investigation of Pulping Effects on Pulp Yield, Lignin Molecular Mass, and Lignin Content of Black Liquor with a Central Composite Pulping Design," $\mathrm{PhD}$ Thesis, University of Florida, Gainesville, FL (1993).

38. Zaman, A.A., "An Investigation of the Rheological Properties of High Solids Kraft Black Liquors," PhD Thesis, University of Florida, Gainesville, FL (1993).

Technology transfer has also been accomplished by presentations at international and national meetings of research and technical societies, and by numerous seminars given at other universities and at industrial sites. The presentations at international and national meetings of research and technical societies on research done in this program are:

1. "Effect of Pulping Conditions on Molecular Weight and Concentration of High Molecular Weight Lignin in Black Liquor from Kraft Pulping of Slash Pine," ACS National Meeting, Denver, CO, (April, 1987). 
2. "Black Liquor Physical Properties," API Research Meeting, New Orleans, LA (November, 1987).

3. "The Effect of Pulping Conditions on Boiling Point Elevation of Kraft Liquor Made from Southern Pine," AIChE National Meeting, Washington, DC (November, 1988).

4. "Solids Concentration, Temperature, Shear Rate Superposition of Viscosity of Kraft Black Liquor of High Solids Concentration to Yield One Master Curve: Effects of Lignin Weight Average Molecular Weight," AIChE National Meeting, Washington, DC (November, 1988).

5. "Molecular Weight and Molecular Weight Distribution of Kraft Lignins," Materials Research Society National Meeting, San Francisco, CA (April,1990).

6. "UV-Visible Response of Kraft Lignin in Black Liquor,"Materials Reseach Society National Meeting, San Francisco, CA (April,1990).

7. "Pulping of Slash Pine", AIChE National Meeting, Los Angeles, CA (November, 1991).

8. "Complete Rheology of a Black Liquor," AIChE National Meeting, Los Angeles, CA (November, 1991).

9. "Relation of Properties Research to Recovery System Control," DOE Research Conference, Seattle, WA (June, 1991).

10. "Kraft Pulping of Slash Pine," AIChE National Meeting, Los Angeles, CA (November, 1991).

11. "Viscosity of Kraft Black Liquors at High Temperatures and Pressures," AIChE National Meeting, Los Angeles, CA (November, 1991).

12. "Vapor Pressure Equilibria of Black Liquor Systems," TAPPI International Conference on Recovery Systems, Seattle, WA (June, 1992).

13. "Development of an On-Line Viscometer for Black Liquors," DOE Research Conference, Providence, RI (November, 1992).

14. "Black Liquor Properties Research," DOE Coperative Research Conference, Orono, ME (September, 1992).

15. "Density and Thermal Expansion of Black Liquors, "AIChE National Meeting, St. Louis, MO ( November, 1993).

16. "Enthalpy-Concentration Relations for Black Liquors," AIChE National Meeting, St. Louis, MO (November, 1993).

17. "On-Line Viscometry: Needs and Requirements for Kraft Recovery," DOE Advanced Sensor Development Conference, Atlanta, GA (April, 1994).

18. "Report on Viscometry Studies," American Forest and Paper Association Conference, Atlanta, GA (April, 1994).

19. "Black Liquor Properties", Industrial Energy Technology Conference, Houston, TX (April, 1994).

20. "Effects of Pulping Conditions or Liquor Composition on the Zero Shear Rate Viscosity of Black Liquors at High Solids," AIChE National Meeting, San Francisco, CA (November, 1994). 
21. "Effects of Pulping Conditions and Black Liquor Composition on the Heat of Combustion of Slash Pine Black Liquor," AIChE National Meeting, San Francisco, CA (November, 1994).

22. "Kraft Black Liquor Rheological Behavior with Respect to Solids Concentrations, Temperature, and Shear Rate," AIChE National Meeting, San Francisco, CA (November, 1994).

23. "Generalized Correlations for Heats of Dilution and Enthalpy-Concentration of Black Liquor," AIChE National Meeting, Miami, FL (November, 1995).

The number of reviewed publications and the quality of the journals in which they were published are an indication of the quantity and quality of results from research in this program, in our opinion. It should be obvious that technology transfer has been given serious consideration in this program and that it has been pursued aggressively. 


\subsection{REFERENCES}

Adams, G, and J.H. Gibbs, "On the Temperature Dependence of Cooperative Relaxation Properties in Glass Forming Liquids," J. Chem. Phys., 43, 139 (1965).

Adams, T.N. and N.J. Frederick, Kraft Recovery Boiler Physical and Chemical Processes, American Paper Institute, New York, NY (1988).

Ahlgren, P.A., W.G. Yean and D.A.I. Goring, "Chloride Delignification of Spruce Wood; Comparison of the Molecular Weight of the Lignin Dissolved with the Size of Pores in the Cell Wall," TAPPI, 54, 5, pp. 737-740 (1971).

Aho,W.O., "Advances in Chemical Pulping Processes," pp.149-181, in Progress in Biomass Conversion, Vol. 4, D.A. Tillman and E.C. Jahn, eds., Academic Press, New York, NY (1983).

Akonis, J.J., and W. J. McKnight, Introduction to Polymer Viscoelasticity, Wiley, New York, NY (1983).

Alder, B.J. and J.H. Hildebrand, "Activation Energy: Not Involved in Transport Processes in Liquids," Ind. Eng. Chem. Fundomentals, 12, 5, pp. 387-388 (1973).

Alen, R., P. Patja and E. Sjostrom, "Carbon Dioxide Precipitation of Lignin from Pine Kraft Black," TAPPIJ., 62, 11, pp. 108-109 (1979).

Alen, R., and E. Sjostrom, "Isolation of Hydroxy Acids from Pine Kraft Black Liquor, Part 1: Preparation of Crude Fraction," Paperi Puu, 62, 5, pp. 328-330 (1980).

Allen, V.R., and T.G. Fox, "Viscosity-Molecular Weight Dependence for Short Chain Polystyrenes," J. Chem. Phys, 41, 2, pp . 337-343 (1964).

Annergren, G.E. et al., Svensk Papperstidning, 71, pp.15 (1968).

Aoki, H., J.L. White and J.F. Fellers, "A Rheological and Optical Properties Investigation of Aliphatic (Nylon 66, P $\square$ BLG) and Aromatic (Kevlar, Nomex) Polyamide Solutions," J. Appl. Ploy. Sci 2 23, pp. 2293 2314 (1979).

Arhippainen, B., and B. Jungerstam, TAPPI J., 52, 6, pp. 1095-1099 (1969).

Arlt, W., and V. Onken, Chem. Eng. Comm., 15, pp.207 (1982).

Arndt, K.-F., "Vapor Pressure Osmometry. Effect of Solution Drop Dilution on the Determination of the Molecular Weight and Second Virial Coefficient," Acta Polymerica, 30, pp. 403-408 (1979).

Ashare, E., "Rheological Properties of Narrow Distribution Polystyrene Solutions," Trans. Soc. Rheology, 12, 4, pp. 535-557 (1968).

Back,E.L. and N.L. Salmen, "Glass Transition of Wood Components Hold Implications for Molding and Pulping Processes," TAPPI, 65, 7, pp/107-110 (1982). 
Bagley, E.B., "End Corrections in the Capillary Flow of Polyethylene," J. Appl. Phys., 28, 5, pp. 624-627 (1957).

Barker, J.A., "Determination of Activity Coefficients from Total Pressure Measurements," Aust. J. Chem., 6, 207 (1953).

Barlow,J.A., Lamb, J. and A.J. Matheson, 'Viscous Behavior of Supercooled Liquids," Proc. Royal Soc.(London), 292A, pp.322-412 (1965).

Barrall, II, E.M., and R.J. Gritter, in Systematic Materials Analysis V4., (J.H. Richardson and R.V. Peterson, eds.), Academic Press, NY, 390 (1978).

Barth, H.G., "Nonsize Exclusion Effects in High Performance Size Exclusion Chromatorgraphy," pp. 29-46, in Detection and Data Analysis in Size Exclusion Chromatography, T.Provdor,ed., American Chemical Society, Washington, DC (1987).

Barton, A.F.M., Handbook of Solubility Parameters and Other Cohesion Parameters, CRC Press, Boca Raton, FL (1983).

Beckwith, W.F., D.L. Kasbohm, and J.C. Hassler, "Analysis of Black Liquor by

Thermogravimetry and Gas Chromatography," AIChE Symp. Series, No. 207, 77, pp. 68-71 (1981).

Beech, G. and R. M. Lintonbon, ThermoChimica Acta, 2, 86 (1971).

Beerbower, A., L.A. Kaye and D.A. Pattison, "Picking the Right Elastomer to Fit Your Fluids," Chemical Engineering. 74, 26, p. 118 (1967).

Benko, J., "The Measurement of Relative Molecular Weight of Lignosulfonates by Diffusion. (i), (II), (III)," TAPPI J., 44, 11, pp. 766-770; 44, 11, pp. 771-775; 44, 12, pp. 849-854.

Benoit, B., Z. Grubistic and P. Rempp, "A Universal Calibration for Gel Permeation Chromatography," J. Poly. Sci., Part B, 5, pp. 753-759 (1967).

Berger, L. and J. Meissner, "Linear Viscoelasticity, Simple and Planar Melt Extension of Linear Polybutadienes with Bimodal Molar Mass Distributions," Rheol. Acta, 31, pp.63-74 (1992).

Bergstrom, R.E., and Waters, H.K., Paper Mill News, pp.12-23, Aug. (1954).

Berry, R., and H.I. Bolker, "The Topochemical Effect in Acid-Sulfite Delignification: A Theoretical Analysis," 1982 Canadian Wood Chemistry Symposium, Sept. 13-15, Niagara Falls, Ontario, pp. 137-141 (1982).

Bersted, B.H., "Molecular Weight Determination of High Polymers by Mean of Vapor Pressure Osmometry and the Solute Dependence of the Constant of Calibration," J. Appl. Poly. Sci, 17, pp. $1415-1430$ (1973).

Billmeyer, Jr., F.W., Textbook of Polymer Science, 3rd ed., John Wiley, New York, NY (1984).

Bird, R.B., W.E. Stewart and E.N. Lightfoot, Transport Phenomena, John Wiley \& Sons, New York (1960).

Bird, R.B., R.C. Armstrong and O. Hassager, Dynamics of Polymeric Liquids, John Wiley \& Sons, New York (1987). 
Birkinshaw, C., Buggy, M. and S. Daly, "Plasticization of Nylon 66 by Water and Alcohols,"Poly. Comm., 28, 2686-288 (1987).

Bodenheimer, B.V., "Viscosity Variations in High Solids Black Liquors," Southern Pulp \& Paper Manufacturers, (June 10, 1969).

Bolker, H.I., and H.S. Brenner, "Polymeric Structure of Spruce Lignin," Science, 170, pp. 173176 (1970).

Bolker, H.I., H.E.W. Rhodes and K.S. Lee, "Degradation of Insoluble Lignin by Chloride Monoxide', J. Agri. \& Food Chem., 25, 4, pp. $708-716$ (1977).

Bonnar, R.U., M. Dimbat and F.H. Stross, Number-Average Molecular Weight, Interscience, New York, Chapter 4 (1958).

Bottger, V.J., Th. Krause and J. Schurz, "Gel-Chromatographic Fractionation of Lignosulfonates," Holzforschung, 30, 2, pp. 41-44 (1976).

Brandup, J. and E.H. Immergut, eds., Polymer Handbook, 3rd ed., Wiley \& Sons, New York, NY (1989).

Brauns, F.E., and D.A. Brauns, The Chemistry of Lignin: Supplement Volume, Academic Press, New York, Chapter 7.

Brice, B.A., G.C. Nutting and M. Halwer, "Correction for Absorption and Fluorescence in the Determination of Molecular Weights by Light Scattering," J. Amer. Chem Soc., 75, pp . 824-828 (1953).

Brown, W., "Solution Properties of Lignin: Thermodynamic Properties and Molecular Weight Determination," J. Appl. Poly. Sci., 11, pp. 2381-2396 (1967).

Brown, W., E.B. Cowling and S.I. Falkehag, "Molecular Size Distribution of Lignins Liberated Enzymatically from Wood," Svensk Papperstidning, 71, pp. 811-821 (1968).

Brunow, G. and G. Miksche, "Some Reactions of Lignin in Kraft and Polysulfide Pulping," Appl. Poly. Symposia, 28, pp.1155-1168 (1976).

Brzezinski, J., H. Glowala and A. Kornas-Calka, "Note on the Molecular Weight Dependence of the Calibration Constant in Vapor Pressure Osmometry," European Poly. J., 9, pp. 1251-1253 (1973).

Bueche, F., Physical Properties of Polymers, Interscience, (1962).

Burge, D.E., "Molecular Weight Measurements by Osmometry," Amer. Lab., (June, 1977).

Burge, D.E., "Calibration of Vapor Pressure Osmometers for Molecular Weights Measurements," J. Appl. Poly. Sci., 24, pp. 293-299 (1979).

Burrell, H., Official Digest, 27, 369, pp. 748-751 (1955).

Burrell, H., "Solubility Parameter Values," in Polymer Handbook, ed. by J. Brandrup, E.H. Immergut (2nd ed.), John Wiley \& Sons, New York, 337 pp. (1975). 
Calahorra, E., GM. Guzman and F. Zamora, "Molecular Weight Influence on Polyethylene 1,2,4,5-tetrachlorobenzene Eutectic System," J. Polym. Sci. PL ed., 20, pp.181-185 (1982).

Callanan, J.E. and S.A. Sullivan, "Development of Standard Operating Procedures for Differential Scanning Calorimeters," Rev. Sci. Instrum., 57, 10, p.2584 (1986).

Clay, D.T. and T.M. Grace, "Measurements of High Solids Black Liquor Boiling Point Rise," TAPPI J., 67, 2, p.92 (1984).

Candau, F., J. Francois and H. Benoit, "Effect of Molecular Weight on the Refractive Index Increment of Polystyrenes in Solution," Polymer, 15, pp. 626-630 (1974).

Carr, C.I., and B.H. Zimm, "Absolute Intensity of Light Scattering from Pure Liquids and Solutions," J. Chem. Phys., 18, 12, pp. 1616-1626 (1950).

Carreau, P.J., Ph.D. Thesis, University of Wisconsin, Madison, Wisconsin (1968).

Carreau, P.J., I.F. MacDonald and R.B. Bird, "A Nonlinear Viscoelastic Model for Polymer Solutions and Melts-II," Chem. Eng. Sci., 23, pp.901-911 (1968).

Casey, J.P., Pulp and Paper Chemistry and Technology, Vol.ume 1, Wiley-Interscience, New York, NY (1980).

Chao, E.E., K. L. McDonald, and A. C. Garby, TAPPI J., 67, 112 (1984).

Chhabra, R.P. and R.J. Hunter, "The Fluidity of Molten Salts," Rheol. Acta, 20,2, pp.203-206 (1981).

Chum, H.L., D.K. Johnson, M.L. Tucker, and M.E. Himmel, "Some Aspects of Lignin Characterization by High Performance size Exclusion Chromatography Using Syrene Divinylbenzene Copolymer Gels," Holzforschung, 41, 2, pp.97-108 (1987).

Chupka, E.I., A.V. Obolenskaya and V.M. Nikitin, "Nature of the Processes Resulting in an Increase of the Molecular Weight of Lignin During Alkaline Cooks (III)," Khim. Drev. (Riga), 9, pp. 85-92 (1971).

Clay, D.T., and T.M. Grace, "Measurement of High Solids Black Liquor Boiling Point Rise," TAPPI J., 67, 92 (1984).

Clay, D.T., and T. M. Grace, Black Liquor Recovery Boiler Symp. (Helsinki), Paper B1 (1982). Clay, D.T., and T. M. Grace, "Measurements of High Solids Black Liquor Boiling Point Rise", TAPPI J., 67, 2, pp.92 (1980).

Clay, D.T., and M. A. Karnofski, TAPPI J., 64, 12, pp. 45 (1981).

Clayton, D.W., "The Chemistry of Alkaline Pulping," in Pulp and Paper Manufacture: I. The Pulping of Wood, 2nd ed., Editors, McDonald, R.G., Franklin, J.N., McGraw-Hill, New York, Chapter 8 (1969).

Co, A., H.K. Kim, M.O. Wight, A.L. Fricke, "Viscosity of Black Liquors at High Temperatures," TAPPI J., 65, 8, pp. 111-113 (1982). 
Co, A. and M.O. Wight, "Rheological Properties of Black Liquors,"Black Liquor Recovery Boiler Symp. (Helsinki), (1982).

Cochran, W.G., and G.M. Cox, Experimental Design, 2nd ed., John Wiley \& Sons, N.Y., Chapter 8A (1960).

Code, R.K. and J.D. Raal, "Rates of Shear in Coaxial Cylinder Viscometers," Rheol. Acta, 12, pp.578-587 (1973).

Combustion Engineering, Chemical Recovery Unit Operational Manual (1980).

Cohen, Y. and A.B. Metzner, "Apparent Slip Flow of Polymer Solutions," J. of Rheology, 29, 1, pp.67-102 (1985).

Concin, R., E. Burtsher and O. Bobleter, "The Molecular Weight Distribution of Hydrothermally Degraded Lignin," Holzforschung, 35, pp. $279-282$ (1981).

Connelly, R.W. and J. Greener, "High-Shear Viscometry with a Rotational Parallel-Disk Device," J. of Rheology, 29, 2, pp.209-226 (1985).

Connors, W.J., L.F. Lorenz and T.K. Kirk, "Chromatographic Separation of Lignin Models by Molecular Weight Using Sephadex LH-20," Holzforschung, 32, pp. 106-108 (1978).

Connors, W.J., "Gel Chromatography of Lignins, Lignin Model Compounds, and Polystyrenes Using Sephadex LH-60," Holzforschung, 32, pp. 145-147 (1978).

Connors, W.J., L.N. Johannson, K.V. Sarkanen and P. Winslow, "Thermal Degradation of Kraft Lignin in Tetralin," Holzforschung, 34, pp. 29-37 (1980).

Connors, W.J., S. Sarkanen and J.L. McCarthy, "Gel Chromatography and Association Complexes of Lignin," Holzforschung, 34, pp. 80-85 (1980).

Couchman, P.R., "Compositional Variation of Glass Transition Temperatures. 2. Application of the Thermodynamic Theory to Compatible Polymer Blends", Macromolecules, $11, \mathrm{pp} .1157$ (1978).

Couchman, P.R., and F.E. Karasz, "A Classical Thermodynamic Discussion of the Effect of Composition on Glass Transition Temperatures," Macromolecules, 11, pp.117 (1978).

Cox, W.P. and E.H. Merz, "Correlation of Dynamic and Steady Flow Viscosities," J. Poly. Sci., 28, pp. 619-622 (1958).

Cross, M.M., "Rheology of Non-Newtonian Fluids: A New Flow Equation for PseudoPlastic Systems," J. Colloid Sci., 20, pp.417-437 (1965).

Crowley, J.D., G.S. Teague, Jr. and J.W. Lowe, Jr., "A Three-Dimensional Approach to Solubility," J. of Paint Tech., 38, 496, pp. 269-280 (1966).

Crowley, J.E., G.S. Teague, Jr. and J.W. Lowe, Jr., "A Three-Dimensional Approach to Solubility, II," J. of Paint Tech., 39, 504, pp. 10-27 (1967).

Darby, R., Viscoelastic Fluids, Marcel Dekker Inc., New York, NY (1976).

Daniel, C., and F. Wood, Fitting Equations to Data, 2nd ed., John Wiley \& Sons, NY (1980). 
Dealy, J.M., Rheometers for Molten Plastics, Van Nostrand Reinhold, New York, NY (1982).

Dealy, J.M. and K.F. Wissbrun, Melt Rheology and Its Role in Plastic Processing, Van Nostrand Reinhold, New York, NY (1990).

Debye, P., "Light Scattering in Solution," J. Appl. Phys., 15, 4, pp. 338-342 (1944).

Ditmars, D.A., S. Ishihara, S.S. Chang, G. Bernstein, and E.D. West, "Enthalpy and Heat Capacity Standard Reference Material: Synthetic Sapphire (-Al203) from 10 to 2250K," J. Res. Nat. Bur. Stand. U.S., 87, pp.159 (1982).

Doolittle, A.K., "Studies in Newtonian Flow. III. The Dependence of the Viscosity of Liquids on Molecular Volume and Free Space," J. Appl. Phys., 23, 2, pp.236-239 (1951).

Doolittle, A. K., "Studies in Newtonian Flow. II. The Development of the Viscosity of Liquids in Free Space," J. Appl. Phys., 22, 12, pp.1471-1475 (1951).

Dong, D.J., Characterization of Kraft Lignin and Investigation of Pulping Effects on Pulp Yield, Lignin Molecular Mass, and Lignin Content of Black Liquor with a Central Composite Pulping Design ,PhD Thesis, University of Florida, Gainesville, FL (1993).

Dong, D.J., and A. L. Fricke, "UV-Visible Response of Kraft Lignin in Soft Wood Black Liquor," Mat. Res. Soc. Symp.Proc., 197, pp.77-86 (1990).

Dong, D. J., and A. L. Fricke, "Investigation of Optical Effect of Lignin Solution and Determination of $\mathbb{M}_{w}$ of Kraft Lignin by LALLS," J. Appl. Poly. Sci., 50, pp. 1131-40 (1993).

Dong, D. J., and A. L. Fricke, "Effects of Pulping Conditions on the Composition of Black Liquor from Slash Pine," Holzforschung, 50,1, pp.75-84(1995).

Dong, D. J., and A. L. Fricke, "Effects of Multiple Pulping Variables on the Molecular Weight and Molecular Weight Distribution of Kraft Lignin," J. Wood Chem. and Tech., 15, pp. 369-393(1995).

Dong, D. J., and A. L. Fricke, "Intrinsic Viscosity of Kraft Lignins," Polymer, 70, 12, pp. 112-116 (1995).

Dong, D. J. and A. L. Fricke, "Electrokinetic Study of Kraft Lignin", TAPPI J., 79, 7, pp.191-197 (1996).

Doty, P., "Depolarization of Light Scattered from Dilute Macromolecular Solutions," J. Poly Sci.. 3, 4, pp. 750-771 (1948).

Drott, E.E., and R.A. Mendelson, "Determination of Polymer Branching with Gel-Permeation Chromatography, I. Theory," J. Poly. Sci., A-2, 8, pp. 1361-1371 (1970).

Eicher, L. D. and B.J. Zwolinski, "Limitations of the Hildebrand-Batschinski Shear Viscosity Equation," Scince, 77, pp. 369 (1972).

Eirich, F.R., Rheology, Vol. 3, Academic Press, New York (1960).

Ekman, K.H., and J.J. Lindberg, "Notes on the Solubility of Lignin in Binary Organic Mixtures," Suomen Kemistilehti, B39, pp. 89-96 (1966). 
Elias, H., Macromolecules VI, NY, Plenum Press, 373 (1977).

Ertl, H. and F.A.L. Dullien, "Hildebrand's Equation for Viscosity and Diffusivity," J. Phys. Chem., 77, 25, pp.3007-3011 (1973).

Ewell, R. H. and H. Eyring, "Theory of the Viscosity of Liquids as a Function of Temperature and Pressure," J. Chem. Phys., 5, pp.726-736 (1937).

Eyring, H., "Viscosity, Plasticity and Diffusion as Examples of Absolute Reaction Rates," $J$. Chem. Phys., 4, pp.283-291 (1936).

Faix, O., W. Lange and O. Beinhoff, "Molecular Weights and Molecular Weight Distributions of Milled Wood Lignins of Some Wood and Bambusoideae Species," Holzforschung, 34, pp. 174176 (1980).

Faix, O., W. Lange and G. Besold, "Molecular Weight Determinations of DHP's from Mixtures of Precursors by Steric Exclusion Chromatography (HPLC)," Holzforschung, 35, pp. 137-140 (1981).

Faix, O., W. Lange and E.C. Salud, "The Use of HPLC for the Determination of Average Molecular Weights and Molecular Weight Distributions of Milled Wood Lignin from Shorea Polysperma (Blco.)," Holzforschung, 35, pp. 3-9 (1981).

Falkehag, S.I., "Lignin in Materials," Appl.Poly. Symp., No. 28, pp. 247- 257 (1975)

Farritor, R.E., and L.C. Tao, Thermo Chimica Acta, 1, pp. 297 (1970).

Fengel, D. and G. Wegener, Wood: Chemistry, Ultrastructure, Reactions, walter de Gruyter Berlin (1984).

Ferry, J.D., E.L. Foster, G.V. Browning and W.M. Sawyer, "Viscosities of Concentrated Polyvinyl Acetate Solution in Various Solvents," J. Colloid Sci.. pp. 377- 388 (1951).

Ferry, J.D., Viscoelastic Properties of Polymers, Third Edition. John Wiley \& Sons, Inc., New York (1980).

Figini, R.V., "On the Molecular Weight Determination by Vapor Pressure Osmometry, 2. Molecular Weight Average Obtained by VPO." Makromol. Chem., 181, pp. 2409-2411.

Figini, R.V., and M. Marx-Figini, "On the Molecular Weight Determination by Vapor Pressure Osmometry, 3. Relationship Between Diffusion Coefficient of the Solute and Non-Colligative Behavior," Makromol. Chem. ,182, pp. 437- 443.

Flory, P.J., Principles of Polymer Chemistry, Cornell University Press, Ithaca, New York, (1953).

Foliadova, Z.I., and A.I. Kiprianov, Izv. f VUZ Lesnoi Zh., 19, 5, pp. $91-93$ (1976) .

Foliadova, Z.I., and A. I. Kiprianov, Bumazh. Prom.,11, pp. 20 (1979).

Forss, K., O. Schott and B. Stenlund, "Light Absorption and Fluorescence of Lignosulfonates Dissolved in Water and Dimethylsulfoxide," Paperi Puu, 49, 8, pp. 525-530 (1967).

Forss, K., and B. Stenlund, "Molecular Weights of Lignosulfonates Fractionated by Gel Chromatography," Paperi Puu, 51, 1, pp. 93-105 (1969). 
Forss, K.,B. Stenlund and P-E. Sagfors, "Determination of the Molecular Weight Distribution of Lignosulfonates nad Kraft Lignin," J. Appl. Poly. Sci.: Appl. Poly. Symp., 28, 1185-1194 (1976).

Forss, K., J. Janson and P-E. Sagfors, "Influence of Anthraquinone and Sulphide on the Alkaline Degradation of the Lignin Macromolecule,"Paperi Puu - Papper Och Tra, No. 2, pp. 77-79 (1984).

Forss, K., B. Stenlund, and P-E. Sagfors, "Determination of the Molar Mass Distribution of Lignins by Gel Permeation Chromatography." Ch. 9 in Lignin:Properties and Materials, W. Glasser and S Sarkarnen, eds., ACS Symposium Series No. 397, American Chemical Society, Washington, DC (1989).

Fox, T.G., and V.R. Allen, "Dependence of the Zero Shear Melt Viscosity and the Related Friction Coefficient and Critical Chain Length on Measurable Characteristics of Chain Polymers," J. Chem. Phys., 4I, 2, pp. 344-352 (1964).

Fox, T.G., and P.J. Flory, "On a General Relaxation Involving the Glass Temperature and Coefficients of Expansion of Polymers", J. Appl. Phys., 21, pp. 581(1950).

Fox, T.G., S. Gratch, and S. Loshaek in F.R. Elrich, ed., Rheology, Vol. 1, Chap. 12, Academic Press, NY (1956).

Frederick, W.J., D.G. Sacks, H.J.Grady, and T.M.Grace, "Boiling point Elevation and Solubility Limit for Black Liquors", TAPPI J., 63, 4, pp. 151 (1980).

Frederickson, A.G., Principles and Apllications of Rheology, Prentice Hall, Englewood Cliffs, NJ (1964).

Fricke, A.L., Physical Properties of Kraft Black Liquor: Final Report Phase I (1983) DOE report No. DOE/CE 40606-Ti (DE 84006996).

Fricke, A.L., Physical Properties of Kraft Black Liquor: Interim Report - Phase II, (1985) DOE report on contract DE AC02-82CE40606.

Fricke, A.L., Physical Properties of Kraft Black Liquor: Summary Report - Phases I and II. (1987), DOE report no. DOE/CE/40606-T5 (DE 88002991).

Fricke, A. L., A Comprehensive Program to Develop Correlations for Physical Properties of Kraft Black Liquor, Iterim Report no. 1, DOE Report No. DOE/CE/40740-T7, (DE94014503), University of Florida, Gainesville, FL (1989).

Fricke, A. L., A Comprehensive Program to Develop Correlations for Physical Properties of Kraft Black Liquor, Iterim Report no. 2, DOE Report No. DOE/CE/40740-T7, (DE94014503), University of Florida, Gainesville, FL (1990).

Fricke, A. L., A Comprehensive Program to Develop Correlations for Physical Properties of Kraft Black Liquor, Iterim Report no. 3, DOE Report No. DOE/CE/40740-T8, (DE95005300), University of Florida, Gainesville, FL (1993). 
Fricke, A. L., A Comprehensive Program to Develop Correlations for Physical Properties of Kraft Black Liquor, Iterim Report no. 4, DOE Report No. DOE/CE/40740-T8, (DE95005300), University of Florida, Gainesville, FL (1997).

Froment, P. and F. Pla,"Determinationns of Average Molecular Weights and Molecular Weight Distributions of Lignin," ch. 10 in Lignin:Properties and Materials, W. Glasser and S Sarkarnen, eds., ACS Symposium Series No. 397, American Chemical Society, Washington, DC (1989).

Fuller, T.R., and A.L. Fricke, "Thermal Conductivity of Polymer Melts,"J. Appl. Poly Sci., 15, pp. 1729 (1971).

Hunter, W. G., and J.S. Hunter, Statistics for Experimenters: Introduction to Design, Data Analysis, and Model Building. John Wiley \& Sons, New York (1978).

Galke, S.N., and H. Veeramani, "Viscosity of Bamboo, Bagasse, and Eucalyptus Black Liquors", TAPPI Non-Wood Plant Fiber Pulping Progress Report, No. 8, pp.33-40 (1970).

Gardon, J.L., and S.G. Mason, "Physicochemical Studies of Lignin-Sulphonates, I. Preparation and Properties of Fractionated Samples," Canadian J. Chem., 33, pp. 1477-1490 (1955).

"Gel Permeation Chromatographic Analysis of Cellulose," Ploymer Notes, 1, 3, Waters Division of Millipore Corporation, Milford, MA (1986).

Gellersted, G., and E-L. Lindforss, "Structural Changes in Lignin During Kraft Pulping," Holzforschung, 38, pp. 151-158.

Gessner, A.W., Chem. Eng. Prog., 61, 2, pp. 68 (1965).

Gibbs, J.H., and E.A. DiMarzio, "Nature of the Glass Transition and the Glassy State," J. Chem. Phys., 28, pp. 373 (1958).

Gierer, J., "Chemical Aspects of Kraft Pulping," Wood Sci. Tech., 14, pp. 241-266 (1980).

Gill, D.S., and K. Malhotra, "Studies on Sparingly Soluble Salts; Part I. Activity Coefficients of Alkali Metal Chlorides in N,NDimethylformamide," Indian J Chem., 19A, pp. 65-67 (1980).

Ginnings, D.C., and G.T. Furukawa, "Heat Capacity Standards for the Range of 14 to 1200K," $J$. Am. Chem. Soc., 75, pp. 522 (1953).

Glasser, W.G. and S.S. Kelly, "Lignin," pp. 544-547 in The Concise Encyclopediaof Polymer Science and Engineering, J.I. Kroschwitz, ed., Wiley \& Sons, New York, NY (1990).

Glasser, W.G., C.A. Barnett, P.C. Muller, and K.V. Sarkarnen, "the Chemistry of Several Novel Bioconversion Lignins," J. Agri. and Food Chem., 31, 5, 921-930 (1983).

Glover, C.A., "Absolute Colligative Methods," in Polymer Molecular Weights, Part I, Ed. by P. Slade, Jr., Marcel Dekker, Inc., New York.

Goldin, M., J. Yerushalmi, R. Pfeffer and R. Shinnar, "Breakup of a Laminar Capillary Jet of a Viscoelastic Fluid," J. of Fluid Mech., 38, Part 4, pp. 689-711 (1969).

Gordon, J.M., G.B. Rouse, J.H. Gibbs and W.M. Risen, Jr., "The Composition Dependence of Glass Transition Properties," J. Chem. Phys., 66, pp. 4971 (1977). 
Gordy, W., and S.C. Stanford, "Spectroscopic Evidence for Hydrogen Bonds: Comparison of Proton-Attracting Properties of Liquid. III," J. Chem. Phys., 9, pp. 204 (1941).

Goring, D.A.I., "Thermal Softening og Lignin, Hemicellulose, and Cellulose," Pullp \& Paper Magazine of Cananda, 64, 12, pp.T517-T527 (1963).

Goring, D.A.I., in Lignin, ed. by Sarkanen and Ludwig, Wiley - Interscience, N.Y., Chapter 17 (1971).

Grace, T.M., and M. S. Funk, CPPA/TAPPI Int. Conf. Recovery Pulping Chemical (Vancover), pp. 53-55 (1981).

Graessley, W.W., R.L. Haleton and L.R. Lindeman, "The Shear-Rate - Dependence of Viscosity in Concentrated Solutions of Narrow Distributions Polystyrene," Trans. Soc.Rheology, 11, 3, pp. 267-285 (1967).

Graessley, W.W., and L. Segal, "Flow Behavior of Polystyrene in Steady Shearing Flow," Macromolecules, 2, 1, pp. 49-57 (1969).

Graessley, W.W., T. Masuda, J.E.L Roovers, and N. Hadjichristidis, "Rheological Properties of Linear and Branched Polyisoprene," Macromolecules, 9, 1, pp.127-141 (1976).

Grant, D.E. and S.E. Dieckmann, "Some Melt Flow Properties of Polypropylene," J. Appl. Ploy. Sci., 9, pp.3231-3243 (1965).

Green, R.P., and T. M. Grace, TAPPI J., 67, 6, pp. 94 (1984).

Greener, J. and R.W. Connelly, "The Response of Viscoelastic Liquids to Complex Strain Histories: The Thixotropic Loop," J. of Rheology, 30, 2, pp.285-300 (1986).

Grolier, J.P.E., A. Inglese and E. Wilhelm, "Excess Molar Heat Capacities of (1,4-dioxane + an nalkane): An Unusual Composition Dependence," J. Chem. Thermo., 16, pp. 67-71 (1984).

Gross, M.M., "Rheology of Non-Newtonian Fluids: A New Flow Equation for Pseudoplastic Systems," J. Colloid Sci., 20, pp.417-437 (1965).

Gudmundson, C., Svensk Papperstidning, 75, 22, pp. 901-908 (1972).

Gudmundson, C., H. Alsholm, and B. Hedstrom, Svensk Papperstidning, 75, 19, pp. 773-83 (1972).

Guggenheim, E.A., "The Theoretical Basis of Raoult's Law," Trans. Faraday Soc., 33, pp.151 (1937)

Guinier, A.,"Diffraction of X-Rays of Very Small Angles - Application of Ultramicroscopic Phenomenon," Ann. Phys., 12, pp. 161-237 (1939).

Gupta, P.R., and D.A.I. Goring, "Physicochemical Studies of Alkali Lignins, I. Preparation and Properties of Fractions," Canadian J.Chem., 38, pp. 248-259 (1960).

Gupta, P.R., and D.A.I. Goring, "Physicochemical Studies of Alkali Lignins, III. Size and Shape of the Macromolecule," Canadian J. Chem., 38, pp. 270-279 (1960). 
Gupta, P.R., and J.L. McCarthy, "Lignin XIV. Gel Chromatography and the Distribution in Molecular Size of Lignin Sulfonates at Several Electrolyte Concentrations, " Macromolecules, 1, 3, pp. 236-244 (1968).

Haegglund, E., "Investigations on the Kraft Cooking Process," Svensk Papperstidning, 48, pp. 195 (1945).

Haegglund, E., "Sulfidity in the Sulfate Process," TAPPI J., 32, 6, p. 241 (1949).

Hager, B.L., and G.C. Berry, "Moderately Concentrated Solutions of Polystyrene. I. Viscosity as a Function of Concentration, Temperature, and Molecular Weight," J. Poly. Sci.: Poly. Phys. Ed., 20, pp. 911-928 (1982).

Halberg, A.K., Svensk Papperstidning, 3 (1963).

Han, C.T., "Criterion for Fully Developed Flow of Polymer Melts in Circular Tubes," AIChE J., 16,3, pp.499-501 (1970).

Han, S.T., "Physical Properties of Neutral Sulfite Spent Liquors," TAPPIJ, 40, 11, pp. 921-925 (1957).

Hansen, C.M., "Three Dimensional Solubility Parameter- Key to Paint Component Affinities - 1," J. Paint Tech., 39, 505, pp. 104-17; 39, 511, pp. 505 (1967).

Hansen, C.M., I\&EC Prod. Res. \& Devel., 8, 1, pp. 2 (1969).

Harvin, R.L., Study of the Thermal and Physical Properties and Heat Transfer Coefficients of Sulfate Paper Mill Black Liquors, PhD Thesis, University of Florida, Gainesville, FL (1955).

Harvin, R.L., and W.F. Brown, "Specific Heat of Sulphate Black Liquor," TAPPI J., 36, pp. 270 (1953).

Hatakeyama, H., K. Kubota, and J. Nakano, "Thermal Analysis of Lignin by Differential Scanning Calorimetry," Cellulose Chem. Tech., 6, pp. 521-529 (1972).

Hatakeyama, T., K. Nakamura, and H. Hatakeyama, "Studies on Heat Capacity of Cellulose and Lignin by Differential Scanning Calorimetry," Polymer, 23, pp. 1801 - 1804 (1982).

Hatton, J.V., J.L. Keays and J. Hejjas, "Effect of Time, Temperature and Effective Alkali in Kraft Pulping of Western Hemlock," Pulp and Paper Mag. of Canada, 73, 4, pp. 63-69 (1972).

Hatton, J.V., "Development of Yield Prediction Equations in Kraft Pulping," TAPPIJ, 56, 7, pp. 97-100 (1973).

Hatton, J.V., "Application of Empirical Equation to Kraft Process Control," TAPPI J., 56, 8, pp. 108- 111 (1973).

Herrick, F.W., Engen, R.J., and O. Goldschmid, "Spent Sulfite Liquor Viscosity nad Lignin Sulfonate Molecular Weight: Effect of Heat Aging," TAPPI, 62,2, pp.81-86 (1979).

Highgate, D.J. and R.W. Whorlow, "End Effects and Particle Migration Effects in Concentric Cylinder Rheometry," Rheol. Acta, 8, 2, pp.142-151 (1969). 
Hildebrand, J., "Motions of Molecules in Liquids: Viscosity and Diffusivity," Science, 174, pp.490-492(1971).

Hildebrand, J.H., "Kinetic Theory of Viscosity of Compressed Fluids," Proc. Nat. Acad. Sci.,USA, 72, 2, pp.1970-1972 (1975).

Hildebrand, J. H. and R. H. Lamoreaux, "Fluidity: A General Theory," Proc. Nat. Acad. Sci.,USA, 69, 11, pp.3428-3431(1972).

Hildebrand, J. H. and R. H. Lamoreaux, "Fluidity and Liquid Structure," J. Phys. Chem., 77, 11, pp.1471-1473 (1975).

Hildebrand, J., and R. Scott, The Solubility of Nonelectrolytes, Dover, New York (1964).

Hildebrand, F.B., Advanced Calculus for Application, Prentice-Hall, Englewood Cliffs, N.J., p. 360 (1962) .

Hill, M.K., and Fricke, A.L., "Ultrafiltration Studies on a Kraft Black Liquor," TAPPI J., 67, 6, pp. 100 (1984).

Hill, M.K., Private Communication (1984).

Hill, M.K., DOE Review Conference Report (1985).

Himmel, M.E., K. Tatumoto, K. Grohmann, D.K. Johnson, and H.L. Chum, "Molecular Weight Distribution of Aspen Lignins Estimated by Universal Calibration," pp.82-99 in ch. 6, in Lignin:Properties and Materials, W. Glasser and S Sarkarnen, eds., ACS Symposium Series No. 397, American Chemical Society, Washington, DC (1989).

Himmel, M.E., K.K. Oh, D.W. Sopher, and H.L. Chum, "High Performance Size Exclusion Chromatography of Low-Molecular Weight Lignins and Model Compounds," J. of Chromat., 267, pp.249-265 (1983).

Himmel, M.E., K. Tatumoto, K. Grohmann, D.K. Johnson, and H.L. Chum, "Molecular Weight Distribution of Aspen Lignins from Conventional Gel Permeation Chromatography, Universal Calibration and Sedimentsation Equilibrium," J. of Chromat., 498, pp.93-104 (1990).

Hinrichs, D.D., "The Effect of Kraft Pulping Variables on Delignification," TAPPI J., 50, 4, pp. 173-175 (1967).

Ho, C.Y., P.D. Desai, K.Y. Wu, T.N. Havill and T.Y. Lee, "Thermophysical Properties of Polystyrene and Poly(vinyl chloride)," Symp. on Thermophysical Prop., 7th, Gaithersburg, MD (1977).

Hombach, H-P., "Virial Coefficients in Determination of Molecular Weights on Solutions of Coal Derivatives," Fuel, 60, pp. 663-666 (1981).

Hougen, O.A., and Watson, K.M., Chemical Process Principles, Wiley, New York (1947).

Huglin, M.B., "Specific Refractive Index Increments," in Light Scattering from Polymer Solutions, ed. by M.B. Huglin, Academic Press, New York, Chapter 6 (1972).

Hultin, S.O., Proc. IUPAC/EUCEPA Symp. Recovery of Pulping Chemicals (Helsinki), pp. 167-182 (1968). 
Hunter, R.E., J. Tracy, R. Cutts, R.E. Young, J. Olin and J.L. McCarthy, "Density, Viscosity, Specific Heat, Thermal Conductivity, and Prandtl Number Versus Concentration and Temperature: Sulfite Waste Liquor," TAPPI J., 36, 11, pp.493-497 (1953).

Huppler, J.D., E. Ashare and L.A. Holmes, "Rheological Properties of Three Solutions. Part I. Non-Newtonian Viscosity, Normal Stresses, and Complex Viscosity," Trans. Soc. Rheology, 11, pp. 159-179 (1967).

Hurley, P.O., Kraft Recovery Alternatives-Energy Balance, Report available through IPC, Appleton, WI (1978).

Huttermann, V.A., "Gel Chromatography of Na-Lignosulfonates on Sepharose CL-6B," Holzforschung, 31, 2, pp. 45-50 (1977).

Huttermann, A., "Gel Permeation Chromatography of Water-Insoluble Lignins on Controlled Pore Glass and Sepharose CL-6B," Holzforschung, 32, 3, pp. 108-111 (1978).

Hutton, J.F., "The Fracture of Liquids in Shear: The Effects of Size and Shape," Proc. Royal Soc., $A 287$, pp.222-239 (1965).

Hutton, J. F., Rheol. Acta, 8, p.54 (1969).

Hyun, K.S., "End Corrections in Capillary Flow of Polystyrene Melts," Poly. Eng. \& Sci., 14, 9, pp. 666-669 (1974).

"Indulun," described in Bulletin L-5, Industrial Chemical Sales Div., West Virginia Pulp and Paper Company.

Instron Capillary Rheometer, Model 3211, Manual No. 10-364-1(C), Instron Corporation, (1981).

Irvine, G.M., "The Glass Transitions of Lignin and Hemicellulose and Their Measurement by Differential Scanning Calorimetry,"TAPPI J., 67, pp. 118-121 (1984).

James, A.N., E. Pickard and P.G. Shotten, "Molecular Size Distributions of Lignosulphonates by Thin Layer Chromatography," J. Chromatography, 32, pp. 64-74.

Janson,J. and L. Soderhjelm, " The Viscosity of Borate Containing Black Liquor," Nord. Pulp Paper Res. J., 3, 2, pp.107-110 (1988).

Jelinek, S.F., "Black Liquor Heat of Mixing and Enthalpy From Heat Capacity Data," TAPPI J., 69, 8, p. 114 (1986).

Jiang, T.Q., Yang, A.C. and A.B. Metzner, "The Rheological Characterization of HPG Gels: Measurement of Slip Velocities in Capillary Tubes," Rheol. Acta, 25, 4, pp.397-404 (1986).

Johansson, A., O. Aaltonen, and P. Ylinen, "Organosolv Pulping-Methods and Pulp Properties," Biomass, 13, pp.45-65 (1987).

Johnson, D.K., H.L. Chum, and J.A. Hyatt, "Molecular Weight Distribution Studies Using Lignin Model Compounds," ch. 8 in Lignin:Properties and Materials, W. Glasser and S Sarkarnen, eds., ACS Symposium Series No. 397, American Chemical Society, Washington, DC (1989). 
Johnson, M.F., W.W. Evans, I. Jordan and J.D. Ferry, "Viscosity of Concentrated Polymer Solutions. II. Polylisobutylene," J. Colloid Sci., 7, pp. 498-510 (1952).

Joseph, J.R., J.L. Kardos and L.E. Nielsen, "Growth, Morphologh, and Reinforcement Potential of Low Molecular Weight Crystals in Amorphous Polymeric Matrices," J. Appl. Poly. Sci., 12, pp. 1151-1165 (1968).

Kalika, D.S. and M.M. Denn, "Wall Slip and Extrudate Distortion in Linear Low Density Polyethylene," J. of Rheology, 31, 8, pp.815-834 (1987).

Kamal, M.R. and H. Nyun, "The Effect of Pressure on Shear Viscosity of Polymer Melts," Trans. Soc. Rheology, 17, 2, pp.271-285 (1973).

Kamide, K., T. Terakawa and H. Uchiki, "Molecular Weight Determination of Macromolecules by Vapor Pressure Osmometry," Makromol. Chem., 177, pp. 1447-1464.

Kataoka, T. and S. Ueda, "Flow Properties of Polyethylene Melts," J. Appl. Poly. Sci., 12, pp.939-953 (1968).

Kaye, W., "Low Angle Laser Scattering - Particle Measurement," J. Coll. \& Surf. Sci., 44, pp. 384-386 (1973).

Kaye, W., and A.J. Havlik, "Low-Angle Laser Light Scattering - Absolute Calibration," Appl. Optics, 12, 3, pp. 541-550 (1973).

Kaye, W., "Liquid-Phase Particulate Contaminants in Water," J.Coll. \& Interface Sci., 46, 3, pp. 543-544 (1974).

Kaye, W., and J.B. McDaniel, "Low-Angle Laser Light Scattering - Rayleigh Factors and Depolarization Ratios," Appl. Optics, 13, 8, pp. 1934-1937 (1974).

Keentok, M. and I. Tanner, "Cone-Plate and Parallel-Plate Rheometry of Some Polymer Solutions," J. of Rheology, 26, 3, pp.301-311 (1982).

Kelly, J.E., The Effect of Particle Size and Concentration on the Capillary Rheometry of Calcium Carbonate/Polystyrene Composites,M.S. Thesis, University of Florida, Gainesville, FL (1989).

Kerker, M., The Scattering of Light and Other Electromagnetic Radiation, Academic Press, New York (1969).

Kim, H-K., Viscosity of Black Liquors by Capillary Measurements, M.S. Thesis, University of Maine at Orono (1980).

Kim, H.K., A. Co and A.L. Fricke, "Viscosity of Black Liquors by Capillary Measurements," AIChE Symp. Series, 77, 207, (1981).

Kim, H.K., The Effect of Pulping Conditions on the Molecular Weights of Kraft Lignin, Ph.D. Thesis, University of Maine (1985).

Kim, H-K., M. L. Hill, and A. L. Fricke, "Preparation of Kraft Lignin from Black Liquor", TAPPI $J ., 70,12$, pp. 112-116 (1987). 
Kimura, F., P.J. D'Arcy and G.C. Genson "Excess Enthalpies and Heat Capacities for (di-npropylether + n-heptane)," J. Chem. Thermo., 15, pp. $511-516$ (1983).

Kirschbaum, E., Chemie-Ing., - Techn., 34, 3, pp. 183-192 (1962).

Kleppe, P.L., "Kraft Pulping," TAPPI J, 55 1, pp. 35-47 (1970).

Kobe, K.A., and E.J. McCormack, "Viscosity of Pulping Waste Liquors," Ind. \& Eng. Chem., 41, 12, pp. 2847-2848 (1949).

Kobe, K.A., and A. J. Sorenson, Pacific Pulp Paper Ind, 13, 2, pp. 12-13 (1939).

Kolpak, F.J., D.J. Cietek, W. Fookes and J.J. Cael, "Analysis of Lignins from Spent Liquors by Gel Permeation Chromatography/Low Angle Laser Light Scattering (GPC/LALLS)," J. Appl. Poly. Sc.: Appl. Poly. Symp., 37, pp. 491-507.

Koorse, G.M., A.Mehrotra, and H.Veerami, Indian Pulp Paper, 32, 1, pp. 7 (1977).

Korpio, E. and N. E. Virkoka, Black Liquor Recovery Boiler Symp. (Helsinki), Paper B4 (1984).

Kozicki, W., Pasari, S.N. and A.R.K. Rao, "Anomolous Effects in Laminar Capillary Flow of Polymer Solutions," Chem. Eng. Sci., 25, pp.41-52 (1970).

Kratochvil, P., "On the Structure and Properties of Vinyl Polymers and Their Models. II. Light Scattering by Solutions of Polyvinyl Chloride in Cyclohexanone or Terahydrofuran," Collection of Czechoslovak Chemical Communications, 29, pp. 2767-2782.

Kratochvil, P., "Particle Scattering Functions," in Light Scattering from Polymer Solutions, ed. by M.B. Huglin, Academic Press, New York, Chapter 7 (1972).

Kraynik, A.M. and W.R. Schowalter, "Slip at the Wall and Extrudate Roughness with Aqueous Solutions of Polyvinyl Alcohol and Sodium Borate," J. of Rheology, 25, 1, pp.94-114 (1981).

Krieger, I.M., "Shear Rate in the Couette Viscometer," Trans. Soc. Rheol., 12, 1, pp.5-11 (1968).

Krieger, I.M. and H. Elrod, "Direct Determination of the Flow Curves of Non-Newtonian Fluids. II. Shearing Rate in the Concentric Cylinder Viscometer," J. Appl. Phys., 24, 2, pp.134-136 (1953).

Krieger, I.M. and S.H. Maron, "Direct Determination of the Flow Curves of Non-Newtonian Fluids," J. Appl. Phys., 23, 1, pp.147-149 (1952).

Krieger, I.M. and S.H. Maron, "Direct Determination of the Flow Curves of Non-Newtonian Fluids. III. Standardized Treatment of Viscometric Data," J. Appl. Phys., 25, 1, pp. $72-75$ (1954).

Kringstad, K.P., and R. Morck, "13C-NMR Spectra of Kraft Lignins," Holzforschung, 37, 5, pp. 237-244 (1983).

Krishnagopalan, J., M. Hill and A.L. Fricke, "Development of Methods for Anionic Analysis of Black Liquors and Application of the Method," Proc. TAPPI 1984 Res. \& Dev. Conf., Appleton, WI, pp. 59-63 (1984). 
Krishnagopolan, J., M.K. Hill, and A.L. Fricke,, "Chromatographic Analysis of Kraft Liquor Anions," TAPPI J., 68, 9, pp. 108 (1985).

Krishnagopolan, J., "Black Liquor Surface Tension," AIChE National Meeting, Boston, MA (1986).

Kristersson,P., K. Lundquist, R. Siimonson, and K. Tingsvik, "Gel Permeation Chromatography of Lignin Carbohydrate Compouinds," Holzforschung, 37, 1, pp.51-53 (1983).

Kucharikova, I., "Some Aspects of the Estimation of Mn by Vapor Pressure Osmometry," J. Appl. Poly. Sci., 23, pp. $3041-3049$ (1979).

La Nieve, H.L. and D.C.Bogue, "Correlation of Capillary Entrance Pressure Drops with Normal Stress Data," J. Appl. Poly. Sci., 12, pp.353-372 (1968).

Landry, G.C., Private Communication, St. Regis Paper Company, Kraft Center Pensacola, Cantonment, FL 32533 (1984).

Lange, W., and W. Schweers, "The Carboxymethylation of Organosolv and Kraft Lignins," Wood Sci. \& Tech. 14, pp. 1-7 (1980).

Lankenau, H.G., and A. R. Flores, "Multiple Effect Evaporation of Sulfate Liquors to 55-65\% Solids," Pulp and Paper Magazine of Canada, 70, 2, pp. 63-66 (1969).

Laun, H.M., "Polymer Melt Rheology with a Slit Die," Rheol. Acta, 22, 3, pp.171-185 (1983).

Laun, H. M. and H. Schuch, "Transient Elongational Viscosities and Drawability of Polymer Melts," J. of Rheology, 33, 1, pp.119-175 (1989).

Legg, G.W., and J.S. Hart, "Alkaline Pulping of Jackpine and Douglas Fir: The Influence of Sulphide and Effective Alkali Charge on Pulping Rate and Pulp Properties," Pulp and Paper Magazine of Canada, (May), pp. T299-T304 (1960).

Levine, H.I., R.J. Fiel and F.W. Billmeyer, Jr., "Very Low-Angle Light Scattering. A Characterization Method for High-Molecular Weight DNA," Biopolymers, 15, pp. 1267-1281 (1976).

Lewis, C.N., and M. Randall, Thermodynamics, 2nd ed., Chapter 26, McGraw Hill, New York (1961).

Lieberman, E.P., "Quantification of the Hydrogen-Bonding Parameter for Resin Solvent," Official Digest Federation Soc. Paint Technology, 34, 444, pp. 30-50 (1962).

Lin, S.Y., and W.J. Detroit, "Chemical Heterogeneity of Technical Lignins - Its Significance in Lignin Utilization," Ekman Day, 4, pp. 44-52 (1981).

Lindberg, J.J., H. Tylli and C. Majani, "Notes on the Molecular Weight and the Fractionation of Lignins with Organic Solvents," Paperi Puu, 46, 9, pp. 521-526 (1964).

Lindberg, J.J., "Studies on Thermodynamics of Lignins and Related Polymers (II). Thermodynamics of Solubility," Suomen Kemistilehti, B40, pp. 225-228 (1967). 
Lindstrom, T., "The Colloidal Behavior of Kraft Lignin, (I) Association and Gelation of Kraft Lignin in Aqueous Solutions," Colloid \& Poly. Sci., 257, 3, pp. 277-285 (1979).

Lodge, A.S., Elastic Liquids, Academic Press, New York (1964).

Lowendahl, L., G. Petersson, and O. Samuelson, TAPPI J., 59, 9, pp. 118 (1976).

Luckas, M. and K. Lucas, "Viscosity of Liquids: An Equation with Parameters Correlating with Structural Groups," AIChE J.,32, 1, pp.139-141 (1986).

Lundquist, K., B. Ohlsson and R. Simonson, "Isolation of Lignin by Means of Liquid-Liquid Extraction," Svensk Papperstidning, 80, 5, pp. 143-144 (1977).

Lundquist, K., and T.K. Kirk, "Fractionation-Purification of An Industrial Kraft Lignins," TAPPI J., 63, 1, pp. 80-82 (1980).

Lundquist, K., B. Josefsson and C. Nyquist, "Analysis of Lignin Products by Fluorescence Spectroscopy," Holzforschung, 32, 1, pp. 27-32 (1978).

Lundquist, K., I. Egyed, B. Josefsson and C. Nyquist, "Lignin Products in Pulping Liquors and Their Fluorescence Properties," Cellulose Chem. and Tech., 15, pp. $669-679$ (1981).

Luyben, W.L., Process Modeling, Simulation and Control for Chemical Engineers, McGraw-Hill (1973).

Lynn, R., "Operators and Fractional Derivatives for Viscoelastic Constitutive Equations," $J$. of Rheology, 27, 4, pp.351-372 (1983).

McCabe, W.L., "The Enthalpy-Concentration Chart. A Useful Device for Chemical Engineering Calculations," Trans. AIChE, 31, p.129 (1935).

Maansson, P., "GPC of Kraft Lignins," Ekman-Days, Int. Symp. Wood Pulping Chem., 5, pp. 9495 (1981).

MacDonald, R.G., and J.N. Franklin (eds.), Pulp and Paper Manufacture Volume I The Pulping of Wood, McGraw-Hill, NY, 347 (1969).

Macedo, P.B. and T.A. Litovitz, "On the Relative Roles of Free Volume and Activation Energy in the Viscosity of Liquids," J. Chem. Phys., 42, 1, pp.245-256 (1965).

MacKenzie, A.P., "Non-equilibrium Freezing Behavior of Aqueous Systems," Phil. Trans. R. Soc. Lond. B, 278, pp. 167-189 (1977).

Malcolm, L.W., Robert, F.L. and J. D. Ferry, "The Temperature Dependence of Relaxation Mechanisms in Amorphous Polymers and Other Glass Forming Liquids," J. Amer. Chem. Soc., 77,pp.3701-3706 (1955).

Malinen, R., and E. Sjostrom, "The Formation of Carboxylic Acids from Wood Polysaccharides During Kraft Pulping," Paperi Puu, 57, pp. 728 (1975).

Marton, J., in Lignin, K.V. Sarkarnen and C.H. Ludwig, Eds, Wiley Inerscience, New York, NY (1971). 
Marton, J., and T. Marton, "Molecular Weight of Kraft Lignin," TAPPI J, 47, 8, pp. 471-476 (1964).

Marx-Figini, M., and R.V. Figini, "On the Molecular Weight Determination by Vapor Pressure Osmometry, 1. Consideration of the Calibration Function," Makromol. Chem., 181, pp. 24012407 (1980).

Massee, M.A., Thermal Analysis of Kraft Black Liquor, M.S. Thesis, University of Maine, Orono, ME (1984).

Massee, M.A., E. Kiran, and A. L. Fricke, "A Thermodynamic Model of the Heat Capacity of Compositionally Complex Multicomponent Polymer Solutions: Kraft Black Liquor," Chem. Eng. Comm.,50, pp. 81-91 (1987).

Massee, M.A., E. Kiran, and A. L. Fricke, "Freezing and Glass Transition Phenomena in PolymerDiluent Mixtures," Polymer, 27, pp. 619 (1986).

Matheson, A.J., "Role of Free Volume in the Pressure Dependence of the Viscosity of Liquids," $J$. Chem. Phys., 44, 2, pp.695-699 (1966).

McDonald, K.L., "Rapid Determination of Kraft Black Liquor Solids," TAPPI J., 62, 1, pp. 80-81 (1979).

McDonald, R.G., Pulp and Paper Manufacture, Vol. I, The Pulping of Wood, 2nd ed., McGrawHill, New York (1969).

McDonald, K.L., TAPPI J., 60, 12, pp. 107-109 (1977).

McLuckie, C. and G.M. Rogers, "Influence of Elastic Effects on Capillary Flow of Molten Polymers," J. Appl. Poly. Sci., 13, pp. 1019-1063 (1969).

McNaughton, J.G., W.Q. Yean and D.A.I. Goring, "Macromolecular Properties of Kraft Lignins From Spruce Made Soluble by a Continuous Flow Process," TAPPI J., 50, 11, pp. 548-552 (1967).

Meares, P. Piolymers:Sructure and Bulk Properties, Van Nostrand, London (1965).

Mehrotra, A., and H. Veeramani, Indian Pulp Paper, 32, 3, pp. 3-5 (1977).

Melcher, III, J., "Simplifying Experimentation by Factorial Design," TAPPI J., 44, 6, pp. 143 A (1961).

Merriam, R.L., Computer Model of a Kraft Recovery Furnace, API Report, (1979).

Milanova, E. and G.M. Dorris, "Effects of Residual Alkali Content on the Viscosity of Black Liquors," International Chem. Recovery Conf. Proc., pp.110-118 (1989).

Miller, A.A., "Free Volume and Viscosity of Liquids: Effects of Temperature,"J. Phys. Chem., 67, pp.1031-1035 (1963).

Miller, M.L., The Structure of Polymers, Reinhold Publ. Corp., New York (1966).

Mita, I., I. Imai, and H. Kahbe, Thermo Chimica Acta, I, pp. 337 (1970). 
Moacacin, J., Y.F. Felicetta and J.L. McCarthy, "Lignin X. Moment Relationship Derivation for the Distribution of Diffusion Coefficients in Polymers," J. Amer. Chem. Soc., 81, pp. 2052-2054 (1959).

Moacanin, J.L., V.F. Felicetta, W. Haller and J.L. McCarthy, "Lignin. VI. Molecular Weight of Lignin Sulfonates by Light Scattering,"J. Amer. Chem. Soc 2 77, pp. 3407 (1955).

Moore, H.K., "Multiple Effect Evaporation Separatlon," Trans. Amer. Inst. Chem. Eng., 15, pp. 244 (1923).

Moore, W.R., and B.M. Tidewell, "Instrumentation of Molecular Weight Measurements," Chem. Ind., No. 2, January 14, pp. 61-68 (1967).

Morie, G.P., T. A. Power, and C. A. Glover, Thermo Chimica Acta, 3, pp. 259 (1972).

Morre, H.K., "Multiple Effect Evaporation Separation," Trans. AIChE, 15, pp.244 (1923).

Morris, C.E.M., "Molecular Weight Determination by Vapor Pressure Osmometry," J. Poly. Sci. Symp. No. 55, pp. 11-16 (1976).

Morris, C.E.M., "Aspect of Vapor Pressure Osmometry," J. Appl. Poly. Sci, 21, pp. 435-448 (1977).

Murray, J.P., K. J. Cavell, and J. O. Hill, Thermo Chimica Acta, 36, pp. 97 (1980).

Narayanan, A.K., M. S. Thesis, University of Maine, Orono, ME (1984).

Nassar, M.M., "Thermal Studies on Kraft Black Liquor," J. Chem. Tech. Biotechnol., 34A, pp.21-24 (1984).

Nguyen, T., E. Zavarin, and E.M. Barrall, II, "Thermal Analysis of Lignocellulosic Materials, Part 1. Unmodified Materials," J. Macromol. Sci. - Rev. Macromol. Chem., C20, 1, pp. 1-65 (1981).

O'Neill, J.M., "Measurement of Specific Heat Functions by Differential Scanning Calorimetry," Analyt. Chem., 38, pp. 1331 (1966).

Obiaga, T. I., and M. Wayman, "Molecular Weight Distribution of Lignin During Alkaline Pulping," Svensk Papperstidning, 76, 18, pp. 669-703 (1973).

Obiaga, T.I., and M. Wayman, "Improved Calibration Procedure for Gel Permeation Chromatography of Lignins," J. Appl. Poly. Sci, 18, pp. 1943-1952 (1974).

O'Connell, J.P. and J.M. Prausnitz, "Thermodynamic and Transport Properties of Water Vapor at Low Densities," I\&EC Fundementals, 9, p.579 (1970).

O'Neill, M.J., "Measurement of Specific Heat Functions by Differentiasl Scanning Calorimetry," Analyt. Chem., 38, 10, p. 1331 (1966).

Oshen, S., Private Communication (1984).

Ostwald, W., Kolloid-Z., 36, pp. 99-117 (1925); also, A. deWaele, Oil and Color Chem. Assoc. J., 6, pp. 33,88 (1923).

Otter,J.L. den, "Some Investigations of Melt Fracture," Rheol. Acta, 10, 2, pp.200-207 (1971). 
Oye, R., N.G. Langforg, F.H. Phillips and H.G. Higgins, "The Properties of Kraft Black Liquors from Various Eucalyptus and Mixed Tropical Hardwoods," APPITA, 31, 1, pp. 33-40 (1977).

Pearson, D.S. and W.E. Rochefort, "Behavior of Concentrated Polystyrene Solutions in Large Amplitude Oscillating Shear Fields," J. Poly. Sci., Poly. Phys. Ed., 20,pp.83-98(1982).

Pellinen, J. and M. Salkinoja-Salonen, "Aqueous Size Exclusion Chromatography of Industrial Lignins," J. of Chromat., 322, pp. 129-138 (1985).

Pellinen, J. and M. Salkinoja-Salonen, "High Performance Size Exclusion Chromatography of Lignin and Its Derivatives," J. of Chromat., 328, pp.299-308(1985).

Perry, R.H. (ed.), Perry's Chemical Engineers' Handbook, Sixth Edition, 3-233, McGraw-Hill (1984).

Philippoff, W. and F.H. Gaskins, "Viscosity Measurements on Molten Polyethylene," J. Poly. Sci., 21, pp. 205-222 (1956).

Pla, F., P. Froment, R. Capitini and A.M. Tistchenko, "Study of an Extractive Lignin by Light Scattering with a Laser Source," Cellulose Chem. and Tech., 11, pp. 711-718 (1977).

Polykov,Y.A., Smokvin,O.A. and A.B. Marshak, "Viscosity of Black Liquors," Trans. Leningrad Tehnol. Inst. Tselly-Bum. Prom., 27,pp.11-20 (1970)

Prausnitz, J.M., T.F.Anderson, E.A. Grens, C.A. Eckert, Hsieh, and J.P. O'Connell, Computer Calculations for Multicomponent Vapor Liquid and Liquid-Liquid Equilibria, Prentice-Hall, New York (1980).

Proctor, A.R., W.Q. Yean and D.A.I. Goring, "The Topochemistry of Delignification in Kraft and Sulphite Pulping of Spruce Wood," Pulp and Paper Magazine of Canada, 68, pp. T445-453 (1967).

Przezdziecki, J.W. and T. Sridhar, "Prediction of Liquid Viscosities," $A I C h E$ J., 31, 2, pp.333335 (1985).

Rabinowitch, R., Z. Phys. Chem., A145, 1 (1929).

Ramamurthy, A.V., "Wall Slip in Viscous Fluids and Influence of Materials of Construction," $J$. of Rheology, 30, 2, pp.337-357 (1986).

Ramiah, M.V., "Thermogravimetric and Differential Thermal Analysis of Cellulose, Hemicellulose, and Lignin," J. Appl. Polym. Scl., 14, pp. 1323-1337 (1970).

Ramsey, J.C., A.L. Fricke, and J.A. Caskey, "Thermal Conductivity of Polymer Melts," J. Appl. Polym. Scl., 17, pp. 1597 (1973).

Reich, L., and S.S. Stivala, Elements of Polymer Degradation, McGrawHill, NY, 164 (1971).

Reid, R.C., J.M. Prausnitz, and T.K. Sherwood, The Properties of Gases and Liquids, McGrawHill, New York (1977).

Reiner, M., Deformation, Strain, and Flow, Interscience, New York, p. 43 (1960). 
Rezanowich, A., W.Q. Yean and D.A.I. Goring, "The Molecular Properties of Milled Wood and Dioxane Lignins; Sedimentation, Diffusion Viscosity, Refractive Index Increment, and Ultraviolet Absorption," Svensk Papperstidning, 66, pp. 141-149 (1963).

Robinson, M.L., and D.T. Clay,AIChE National Meeting (San Francisco) (1984).

Rosenblad, A.E., TAPPIJ., 56, 9, pp. 85-88 (1973).

Ross, G., and L. Frolen, "The Characterization of Linear Polyethylene SRM 1475. X. Gel Permeation Chromatography," J. Res. National Bureau of Standards, 76A, pp. 163-170 (1972).

Rowlinson, J.S. and F.L. Swinton, Liquids and Liquid Mixtures, 3rd Ed., Butterworth, London, 1982.

Rudin, A., The Elements of Polymer Science and Engineering: An Introductory Text for Engineers and Chemists, Academic Press, NY, Chapters 2 and 12 (1982).

Rydholm, S.A., Pulping Processes, Interscience Publishers, NY, 576 (1965).

Sakata, I. and R. Senju, "thermoplastic Behavior of Lignin with Various Synthetic Plasticizers," $J$. Appl. Poly. Sci., 19, pp. 2799-2810 (1975).

Sandquist, K., "Rheological Properties of Black Liquor," Svensk Papperstidn, 84, 18, pp.R141R145 (1982).

Sandquist, K., "Rheological Properties and Evaporation of Black Liquor at High Dry Solids Content," Pulp \& Paper Canada, 84, 2 pp.30-34 (1983).

Sarkanen, S., D.C. Teller, J. Hall and J.L. McCarthy, "Lignin. 18. Associative Effects Among Organosolv Lignin Components," Macromolecules, 14, pp. 426-434 (1981).

Sarkanen, S., D.C. Teller, E. Abramowski and J.L. McCarthy, "Lignin. 19. Kraft Lignin Component Conformation and Associate Complex Configuration in Aqueous Alkaline Solution," Macromolecules, 15, 4, pp. 1098-1104 (1982).

Sarkanen, K., and C.H. Ludwig (eds.), Lignins: Occurrence, Formation, Structure and Reactions, NY, Wiley-Interscience (1971).

Schmidl, W. G., "Molecular Weight Characterization and Rheology of Lignin for Carbon Fibers," Ph.D. Dissertation, University of Florida, Gainesville, FL (1992).

Schmidl, W., D.J. Dong, and A.L. Fricke, "Molecular Weight and Molecular Weight Distribution of Kraft Lignins," Mat. Res. Soc. Symp. Proc., 197, pp. 21 (1990) .

Schuerch, C., "The Solvent Properties of Liquids and Their Relation to the Solubility, Swelling, Isolation and Fractionation of Lignin," J. Amer. Chem.Soc., 74, pp. 5061-5067 (1952)

Sebera, D., Electronic Structure and Chemical Bonding, Blaisdell Publishing Co., New York (1965).

Seymour, R.B., "Solubility Parameters: Yesterday and Today," Proc. ACS Div. Poly. Matls. Sci. and Eng., 51, ACS Fall Meeting, pp. 512-517 (1984).

Shogenji, T., and M. Koyania, Kami Pa Gikyoshi, 20, 11, pp. 626-30, (1966) . 
Shotton, P.G., P.C. Hewlett and A.N. James, "The Polydisperse Nature of Lignosulfonates," TAPPI J., 55, 3, pp. 407-415 (1972).

Simha, R., J. Appl. Phys., 23, pp. 1020 (1952).

Simha, R., and R.F. Boyer, "Second Order Transition Temperatures and Related Properties of Polystyrene. I Influence of Molecular Weight," J. Chem. Phys., 37, pp. 1003 (1962).

Simonson, R., "The Hemicellulose in the Sulfate Pulping Process", Svensk.Papp., 74, pp. 691 (1971).

Siochi, E.J., M.A. Haney, W. Mahn, and T.C. Ward, "Molecular Weight Determination of Hydroxypropylated Lignins," pp. 100-108, ch. 7 in Lignin:Properties and Materials, W. Glasser and S Sarkarnen, eds., ACS Symposium Series No. 397, American Chemical Society, Washington, DC (1989).

Sjostrom, E., Wood Chemistry: Fundamentals and Applications, Academic Press, New York,NY (1981).

Sjostrom, E., "The Behavior of Wood Polysaccharides During Alkaline Pulping Processes," TAPPI J., 60, pp. 151 (1977).

Siochi, E.J., M.A. Haney, W. Mahn, and T.C. Ward, "the Absolute Molecular Weight Distribution of Hydroxypropylated Lignins," Macromolecules, 23, pp. 1420-1429 (1990).

Small, J.D.,Jr., The Thermal Stability of Kraft Black Liquor at Elevated Temperatures, M.S. Thesis, University of Maine, Orono, ME (1984).

Small, J.D., Jr. and A.L. Fricke, "Thermal Stability of Kraft Black Liquor Viscosity at Elevated Temperatures," Ind.\& Eng. Chem. Prod. Res. \& Devel., 24, pp. 608 (1985) .

Small, J.D., Jr. and A.L. Fricke, "A Dual Chamber Capillary Viscometer for Viscosity Measurements of Concentrated Polymer Solutions at Elevated Temperatures, "J. Sci. Instru.,57, 6, pp.1182-1184 (1986) .

Smith, P., and A.J. Pennings, "Eutectic Solidification of the Quasi Binary System of Isotactic Polypropylene and Pentaerythrityl Tetrabromide," J. Poly. Sci. PP ed., 15, pp. 523-540 (1977).

Smith, P., and A.J. Pennings, "Eutectic Crystallization of Pseudo Binary Systems of Polyethylene and High Melting Diluents," Polymer, 15, pp. 413 (1974).

Sobczynski, S.F., AIChE National Meeting (Washington) (1982).

Soderhjelm, L., "Viscosity of Strong Black Liquors From Birch Pulping," Paperi Puu. 70, 4, pp. 348-354 (1988).

Soderhjelm, L. and P.E. Sagfor, " Relationship Between the Viscosity and Composition of Black Liquor, International Chem. Recovery Conf., Book 2, pp.513-519 (1992).

Soderhjelm, L., "Viscosity of Strong Black Liquor," Paperi Puu, 68, 9, pp.642-652 (1986).

Spencer, R.S. and R.E. Dillon, "The Viscous Flow of Molten Polystyrene," J. Colloid Sci., 3, pp.163-180 (1948). 
Spencer, R.S. and R.E. Dillon, "The Viscous Flow of Molten Polystyrene II," J. Colloid Sci., 4, pp.241-255 (1949).

Sridar,T., Chhabra,R.P. Uhlerr, P.H.T. and O.E. Potter, "Application of Hildebrand's Fluidity Model to Non-Newtonian Solutions," Rheol. Acta, 17, 5, pp.519-524 (1978).

Stacy, K.A., Light Scattering in Physical Chemistry, Academic Press, New York, NY (1956).

Stamm, A.J., Wood and Cellulose Science, Ronald Press Co., New York, Chapter 6 (1964).

Stenhof, T.J., and L. Agrawal, "Viscosity of Black Liquor," AIChE Symposium Series, 77, 207, pp.13-17 (1981).

Stevens, S., Rheology of Concentrated Black Liquors, M.S. Thesis, University of Florida, Gainesville, FL (1987).

Stevens, S., Private Communication (1986).

Stoy, M. A., "Dependence of the Enthalpy and Vapor Pressure of Kraft Black Liquor on Solids Content," Ph.D. Dissertation, University of Florida, Gainesville,FL (1992).

Stoy, M. A., Zaman, A. A., A. L. and Fricke, "Vapor Liquid Equilibria for Black Liquors", 1992 International Chemical Recovery Conference, pp. 495 - 511(1992).

Stoy, M. A. and A. L. Fricke, "Development of a Method for Measuring the Heat of Dilution of Kraft Black Liquor and Water," TAPPI J., 77, 8, pp. 169-174(1994).

Stoy, M. A., and A. L. Fricke, "Enthalpy Concentration Relations for Black Liquor," TAPPI J., 77, 9, pp. 103-110(1994).

Szymonski, K. A., and T. M. Grace, "A Method of Measuring the Water Vapor Pressure of Black Liquor", TAPPI J., 68, 2, pp. 87 (1985).

Tanaka, Genzo and K. Solc, "Second Virial Coefficient of Polydisperse Polymers," Macromolecules, 15, pp. 791-800 (1982).

Taylor, H.S., and H.A. Taylor, Elementary Physical Chemistry, 3rd ed., Van Nostrand, New York, p. 216 (1942).

Teas, J.P., "Predicting Resin Solubilities," Ashland Chemical Company Tech. Bull. 1206, Ashland Chemical Company, Ashland, KY (1971).

Thomas, D.G., J. Colloid Sci., 20, pp. 267-277 (1965).

Turnbull, D. and M.H. Cohen, "Free Volume Model of the Amorphous Phase: Glass Transition," J. Chem. Phys., 34, 1, pp.120-124 (1961).

Turnbull, D. and M.H. Cohen, "On the Free Volume Model of the Liquid-Glass Transition, "J. Chem. Phys., 52, 6, pp. 3038-3041 (1970).

Turi, E.A. (ed.), Thermal Characterization of Polymeric Materials, NY, Academic Press, 235 (1981). 
Utracki, L.A., and B. Fisa, "Rheology of Fiber- or Flake-Filled Plastics," Polymer Composites, 3, No. 4, pp. 193-211 (1982).

Utracki, L.A., and R. Simha, J. Rheology, 25, pp. 329 (1981).

Velzen, D. V., Cardozo, R.L. and H. Langenkamp, "A Liquid Viscosity-Temperature-Chemical Constitution Relation for Organic Compounds," I\&EC Fundementals, 11, 1, pp.20-25 (1972).

Veeramani, H., TAPPI Nonwood Plant Fiber Pulping Progress Rept. No. 9, pp. 97 (1978).

Villa, J., "Fast Determination of the Inorganic Fraction in Kraft Black Liquors," TAPPI J., 63, 11, pp. 153 (1980).

Volkov, A.D., and G. P. Grigor'ev, Physical Properties of Spent Liquors of the Pulp Industry, Lesnaya Promyshlenost, Moscow (1970).

Volkov, A.D., Sokolov, V.V. and G. P. Blekhert, Bumazh. Prom., 22, pp. 63 (1969).

Wagner, H.L., and F.L. McCrackin, "Branching and Molecular Weight Distribution of Polyethylene SRM 1476," J. Appl. Poly. Sci., 21, pp. 2833-2845 (1977).

Wagner, A.R., T. Thanh, D.E. Teller, and J.L. McCarthy, "Estimation of the Distribution of Molecular Weights of Lignins by Use of Low Pressure Size Exclusion Chromatography," Holzforschung, 40 Supplement, pp. 67-73 (1986).

Walsh, A. R., and A. G. Campbell, "HPSEC Analysis of Kraft Lignin on a Bondagel Column," Holzforschung,40, 5, pp. 263-266 (1986).

Wein,O. and V.V. Tovchigrechko, "Rotational Viscometry Under Presence of Apparent Wall Slip," J. of Rheology, 36, 5, (July, 1992).

Weissenberg, H.L., "End Correction for Slow Viscous Flow Through Long Tubes," Phys. of Fluids, 5, 9, pp.1033-1036 (1962).

Wennberg, O., "Rheological Properties of Black Liquor," 1988 TAPPI International Chemical Recovery Conf., pp. 89-93 (1989).

Wennberg, O., "Boiling Point Elevation and Viscosity of Black Liquor at High Solids Content and High Temperatures", 1985 TAPPI International Chemical Recovery Conf., pp. 275 (1986).

Wetherhorn, D., TAPPI J., 56, 6, pp. 88-90 (1973).

Whalen, D.M., "A Simple Method for Precipitating Easily Filterable Acid Lignin from Kraft Black Liquor," TAPPI J., 58, 5, pp. 110-112 (1975).

Wight, M.O., An Investigation of Black Liquor Rheology Versus Pulping Conditions, Ph.D. Thesis, University of Maine at Orono (1985).

Wight, M.O., T.E. Farrington, and A.L. Fricke, AIChE National Meeting (San Francisco) (1984)

Wight, M.O., A. Co, and A. L. Fricke, "Viscosity of Black Liquor by Cone-and-Plate and Parallel-Disk Viscometry," AIChE Symp. Series, No. 207, pp. 77 (1981).

Wight, M.O., Private Communication (1984). 
Wynne-Jones, W.K.F. and H. Eyring, "The Absolute Rate of Reactions in Condensed Phases," J. Chem. Phys., 4, pp. 283-291 (1936).

Yasuda, K.Y., PhD Thesis, Massachusetts Institute of Technology, Cambridge, MA (1979).

Yasuda, K.Y., Armstrong, R.C. and R.E. Cohen, Rheol. Acta, 20, pp. 163-178 (1981).

Yan, J.F., and D.C. Johnson, "Molecular Weight Distribution in the Lignin Sol," $J$ Agric. \& Food Chem., 28, pp. 850-855 (1980)

Yan, J.F., "Molecular Theory of Delignification," Macromolecules, 14, 5, pp. 1438- 1445 (1981) Yan, J.F., F. Pla, R. Kondo, M. Dolk and J.L. McCarthy, "Lignin. 20. Depolymerization by Bond Cleavage Reactions and Delegation," Macromolecules, 17, pp. 2137-2142 (1984).

Yean, W.Q., and D.A.I. Goring, "Simultaneous Sulphonation and Fractionation of Spruce Wood by a Continuous Flow Method," Pulp and Paper Magazine of Canada, 65, (Convention Issue), pp. 127-132 (1964).

Yean, W.Q., and D.A.I. Goring, "The Molecular Weights of Lignosulphonates from Morphologically Different Subdivisions of Wood Structure," Svensk Papperstidning, 68, pp. 787-790 (1965).

Yean, W.Q., and D.A.I. Goring, "Molecular Properties of Sodium Lignosulphonates by a Continuous Flow Bisulphite Process," Svensk Papperstidning, 71, pp. $739-743$ (1968).

Yilmazer, U. and D.M. Kalyon, "Slip Effects in Capillary and Parallel Disk Torsional Flows of Highly Filled Suspensions," J. of Rheology, 33, 8, pp. 1197-1212 (1989).

Yosida, H., R. Morck, and K.P. Kringstad, "Fractionation of Kraft Lignin by Successive Extraction with Organic Solvents. II. Thermal Properties of Kraft Lignin Fractions," Holzforschung, 41, 3, pp. 171-176 (1987).

Yoshinura, A.S. and R.K. Prud'homme, "Wall Slip Corrections for Couette and Parallel Disk Viscometers," J. of Rheology, 32, 6, pp. 575-584 (1988).

Yoshinura, A.S. and R.K. Prud'homme, "Response of an Elastic Bingham Fluid to Oscillatory Shear," Rheol. Acta, 26, pp. 428-436 (1987).

Young, R.J., Introduction to Polymers, Chapman and Hall, London, 204 (1981).

Zaman, A. A., "An Investigation of the Rheological Properties of High Solids Kraft Black Liquors," Ph.D. Dissertation, University of Florida, Gainesville, FL (1993)

Zaman, A. A., and A. L. Fricke, "Viscosity of Black Liquor up to $140^{\circ} \mathrm{C}$ and $80-85 \%$ Solids", AIChE 1991 Forest Products Symp., pp. 59-77 (1991).

Zaman, A. A., D. J. Dong, and A. L. Fricke, "Kraft Pulping of Slash Pine", AIChE Forest Products Symposium, pp. 49-57 (1991).

Zaman, A. A. and A. L. Fricke, "Correlations for Viscosity of Kraft Black Liquors at Low Solids Concentrations," AIChE Journal, 40, 1, pp.187-192 (1994). 
Zaman, A. A. and A. L. Fricke, "Newtonian Viscosity of High Solids KraftBlack Liquors: Effects of Temperature and Solids Concentrations" Ind. \& Eng.Chem. Res., 33, 2, pp. 428435 (1994).

Zaman, A. A., M. O. Wight and A. L. Fricke, "Density and Thermal Expansion of Black Liquors," TAPPIJ, 77, 8, pp. 175-181 (1994).

Zaman A.A., and A. L. Fricke, "Viscosity of Softwood Kraft Black Liquors at Low Solids Concentrations: Effects of Solids Content, Degree of Delignification, and Liquor Composition," J. Pulp andPaper Sci. of Canada, 21, 4, pp. J119-J126 (1995).

Zaman, A. A. and Fricke, A. L., "Viscoelastic Properties of High Solids Softwood Kraft Black Liquors", Ind. \& Eng. Chem. Res., 34, 1, pp.382-391 (1995).

Zaman, A. A. and A. L. Fricke, "Effects of Pulping Conditions and Black Liquor Composition on Viscosity of Softwood Kraft Black Liquors: Predictive Models with Statistical Approach", TAPPIJ, 78, 10, pp. 107-119(1995).

Zaman, A. A. and A. L. Fricke, "Effects of Pulping Conditions and Black Liquor Composition on the Heat of Combustion of Slash Pine Black Liquor", Advances in Pulp \& Papermaking,_AIChE Symp. Series, 91, 307, pp. 154-161(1995).

Zaman, A. A. and A.L. Fricke, "Shear Flow Properties of High Solids KraftBlack Liquors: Effects of Temperature, Solids Concentrations, Lignin Molecular Weight and Shear Rate," Chem. Eng. Comm., 139, pp.201-221 (1995).

Zaman, A. A. and A.L. Fricke, "Kraft Black Liquor Rheological Behavior with Respect to Solids Concentrations, Temperature, and Shear Rate,"Advances in Pulp \& Papermaking, AIChE Symp. Series, 91, 307, pp.162-171 (1995).

Zaman, A. A. and A.L. Fricke, "Effects of Pulping Conditions and Black Liquor Composition on the Zero Shear Rate Viscosity of Softwood Kraft BlackLiquors", Ind. \& Eng. Chem. Res., 35, 2, pp.590-597 (1996).

Zaman, A. A. and A.L. Fricke, "Heat of Dilution and Enthalpy Concentration Relations for Slash Pine Kraft Black Liquors", Chem. Eng. Comm., 155, pp. 197-216 (1995).

Zaman, A. A., S. A. Taveres, and A. L. Fricke, "Studies on Heat Capacity of Slash Pine Kraft Black Liquors: Effects of Temperature and Solids Concentration", J. Chem. \& Eng. Data, 41, pp.266-271 (1996).

Zaman, A. A. and A.L. Fricke,"Effects of Pulping Conditions on Enthalpy of Slash Pine Kraft Black Liquors: Predictive Models", Ind. \& Eng. Chem. Res., 35, 7, pp.2438-2443 (1996).

Zaman, A. A., J. Deery, T. W. McNally, and A. L. Fricke, "Effect of Pulping Variables on Density of Slash Pine Kraft Black Liquors: Predictive Models", TAPPI J., 80, 9, 199-207 (1997). 
Zaman,A.A., T.W.McNally and A.L. Fricke, "Vapor Pressure and Boiling Point Elevation of Slash Pine Black Liquors: Predictive Models with Statistical Approach, I\&EC Research, 39, pp. 275-283 (1998).

Zamora, F., and M.C. Gonzalez, "Polydispersity Influence on Polymeric Eutectic Mixtures," J. Poly. Sci. PL ed., 22, pp. 267-271 (1984).

Zebbs, F.L., "The Effect of Sulfidity in Southern Pine Kraft Pulping," TAPPI J. , 39, 4, pp . $180 \mathrm{~A}(1956)$. 